\title{
Sustainable agricultural development in China
}

\author{
Citation for published version (APA):
}

Wang, J. (2017). Sustainable agricultural development in China: an assessment of problems, policies and perspectives. [Doctoral Thesis, Maastricht University]. Datawyse / Universitaire Pers Maastricht. https://doi.org/10.26481/dis.20171018jw

Document status and date:

Published: 01/01/2017

DOI:

10.26481/dis.20171018jw

Document Version:

Publisher's PDF, also known as Version of record

\section{Please check the document version of this publication:}

- A submitted manuscript is the version of the article upon submission and before peer-review. There can be important differences between the submitted version and the official published version of record.

People interested in the research are advised to contact the author for the final version of the publication, or visit the DOI to the publisher's website.

- The final author version and the galley proof are versions of the publication after peer review.

- The final published version features the final layout of the paper including the volume, issue and page numbers.

Link to publication

\footnotetext{
General rights rights.

- You may freely distribute the URL identifying the publication in the public portal. please follow below link for the End User Agreement:

www.umlib.nl/taverne-license

Take down policy

If you believe that this document breaches copyright please contact us at:

repository@maastrichtuniversity.nl

providing details and we will investigate your claim.
}

Copyright and moral rights for the publications made accessible in the public portal are retained by the authors and/or other copyright owners and it is a condition of accessing publications that users recognise and abide by the legal requirements associated with these

- Users may download and print one copy of any publication from the public portal for the purpose of private study or research.

- You may not further distribute the material or use it for any profit-making activity or commercial gain

If the publication is distributed under the terms of Article $25 \mathrm{fa}$ of the Dutch Copyright Act, indicated by the "Taverne" license above, 


\section{Sistatiatile agniouliural ievelopment in Cilliat}

an assessment of problems, policies and perspectives 


\title{
Sustainable agricultural development in China: an assessment of problems, policies and perspectives
}

\author{
DISSERTATION \\ to obtain the degree of Doctor at Maastricht University, \\ on the authority of the Rector Magnificus, Prof. Dr. Rianne M. Letschert \\ in accordance with the decision of the Board of Deans, \\ to be defended in public \\ on Wednesday, 18 October 2017, at 14.00 hours
}

by

Jing Wang 


\section{Supervisors}

Prof. dr.ir. Harro van Lente

Dr. Joop de Kraker

\section{Assessment committee}

Prof. dr. Pim Martens (chair)

Prof. Frank Vanclay (University of Groningen)

Prof.dr.ir. Rudy Rabbing (Wageningen University)

Prof. dr.Jan Douwe van der Ploeg (Wageningen University) 


\section{Contents}

$\begin{array}{ll}\text { Figures } & 7\end{array}$

Tables $\quad 8$

$\begin{array}{ll}\text { Abbreviations } & 9\end{array}$

Chapter 1 General introduction $\quad 11$

1.1 Objectives of this dissertation $\quad 13$

$\begin{array}{ll}1.2 \text { Context of this dissertation } & 14\end{array}$

1.3 Research approach and outline of this dissertation 24

Chapter 2 Sustainable agricultural development in China: an integrated assessment of problems and solution strategies $\quad 27$

2.1 Introduction 29

2.2 Agricultural development in China 30

2.3 Sustainability problems in Chinese agriculture 32

2.4 Strategies for agricultural development 38

2.5 Assessment of the three strategies for agricultural development 43

2.6 Discussion and conclusions 46

Chapter 3 Farmers' perspectives and practices in the Guanzhong Plain of Shaanxi Province, China $\quad 51$

3.1 Introduction 53

3.2 Methodology 53

3.3 Results $\quad 55$

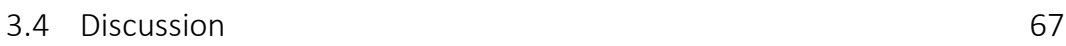

Chapter 4 Farmers' perspectives in Daijia, a village in the Guanzhong Plain of Shaanxi Province, China $\quad 83$

$\begin{array}{lll}4.1 & \text { Introduction } & 85\end{array}$

$\begin{array}{ll}4.2 \text { Methods } & 86\end{array}$

4.3 The context of Daijia village 90

4.4 Farmers' perspectives in Daijia village 94

$\begin{array}{ll}4.5 \text { Discussion } & 105\end{array}$

Chapter 5 Farmers' perspectives in Chiniuwa, a village in the Loess Plateau area of Shaanxi Province, China 111

5.1 Introduction 113

$\begin{array}{ll}5.2 \text { Methods } & 114\end{array}$ 
Chapter 6 Farmers' perspectives in Donghe, a village in the Qinba Mountains, Shaanxi Province, China

6.1 Introduction

6.2 Methods

6.3 The context of Donghe village

6.4 Farmers' perspectives in Donghe village

6.5 Discussion

Chapter 7 Comparing high-level strategies for agricultural development with the perspectives of Chinese farmer

7.1 Introduction

7.2 Assumptions concerning farmers underlying high-level strategies

7.3 Farmers' perspectives on problems and solutions

7.4 Correspondence between assumptions concerning farmers and farmers' perspectives

7.5 Discussion

Chapter 8 General discussion

8.1 Summary of major findings

8.2 Discussion

8.3 Recommendations

References

Summary

Valorisation

Curriculum vitae 


\section{Figures}

Figure 1.1 Outline of the dissertation

Figure 2.1 Farmers' per capita net real income in China from 1978 to 2013 (in $\mathrm{RMB}$ ). Real income is calculated as the nominal income divided by the consumer price index. (Source: NBSC, 2014a and 2014b)

Figure 2.2 Numbers and percentages of measures focusing on economic, social and ecological issues in agriculture and rural development in 17 Documents No.1.

Figure 3.1 The location of the study area, Guanzhong Plain, in Shaanxi Province, central China

Figure 3.2 Four clusters of farm households in the survey, based on five household characteristics. The location of the circles indicates which characteristic was predominant in a cluster, and the size of the circle indicates the number of respondents per cluster

Figure 3.3 Percentage of respondents per cluster opting for the answers that were overall the most favored for questions addressing perspectives on economic aspects of farming.

Figure 3.4 Percentage of respondents per cluster opting for the answers that were overall the most favored for questions addressing perspectives on social aspects of farming.

Figure 3.5 Percentage of respondents per cluster opting for the answers that were overall the most favored for questions addressing perspectives on environmental aspects of farming.

Figure 3.6 Percentage of respondents per cluster opting for the answers that were overall the most favored for questions addressing decisionmaking aspects of farming.

Figure 3.7 Percentage of respondents per cluster opting for the answers that were overall the most favored for questions addressing farmers' behaviors

Figure 4.1 Daijia village: geographic location; wheat field and apple orchard; intercropping of apples and wheat; brick factory in Renqu village; interviewing an old farmer

Figure 5.1 Chiniuwa village: geographic location; overview of the village; terraces planted with jujube trees; plastic covers after sowing maize to preserve moisture for the seeds; interviewing a female farmer 
Figure 6.1 Donghe village: geographic location; overview of the village; rice seedlings in the nursery before transplanting; ducks near a flooded paddy field; interviewing a female farmer

Figure 7.1 Location of Daijia, Chiniuwa and Donghe villages in Shaanxi Province, China

\section{Tables}

Table 2.1 Total use of fossil oil-based based inputs (104 ton), agricultural machinery power (104 kw) and irrigation (103 ha) in Chinese agriculture from 1990-2013 (Sources: NBSC 2006, 2011, and 2014)

Table 2.2 Total production, productivity and per capita production of grains in China from 1990-2013 (Sources: NBSC 2006, 2011 and 2014)

Table 2.3 Per capita net income of rural households: total and income from wages and farming (Sources: NBSC 2006, 2011 and 2014)

Table 2.4 Gender, age, and education of on-farm agricultural labor and offfarm migrant labor in China (Source: NBSC, 2008)

Table 3.1 Additional characteristics of the farm households in the four clusters, presented as cluster averages and their standard deviations

Table 4.1 Characteristics of the interviewees in Daijia village 88

Table 4.2 Three teams in Daijia village proper 93

Table 4.3 Inputs and input costs of maize per mu in Daijia village 96

Table 4.4 Inputs and input costs of wheat per mu in Daijia village 96

Table 4.5 Inputs and input costs of apple per mu in Daijia village * 97

Table 5.1 Characteristics of the interviewees in Chiniuwa village 116

Table 6.1 Characteristics of the interviewees in Donghe village 140

Table 6.2 Inputs and input costs of conventional rice per mu in Donghe village 148

Table 7.1 Assumptions concerning farmers underlying three strategies for $\begin{array}{ll}\text { agricultural development } & 169\end{array}$

Table 7.2 Farmers' perspectives in three villages in Shaanxi Province 174

Table 7.3 Additional policy goals for a sustainable agricultural development strategy based on an analysis of farmers' perspectives 


\section{Abbreviations}

CCCPC Central Committee of the Communist Party of China

CPC Communist Party of China

CEA Chinese Ecological Agriculture

EPC Ecological Province Construction

MEP Ministry of Environment Protection

MFAC Ministry of Foreign Affairs of China

MLRC Ministry of Land and Resources of China

MWRC Ministry of Water Resources of China

NBSC National Bureau of Statistics of China

OECD Organization for Economic Co-operation and Development

SLCP The Sloping Land Conservation Program

UN United Nations

WB World Bank 

Chapter

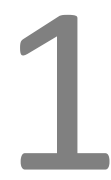

General introduction 



\subsection{OBJECTIVES OF THIS DISSERTATION}

In recent decades, Chinese agriculture has achieved a series of great successes, such as food security and strongly increased agricultural productivity and farmers' income. However, these successes have come at a cost, economically, socially, and ecologically. Now that this has become apparent, the direction of agricultural development has moved to the center of attention of both the Chinese government and many scholars. Due to China's rapid urbanization and industrialization, its agriculture appears to be at a crossroads (Huang, 2011, 2014), and different strategies for agricultural development are presented. The government attributes the problems of agriculture to its current small-scale character and has chosen for a modernization strategy involving scale enlargement and technology development, but others have criticized this approach and make a plea for the conservation of small-scale agriculture (He, 2013; He, 2014a, 2014b; Huang, 2011, 2014) or the development of ecological agriculture with strongly reduced external inputs (Li et al., 2011; Wang et al., 2007).

All participants in this debate strive for a sustainable agriculture, including the government, but rarely in a balanced way. In some strategies, the focus is more on the economic aspects, in others more on the social or environmental dimension of sustainability. However, the voices of Chinese farmers are generally absent in this debate and in the strategies for sustainable agricultural development proposed by government and scholars. This casts doubts on the effectiveness of these strategies. First, these strategies may not address the problems as experienced by the farmers. Second, the strategies may be based upon assumptions about what farmers want and need which are not valid. Third, the proposed solutions may not be accepted by the farmers, who are eventually the decision-makers in agriculture. There is, therefore, an urgent need to learn more about the perspectives of Chinese farmers on problems and possible solutions in the development of agriculture.

The point of departure of this dissertation is that agricultural development must include economic viability, social equity and protection of the environment and the natural resource base to be sustainable, and that, to be effective, a strategy for sustainable agricultural development must account for farmers' perspectives and diverse conditions. The objectives of this dissertation are:

(1) to assess in how far the Chinese governmental strategy for agricultural development and major alternative strategies address the sustainability problems of China's agriculture in a comprehensive way, i.e., whether the economic, social and environmental dimensions of sustainable development are taken into account. 
(2) to assess the perspectives on economic, social and environmental problems and solutions of Chinese farmers from different ages, levels of education, farm household types, and agro-ecological contexts.

(3) to assess the extent to which the Chinese governmental strategy for agricultural development and major alternative strategies address the problems as experienced by farmers from a broad range of contexts, and to determine how such strategies better could account for farmers' perspectives.

\subsection{CONTEXT OF THIS DISSERTATION}

The context of this dissertation is formed by agriculture in China, China's agricultural and rural development policies, and the concept of sustainable agriculture. These three topics will be elaborated in the following sections.

\subsubsection{Agriculture in China}

Due to the large regional differences in the distribution of natural resources and climatic conditions, agricultural production systems vary greatly across China. The Qinling Mountains - Huaihe River Line forms a major geographic and climatic boundary, which divides China into a dry northern and a wet southern part (OECD, 2001; Tso, 2004). It is also an important dividing line for agriculture, separating the main wheat and rice producing areas, located in the north and the south, respectively. In both parts, however, the practice of double-cropping, growing two crops in rotation within one year, is dominant $^{1}$ (Frolking, Xiao, Zhuang, Salas, \& Li, 1999). Double-cropping practices include the rotation of rice and rice, maize and winter wheat, rice and winter wheat, and the rotation of rice and oilseed rape (Frolking et al., 1999). The maize and winter wheat rotation is the major type of double-cropping in the North of China, whilst the rotation of rice and oilseed rape is one of the major cropping practices in the South of China. The Loess Plateau in the northern part presents an exception. The area has a semi-arid temperate climate, and is plagued by droughts, as well as serious water and soil erosion (Chen et al., 2015). As a consequence, the cultivation of jujube, a traditional Chinese fruit tree with good drought resistance, is widespread on the Loess Plateau (Chen et al., 2015; Gao, Wu, Zhao, Wang, \& Shi, 2014; Liu, Wang, Wei, Wang, \& Zhang, 2013).

In addition to cropland, major land use types in China include forest, grassland, residential area, land occupied by mines and factories, infrastructure, and land used for water conservation (NBSC, 2015). In the last decades, land use in China has changed pro-

\footnotetext{
${ }^{1}$ In addition to these double-cropping systems, there is single-cropping in the northernmost province (Heilongjiang Province) and triple-cropping in the southernmost province (Hainan island).
} 
foundly (Lichtenberg \& Ding, 2008). With the rapid expansion of industrial and urban areas, the loss of farmland has become a serious issue. For instance, the net loss of cultivated land was 361,600 ha in 2001 (MLRC, 2002, 2006, 2009, 2014 and 2015). At the same time, the population of China increased from 1.14 billion in 1990 to 1.35 billion in 2014 (NBSC, 2015), and the loss of farmland is therefore considered by the Chinese government as a threat to food security. To limit further losses, the government has introduced a strict policy of farmland protection and restoration ${ }^{2}$ (Lichtenberg \& Ding, 2008). For example, in 2014 the loss of cultivated land was 38,800 ha, while 28,070 ha were restored (MLRC, 2015). Despite this farmland conservation policy, cultivated land continues to decline annually (Lichtenberg \& Ding, 2008).

Perhaps surprisingly, but industrial and urban expansion are not the major causes of loss of cultivated land. The most important cause are large-scale ecological restoration programs converting farmland into forests or natural grasslands (Qu et al., 2011). These programs were launched after devastating floods in 1998 which were attributed to widespread deforestation and soil erosion. The Sloping Land Conservation Program (SLCP), commonly known as the "Grain for Green" program, is one of the largest and ambitious ecological restoration program in the world (Bennett, 2008; Liu \& Henningsen, 2016; Yin, Liu, Zhao, Yao, \& Liu, 2014). In 1999, three provinces, Shaanxi, Sichuan and Gansu Province, were chosen as the pilot and primary sites of SLCP (Bennett, 2008). Since 2000, the SLCP has been scaled up and in 2003 the rules were formally established. Currently, 25 provinces (out of 34 provinces) participate in SLCP (Bennett, 2008). The goals of SLCP include an increase in forest area by $10-20 \%$ and a decrease in farmland by $10 \%$ on a national scale (Bennett, 2008). The program area includes predominantly mountainous and hilly terrain, but also some plain areas where desertification of land is serious and grain yield is low (Bennett, 2008; Liu \& Henningsen, 2016; Yin et al., 2014). The SLCP subsidies include food ${ }^{3}$ and cash. During the first stage of SLCP (1999-2007), the farmers received subsidies for two years for grassland, for five years for tree crops, and for eight years for forest (Grosjean \& Kontoleon, 2009). After the first stage, the Chinese government has extended the SLCP program with a second stage, running from 2008 to 2020. The subsidies in the second stage are reduced by half compared to the first stage (Yin et al., 2014).

Due to the SLCP and similar ecological restoration programs, the area of forest is increasing again in China and surface water runoff and soil erosion are effectively reduced (Qu et al., 2011; MLRC, 2015). In addition to ecological restoration, SLCP has positive effects on farmers' income and contributes to rural poverty alleviation (Yin et al., 2014).

\footnotetext{
${ }^{2}$ The Basic Farmland Protection Regulation (1994) and the New Land Administration Law (1999) (Lichtenberg \& Ding, 2008).

${ }^{3}$ These food subsidies mainly concern wheat. The amount of wheat compensation is $100 \mathrm{~kg}$ per mu farmland in Huanghe valley and Haihe river basin (in the north part of China), and $150 \mathrm{~kg}$ per mu farmland in Yangtze River valley and Huaihe River Basin (in the south part of China).
} 
This is not only due to the subsidies, but also because the surplus farming labor after conversion of low-productive cropland can engage in more remunerative off-farm work (Grosjean \& Kontoleon, 2009; Yin et al., 2014). However, the SLCP has also negative impacts, mainly due to a lack of attention for the regional context of implementation (Cao, 2011; Qu, Kuyvenhoven, Shi, \& Heerink, 2011). The large-scale planting of exotic trees is affecting local ecosystems. First, because these trees have a high water demand compared to the native grassy vegetation and to the water supply in the northern part of China including the Loess Plateau (Cao, 2011; Qu et al., 2011). As the evaporation by the trees is also much higher than by grassland, the result is a depletion of soil moisture in the long term (Cao, 2011; Qu et al., 2011). Second, the high water use and evaporation by the planted trees strongly reduces water run-off, which results in much lower water levels in the rivers (Cao, 2011). Third, afforestation has a negative effect on the local biodiversity, because in most SLCP areas just one or a few tree species are planted, partly replacing the native, biodiverse vegetation (Qu et al., 2011). In addition, the tree cover decreases the amount of sunlight for the understory vegetation (such as native grassland), to the extent that this vegetation dies off (Cao, 2011). Also economically, the results are mixed. The SLCP compensation comes from the central government, while the costs of monitoring, grain transportation and implementation are the responsibility of the local government (Qu et al., 2011). Often, these costs are deducted from the compensation for the farmers, and as a result, the subsidy reaching the farmers is too low to supplement their lost livelihood due to farmland conversion (Cao, 2011; Qu et al., 2011). There is a risk that a considerable part of the farmers will cultivate their land again as soon as the subsidies stop (Cao, 2011; Qu et al., 2011).

Despite the decrease in area of cultivated land and the increase in population size, China has achieved the goal of national food security, known as "take good control of our own bowl". The per capita grain production has increased from $390 \mathrm{~kg}$ in 1990 to $444 \mathrm{~kg}$ in 2014, and the total grain output in China has continued to grow year after year, reaching over 60 million tons in 2014 (NBSC, 2006, 2011 and 2014). The average grain yield per hectare also rapidly increased from $3933 \mathrm{~kg} / \mathrm{ha}$ in 1990 to $5385 \mathrm{~kg} / \mathrm{ha}$ in 2014 (NBSC, 2006, 2011 and 2014). The increase in production is achieved mainly by means of agricultural intensification. The input of agrochemicals (fertilizers and pesticides), agricultural machinery, and fossil fuel has increased unprecedentedly (Zhang et al., 2015; the specific statistics and details are presented in Chapter 2).

\subsubsection{Agricultural and rural development policies}

Since the end of the 1970s, liberalization policies have transformed Chinese agriculture in a fundamental way from a 'command economy' to a market economy. The implementation of the so-called Household Responsibility System has played a crucial role in these market liberalization policies. Another very influential policy is the Household 
Registration System (hukou in Chinese), which dates back to the early years of the People's Republic of China. Below, these policies will be introduced and summarized from a historical perspective.

\subsubsection{Market liberalization}

In the past decades, China has embarked on a radical and profound reform, shifting from a 'state command economy' to a market economy (Feng, Bao, \& Jiang, 2014; OECD, 2001; Oi, 1989; Painter, 2008; Park \& Rozelle, 1998; Webber, 2008). In the prereform era (from $1949^{4}$ to $1978^{5}$ ), the state had a tight relationship with the collectives in the rural areas (Feng et al., 2014; OECD., 2001; Oi, 1989; Painter, 2008; Park \& Rozelle, 1998; Webber, 2008). In this period, there were three administrative levels in rural China: the people's commune, the production bridge, and the production team (Park \& Rozelle, 1998). The people's commune was the highest collective level, and was directed by the state in terms of required grain production (Park \& Rozelle, 1998). The state and the people's commune decided about the what, how and when of the farming work (Feng et al., 2014; OECD, 2001; Oi, 1989; Painter, 2008; Park \& Rozelle, 1998; Webber, 2008). During this period, agricultural labor (farmers), agricultural capital and arable land were all in the hand of the state (Xin \& Gao, 2009). The collective management system and the planned economy of the people's commune were the main characteristics of Chinese agriculture in this period. The state kept the price of agricultural commodities at a very low price to guarantee a stable supply of affordable food. The main institutions involved in the planned rural economy were the Grain Bureau (Liang shi ju), the supply and marketing cooperatives (Gong xiao he zuo she), and the Agricultural Bank of China. Together they decided about the type and allocation of agricultural production, the prices of agricultural products, the production and use of agricultural inputs, and agriculture-related loans (Feng et al., 2014). Farmers' performance was assessed by collective leaders, and farmers' income was determined by the total collective production (Feng et al., 2014; OECD., 2001; Oi, 1989; Painter, 2008; Park \& Rozelle, 1998; Webber, 2008). During this period, the enthusiasm for farming work gradually decreased.

From the early-1980s to 1990, the Chinese government started to loosen central state control (Park \& Rozelle, 1998). In this period, the government began to introduce market mechanisms, but the command economy was not yet completely dismantled (Park \& Rozelle, 1998). The rural economy was a dominant theme in government policy, as witnessed by the five Documents No.1 (1982-1986) focusing on this issue ${ }^{6}$ (CCCPC, 1982, 1983, 1984, 1985, 1986). In 1982, the "Household Responsibility System", a sys-

\footnotetext{
${ }^{4}$ The People's Republic of China was founded in 1945.

${ }^{5}$ In December of 1978, in the Third Plenary Session of the 11th Central Committee of the Chinese Communist Party, the policy of reform and opening up was started, which was led by Deng Xiaoping.

${ }^{6}$ Document No. 1 is the first policy document jointly released each year by the Central Committee of the Communist Party of China and the State Council.
} 
tem establishing the responsibilities for agricultural production was introduced in approximately $90 \%$ of the communes. The economic slogan promoted by the government was "integrate the planned economy with the market economy: the planned economy should play the main role and the market economy play a supplementary role in agricultural development" (CCCPC, 1982, 1983, 1984, 1985, 1986). In the new system, individual farmers signed contracts with collectives to take the responsibility of farmland. Farmers had to pay tax to the state over their agricultural production, and sell fixed quota of the production to the government (Oi, 1989). The remaining part of the production could be used for own consumption or sold in the market (Oi, 1989). This new rule stimulated the enthusiasm of the farmers for agricultural production. However, due to the high agricultural tax and production quota, their economic burden was heavy (Oi, 1989). In this period, also the state purchasing policy was adjusted. The types and quantities of agricultural products purchased by the state were reduced (CCCPC, 1982, 1983, $1984,1985,1986)$. The gradual reduction of agricultural production quota stimulated the farmers' market orientation (CCCPC, 1982, 1983, 1984, 1985, 1986). In 1985, the state monopoly for purchasing and marketing of grains was abolished. From then on, farmers were completely free to decide about their own agricultural production and to enter the market.

Since 2002, the government's basic policy principle for agricultural development is "giving more, taking less and loosening control" (Hou, 2006; Hu, 2014; Ren, Yu, \& Wang, 2009; Zhou, 2014). "Giving more" refers to enhancing investments in rural areas and agriculture (Hou, 2006; Hu, 2014; Ren et al., 2009; Zhou, 2014). Since 2004, several policies benefitting farmers (惠民政策Hui min zheng ce) have been introduced, such as direct subsidies to grain growers, and subsidies for agricultural machinery and seeds. In addition, the government has invested in the development of the agricultural infrastructure, such as irrigation systems. "Taking less" refers to reducing the economic burden of farmers (Hou, 2006; Hu, 2014; Ren et al., 2009; Zhou, 2014). The national agricultural tax, which had existed in China for over 2600 years, was abolished in 2006. In addition, local governments were no longer allowed to charge agriculture-related fees. "Loosening control" refers to a further introduction of market mechanisms to stimulate the production and effective distribution of agricultural products (Hou, 2006; Hu, 2014; Ren et al., 2009; Zhou, 2014). Individual farmers (or households) replaced the collectives as the basic units in the rural market system.

\subsubsection{Household Responsibility System}

The Household Responsibility System revolutionized Chinese agriculture by dismantling its collectivized and centralized system (Chen \& Brown, 2001; Watson, 1983). From the end of the 1950s until 1978, all agricultural decisions were made at the level of the communes (Watson, 1983). However, the drawbacks of the collective system became increasingly clear during this period, and included inefficiency of farming, hidden unem- 
ployment, low investments in agriculture, and low farmers' income (Watson, 1983). The enthusiasm of individual farmers for the farming work was extremely low. In 1978, the Household Responsibility System was introduced to embark on a radically different path, a process of decentralization and decollectivization of agriculture (Chen \& Brown, 2001). With the Household Responsibility System, individual households (farmers) regained a central position in agricultural development and the direct relation between farmers' income and their individual production was restored (Chen \& Brown, 2001; Watson, 1983; Yep, 2015).

In the Household Responsibility System, the right of use of the collectives' farmland was transferred to individual households (Chen \& Brown, 2001; Watson, 1983; Yep, 2015). The distribution of the farmland was initially based on the combination of household size and household labor supply (Tian, Song, \& Boyle, 2012), but after protests from farmers the quality of the farmland was also taken into account (Tian et al., 2012). The farmland is still collectively owned (Kung, 2000; Yan \& Chen, 2015; Yep, 2015). In other words, individual households have a right of use and not a property right, so farmers are not allowed to sell farmland (Tian et al., 2012). Individual households signed contracts with collectives which give them the right of use for a fixed period of time (Tian et al., 2012). In the initial stage of the Household Responsibility System, the duration of the contracts was 1 or 2 years, but in that situation farmers were not motivated to invest in the farmland (Tian et al., 2012). In 1984, the duration of the contracts was extended to 15 years to provide more land-tenure security (CCCPC, 1985, 1986). In 1994, it was decided to extend this to 30 years after the original 15 years had expired (Krusekopf, 2002). Due to the extended duration of the contracts, farmers have greatly increased investments in production and the grain output has increased rapidly.

Currently, however, after years of massive urbanization and industrialization, several shortcomings of the Household Responsibility System have emerged. The major shortcoming is the very small size of the farms (Yan \& Chen, 2015). Due to the small area of farmland per household, farmers' agricultural incomes are low. Another issue is farmland abandonment by farmers engaged in rural-to-urban migrant work in urban areas (Yan \& Chen, 2015). Furthermore, according to the government, the CPC party and many scholars, the system hinders the modernization of Chinese agriculture, which should include scale enlargement (Tian et al., 2012). Since 2004, in each annual Document No.1, agricultural cooperatives, large family farms, and dragon-head enterprises ${ }^{7}$ have been promoted as the new production units of Chinese agriculture (Yan \& Chen, 2015), replacing the current small-holder agriculture (He, 2013; He, 2014a, 2014b; Huang, 2011, 2014). To achieve this, the government encourages the development of a market for farmland transfer (He, 2013; He, 2014a, 2014b; Huang, 2011, 2014).

\footnotetext{
${ }^{7}$ Large, leading agribusiness firms
} 
Based on demographic changes in households through marriage, births and deaths, village leaders may reallocate the collective farmland (Kung, 2000). However, the government was afraid that this might have a negative effect on farmers' land-tenure security, as they might lose part of their farmland in a reallocation round (Kung, 2000). In 1984, the government therefore proclaimed that village leaders should not reallocate farmland within the contract period (Krusekopf, 2002). At the same time, the government encouraged farmers to transfer their land rights through a farmland transfer market, based on the idea that the market could provide for a more efficient reallocation of farmland than the village leaders (Krusekopf, 2002). However, the farmland transfer market developed only extremely slowly. In 2003, the Rural Contracting Law came into force to make clear that farmers were allowed to transfer their land use rights to other citizens or agricultural enterprises, under the condition that the land should remain in agricultural use (Tian et al., 2012). In addition, in 2012, at the 18th National Congress of Communist Party, the establishment of a rural farmland transfer market was given priority and since then a farmland transfer market has developed in several areas (Shao, Zhang, \& Li, 2016).

There are three main types of transfer of land use rights: transfer to another household, to the village committee, or to an agricultural enterprise (large-scale farm) (Tian et al., 2012). The first type applies to, for example, rural-to-urban migrants who can subcontract their farmland to other households in the village who have more labor available (Ma, Heerink, Feng, \& Shi, 2015). In this situation, the land rent is very low, or can even be zero. In case of the second type, the village committee can rent out the land to other households. The third type, households subcontracting their farmland to largescale farms, is the most complex due to the involvement of multiple households (Tian et al., 2012). It requires several rounds of bargaining with households. In addition, the land rent is generally higher and the transfer is more formal, with long-term contracts (Tian et al., 2012). Systematic scientific assessments of the farmland transfer market are still lacking (Mu, Zhang, Wang, \& Dhruba Bijaya, 2012).

\subsubsection{Household Registration System}

The duality between city and countryside has a long history in China (Bai \& Bai, 2007; Ren, 2004). In 1958, a new dimension was added with the introduction of the so-called Household Registration System, with the aim to restrict the population flow from rural to urban areas (Liu, 2005). Since then, Chinese residents are officially categorized into two groups, with either rural or urban residential permits or hukou (Ge, 2003; Wu, 2011). The overwhelming majority of the people (approximately 90\%) were registered as rural hukou. The Household Registration System created an invisible wall between rural and urban residents, and placed rural residents in an extremely disadvantaged position compared to urban residents (Chan et al., 1999; Z Liu, 2005; Quheng \& Gustafsson, 2014; Whalley \& Zhang, 2007; Zhu, 2007). In allocating the scarce re- 
sources, the government gave priority to urban residents, for example through subsidized grain rations ${ }^{8}$, housing benefits, allocation of employment positions, medical care, and pensions. Rural residents were not entitled to these benefits and were expected by the government to be self-sufficient (Chan et al., 1999; Z Liu, 2005; Quheng \& Gustafsson, 2014; Whalley \& Zhang, 2007; Zhu, 2007).

In the period from 1958 to 1978, population mobility from rural to urban areas was strictly controlled (Zhu, 2007), and it was very difficult for rural residents (farmers) to change to an urban hukou (Chan, Liu, \& Yang, 1999; Zhu, 2007). The rural residents were bound to the farmland in the villages and only a very small portion had the chance to obtain an urban hukou through their career (Quheng \& Gustafsson, 2014). The main channel was recruitment by the state, for example in government departments, schools, and state-owned companies. Other channels included a university education, a position in the military, or outstanding accomplishments such as in sports (Liu, 2005; Quheng \& Gustafsson, 2014).

In the 1980s, due to the policies of reform and opening up, the flow from rural to urban areas increased, in particular of young migrant workers (Liu, 2005). The regulation of population mobility based on the Household Registration System became less strict. Since 1980, there are two other types of residential permit, including a temporary permit and a semi-permanent 'blue-stamp' hukou (Liu, 2005). These differ from the regular hukou in that they are issued by the local government instead of the central government (Liu, 2005). With a temporary permit and blue-stamp hukou, rural migrants can live in urban areas and invest, buy, be employed, operate a business, and even enter primary and secondary education (Webber, 2008). However, for the majority of migrants these special types of hukou are difficult to obtain due to the high entry fee (Goodkind \& West, 2002). In some attractive cities, this so-called "urban administrative fee" can be up to 50,000 yuan (Goodkind \& West, 2002).

In the 1990s, the privileges connected to urban hukou were reduced (Zhu, 2007). For instance, the distribution of grain rationing coupons was terminated in 1992. In 1993, the State Council called for a replacement of the dual urban-rural hukou system with a unified system (Goodkind \& West, 2002). However, despite that the need for a reform of the Household Registration System has been acknowledged by the government and Chinese scholars already for a long time, there are still no concrete, detailed plans.

With the large-scale industrialization and urbanization of the past decades, another problem of the Household Registration System has gradually emerged (Zhu, 2007). In the cities, there is a strict distinction between the local urban residents and the rural-to-

\footnotetext{
${ }^{8}$ The grain rationing system was introduced in the 1950 s to control the production of food and to boost industrialization. Urban households were given grain coupons with which they could buy grain at a low, stateimposed price. Available from: https://en.wikipedia.org/wiki/Grain_rationing_in_China
} 
urban migrants. The latter group, often referred to as "China's floating population", increased from 21 million in 2000 to 253 million $^{10}$ in 2014 (NBSC, 2015). The majority of floating people has a double residential status (Zhu, 2007), but, although they live in urban areas, permanent settling is not possible without an urban hukou.

There are four major reasons why successful settlement in cities is very difficult for rural-urban migrants. First, it is difficult for migrants to gain an urban hukou, especially in the bigger cities (Chan et al., 1999). As a consequence, there is a large majority of non-hukou migrants and a small minority of hukou migrants (Chan et al., 1999). The hukou migrants, who have successfully applied for an urban hukou, are generally highly educated and skilled workers, whereas the non-hukou migrants are unskilled and poorly educated (Lichtenberg \& Ding, 2008). Second, in the cities non-hukou migrants do not have access to services and social benefits, such as schools and health benefits, and are not allowed to buy a house (Whalley \& Zhang, 2007). The social benefits are provided by the state and distributed by the local governments, mainly based on the registered place of residence. Thus, local governments have the means or right to exclude rural-tourban migrants from social benefits (Whalley \& Zhang, 2007). Third, most migrant farmers are in fact not very motivated to change their hukou, because they would then lose their land use rights (Zhu, 2007). Even though their land holdings are small, the farmland is often the last resort for migrants confronted with unstable employment and low salaries in the cities (He, 2013; He, 2014a, 2014b; Hebel, 2003). Fourth, as migrant work usually means low salaries and unstable employment, the majority of rural-tourban migrants move to the cities for survival rather than with the aim of permanent settlement (He, 2013; He, 2014a, 2014b; Hebel, 2003).

\subsubsection{Sustainable agriculture}

In recent decades, the shortcomings of modern, input-intensive agriculture have gradually become apparent, such as environmental degradation. From the perspective of yield, modern agriculture is very successful given the strong increase in productivity (Gray \& Gibson, 2013), but in the long run it is not sustainable (Wiggins, 2013; Khan, Hanjra, \& Mu, 2009). In the 1980s, the concept of sustainable agriculture emerged in the United States in response to the problems of modern agriculture, and since then it has become increasingly popular among scholars and policy makers. For instance, in 1992 the Chinese government included the goal of sustainable agriculture and rural development into China's Agenda 21. However, there is no generally agreed definition of sustainable agriculture thus far (Pfeffer, 1992; Wang, Liu, \& Wu, 2009), and more

\footnotetext{
9 The "floating population" (流动人口, Liu dong ren kou) refers to migrants who have moved across a township border for more than 6 months, without changing their residential registration (Goodkind \& West, 2002; Zhu, 2007).

${ }^{10}$ Available from: http://www.stats.gov.cn/tjsj/ndsj/2015/indexch.htm
} 
than 400 definitions with different indicators have been proposed (Golusin \& Munitlak Ivanović, 2009). As a general concept, sustainable agriculture is vague (Rigby, Woodhouse, Young, \& Burton, 2001), not precisely defined (Pretty, 1995), and should be made time- and space-specific when applied (Pretty, 1995; Zhen et al., 2005).

The fundamental aim of sustainable agriculture is to maintain a social-ecologicaleconomic balance (Baker, 2006; Wang et al., 2009). An integrative approach to these three interdependent dimensions is central to the concept of sustainable agriculture (Golusin \& Munitlak Ivanović, 2009; Raedeke \& Rikoon, 1997; Robertson, 2015; Rosset \& Altieri, 1997; Trauger, 2009; Urech, 2000; Wang et al., 2009; Zhen et al., 2005). The three dimensions of sustainable agriculture are widely recognized (Prandl-Zika, 2008; Zhao, Luo, Deng, \& Yan, 2008; Zhen et al., 2005), and sustainability is understood to include economic viability, social equity and cohesion, and protection of the environment and natural resources (Golusin \& Munitlak Ivanović, 2009; Raedeke \& Rikoon, 1997; Robertson, 2015; Rosset \& Altieri, 1997; Trauger, 2009; Urech, 2000; Wang et al., 2009; Zhen et al., 2005). For each dimension, more detailed requirements have been proposed. For example, according to Robertson (2015), for economic sustainability, the value of agricultural products (output) should exceed the cost (input); for social sustainability, agriculture development should benefit human welfare in terms of social justice and security; and for ecological sustainability, agriculture must conserve water, soil, biodiversity and climate. In the view of Zhen et al. (2005), the economic dimension of sustainable agriculture relates to productivity and income; the social dimension to food self-sufficiency and an efficient knowledge extension system; and the ecological dimension to the protection of water and soil, and the prevention of pollution and ecological degradation.

Stakeholder participation is generally perceived as a prerequisite for sustainable development, including the development of sustainable agriculture (Pimbert, 2004; Reed, 2008). Normatively, the argument for participation is that it is a democratic right (Arnstein, 1969; Reed, 2008); pragmatically, the argument is that it enhances the quality of decision-making (Reed, 2008), based on 'ground truthing' of the specific natural, social, economic, and cultural conditions in the area of implementation (Pimbert, 2004). The underpinning philosophy is empowerment, equity, trust, and learning (Reed, 2008). However, due to social marginalization and exclusion, "the voice from below" often cannot be heard, and local people's knowledge and values are ignored by those in power (Pimbert, 2004). With regard to the first argument, participation involves a reallocation of power, giving the "have-nots" (powerless people) the right to obtain information and to join the process of policy planning, design, and implementation (Arnstein, 1969). With regard to the second argument, mutual learning between scientists and local people is needed to generate new, integrative and comprehensive knowledge. According to Pimbert (2004), this requires that scientists and policymakers abandon their top-down approach and learn from local traditions of knowledge and local people's values. 
In agricultural development, farmers are the basic decision-making units, and the cooperation of farmers is therefore essential to achieve the goal of sustainable agriculture (Ma et al., 2009). Farmers should, however, not be treated as passive followers (Van der Ploeg, 2003). Sustainable agriculture projects may fail when the local conditions and the perspectives of the farmers are ignored (Grudens-Schuck, 2000). Moreover, as farmers are the subjects and direct beneficiaries of sustainable agriculture, their voices should be emphasized and they should be treated as "insiders" rather than "outsiders" in agricultural policy development (Sillitoe \& Marzano, 2009). It is important to recognize that different actors - farmers, scientists, and policymakers - have different perspectives on sustainable agriculture, depending amongst other, on their actor-specific knowledge (Grudens-Schuck, 2000). Cooperation amongst farmers, scientists, and policymakers to share their diversified agriculture-related knowledge, is therefore essential to develop effective plans for sustainable agriculture (Pretty, 1995).

Fujisaka $(1989,1994)$ studied the design and implementation of technologies and policies aiming at sustainable agriculture in Southeast Asia. He concluded that success or failure depended on whether the farmers' problems were correctly identified; farmers' knowledge was taken into account; a comprehensive assessment of costs, benefits and risks was made; the appropriateness of a general solution for the local conditions and values was considered; new technologies were significantly better than current farmer practice; and incentives were not likely to have perverse effects. Sound problem diagnosis based on field visits and participation of farmers in local adaptation based on a 'menu' of options greatly enhanced the probability of successful implementation.

\subsection{RESEARCH APPROACH AND OUTLINE OF THIS DISSERTATION}

The objectives of the study presented in this dissertation were, in sum, to assess how comprehensive the Chinese governmental strategy for agricultural development and major alternatives are; to determine the perspectives of Chinese farmers on problems and possible solutions in agricultural development; and to assess whether the strategies take farmers' perspectives into account and how this can be improved. The mixed methods research approach to achieve these objectives consisted of four steps (Figure 1.1).

In step I, the concept of sustainable agriculture is introduced and the context of the study is described, with particular attention for the policies that have shaped agricultural and rural development in China during the past decades (Chapter 1). This introduction is followed by an integrated assessment of problems and solution strategies concerning sustainable agricultural development in China (Chapter 2). The aim was to assess in how far the current sustainability problems of Chinese agriculture are addressed in three alternative strategies in a comprehensive way, i.e., whether the economic, 
social and environmental dimensions of sustainable development are taken into account. The assessment was conducted as a desk-study, based on secondary sources, such as statistical yearbooks, and reports or bulletins from different governmental ministries. A novel element is the quantitative content analysis of "Document No. 1" national policy statements with respect to the balance between measures focusing on the economic, social and environmental dimensions of agricultural development.

In step II, the perspectives and practices of Chinese farmers were studied following a quantitative survey approach (Chapter 3 ). The focus was on the Guanzhong Plain (Shaanxi Province), where the natural conditions are favorable and agriculture is relatively advanced. In other words, an area with good prospects for further agricultural development. Moreover, as the dominant system is double-cropping of maize and winter wheat, the area is representative of agriculture in the North China Plain, the major agricultural production region of China. Questionnaires were administered face-tot-face in 24 villages and the results from 165 respondents were analyzed statistically. Using cluster analysis, four types of households could be distinguished and compared with respect to their practices and perspectives on economic, social and environmental aspects of agriculture and future development. The results made clear that even in a fairly homogeneous area as the Guanzhong Plain, there is considerable diversity in farmers' practices and perspectives, which in our study was associated with farm household type, age, and level of education.

In step III, a qualitative case study approach was followed to gain in-depth insights into farmers' perspectives. For the case studies, three villages were selected, located in agro-ecologically very distinct parts of Shaanxi Province. Daijia is a village located in the Guanzhong Plain, in the central part of Shaanxi Province. As in the villages included in the survey, the dominant system is double-cropping of maize and winter wheat with apples as a cash crop. The two villages contrasting with Daijia are Donghe in the south and Chiniuwa in the north of Shaanxi Province. Donghe village is situated in the Qinba Mountains, where the dominant system is a rotation of oilseed rape and rice, and Chiniuwa village is located in the Loess Plateau region. Here the farmers specialize in the cultivation of jujube fruit. In each village, semi-structured interviews were conducted with about 15 residents, focusing on the economic, social and environmental aspects of farming, the problems the respondents experienced and their ways of coping (including migrant work), and their outlook on the future. The case studies are presented in three separate chapters (Chapter 4-6), which have largely the same introduction and methods sections.

In Step IV, the assumptions concerning farmers' problems and preferred solutions underlying the three strategies for agricultural development, are compared with the findings about farmers' perspectives from the three case study villages (Chapter 7). An assessment is made to what extent these strategies take farmers' perspectives and 
preferences into account, and possible ways are identified how this could be improved. The thesis concludes with a general discussion, summarizing the main findings and conclusions and outlining the research and policy implications (Chapter 8).

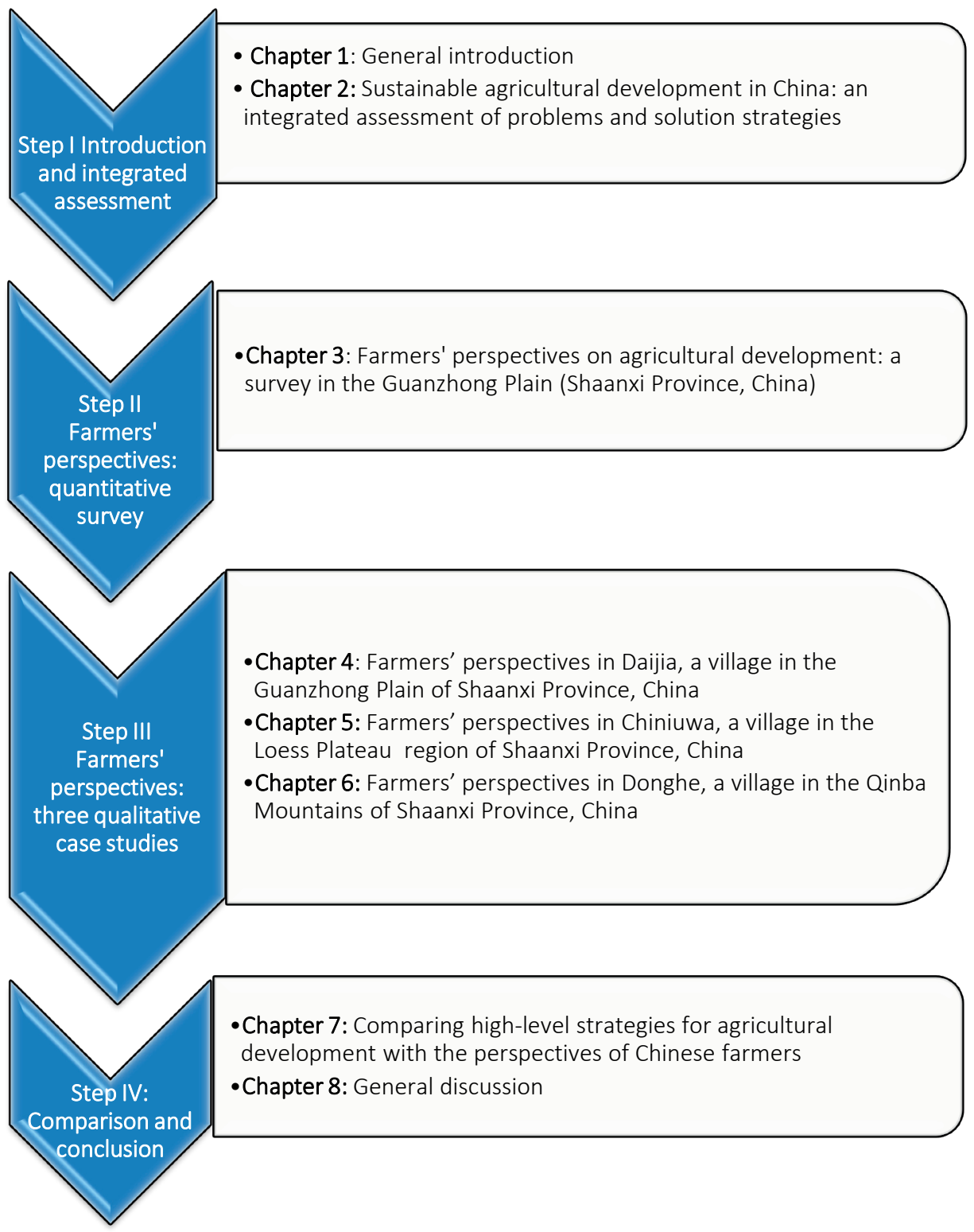

Figure 1.1 Outline of the dissertation 
Chapter

Sustainable agricultural development in China: an integrated assessment of problems and solution strategies 
Abstract: China's agricultural development is characterized by a strong increase in agricultural production and the income of farmers. Major policy goals concerning national food security and rural poverty alleviation have been reached, but at the same time environmental, as well as economic and social problems threaten the sustainability of agriculture. The government aims to address these problems with a modernization strategy in combination with urbanization. Alternative strategies focus on the conservation of small-scale agriculture or the development of ecological agriculture. Here, we present an integrated assessment of these three strategies for agricultural development. The aim was to assess in how far the current sustainability problems of Chinese agriculture are addressed in a comprehensive way, i.e., whether the economic, social and environmental dimensions of sustainable development are taken into account. We found that neither the government's modernization strategy nor the two major alternatives offer a comprehensive and integrated response to the current threats to the sustainability of agriculture. The modernization strategy neglects the need for rural migrant workers to maintain their small land holdings as a fallback option, and measures to control agrochemical pollution are ineffective due to its emphasis on enhancing agricultural production. The alternative strategy to conserve small-scale agriculture does not offer a solution for the widening urban-rural gap and the current environmental problems. The weak spot of the strategy promoting ecological agriculture lies in the difficulty to create an effective market for high added value products and ecosystem services. Moreover, all three strategies neglect the huge variation in local conditions across China and make unverified key assumptions about the needs and wants of Chinese farmers. Investigation of farmers' perspectives on agricultural development and how these vary with local conditions is therefore a much needed step towards a comprehensive and broadly supported strategy for sustainable agricultural development in China.

Keywords modernization; small-scale agriculture; Chinese Ecological Agriculture; urbanization; migrant workers; Document No. 1 


\subsection{INTRODUCTION}

Agricultural development in China during the past decades is characterized by a strong increase in agricultural production and the income of farmers (MEP, 2014). In this way, national food security and rural poverty alleviation, two important policy objectives of the Chinese government, have been achieved (Zhao et al., 2008). However, these achievements have come at a cost. The increase in production is largely based on the intensive use of land and water and application of agrochemicals, in particular fertilizers (Khan et al., 2009; Shen et al., 2013). This has resulted in widespread environmental pollution and degradation of land and water resources (Qu et al., 2011; Yu, 2016). Moreover, although household income from agriculture has increased, this is in most cases insufficient to support the household, and at the same time, the income gap between rural and urban households has widened (Khan et al., 2009; Tian et al., 2016). This gap can also be observed for social security, education and health (Ye, 2009).

The Chinese central government aims to solve these problems, while maintaining national food security, through a transformation to intensive, labour-efficient, large-scale agriculture. The majority of the current rural work-force is expected to find new employment in the rapidly expanding cities. In the scholarly literature, two prominent alternative views can be found on how Chinese agriculture should develop. One of the alternatives argues that the government overestimates the potential for successful urbanization and makes a plea for the conservation and further development of smallscale agriculture. The other alternative view argues that pollution and depletion of natural resources will constrain the future agricultural development, and that the focus should be on resource conservation and reduction of external inputs.

Here, we present an integrated assessment of the governmental policy on agricultural development and the two alternative views described above. The aim is to assess in how far these three (proposed) development strategies address the current sustainability problems of Chinese agriculture in a comprehensive way, i.e., whether the economic, social and environmental dimensions of sustainable agricultural development are taken into account. These three dimensions are an accepted representation of the notion that sustainable agricultural development encompasses more than the biophysical sustainability of agricultural production and can already be found in the Agenda 21 chapter on 'Promoting sustainable agriculture and rural development' (UN, 1992). Thus, a sustainable agriculture is one which is environmentally sound, socially equitable, and economically viable (Allen et al., 1991). In assessments, this refers in more concrete terms to socioeconomic factors such as productivity, farmer income, education, and health, and to environmental factors such as pollution and depletion of natural resources (Smith and McDonald, 1998; Zhen and Routray, 2003; Rao and Rogers, 2006). We start our assessment with a summary of agricultural development in China, followed by an overview of the major economic, social and environmental sustainability problems. Both sections 
focus on the past 25 years and are largely based on primary statistical sources. We then describe the governmental policy for agricultural development and the two major alternative views, and assess to what extent each of these solution strategies addresses the presented range of sustainability problems. We end with a discussion of the limitations and implications of our assessment study and our conclusions.

Previous reviews and assessments of sustainable development of Chinese agriculture focused on problems and solution strategies concerning the environmental impacts of agricultural production (Cheng et al., 1992; Wen et al., 1992; Zhao et al., 2008; Chen et al., 2014; Shen et al., 2013; Yu, 2016). The major novel element of our assessment is the integrated approach with ample attention to all three dimensions of sustainable agricultural development and a comparison of the government's development strategy with two major alternatives. Another novel element is the quantitative content analysis of the so-called 'Document No. 1' papers, the first policy document jointly released each year by the Central Committee of the Communist Party of China and the State Council, with respect to the balance between measures focusing on the economic, social and environmental dimensions of agricultural development.

\subsection{AGRICULTURAL DEVELOPMENT IN CHINA}

In the past three to four decades, since the reforms of the late 1970s, Chinese agriculture has strongly intensified in terms of use of external inputs. As table 1 shows, the use of fossil oil-based inputs in Chinese agriculture (chemical fertilizer, chemical pesticides, plastic sheeting and diesel) has more than doubled between 1990 and 2010. During the same period, the total power of agricultural machinery increased more than threefold, whereas the area under irrigation increased by one third. Except for irrigation, the increase in the use of the other inputs has leveled off since 2010. Compared to the 1950s, when Chinese farmers started using external inputs, the increases are even much larger, such as a 30-fold increase for pesticides (Wang, 2013).

Table 2.1 Total use of fossil oil-based based inputs (104 ton), agricultural machinery power (104 kw) and irrigation (103 ha) in Chinese agriculture from 1990-2013 (Sources: NBSC 2006, 2011, and 2014)

\begin{tabular}{lllllll}
\hline Year & Chemical fertilizer & $\begin{array}{l}\text { Chemical } \\
\text { pesticides }\end{array}$ & $\begin{array}{l}\text { Plastic } \\
\text { sheeting }\end{array}$ & Diesel & Agricultural machinery & $\begin{array}{l}\text { Irrigated } \\
\text { area }\end{array}$ \\
\hline 1990 & 2,590 & 73 & 48 & - & 28,708 & 47,403 \\
1995 & 3,594 & 109 & 92 & 1,088 & 36,118 & 49,281 \\
2000 & 4,146 & 128 & 134 & 1,405 & 52,574 & 53,820 \\
2005 & 4,766 & 146 & 176 & 1,903 & 68,398 & 55,029 \\
2010 & 5,562 & 176 & 217 & 2,023 & 92,781 & 60,348 \\
2012 & 5,839 & 181 & 238 & 2,108 & 102,559 & 62,491 \\
2013 & 5,912 & 180 & 249 & 2,155 & 103,907 & 63,473 \\
\hline
\end{tabular}


As a result of this intensification, agricultural production and productivity per area has strongly increased, with positive consequences for national food security, farmer income and rural poverty (Khan et al., 2009). Between 1990 and 2013, the total production of grains (including the three major food crops rice, wheat, and corn) has increased almost each year (Table 2). This increase was mostly due to an increase in the production of corn and to a lesser extent of wheat. As table 2 shows, the productivity, the grain production per unit of land, increased with a similar percentage as the total grain production over this period: $37 \%$ and $35 \%$ respectively. This means that the increase in production was exclusively due to an increase in land productivity and not to an increase in the total area of land available for grain production. Due to this increase in productivity, the grain production per capita, an important indicator of food security, also rose between 1990 and 2013, despite a growth in population from 1.14 to 1.36 billion. It is, however, also important to note that the efficiency of input use in Chinese agriculture has decreased substantially over the past decades, given that the use of inputs more than doubled whereas the production increased by 'only' one-third.

Table 2.2 Total production, productivity and per capita production of grains in China from 1990-2013 (Sources: NBSC 2006, 2011 and 2014)

\begin{tabular}{|c|c|c|c|c|c|c|c|c|c|}
\hline \multirow[t]{2}{*}{ Year } & \multicolumn{4}{|c|}{ Grain production ( $10^{4}$ ton) } & \multicolumn{4}{|c|}{ Grain productivity $\left(\mathrm{kg} \mathrm{ha}^{-1}\right)$} & \multirow{2}{*}{$\begin{array}{l}\text { Grain } \\
\text { production per } \\
\text { capita }(\mathrm{kg})\end{array}$} \\
\hline & Total & Rice & Wheat & Corn & Total & Rice & Wheat & Corn & \\
\hline 1990 & 44,624 & 18,933 & 9,823 & 9,682 & 3,933 & 5,726 & 3,194 & 4,524 & 390 \\
\hline 1995 & 46,662 & 18,523 & 10,221 & 11,199 & 4,240 & 6,025 & 3,541 & 4,917 & 385 \\
\hline 2000 & 46,218 & 18,791 & 9,964 & 10,600 & 4,261 & 6,272 & 3,738 & 4,598 & 365 \\
\hline 2005 & 48,402 & 18,059 & 9,745 & 13,937 & 4,642 & 6,260 & 4,275 & 5,287 & 370 \\
\hline 2010 & 54,648 & 19,576 & 11,518 & 17,725 & 4,974 & 6,553 & 4,748 & 5,454 & 408 \\
\hline 2012 & 58,958 & 20,424 & 12,102 & 20,562 & 5,302 & 6,777 & 4,987 & 5,870 & 435 \\
\hline 2013 & 60,194 & 20,361 & 12,193 & 21,849 & 5,377 & 6,717 & 5,056 & 6,016 & 442 \\
\hline
\end{tabular}

Even more spectacular than the increase in agricultural production, has been the rise of farmers' income. According to the Chinese National Bureau of Statistics, per capita net income of rural households improved from 134 RMB in 1978 to 8896 RMB in 2013 (NBSC, 2014a). After a stagnation around the year 2000, farmers' incomes are rising again (Figure 1). The increase in farmers' income has resulted in a strong reduction in rural poverty. According to the latest report on China's implementation of the Millennium Development Goals (MFAC, 2015), the part of the population in extreme poverty decreased from 0.69 billion in 1990 to 0.25 billion in 2011. This reduction has greatly contributed to the successful achievement of the Millennium Development Goal on global poverty reduction, proposed by the United Nations (UN, 2015). 


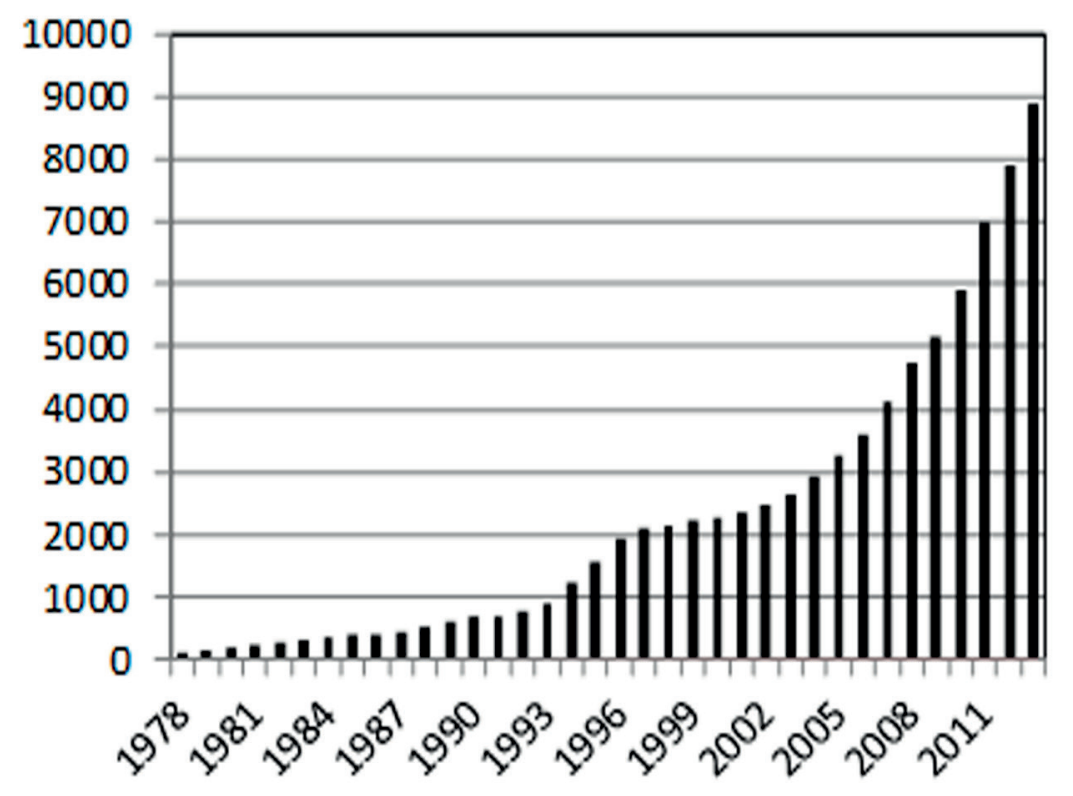

Figure 2.1 Farmers' per capita net real income in China from 1978 to 2013 (in RMB). Real income is calculated as the nominal income divided by the consumer price index. (Source: NBSC, 2014a and 2014b)

\subsection{SUSTAINABILITY PROBLEMS IN CHINESE AGRICULTURE}

The achievements in agricultural development in China over the past decades are impressive, but farmers and farming are not without problems and these problems threaten the long-term sustainability of Chinese agriculture. These problems not only relate to the widespread environmental pollution, degradation of land and water resources and loss of biodiversity. Chinese farmers also face significant economic and social problems, mostly as a result of the widening gap in socio-economic development between the rural areas and the cities. These economic, social and environmental issues in Chinese agriculture are elaborated below.

\subsubsection{Economic problems}

The Chinese National Bureau of Statistics divides the income of rural households into four components ${ }^{11}$ : wages, net income from household operations, property income,

\footnotetext{
${ }^{11}$ 1. Wages: income from members of rural households who are employed by individuals or companies, mainly as migrant workers. 2. Household operations include farming, forestry, animal husbandry, fisheries, industry, construction, transport, postal and telecommunication services, social services, culture, education, health care, and others. 3. Property income is the income from movable and immovable property, such as the interest on bank deposits, the rent of house and land. 4. Transfer income mainly concerns various subsi-
} 
and transfer income. The income from wages and household operations (mainly farming) constitute the major parts of the total net income. Table 3 shows how the share of the incomes from wages and farming has developed from 1990 to 2012 . Whereas in absolute terms both have increased strongly over this period, in relative terms (percentages) the proportion of income from farming has almost halved and the proportion of income from wages more than doubled. Nowadays, the income from wages is the dominant source of income of rural households and it is almost twice as important as the income from farming. This means that overall, Chinese farmers are mainly dependent on income from wages from migrant labour, whereas farming plays only a minor role as a source of income. Moreover, the future significance of income from farming is severely limited by the scale of Chinese farms, about 0.5 ha per household (Tian et al., 2016), which is even by Asian standards very small (Fan and Chan-Kang, 2005).

The strong increase in farmers' income over the past decades has not resulted in a narrowing of the gap in per capita income between rural and urban residents. In fact, the gap has widened as the ratio of per-capita income in urban versus rural areas has grown from $2.6: 1$ in 1978 to $3.1: 1$ in 2013 (Mu and Fan, 2015). Since 2001, this ratio is approximately stable at 3:1 (OECD, 2004; Sicular et al,. 2007), which makes China the country with the largest urban-rural income gap in the world (Zeng and Hu, 2007). The actual gap is probably even much larger due to the lack of social security for rural residents and the need for farmers to re-invest a large proportion of their income in inputs for agricultural production.

Table 2.3 Per capita net income of rural households: total and income from wages and farming (Sources: NBSC 2006, 2011 and 2014)

\begin{tabular}{llll}
\hline Year & Net income per capita (RMB) & $\begin{array}{l}\text { Wages income, } \\
\text { absolute (RMB) and } \\
\text { proportion (\%) }\end{array}$ & $\begin{array}{l}\text { Farming income, } \\
\text { absolute (RMB) and } \\
\text { proportion (\%) }\end{array}$ \\
\hline 1990 & 686 & $139(20 \%)$ & $345(50 \%)$ \\
1995 & 1,578 & $354(23 \%)$ & $799(51 \%)$ \\
2000 & 2,253 & $702(31 \%)$ & $834(37 \%)$ \\
2005 & 3,255 & $1,175(36 \%)$ & $1,098(34 \%)$ \\
2010 & 5,919 & $2,431(41 \%)$ & $1,723(29 \%)$ \\
2011 & 6,977 & $2,963(43 \%)$ & $1,897(27 \%)$ \\
$2012^{\text {a }}$ & 7,917 & $3,447(45 \%)$ & $2,107(27 \%)$ \\
\hline
\end{tabular}

a. Income data for 2013 are not included in the China Rural Statistical Yearbook 2014

A third major trend, in addition to the growing importance of income from migrant wages and the widening income gap between rural and urban residents, is the change

dies from the government, such as pension subsidy, direct subsidy for grain farmers and subsidy for agricultural machinery. Source of income definitions: website of the National Bureau of Statistics of China,

http://data.stats.gov.cn/easyquery.htm?cn=C01\&zb=A0A0C\&sj=2014 


\section{Chapter 2}

in the agricultural labour force, both in numbers and composition. According to agricultural census data (NBSC, 2008), the number of people active in farming decreased from about 424 million in 1996 to 349 million in 2006. A comparison of the characteristics of members of rural households active in farming with those active off-farm as migrant workers in cities, shows that those active in farming are predominantly female, older and less educated (Table 4). In China, this phenomenon is popularly referred to as the "3899" brigades of agricultural labor ("38" means Women's day, and "99" means Chong Yang, Old People's Festival).

Finally, there is a growing trend of farmers abandoning their cultivated land (Guan and Wang, 2013). More and more, the income that farmers can generate from their small pieces of land (approximately 0.1 hectare per capita), is not considered worth the effort, in particular when compared to the income that can be generated from migrant labor in the cities.

Table 2.4 Gender, age, and education of on-farm agricultural labor and off-farm migrant labor in China (Source: NBSC, 2008)

\begin{tabular}{lll}
\hline & $\begin{array}{l}\text { Farmers } \\
(349 \text { million })\end{array}$ & $\begin{array}{l}\text { Migrant workers } \\
(132 \text { million })\end{array}$ \\
\hline $\begin{array}{l}\text { Gender } \\
\text { Male }\end{array}$ & $47 \%$ & $64 \%$ \\
Female & $53 \%$ & $36 \%$ \\
Age & & \\
$<20$ & $5.3 \%$ & $16.1 \%$ \\
$21-30$ & $14.9 \%$ & $36.5 \%$ \\
$31-40$ & $24.2 \%$ & $29.5 \%$ \\
$41-50$ & $23.1 \%$ & $12.8 \%$ \\
$>50$ & $32.5 \%$ & $5.1 \%$ \\
Education & & $1.2 \%$ \\
Illiterate & $9.5 \%$ & $18.7 \%$ \\
primary school & $41.1 \%$ & $70.1 \%$ \\
middle school & $45.1 \%$ & $8.7 \%$ \\
high school & $4.1 \%$ & $1.3 \%$ \\
university/college & $0.2 \%$ & \\
\hline
\end{tabular}

\subsubsection{Social problems}

Not only economically in terms of income, but also in many other, social aspects there is a big gap between the conditions of rural and urban residents. Most notable are the differences between rural and urban areas with respect to health, education and social security (Ye, 2009). 
In China, life expectancy, as a major indicator of people's health status, has increased substantially from 43 years in 1960 to 73 years in 2010 (Li et al., 2014; Hu, 2010). However, there is a widening gap in life expectancy between urban and rural residents. For instance, in 1982, the life expectancy of urban residents was 4 years longer than that of their rural counterparts ( $\mathrm{Hu}, 2010)$, and this difference has increased to 4.5 years in 2010 (Li et al., 2014). In this year, the life expectancy of urban residents was 76.6 years, whilst the life expectancy of rural dwellers was 72.1 (Li et al., 2014). In the literature, several major causal factors are suggested for this growing difference between urban and rural life expectancy. First of all, the level of health care and access to the health care system in rural areas is not as good as in cities (Gong et al., 2012). Second, water sanitation in many rural areas is poor. For instance, in half of the rural areas there is no centralized water distribution system and no access to public water supply, meaning that the drinking water in these areas is untreated (Zhang et al., 2010). Third, in-door air pollution is generally high in rural areas, due to the use of firewood, coal and other highly polluting household fuels (Gong et al., 2012).

Also with respect to education, there is a gap between the urban and rural areas, and also this gap is widening (Liu, 2010; Wang, 2014; Wang, 2008). In 2009, there were ten times more high schools per 100 thousand students in urban areas than in rural areas (Wu, 2014). The proportion of college students from rural areas continues to drop. In the 1980s, the proportion of college students from rural households was still more than $30 \%$, whereas this proportion has decreased to $15 \%$ during the past 30 years (Hou et al., 2014).

After the founding of the People's Republic of China in 1949, a social security system was developed for urban residents. The development of a substantial social security system for rural residents, however, has only recently begun. For example, the new cooperative medical scheme and the new rural pension system were adopted in 2008 and 2009, respectively (You and Kobayashi, 2009; Liu et al., 2015; Wang and Béland, 2014). Indicative of the rural-urban gap in social security is the difference in transfer income between rural and urban citizens. In 2006, the transfer income, which concerns various subsidies from the government such as pensions, constituted only $5 \%$ of rural citizens' income versus $20 \%$ of urban citizens' income (NBSC, 2006).

\subsubsection{Environmental problems}

The large-scale intensification of Chinese agriculture has resulted in widespread environmental pollution, emission of greenhouse gases, degradation of land and water resources and loss of biodiversity. These problems will be elaborated below.

\subsubsection{Water resources}

Due to the intensive use of chemical fertilizers and pesticides, agriculture is currently the main non-point source of water pollution in China (Ongley et al., 2010; Qu et al., 
2011; Li et al., 2015). The major part of these chemicals does not reach the target, the crop. The uptake of chemical fertilizer by crops ranges from 30 to 40\% (Ren et al., 2009; Sun and Song 2008). For phosphate fertilizers, it is even estimated to be less than $20 \%$ (Li et al., 2015). The amount of pesticides applied per hectare is on average two or three times the recommended amount, and only 30\% reaches effectively the crop plants (Sun et al., 2012). The remainder of these agrochemicals leaches into the ground water and runs from the cropland to the surface water(Sun et al., 2012; Zhen et al., 2005). The combination of fertilizer application and irrigation, which is prevalent in China, results in even more serious surface and ground water pollution (Zhen et al., 2005). The total nitrogen loss from agricultural activities through surface runoff and underground leaching is about 1,597,800 tons (Sun et al., 2012), whereas the total phosphorus loss is about 108,700 tons from cropland and 160,400 tons from animal husbandry (Li et al., 2015). The problem is expected to grow worse, because among Chinese famers the trend is to increase the amounts of applied fertilizer even further (Yang and Fang, 2015).

Precise data on the extent of water pollution at the scale of the entire country are not available, nor on the exact contribution of agriculture to the total water pollution in China (Ongley et al., 2010). Overall, the quality of water in China appears to be in a poor state (Khan et al., 2009), with fertilizer-based eutrophication as a major contributing factor (Liu and Raven, 2010). According to a report of the Ministry of Water Resources of China (MWRC, 2014), both surface and ground water are confronted with serious degradation in quality. For instance, $4.5 \%$ of reservoirs, $11.7 \%$ of rivers and $20.7 \%$ of lakes are in class $\mathrm{V}+$, which is below the quality class (V) with the lowest environmental quality standards for surface waters in China. The quality of ground water is even more seriously degraded, with $35.9 \%$ in class V+ (MWRC ,2014).

In addition to pollution, the depletion of water resources in Chinese agriculture is also a serious problem (Jiang, 2009). Agricultural water use accounts for about two-thirds of the total water consumption in China (MWRC, 2014). However, the efficiency of agricultural water use is very low, as nearly half of the water is wasted and the water demand of $1 \mathrm{~kg}$ grain in China is twice that in developed countries (Zhao et al., 2008). Two other factors make the problem even worse. First, China's average annual water supply per capita (about 2,100 $\mathrm{m}^{3}$ ) is only one quarter of the world average of $8,513 \mathrm{~m}^{3}$ (Khan et al., 2009; World Bank, 2006). Second, the water distribution is very unbalanced between the north and the south of China (Tso, 2004). The north part of China covers more than half of the arable land but has only $20 \%$ of the water resources (Tso, 2004), resulting in severe water shortage in the north (WorldBank, 2006). To meet irrigation needs, overextraction of ground water is widespread and results in rapidly dropping water tables (Liu and Raven 2010; Zhen et al. 2005; Qu et al.2011).With government support for electromechanical irrigation pumps and increasing area of irrigated land (Table 1), the depletion of water resources is expected to increase further (Zhen et al., 2005). 


\subsubsection{Land resources}

Every year, large areas of land are lost for agriculture in China due to construction projects, natural disasters and, most importantly, ecological restoration projects converting farmland into forests or natural grasslands (Qu et al., 2011). For instance, the net loss of cultivated land was 361,600 ha in 2001 and 80,200 hectare in 2012 (MLRC, 2001, 2005, 2008 and 2013). In addition, there is serious farmland degradation and pollution in China. Almost $20 \%$ of the cultivated land is polluted due to overuse of chemicals and pollution from rural industries and mining activities (MEP and MLRC, 2014). An important agricultural source of pollution is plastic sheeting, which is used in ever larger quantities by Chinese farmers (table 1). It is made of a synthetic polymer which only degrades very slowly in the soil (Wei, 2014), and almost $42 \%$ of the plastic sheeting is left in the soil after use (Sun and Song, 2008). Soil erosion is also serious and results in large nutrient losses from arable land each year (Wang et al., 2007). Almost 3 million square kilometers of land are eroded, which represents approximately $30 \%$ of the total land area (MWRC, 2013). Water and wind are about equally important factors in soil erosion (MWRC, 2013).

\subsubsection{Greenhouse gas emissions}

The agricultural sector is responsible for $11 \%$ of the total greenhouse gas emissions of China, through emissions of $\mathrm{CO}_{2}, \mathrm{CH}_{4}$, and $\mathrm{N}_{2} \mathrm{O}$ (Li et al., 2012; Liu and Zhang, 2011; Nayak et al., 2015). The main sources are paddy rice cultivation, livestock, fertilizer use, production of agrochemicals and use of fossil fuels (Tan, 2011). More specifically, the emissions from the production of chemical fertilizers, pesticides, and plastic sheeting, and the use of fossil fuel account for almost 35\% of agriculture-related emissions, and are expected to increase even further given the persistent growth in use of agrochemical inputs (Tan, 2011). For instance, a 15\% increase in nitrogen fertilizer application in rice will result in a $12 \%$ increase of soil $\mathrm{N}_{2} \mathrm{O}$ emissions (Nayak et al., 2015).

\subsubsection{Biodiversity}

Data on biodiversity trends in the agricultural landscapes of China are not available, because in the Chinese biodiversity statistics no distinction is made between natural and agricultural landscapes. However, the aggregated statistics show a continuing decline of biodiversity in China (MEP, 2014). For example, the conservation status of threatened species of birds, and especially mammals, freshwater fish and plants has deteriorated each year from 1998 to 2004 (Xu et al., 2009; MEP, 2014). Currently, about $35 \%$ of invertebrate and vertebrate animal species are endangered, and $30 \%$ of the higher plant species require attention and protection (MEP, 2014). Major drivers of biodiversity loss in agricultural landscapes are (1) habitat loss due to conversion of (semi-) natural ecosystems to cultivated land and (2) pollution by agrochemicals (MEP, 2014). In China, large-scale, subsidized afforestation of marginal croplands on steep slopes has actually resulted in an increase in forest area from 2000 onwards (Xu et al., 
2009; Lü et al., 2011; MEP, 2014). However, these new forests consist mostly of exotic species and single-species tree plantations (Liu and Raven, 2010; Lü et al., 2011) and their contribution to biodiversity may even be negative (Cao et al., 2009). Furthermore, the area of grasslands and wetlands has decreased continuously since the early 1980s, mainly due to conversion to farmland (Liu and Diamond, 2005; Xu et al., 2009; Zhao et al., 2015). In combination with the strong increase in the use of pesticides and nitrogenand phosphate-based chemical fertilizers, as described above, it is highly probable that the biodiversity of many agricultural landscapes has severely suffered from decades of continuing agricultural intensification and expansion (Liu et al., 2013, Xu et al., 2009).

\subsection{STRATEGIES FOR AGRICULTURAL DEVELOPMENT}

\subsubsection{Governmental policy}

In the People's Republic of China, the central government has a large impact on agricultural development and its policy has led to significant changes in Chinese agriculture. Historically, Chinese agricultural policy is usually divided into three periods (Hou, 2006; Hu 2014; Ren et al., 2009; Zhou, 2014a): the traditional, the transformational, and the new period. The 'traditional period' starts with the founding of the People's Republic of China in 1949 and ends with the reforms and opening to the outside world in 1978. During this period, agricultural labor, capital and land were all employed by the state (Xin and Gao, 2009). The main characteristics of Chinese agriculture in this period were the planned economy and the collective farm management system of the people's communes. The 'transformational period' runs from 1978 to 2002. The reforms that started in 1978 concerned primarily the replacement of the collective farms with the socalled household responsibility system. Arable land was allocated to each household according to family size and land quality. The 'new period' of agricultural policy is still on-going and started in 2003. The basic principles of the government's policy in this period are expressed in the slogan "giving more, taking less, and loosening control". "Giving more" refers to increased investment in rural and agricultural infrastructure and subsidies. "Taking less" refers to the lowering or abandoning of agricultural taxes. Finally, "loosening control" refers to further development of the rural and agricultural market system and stimulation of self-employment and private business development.

To obtain a better insight into the balance of Chinese agricultural policy with respect to economic, social and environmental dimension of development, we conducted a content analysis of a set of primary sources of governmental policy called the 'Document No. $1^{\prime}$ papers. Document No. 1 is the first policy document jointly released each year by the Central Committee of the Communist Party of China (CPC) and the State Council ${ }^{12}$.

${ }^{12}$ See: http://baike.baidu.com/view/1391355.htm (in Chinese) 
As the name already indicates, this document intends to set the annual policy agenda and guide the work of governments and party organizations at all levels in China (Ye, 2009). Each year, the document has a certain focus, usually reflected in the title. The issues addressed in these documents can be understood as the problems considered most important by the Chinese central government (Chen et al., 2016; WeigelinSchwiedrzik, 2008). Over the period 1982-2015, 17 of these policy documents focused on agricultural and rural development. We analyzed the 17 documents with respect to overall focus (as reflected in the title), problems identified, goals to be achieved, and measures proposed. These measures we classified according to their focus on economic, social or environmental issues. Below we describe the results of this analysis, which are summarized in figure 2 and in the table in the appendix.

During the 'transformational period' (1978-2002), five consecutive Documents No.1 focused on agriculture. These policy documents, from 1982 to 1986, aimed to guide the reform of the rural economy and the establishment of the household responsibility system in Chinese agriculture. The focus of these documents, as well as the problems identified, goals to be achieved and measures proposed are predominantly located in the economic realm. Major issues are the growth of agricultural production and the functioning of the new market system. During the 'new period' (2003-present), all Documents No.1 since 2004 have focused on agricultural and rural development, indicating the priority status of these issues for the central government. The main goals in this period are rural development and raising farmers' income, in addition to further growth of the agricultural production. To achieve these three goals, the measures focus on food security, agricultural production capacity, rural and agricultural infrastructure, agricultural technology, farmers' income, and integrated development of urban and rural areas. Compared to the 1982-1986 documents, there is more attention for the social dimension of agricultural development, triggered by a concern for the widening gap in development between urban and rural areas. Whereas in the 1982-1986 documents the majority of the measures was always directed at economic issues, this is no longer the case in the Documents No.1 of the 2004-2015 period (figure 2). In the 1982-1986 documents, the average percentage of measures directed at economic, social and environmental issues was 68\%, 24\%, and $8 \%$, respectively. In the 2004-2015 documents, these percentages are on average $49 \%, 37 \%$, and $14 \%$, respectively. The larger proportion of socially-oriented measures in the past decade is mainly directed at narrowing the urban-rural gap and concerns, for example, improvement of the rural education and social security systems (Ye, 2009). During both periods, the environmental dimension of rural and agricultural development has received much less attention in the Documents No.1, except in 2011. Generally, less than $15 \%$ of the measures proposed in these policy documents are directed at environmental issues. 


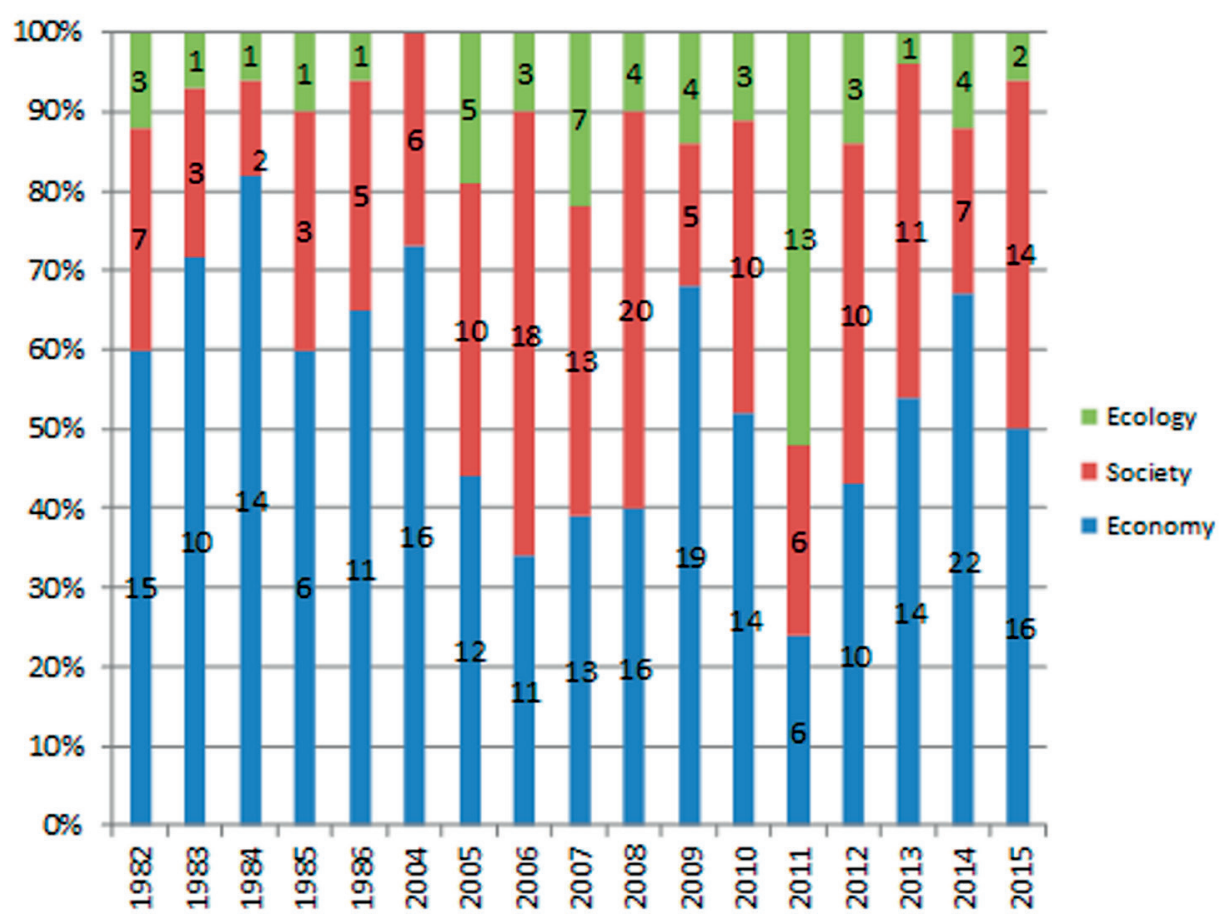

Figure 2.2 Numbers and percentages of measures focusing on economic, social and ecological issues in agriculture and rural development in 17 Documents No.1.

The analysis of the Documents No.1 shows that the Chinese government views agricultural development essentially as a socio-economic issue, with maintaining food security, raising farmer incomes and narrowing the urban-rural gap as the overarching policy goals. To achieve these goals, the government has explicitly chosen for a policy of agricultural modernization, in synchronous development with industrialization, urbanization and informatization, as proposed by the 18th National Congress of the CPC in 2012 (Hao, 2014; Yang et al., 2013). The idea is that industrialization and informatization can create employment opportunities in urban areas and can support the modernization of agriculture. Conversely, agricultural modernization will result in surplus rural labor, which can find employment in the urbanized areas (Yang et al., 2013). The goal of agricultural modernization is explicitly included in the Documents No.1 from 2012 onwards, and since 2013 even in the titles (see Appendix). The specific goals and measures listed in the documents show that the government's modernization policy follows two tracks. On the one hand, it aims at further technological development of input-intensive agriculture to achieve a higher production with less need for human labor. On the other hand, it aims at scale enlargement to raise farmers' income and avoid land abandonment. However, an increase in farm size requires changes in the household responsibility system. The government therefore encourages the separation of ownership, land 
contracting right, and land management right ${ }^{13}$. This allows farmers to rent out their piece of farmland to other farmers or to large companies ${ }^{14}$, thus preventing land abandonment and enabling scale enlargement (Zhou, 2014b; Zhong, 2013).

\subsubsection{Alternative views}

In the scholarly literature, there is support for the governmental modernization strategy, but there are also alternative views expressed on agricultural development in China. Here we present the two major alternative development strategies, the 'school of small-scale agriculture' and the 'school of Chinese ecological agriculture'.

\subsubsection{Small-scale agriculture}

The scholars of the school of small-scale agriculture criticize the assumptions underlying the governmental strategy with respect to urbanization. Their main point is that urbanization is not the perfect solution the government presents it to be. Urbanization is a long-term process and the current state of the urbanization process in China should be understood as "half urbanization" rather than "real urbanization" (He, 2014). The majority of the rural migrant workers does not have adequate employment opportunities and income in urban areas. Their salary is lower than that of urban residents and insufficient for a decent life in the city (Démurger and Xu, 2011; He, 2013 and 2014). They live in poor housing conditions, their children often do not have access to public schools, and their labour rights position is weak. Thus, most of the migrant workers' stay in the cities is temporary. Especially when they are older than 50 years it becomes difficult to find employment and they have to return to their home villages and rely on farming again for food and income. This also applies to younger migrant farmers when they lose their jobs. Thus, it would not be wise to radically speed up scale enlargement of agriculture. If migrant workers no longer have their land as a last resort, there will be a risk of urban slum development and social instability (He, 2014; Tian et al., 2016). The governmental strategy of scale-enlargement thus seems more in the interest of capital investors than in the long-term interest of the current small-holder farmers (He, 2013).

\footnotetext{
${ }^{13}$ Ownership: the farmland in China is collectively owned by a town or village community or village teams. Land contracting right: households in a village are naturally entitled to the contracting right of a piece of the collectively owned farmland. Land management right: normally, the contracting right and the management right are with the same household. In case of a separation of these rights, migrant farmers can rent out their farmland to others.

${ }^{14}$ There are four main types of renting out the farmland to others. The first type is "subcontracting", which means farmers sub-contract their farmland to other farmers within the same collective; the second type is "leasing", which allows farmers to rent out their farmland to other people within or outside of their same collective; the third type is "interchanging" which means that farmers within the same village exchange farmland on different locations. These three types do not change farmers' contracting rights with the collective (Ma et al. 2015). However, the fourth type is "transferring" which means that the contracting right will be transferred to other people (within or outside of the same collective), and farmers lose their farmland contracting right with the collective(Ma et al. 2015).
} 
Moreover, the current small-scale structure of Chinese agriculture not only provides rural migrant workers with a fallback option, but is also important for supporting the rural communities and their social life and culture (Lu and Zhu, 2011; Zhu and Lu, 2011).

The solution to the current problems of Chinese agriculture should therefore not be sought in scale enlargement, but rather in the conservation and further development of small-scale agriculture (He, 2014). One way to do this could be through a policy stimulating the exchange of scattered pieces of land between households to form larger units. Although the proponents of the small-scale agriculture school view the transition from small-scale to larger-scale agriculture as an inevitable process in China, they are opposing the high-paced capital-driven scale enlargement supported by the government (He, 2014). Without an explicit government policy, scale enlargement is happening 'naturally' and at a slower pace, better matching the pace of the urbanization process. For instance, when entire rural households migrate to the city, they tend to rent out their farmland to their relatives or other villagers, thereby gradually enlarging farm scale (He, 2014).

\subsubsection{Chinese Ecological Agriculture}

In the 1980s, government-affiliated scientific experts developed the concept of 'Chinese Ecological Agriculture' (CEA) in response to the 'crisis' of environmental pollution and depletion of natural resources caused by the intensification of agriculture (Wang et al., 2007; Li et al., 2011; Ye et al., 2002). The aim was to combine modern science and technology with traditional knowledge and practices to develop a type of agriculture that delivers a high output of high-quality products with minimal negative impacts on the rural environment and the local resource base (Li et al., 2011). The concept was labeled 'Chinese' to distinguish it from 'Western' ecological agriculture, which was associated with low input levels and correspondingly low yields (Wang et al., 2007). However, in the Chinese context, with its low per capita availability of farmland, high productivity was considered a prerequisite for any serious alternative to conventional 'modern agriculture' (Wang et al., 2007). Moreover, CEA would combine a rational, scientific approach with traditional Chinese values and knowledge of agriculture (Wang et al., 2007; Li et al., 2011).

The main underlying principle of CEA is a strong focus on internal recycling. Recycling reduces both the need for external inputs and the emission of waste products, by reusing the waste of one process as input for another, e.g., using animal manure to produce biogas or chicken droplets to feed fish (Wang et al., 2007; Li et al., 2011). CEA distinguishes itself from organic agriculture by allowing minimal use of agrochemicals and genetic modification (Shi, 2002). It emphasizes both the need for adapting to the local resources, conditions and socio-cultural values (Shi, 2002) and the need for rational, large-scale production to enhance the efficiency of resource use (Wang et al., 2007). The current very small land holdings are seen as one of the causes of overuse of agrochemi- 
cals, as the farmers try to squeeze the maximum production out of their small pieces of land (Cheng et al., 1992), with minimum investment of labour, which competes with the much more profitable migrant labour in cities (Shi, 2002). The small-scale structure is also seen as hampering the adoption of more resource-efficient methods that require larger-scale implementation to be effective (Shi, 2002; Cheng et al., 1992). Associated with the focus on recycling is the emphasis on integrating production and processing into one system, at larger, if possible even regional scales (Wang et al., 2007; Ye et al., 2002). Establishment of local processing enterprises not only provides more opportunities for internal recycling, but also has economic and social advantages (Ye et al., 2002). With processing, the added value of the products can be enhanced and higher profits can be made (Ye et al., 2002). Local processing and marketing enterprises also provide rural employment, thus diminishing the need for migrant labour (Ye et al., 2002; Shi, 2002).

Currently, CEA is practiced on about 7-8\% of the total farmland area in China (Wang et al., 2007), but it is no longer growing (Li et al., 2011). According to Shi (2002), this is - at least partly - due to a lack of strong governmental support for CEA. The government strongly prioritizes production over environmental goals, because wide adoption of CEA would mean - at least at the short-term - accepting a lower agricultural production to achieve long-term ecological sustainability, and lower food production may give rise to social unrest and instability (Shi, 2002). To overcome this dilemma, the proponents of CEA propose to placemore emphasis on product quality than on quantity and to establish higher prices for higher quality. In addition, they make a plea for strengthening supervision of food safety and 'green food' certification, a stronger focus on export to foreign markets, and a multi-functional agriculture including agritourism, maintenance of cultural heritage and payments for ecosystem services to farmers (Li et al., 2011 Wang et al. 2007).

\subsection{ASSESSMENT OF THE THREE STRATEGIES FOR AGRICULTURAL DEVELOPMENT}

In section 3, we have presented an overview of the economic, social and environmental problems threatening the long-term sustainability of Chinese agriculture. Economically, farming has become insufficient and relatively unimportant as a source of income for rural households, whereas wages from migrant labour have become the major source of income. Young farmers go the cities to find employment and the remaining agricultural labor force is relatively old and poorly educated. Increasingly, rural households even abandon their farmland. The major social issue is the widening rural-urban gap, not only in terms of income, but also with respect to health status, education, and social security. Living in the rural areas as compared to the cities, becomes less and less attractive. The consequence of these socio-economic developments for rural inhabitants 
is a very strong push towards the cities, as the better places to live and to work and villages are drained of young and talented people. At the same time, the very intensive use of external inputs in Chinese agriculture undermines its own long-term resource base through large-scale pollution and degradation of land and water. Moreover, the current intensive, high-input agriculture is an important cause of biodiversity loss and a major contributor to the national emissions of greenhouse gases. In this section, we will assess to what extent these sustainability problems are addressed (or not) by the three strategies for agricultural development presented above.

\subsubsection{The modernization strategy}

The focus of the government's modernization strategy is on the socio-economic sustainability problems. Modernization should result in higher agricultural production and labor productivity, thereby raising farmer incomes and narrowing the urban-rural gap. Many additional measures also aim to narrow this gap. An important element of the modernization strategy is the combination of farm scale enlargement on the one hand and urbanization to absorb surplus labor on the other. However, as argued by the proponents of the small-scale agriculture strategy, it appears that with the current limited urban employment opportunities and low wages for rural migrant workers, the small land holdings of rural households are still needed as a fallback option. It seems that this is not adequately accounted for in the government's modernization strategy.

In the modernization strategy, there is generally much less attention for environmental sustainability problems, although a significant exception are the multi-billion dollar 'ecological restoration programs': the Natural Forest Conservation Program and the Sloping Land Conversion Program, also known as the Green-for-Grain Program (ref: Qu et al., 2011; Zheng and Cao, 2015). These programs were launched after devastating floods in 1998 which were attributed to widespread deforestation and soil erosion. The programs have resulted in large-scale conversion of cropland on steep slopes to forests and natural grasslands and an effective reduction of surface water runoff and soil erosion (Qu et al., 2011). However, at the same time, the focus on planting of fast-growing trees has less led to deep soil desiccation and loss of native vegetation and biodiversity (Zheng and Cao, 2015; Cao, 2011). The government's policy also includes agrienvironmental measures addressing overuse of agrochemicals and pollution of water and land. Yet, in practice these are not very effective as they conflict with the government's primary goal of increasing production (Chen et al., 2016; Yu, 2016).

\subsubsection{The small-scale agriculture strategy}

The school of small-scale agriculture is convincing in its criticism of the government's focus on rapid urbanization and farm scale enlargement, but it does not really present an 
alternative solution strategy for most of the current economic, social and environmental sustainability problems in Chinese agriculture. The very small land holdings per household that these scholars aim to conserve are an important cause of these problems: low incomes from agriculture, the large and widening urban-rural income gap and the intensive, environmentally unsustainable use of external inputs to maximize production. Moreover, given the growing urban-rural gap in income, health, education and social security, there is a strong push for farmers to leave the rural areas and even abandon the farmland, despite their often marginalized position in the cities. Except for a modest form of land consolidation, the small-scale agriculture strategy does not have incentives in store that may stop or slow down the urbanization process. It seems that this strategy will mainly result in conservation of the status quo, including all its problems.

\subsubsection{The Chinese Ecological Agriculture strategy}

The Chinese Ecological Agriculture strategy focusses on addressing the environmental sustainability problems, but it also pays attention to the economic and social problems. The CEA and the modernization strategy share the goal of enlarging farm size, but in contrast to the government's strategy of enhancing agricultural productivity and urban employment, the CEA strategy aims at enhancing the quality of agricultural production and expanding rural employment. The main ingredients are production of high quality 'green food', processing in local enterprises, rural education for new skills, and diversification, including agri-tourism. The higher added value of the rural production generated in this way, would provide the basis for higher incomes, jobs and better rural living conditions. The weak spot in the CEA strategy, however, is to effectively market these higher-value products and obtain a higher price (Li et al., 2011). High-quality, locally processed products are generally a niche market, precisely because of their higher price. Moreover, the rather vaguely defined 'green food' products from CEA experience increasing competition from 'classic', Western-style organic products (Scott et al., 2014). Also agri-tourism is a niche market, only applicable to very scenic landscapes or rural areas near cities.

More recently, also 'payments for ecosystem services' have been added to the CEA strategy to raise rural incomes in combination with resource conservation ( $\mathrm{Li}$ et al., 2011). The governmental subsidies to convert croplands to forest or grassland in the Sloping Land Conversion Program can be seen as an example of such payments (Qu et al., 2011). However, although the program is effective in reducing soil erosion, it does not have a significant effect on the income of participating farmers (Qu et al., 2011), and many farmers have indicated that they will convert the land back to cropland when the subsidies will stop (Cao, 2011). This program and projects on payment for water services show that the major bottleneck in 'payment for ecosystem services' schemes is in passing sufficient and stable benefits to the farmers supplying these services (Qu et al., 2011). 


\subsection{DISCUSSION AND CONCLUSIONS}

\subsubsection{Major findings}

To be sustainable, agriculture should be environmentally sound, economically viable and socially equitable. Our overview of the problems threatening the sustainability of China's agriculture shows that the current situation is problematic not only with respect to the environmental dimension, but also concerning the economic and social dimension. On the long term, the natural resource base of agriculture is being eroded, whereas on the shorter term the low income from the very small land holdings and the widening urban-rural gap in income, health, education and social security undermine the economic and social basis of Chinese agriculture.

Neither the central government's modernization strategy nor the two major alternatives proposed in the scholarly literature offer a comprehensive and integrated response to this threefold threat to the sustainability of agriculture. The modernization strategy neglects the slow pace of urbanization and the corresponding need for rural migrant workers to maintain their small land holdings as a fallback option. In addition, the emphasis on enhancing agricultural production renders measures to reduce agrochemical inputs and control pollution largely ineffective. The alternative strategy to conserve and develop small-scale agriculture does not offer a solution for the widening urban-rural gap and the environmental problems of the current situation. The weak spot of the strategy promoting Chinese Ecological Agriculture is in the economic dimension: the difficulty to create an effective market for high added value products and ecosystem services.

\subsubsection{Limitations and implications}

Our study is probably unique in presenting an integrated assessment of problems and strategies with respect to the sustainable development of China's agriculture. A consequence of this broad, integrated approach was a necessary focus on the national level and the agricultural sector. Agricultural development, however, is not only determined by the policy of the central government, but also by the policies of regional and local governments (Weiglin-Schweidrc, 2008; Long et al., 2010). As these lower levels of government usually have a stronger focus on economic development and short-term benefits, this weakens the central government's policy with respect to sustainability. According to Zheng and Cao (2015), many environmental regulations are not enforced when they conflict with local governments' enthusiasm for economic development. Furthermore, the development of the agricultural sector is also tightly connected the development of the other sectors of the economy in China, which means that ideally not only policies for agricultural development should be considered in an assessment, 
but the entire development policy framework and the interactions between sectors (Tian et al., 2016).

The realization that the effects of national-level strategies for agricultural development are co-determined by lower level interference and interaction with developments in other sectors, suggests that it probably does not make much sense for an enormous and diverse country like China to pursue one single national strategy for agricultural development. All of the three strategies assessed in this study may work in one location but not in another. This implies that a national strategy should be broad and comprehensive and allow for considerable adaptation to local diversity in conditions and needs. With respect to the latter, in all three strategies there is a striking lack of attention for the farmers' perspectives, for their view on the problems and their preferred solutions. In fact, all three strategies make unverified key assumptions about the needs and wants of Chinese farmers. The government's modernization strategy assumes that the majority of farmers is willing to give up their land management rights and that a minority is interested in continuing with a larger, 'modernized' farm. In contrast, the small-scale farming strategy assumes that most farmers want to stay in the rural areas and continue with cultivating their small parcels of land. Finally, the Chinese Ecological Agriculture strategy assumes that farmers are willing to trade quantity for quality of production and to minimize or quit using external inputs such as chemical fertilizers and pesticides. However, in case the key assumptions of a strategy turn out to be wrong, successful implementation is unlikely.

\subsubsection{Conclusions}

In conclusion, to address the multidimensional sustainability problems of Chinese agriculture, a solution strategy is needed that addresses not only the environmental, but also the economic and social dimensions of sustainable development. At the same time, such a comprehensive strategy should allow for local variation to address the large diversity in conditions and needs of Chinese farmers. To avoid conflicts between the perspectives of policymakers and farmers on what the problems and preferred solutions are, and the risk of lacking support for policy implementation, a strategy for sustainable agricultural development should take farmers' perspectives into account. Involving farmers in strategy development, will also allow policymakers to make use of farmers' knowledge and problem-solving capacities. The current policy for agricultural development of the Chinese central government and the major alternatives proposed by Chinese scholars do not yet match these requirements. Investigation of farmers' perspectives on needs, problems and solutions in a diversity of rural contexts could thus provide important inputs for further strategy development. 


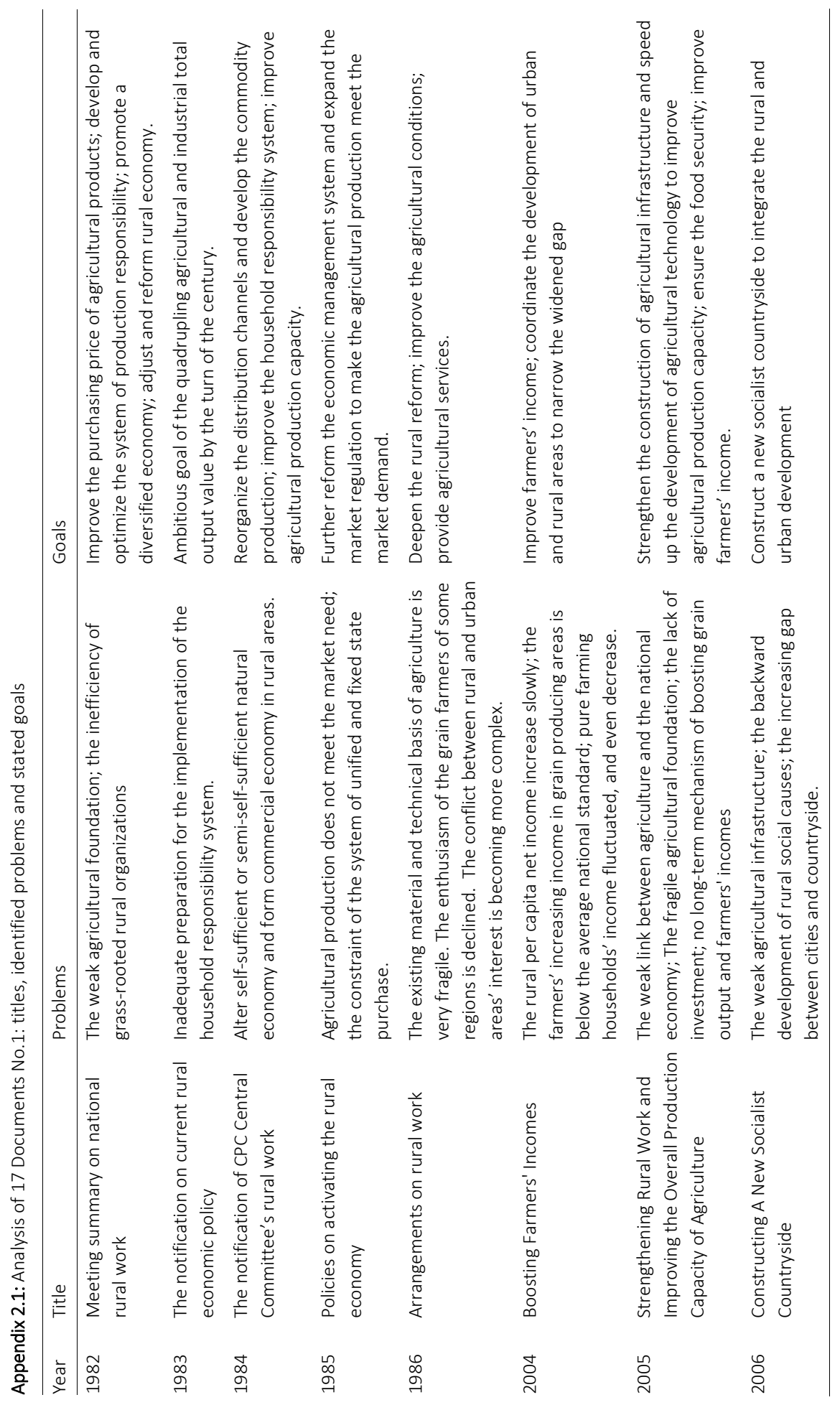




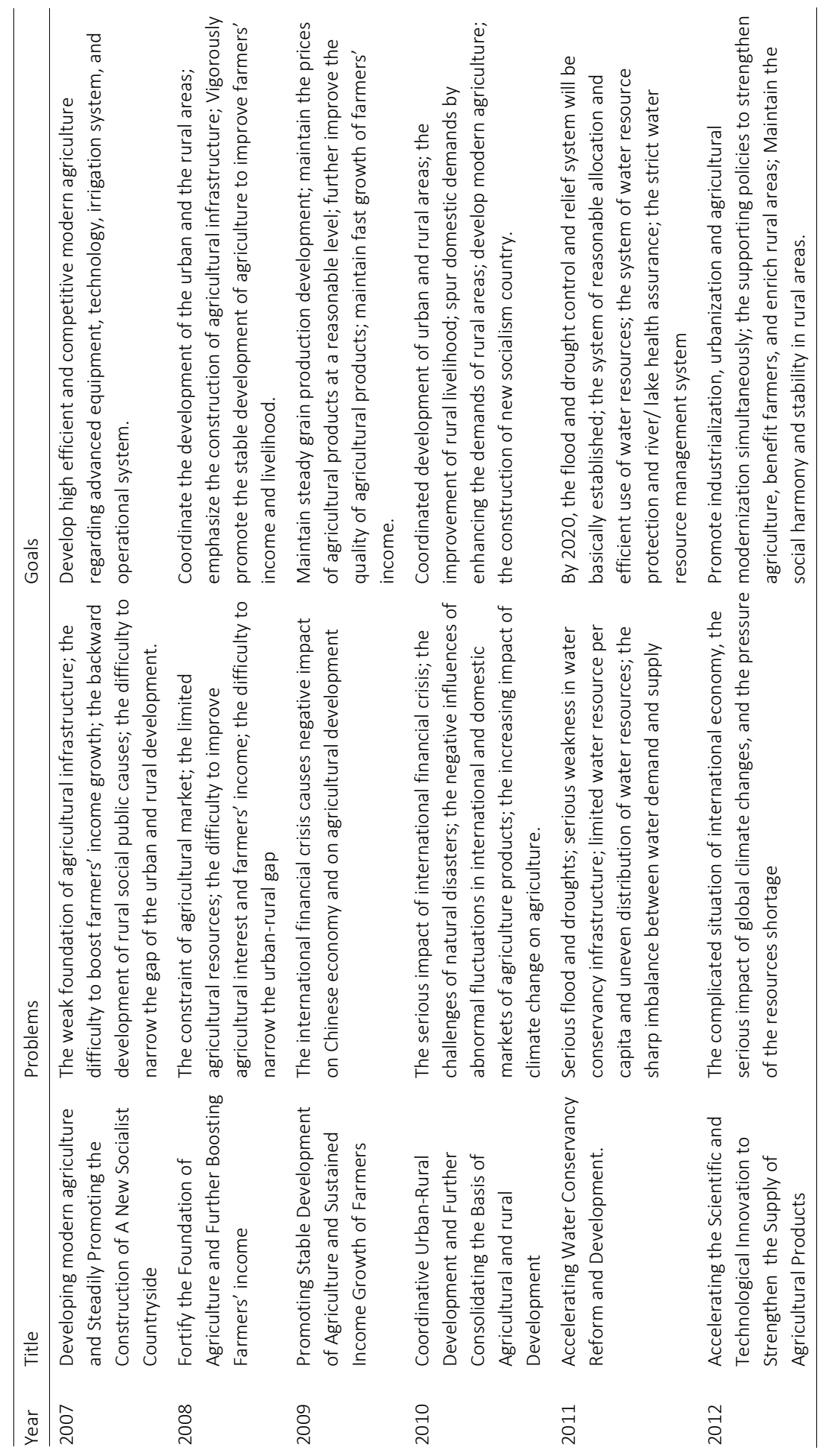


Chapter 2

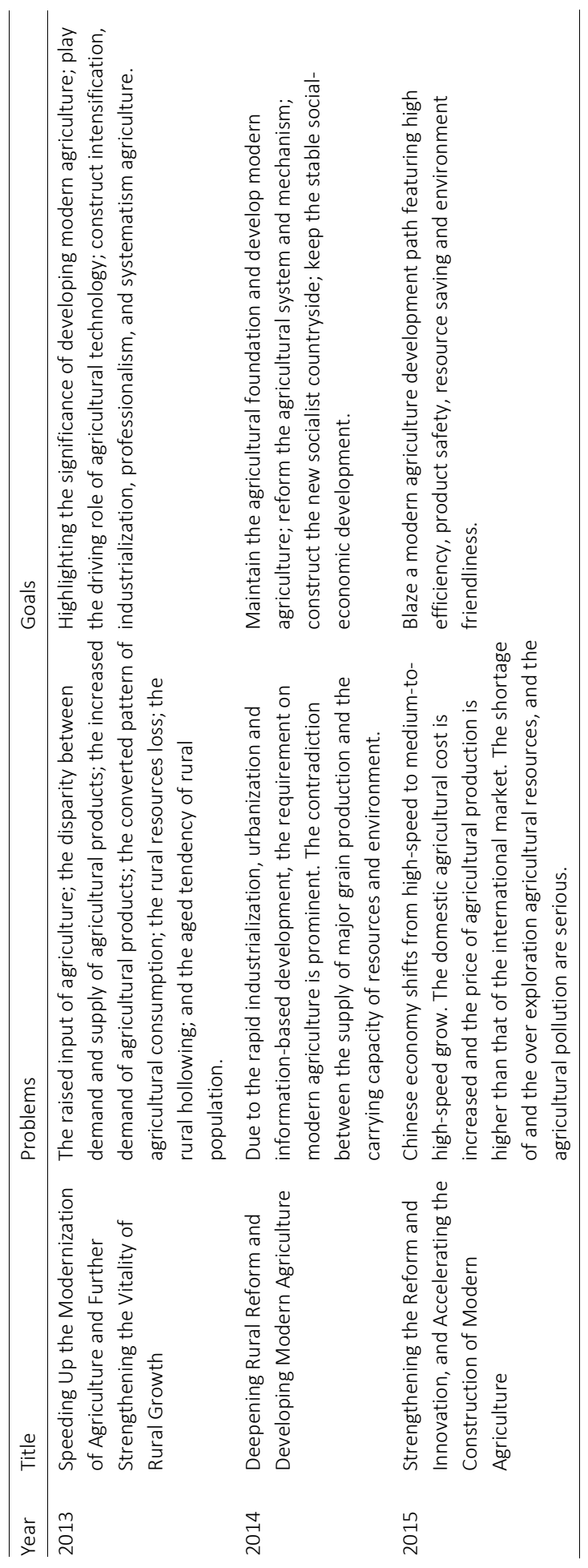


Chapter

Farmers' perspectives and practices in the Guanzhong Plain of Shaanxi Province, China 
Abstract: The perspectives and practices of Chinese farmers were studied following a quantitative survey approach. The focus was on the Guanzhong Plain (Shaanxi Province), where the natural conditions are favorable and agriculture is relatively advanced. As the dominant system is double-cropping of maize and winter wheat, the area is representative of agriculture in the North China Plain, the major agricultural production region of China. The survey covered 165 farm households from 24 villages. It appears that even in a fairly homogeneous agricultural production area like the Guanzhong Plain, there is a large diversity in farmers' perspectives and practices, with many significant differences between respondents depending on their farm household type, age and level of education. The governmental agricultural development strategy as well as major critical alternatives match poorly with the dominant perspectives and practices of the respondents and with the large diversity in these perspectives and practices. Our conclusion is that a strategy for sustainable development of agriculture in China should address a wide diversity of needs and goals as articulated by Chinese farmers themselves, otherwise it will lack the support it needs to be successful. 


\subsection{INTRODUCTION}

As described in the previous chapters, China's agricultural development over the past 40 years is characterized by a steep increase in agricultural production and farmer income. Major policy goals concerning national food security and rural poverty alleviation have been achieved, but at the same time environmental, as well as economic and social problems threaten the sustainability of agriculture. The government aims to address these problems with a modernization strategy in combination with urbanization. Alternative strategies focus on the conservation of small-scale agriculture or the development of ecological agriculture. However, each of these strategies tends to focus on one dimension of sustainability at the cost of attention for the other dimensions. Moreover, all three strategies make unsupported, generic assumptions about the needs of Chinese farmers. Investigation of farmers' perspectives and practices taking an integrative approach is therefore a much needed step towards a comprehensive and broadly supported strategy for sustainable agricultural development in China. This chapter reports on a survey we conducted to study the perspectives and practices of farmers in the Guanzhong Plain of Shaanxi Province in China. In our survey we paid attention to the economic, social as well as environmental aspects of farming, and also asked about the use and acquisition of new agricultural knowledge and technologies. The latter aspects are particularly relevant when considering how high-level strategies for agricultural development could connect with the everyday practices of farmers.

\subsection{METHODOLOGY}

\subsubsection{Study area}

The survey was conducted in the Guanzhong Plain, located in the middle part of Shaan$x i$, a province in central China (figure 3.1). The Guanzhong Plain is the basin of the Wei river, with very favorable conditions for agriculture, due to the flat terrain, fertile fluvial soils, and a temperate, semi-humid climate (Min and Han, 2008). It is a nationally important grain producing area, and its dominant cropping system of maize and winter wheat is representative of agriculture in the North China Plain, the major agricultural production region of China. Agriculture in the Guanzhong Plain is relatively welldeveloped, with high levels of irrigation and agrochemical inputs, and high yields (Min and Han, 2008). 


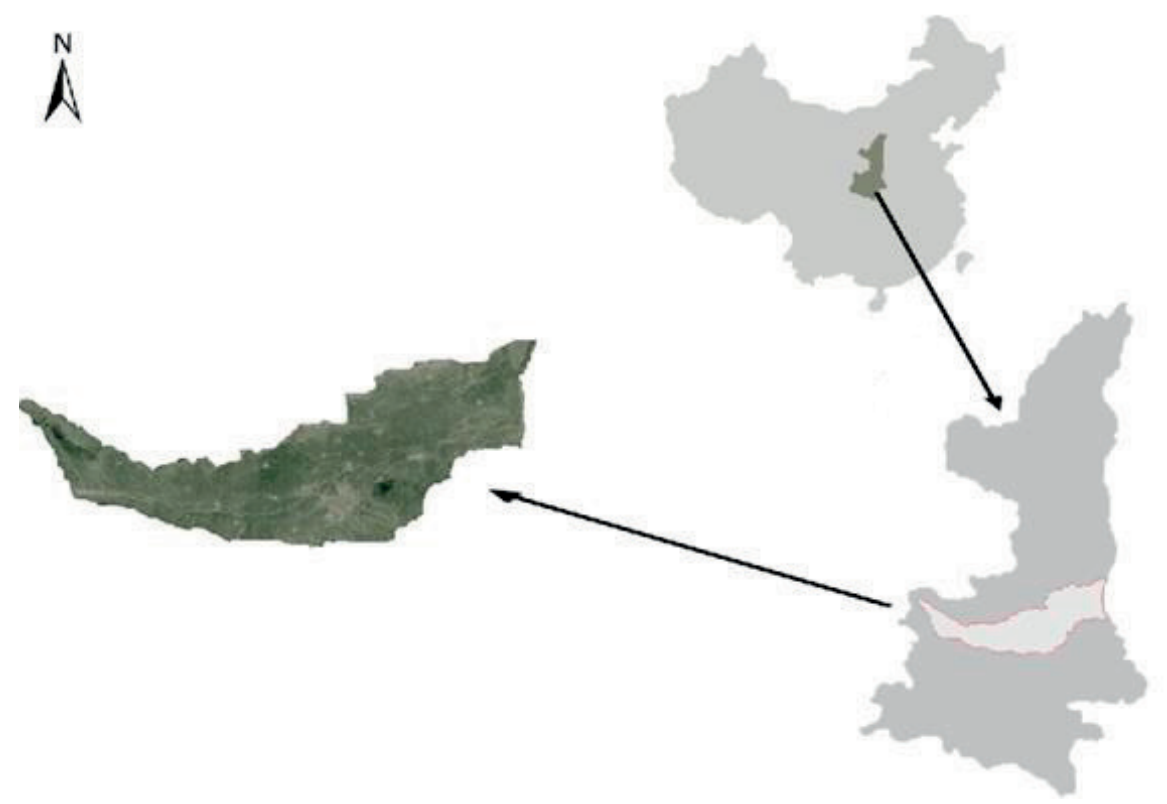

Figure 3.1 The location of the study area, Guanzhong Plain, in Shaanxi Province, central China

\subsubsection{Survey}

The survey was conducted in July and August 2014, in 24 villages across the Guanzhong Plain ${ }^{15}$. In each village, a questionnaire was administered in person by sociology students from the nearby Northwest Agriculture \& Forestry University to seven randomly selected respondents from different farm households. In case respondents were illiterate, the questionnaire was read to them and filled out by the interviewers. In total, 165 completed questionnaires were retrieved, from 82 male and 83 female respondents. Concerning age distribution, $30.3 \%$ of the respondents were 21 to 40 years old, $58.2 \%$ were 41 to 60 years old, and $8.5 \%$ of respondents were above 60 . In terms of education, $7.3 \%$ of the respondents did not have a school education, $26.1 \%$ finished primary school, $57.0 \%$ finished middle school, and $9.7 \%$ had a college degree or higher. This is comparable to the provincial and national average (Min and Han, 2008).

\subsubsection{Questionnaire}

The questionnaire contained about 50 brief, mostly closed-type questions, organized into four parts (Appendix 3.1). The first part concerned basic information about the

\footnotetext{
${ }^{15}$ The 24 villages are: Kouyabai, Xiatun, Baizitang, Xichuan, Qiqu, Beixinzhuang, Shuxing, Shihuan, Bailong, Tiandong, Liujiapu, Xibai, Bigong, Dazhai, Rougu, Wanjiapo, Guan, Niujialing, Wuping, Renjiatan, Liulinzi, Dongping, Luanshiping, Nangou.
} 
respondents and their households, the second part concerned the perspectives of the respondents on economic, social and environmental aspects of farming, the third part concerned farmers' practices in terms of decision-making and actual behavior, and the fourth part addressed farmers' practices and perspectives concerning the acquisition and use of agricultural knowledge.

\subsubsection{Data analysis}

The survey data were statistically analyzed with SPSS 20.0 in four steps. First, the distribution of responses to the questions was determined for the whole study population of 165 respondents by calculating the percentage per answer option. Second, a two-step cluster analysis was applied to determine whether the farm households of the respondents could be classified into distinct groups, based on the following five household characteristics: (1) economic orientation of agricultural production, (2) age of household member doing most of the farming work, (3) main mode of farming, (4) main source of household income, and (5) main source of agricultural income. This resulted in four clusters of acceptable quality ('fair') with respect to cohesion within clusters and separation between clusters, which differed very significantly $(P=0.000)$ on all five household characteristics (Figure 3.2). Third, differences between these four clusters of farm households in responses to the survey questions were determined by one-way ANOVA for numerical data and Chi-square test using Likelihood Ratios for categorical data. Fourth, in addition to the effect of farm household type, we determined (with Chisquare test) the effect of age and level of education of the respondents on the perspectives and practices studied with the questionnaire.

\subsection{RESULTS}

First we describe the four types of farm households in the Guanzhong Plain that were distinguished with a cluster analysis of the survey data. Then we present the survey results on farmers' perspectives and practices in the Guanzhong Plain, with particular attention for the effects of farm household type, age, and education level of the respondents. The answers to the questionnaire in terms of the percentage of all respondents that chose a given option, can be found in Appendix 3.1. Radar charts are used to visualize differences and similarities in responses between the four household clusters by depicting the percentage of respondents per cluster opting for the answer that was overall the most favored. Appendix 3.2 presents the favored responses per cluster and the P-values indicating the level of significance of the differences in responses between the clusters of farm households. 


\subsubsection{Farm household types in the Guanzhong Plain}

Cluster analysis of the survey data based yielded four distinct types of farm households in the study population (Figure 3.2). In addition to the five household variables on which the analysis was based, these clusters also differed significantly with respect to several other household characteristics (Table 3.1). Below, the four clusters are described in terms of their predominant characteristics.

Cluster 1 - This cluster comprises $23 \%$ of the respondents and consists of farm households that mainly produce for the market, growing mostly annual, arable crops with 'modern' methods of agricultural production (i.e., a high level of mechanization and use of agrochemicals). Yet, the main source of household income is from off-farm migrant work. The members of the household doing most of the farm work are middle-aged.

Cluster 2 - This is the largest cluster, comprising 39\% of the respondents. It consists of farm households that mainly produce for the market, growing mostly perennial tree crops, including cash crops such as apples and nursery trees for tree planting projects. These households have adopted a modern farming mode and their main source of income is from agriculture. The members of the household doing most of the farm work are middle-aged.

Cluster 3 - This cluster comprises 20\% of the respondents and consists of farm households that grow arable crops using 'modern' methods, but mainly for domestic consumption. The main source of household income is from migrant work. As in cluster 1 and 2, the members of the household doing most of the farm work are middle-aged.

Cluster 4 - This is the smallest cluster, comprising $18 \%$ of the respondents. It consists of farm households that apply traditional agricultural methods to produce arable food crops (with limited use of machinery and agrochemicals), mainly for domestic consumption. Their main source of income is from agriculture, and, in contrast to the other three clusters, most of the farm work is done by elderly members of the household (of above 60 years old).

Farm size ranged from an average of $3.4 \mathrm{mu}$ (cluster 4 ) to $4.4 \mathrm{mu}$ (cluster 1). As $1 \mathrm{mu}$ equals about 0.07 ha, this means that the size of most farms was below 0.5 ha, which is representative of Chinese farms, but extremely small compared to other countries (Fan \& Chan-Kang, 2005). A farm household generally consisted of four to five members, with one or two migrant workers. Household sizes were smaller and both the number of migrant workers and income from migrant work was lower in the two household clusters that focused on agricultural income (clusters 2 and 4). The highest agricultural income was found in cluster 2 , which focused on growing perennial cash crops for the market. 

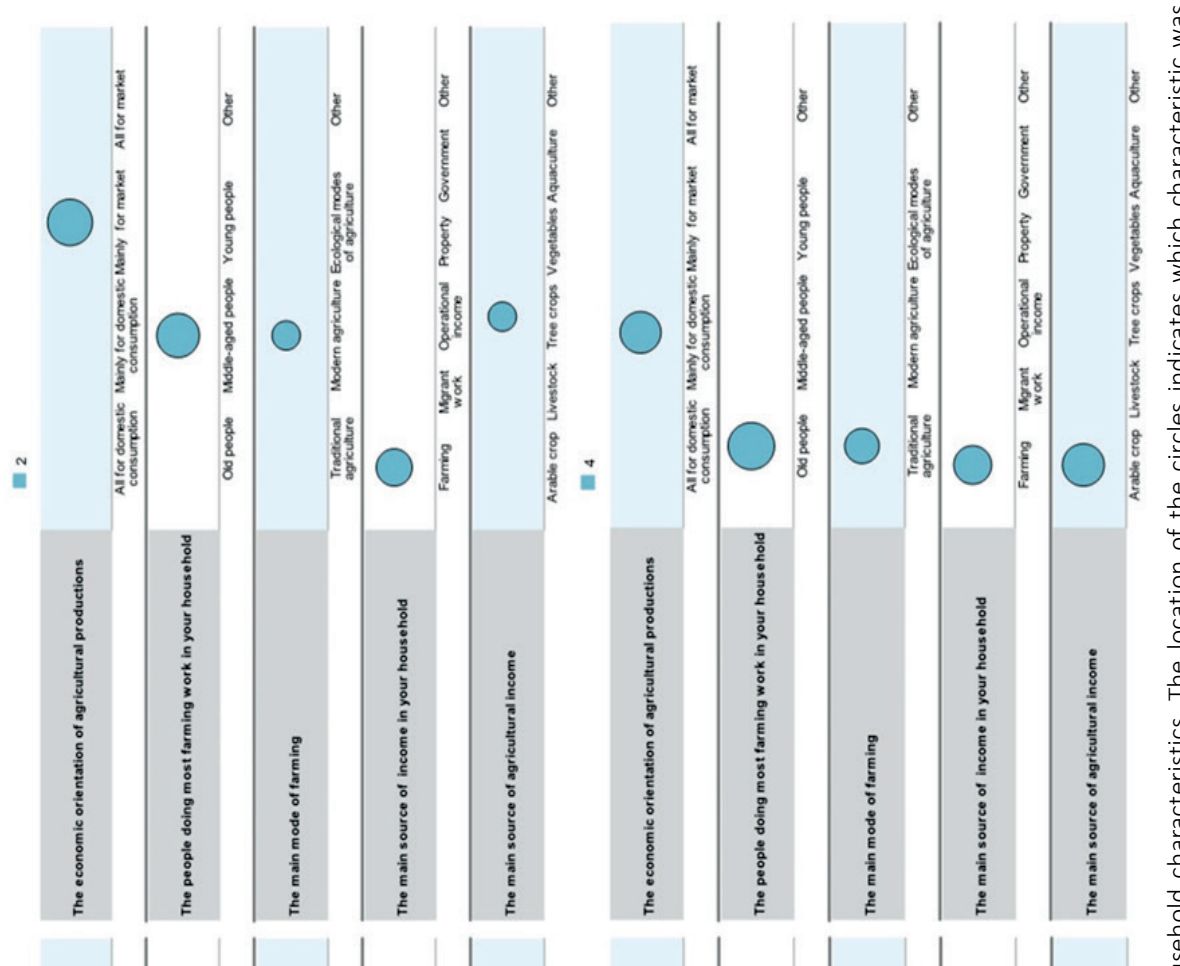

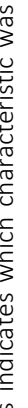

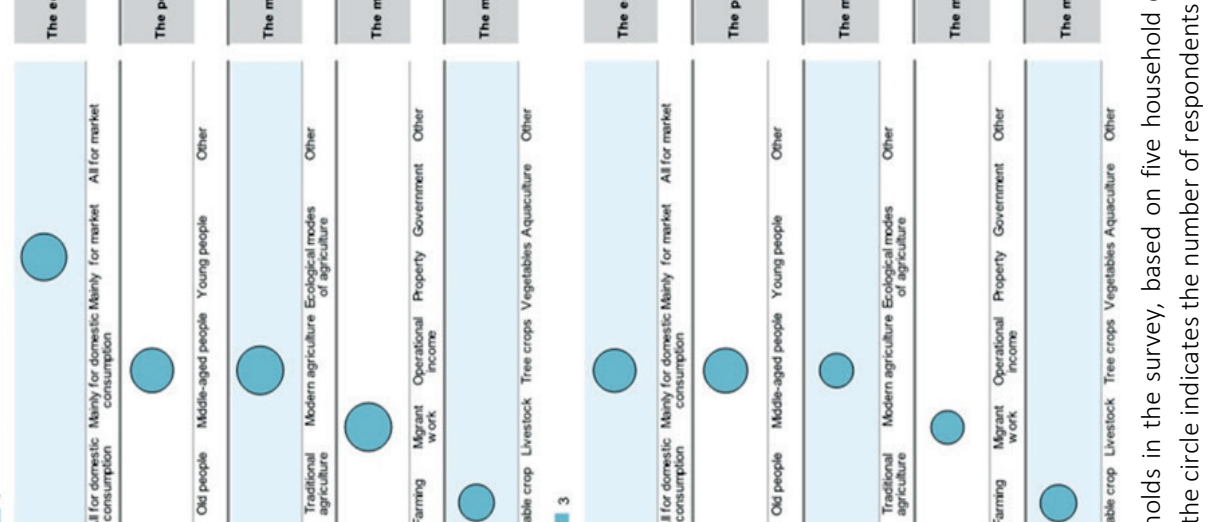

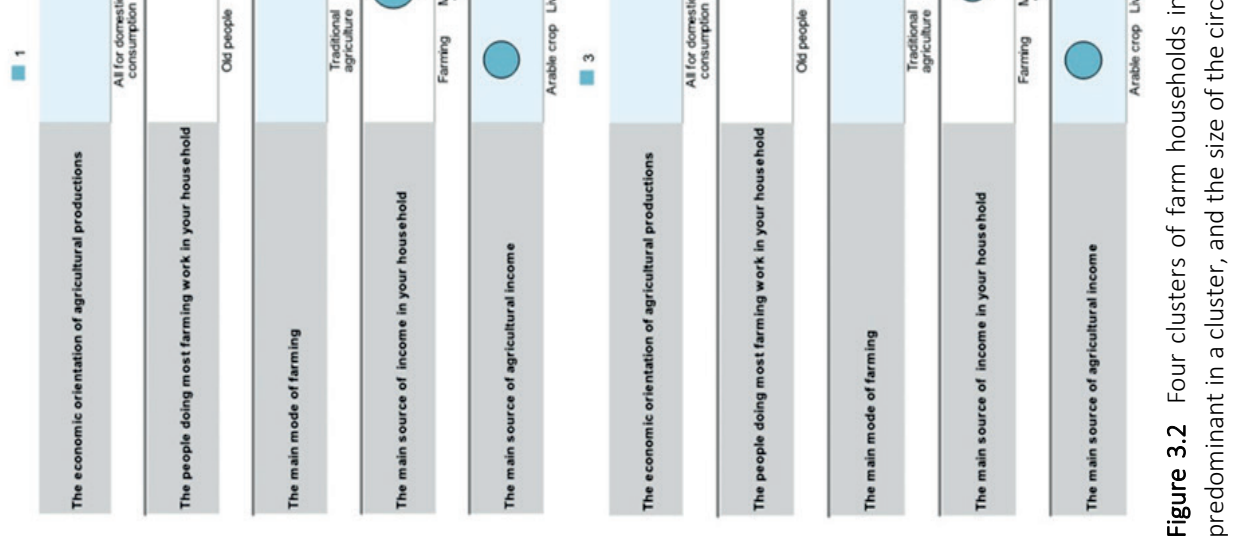




\section{Chapter 3}

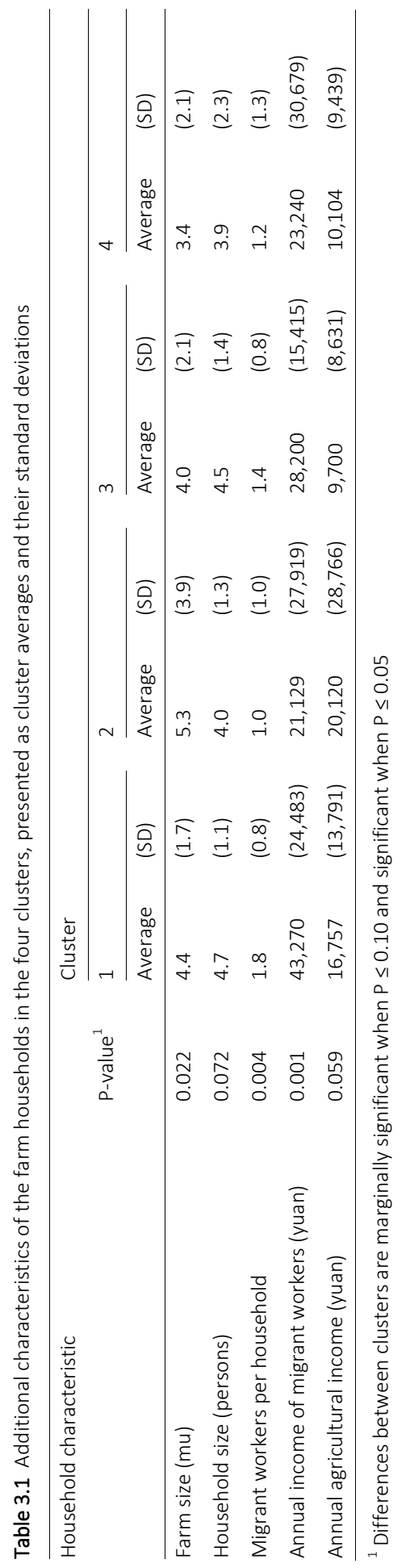




\subsubsection{Perspectives on farming}

To obtain a comprehensive insight into the perspectives of farmers in the Guanzhong Plain, the questionnaire addressed economic, social as well as environmental aspects of agriculture. The results are presented below, including (marginally) significant effects of farm household type, age and education.

\subsubsection{Economic aspects}

The survey contained six questions about the respondents' perspectives on economic aspects of agriculture (Figure 3.3; Appendix 3.1). Concerning the functions of agriculture, 'food production for domestic consumption' was the option most often selected by the respondents (73\%), with 'generation of income' ranking second (59\%). Differences between household types were marginally significant $(P=0.066)$, with the highest level of support for 'generation of income' found in cluster 2, which is characterized by growing cash crops for the market. With respect to their household's agricultural income, many respondents (49\%) showed a neutral attitude, although a substantial part (30\%) indicated that they were not satisfied with it. The level of the agricultural income was by far the most important factor determining the respondents' satisfaction with farming (62\%). However, this differed significantly between respondents with different levels of education $(P=0.000)$ and of different age classes $(P=0.059)$. Among respondents with no school education or with a college degree, and, in terms of age, both those below 40 or above 60 years old, the reduced need for human labor was the most important factor determining their satisfaction with farming. When asked about the future mode of the agricultural production, the largest part of the respondents (46\%) expected more 'modern' agriculture, i.e., more mechanization and application of agrochemicals. However, an almost similar proportion (45\%), expected an expansion of the 'ecological' mode of farming, with more attention for environmental protection. This view was supported in particular by respondents of below 40 years old $(P=0.080)$, and with secondary education or higher $(P=0.062)$. Only few respondents $(6 \%)$ expected that the traditional mode of agriculture will be conserved. The large majority of the respondents (61\%) considered that saving labor and raising productivity are the most important impacts of modern agricultural technology, and less than $8 \%$ chose for the adverse effects of this technology on the environment. Also when explicitly asked to compare modern and traditional agriculture, the respondents stressed the rationalization of production in modern agriculture, resulting in reduced need for human labor, greater efficiency and higher yields. However, there were marginally significant differences between the clusters $(P=0.076)$, with a relatively large proportion of respondents in cluster 4 (older, traditional farmers producing for domestic consumption) choosing the large negative impact on nature and environment as a major feature of modern agriculture. 


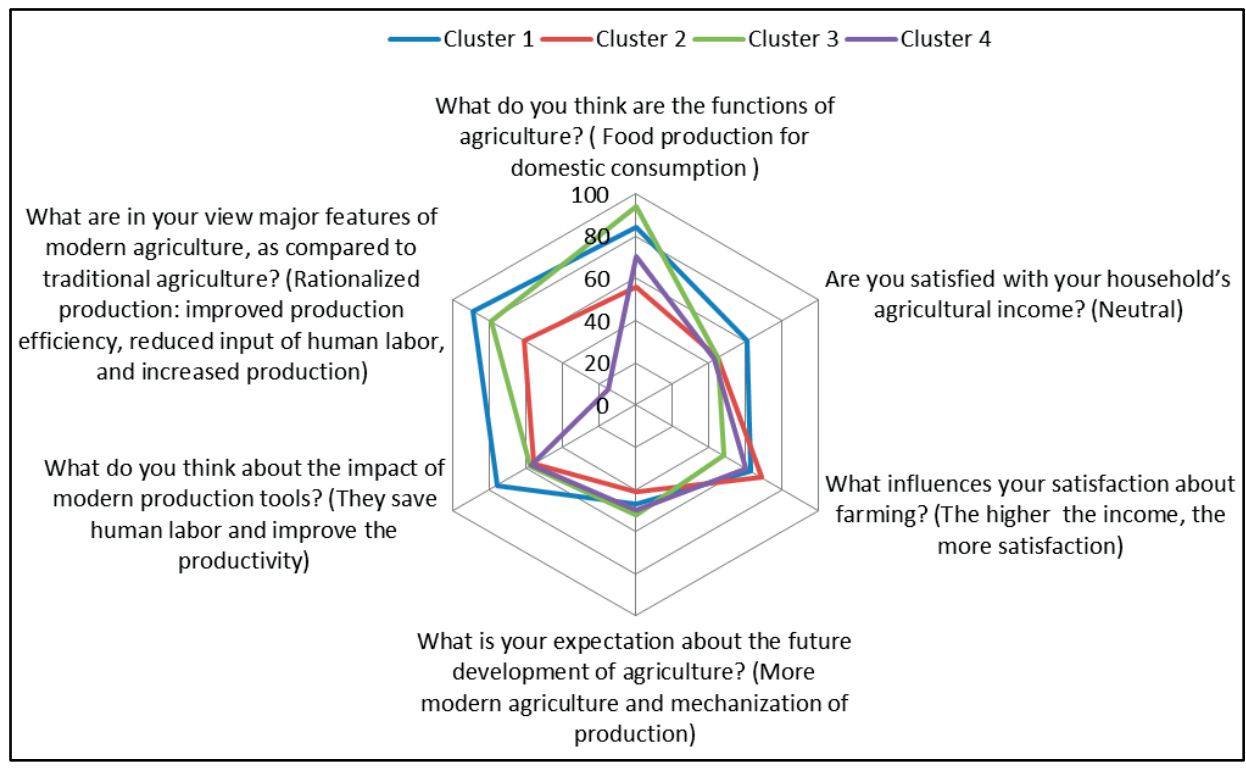

Figure 3.3 Percentage of respondents per cluster opting for the answers that were overall the most favored for questions addressing perspectives on economic aspects of farming.

\subsubsection{Social aspects}

The survey contained four questions about the respondents' perspectives on social aspects of agriculture (Figure 3.4; Appendix 3.1). The majority of respondents (66\%) indicated to enjoy rural life. However, there were marginally significant differences between respondents from different household types $(\mathrm{P}=0.080)$. A relatively large proportion of respondents in clusters 1 and 3 indicated not to enjoy rural life. Both clusters are characterized by a focus on income from migrant work. There were also significant differences between age groups $(P=0.000)$, with the largest proportion of respondents of below 40 years old indicating that they did not enjoy rural life. The major reason for the respondents to enjoy rural life was the lower level of pollution as compared to urban areas (47\%), and the major reason to dislike rural life was the low level of income in the rural areas (32\%). With respect to the latter, there were significant differences between respondents from different household types $(P=0.023)$. A large proportion of respondents in clusters 1 and 3 mentioned that they dislike rural life because of the inconvenience and poor infrastructure, and a large proportion in cluster 4 indicated they dislike rural life because it is difficult and farming is tiresome. Clusters 1 and 3 are characterized by a focus on migrant work, and cluster 4 by relatively old and traditional farmers. Concerning their view on being a farmer and the farming profession, about half of the respondents showed a neutral attitude (49\%). The other half of the respondents was equally divided over a positive view on being a farmer and the farming profession (26\%), and a negative view (24\%). Differences between age groups were very significant 
however $(\mathrm{P}=0.000)$, with most of the older farmers (above 60 years old) having a positive view, and a large proportion of the younger farmers (below 40 years old) having a negative view.

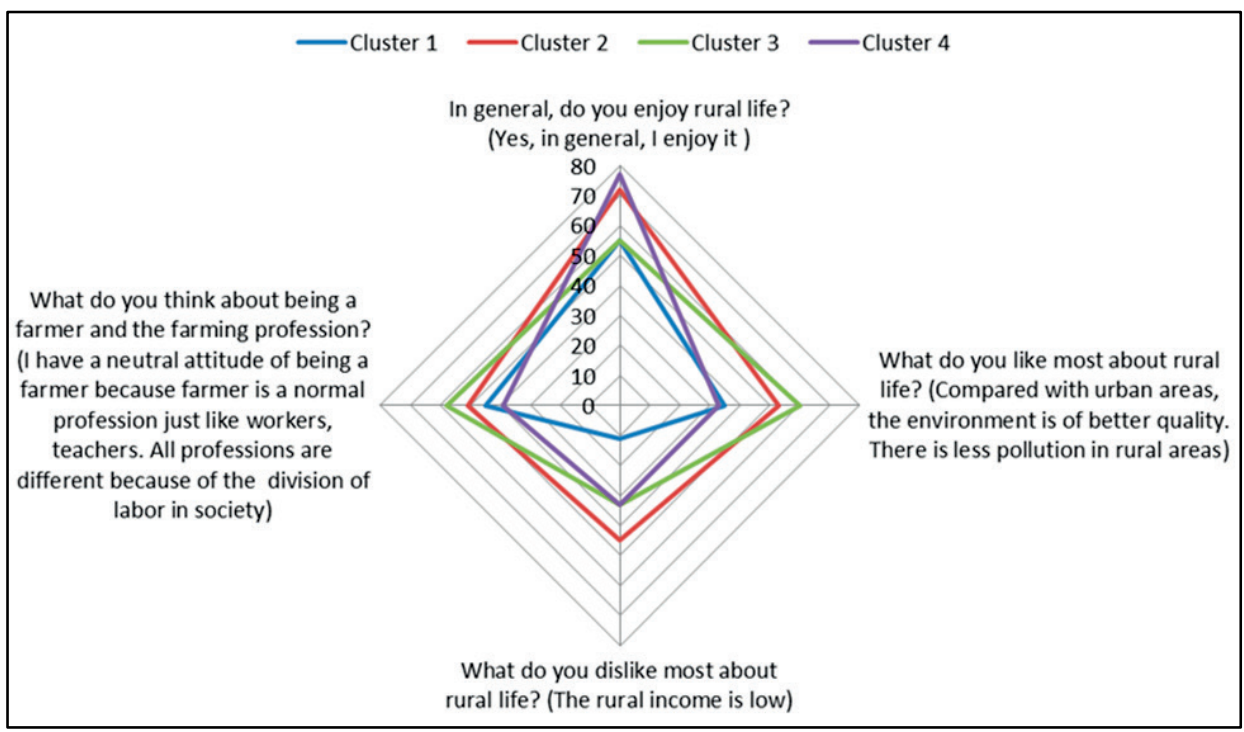

Figure 3.4 Percentage of respondents per cluster opting for the answers that were overall the most favored for questions addressing perspectives on social aspects of farming.

\subsubsection{Environmental aspects}

The survey contained six questions about the respondents' perspectives on environmental aspects of agriculture (Figure 3.5; Appendix 3.1). When asked about the relationship between agriculture and the natural ecosystem, the largest proportion of respondents held the view that agriculture is partly dependent on the natural ecosystem (41\%). This varied significantly with level of education $(P=0.001)$ and age group $(P=0.009)$, however, with respondents without school education and above 60 years old mostly supporting the view that agriculture and nature are independent from each other. Concerning the use of agrochemicals, the majority of respondents (52\%) indicated that they are very dependent on chemical fertilizers and pesticides considering their beneficial effects on yield and farmers' workload. There were (marginally) significant effects of farm household type $(P=0.072)$, education $(P=0.086)$ and age $(P=0.0018)$ on the responses. In cluster 4 (elderly, traditional farmers), the largest proportion of respondents indicated that they had never considered whether it is good or not to use agrochemical fertilizers and pesticides, because they just follow the example of the previous generation. This was also the case for older respondents (above 60 years old) and respondents with only primary school education. Concerning their attitude toward environmental degradation and pollution, almost half of the respondents indicated that 
they saw it as the government's responsibility to deal with this (49\%). Only a relatively small part of the respondents took the position that individual farmers should be aware of the need to protect the environment and take initiative (20\%). This proportion was even significantly lower ( $\mathrm{P}=0.015)$ in household cluster 3 (focusing on migrant work and income) and 4 (elderly, traditional farmers). The largest proportion of the respondents showed a positive attitude toward ecological modes of agriculture (43\%). However, this differed according to level of education ( $\mathrm{P}=0.055$, marginally significant): respondents with only primary or secondary school education showed mostly a negative attitude. Concerning the adoption of ecological modes of agriculture, the most important reasons not to adopt were skepticism due to unfamiliarity (41\%) and hesitancy given that it is a relatively new approach (40\%). The most important reasons to adopt would be more governmental support for ecological modes of agriculture (58\%) and a clear market demand for ecological products (56\%). A significant effect of age $(P=0.038)$, was that the younger respondents (below 40 years old), most frequently indicated that they valued ecological agriculture but that their worries about the large market risks made them unwilling to adopt.

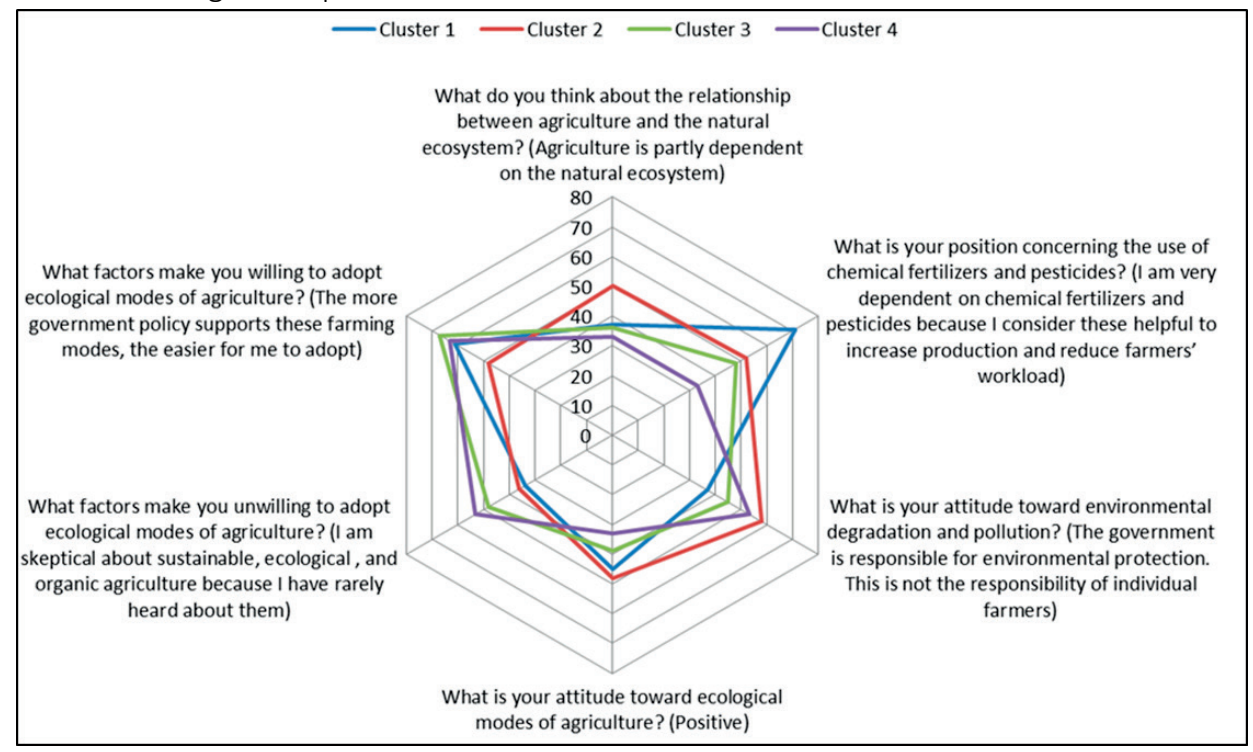

Figure 3.5 Percentage of respondents per cluster opting for the answers that were overall the most favored for questions addressing perspectives on environmental aspects of farming.

\subsubsection{Farming practices}

The questionnaire addressed both decision-making and actual behavior as important aspects of farmers' practices. The results are presented below, including effects of farm household type, age and education, when (marginally) significant. 


\subsubsection{Decision-making}

The survey contained five questions about the respondents' decision-making practices (Figure 3.6; Appendix 3.1). According to a very large majority of the respondents (78\%), the quantity of the production is their main consideration in decision-making as farmer. There were (marginally) significant effects of farm household type $(P=0.063)$ and level of education ( $\mathrm{P}=0.009$ ) in this respect, with relatively large proportions of respondents in cluster 2 (mostly growing perennial cash crops like apples) and respondents with secondary or higher education indicating that the quality of the production was their main consideration. Considerations about the relationship between agriculture and nature have no influence on farming practices, according the majority of the respondents (51\%). Decisions about the level of fertilizer and pesticide use are, for a very large majority (71\%), driven by considerations about the productivity. Only a minor part of the respondents (12\%), indicated that they (also) take the potential negative environmental impact of these agrochemicals into consideration. Decisions about the type of agriculture (e.g., grain crops, vegetables, fruit), are either determined by habit (33\%) or by the opportunity to improve the household income (33\%). However, the responses differed significantly between household clusters ( $P=0.009)$ : in clusters 1,3 , and 4 , the largest proportion of the respondents indicated that habit was the main factor, whereas in cluster 2 (mostly growing cash crops) the majority indicated that income opportunities were the most impact factor in their decisions on the type of production. The effect of the level education was similar, with the largest proportion of respondents with no or only primary school education opting for 'habit', and the largest proportion with secondary education for 'opportunity to improve income'. Finally, when asked whether they would like to participate in a farmers' cooperative, almost half of the respondents (46\%) expressed their interest as they considered it would help to improve their market competitiveness, whereas the other half $(46 \%)$, indicated that it was not relevant for them, due to the small size of their farm. These responses differed significantly between levels of education, however $(\mathrm{P}=0.018)$. Respondents with no or only primary school education were mostly not interested, whereas respondents with secondary education or higher mostly showed interest in participating in a farmers' cooperative. 


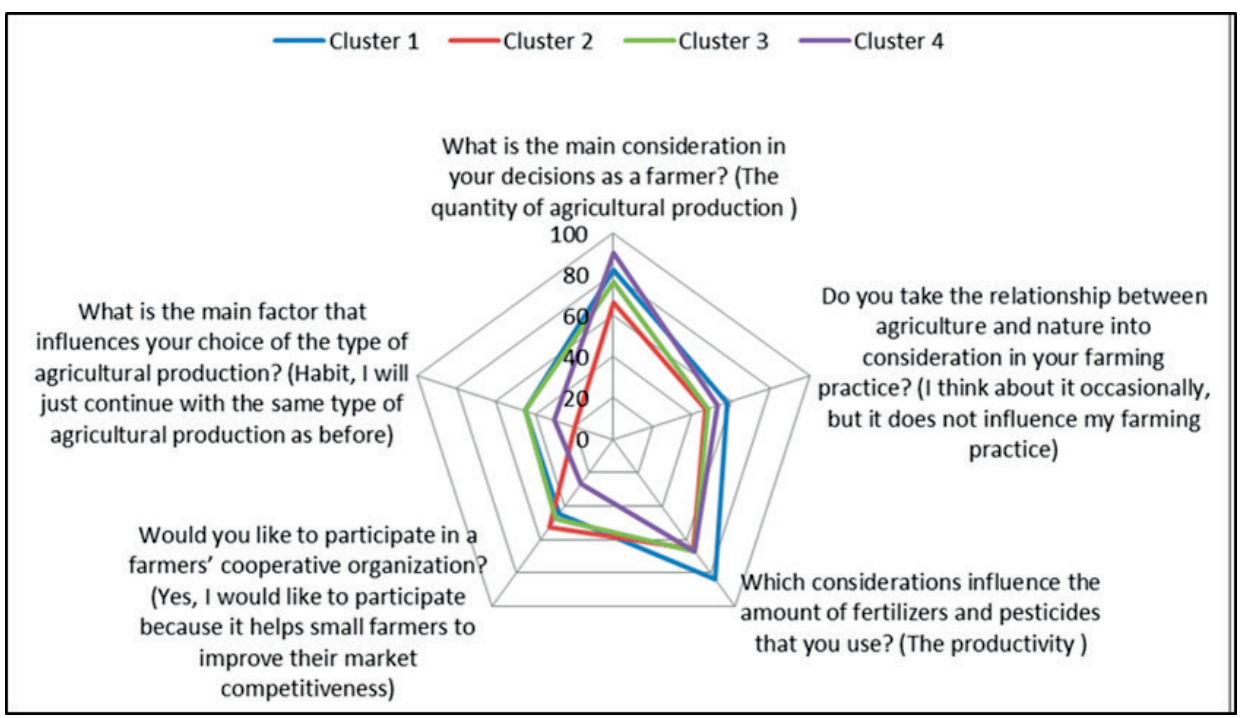

Figure 3.6 Percentage of respondents per cluster opting for the answers that were overall the most favored for questions addressing decision-making aspects of farming.

\subsubsection{Farmers' behavior}

The survey contained four questions about the respondents' actual behaviors (Figure 3.7; Appendix 3.1). With respect to fertilization, the very large majority of the respondents indicated to use chemical compound fertilizers (87\%), whereas only few respondents indicated to use animal manure (9\%) or organic fertilizer (4\%). The use of the latter two types of fertilizer was significantly higher in household clusters 2 and 4 ( $P=0.039)$, both characterized by a focus on income from agriculture rather than migrant work, either with a market (cluster 2) or a subsistence orientation (cluster 4). When applying fertilizers and pesticides, the majority of the respondents does not pay attention to the instructions nor to the precise quantities they apply (57\%). However, this differed significantly between household clusters $(P=0.029)$ and education levels $(P=0.054)$. A large proportion of respondents in cluster 2 (mostly growing cash crops, like apples, for the market) and of respondents with a college degree indicated that they use fertilizers and pesticides strictly in accordance with the application instructions. Concerning the mechanization of farming, almost two-thirds of the respondents are mainly dependent on machinery (64\%), and less than one-third is mainly dependent on manual labor (30\%). There was a significant difference between household clusters in this respect $(p=0.056)$, with about equal proportions being mainly dependent on machinery or manpower in cluster 3 (with households mostly growing food crops for domestic consumption). Participation in farmers' cooperatives was low (6\%), and the majority of the respondents had never participated, although they had heard about the cooperatives (55\%). Participation was significantly associated with farm household type $(P=0.010)$ and education level $(P=0.017)$, with relatively high proportions of respondents indicat- 
ing that they participate in a farmers' cooperative and find it helpful in cluster 2 (mostly market oriented growers of cash crops) and among those with a secondary school education or higher.

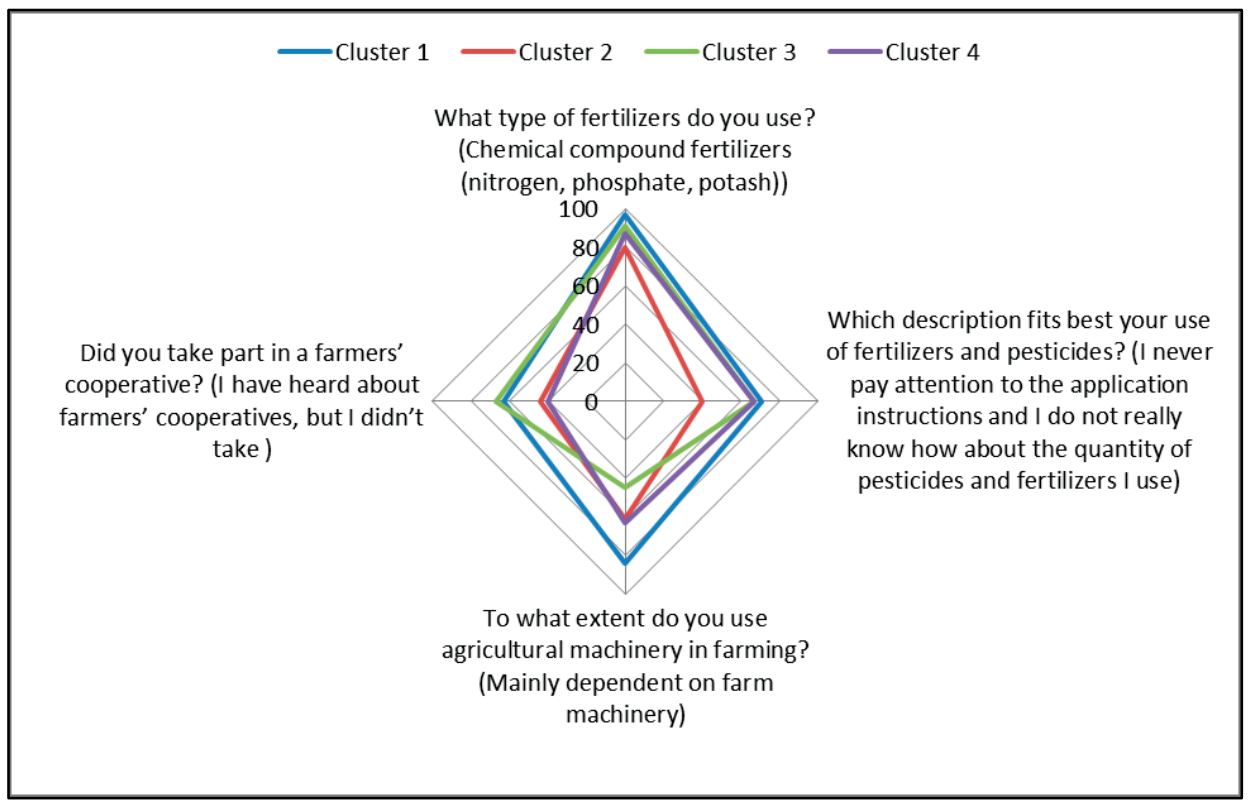

Figure 3.7 Percentage of respondents per cluster opting for the answers that were overall the most favored for questions addressing farmers' behaviors

\subsubsection{Acquisition and use of agricultural knowledge}

The survey contained eleven questions about the respondents' acquisition and use of agricultural knowledge (Appendix 3.1). A first question addressed the type of agricultural knowledge used in farming work. The largest proportion of respondents indicated that they mainly used traditional agricultural knowledge learned from older generations (45\%). However, this differed significantly between household clusters $(P=0.053)$ and age groups $(\mathrm{P}=0.006)$. In cluster 1 (households mostly growing food crops for the market with 'modern' production methods) and among younger respondents (below 40 years old), the favored answer was a combination of traditional and scientific knowledge. In response to the question how agricultural knowledge was obtained, the major part of the respondents indicated that they obtain this knowledge very actively, e.g., by watching TV programs or reading books (41\%). Household type $(P=0.0017)$, education level $(P=0.003)$, as well as age $(P=0.041)$ had a significant effect on the response. In cluster 1 (growing food crops for the market with modern methods) and 4 (growing food crops for domestic consumptions with traditional methods), among respondents with no or only primary school education, and among older respondents 
(above 60 years old), the most common answer was that this knowledge was not obtained in a structured way, but rather by hearing from friends or relatives, for example. When asked about their opinion about traditional agricultural knowledge, most respondents were positive (39\%), given the limited impact of traditional farming methods on the environment. However, another large part of the respondents were negative about traditional agricultural knowledge (33\%), because the efficiency and income of traditional agriculture are low. When comparing traditional agricultural knowledge with modern scientific agricultural knowledge, the majority of the respondents (55\%), indicated that they try to combine both types of knowledge. Only a minor part of the respondents indicated that they tend to give up traditional knowledge and fully accept scientific agricultural knowledge (16\%). When asked whether they were satisfied with their current agricultural knowledge, the largest part of the respondents indicated that they were not (42\%). However, this differed among household clusters $(P=0.023)$ and education levels $(P=0.002)$, with a neutral attitude being dominant among the respondents in all clusters, except 2 (households focusing on high-quality cash crops), and among respondents with no or only primary school education. Although a substantial part of the respondents indicated that they found training courses in modern, scientific agricultural knowledge very useful (38\%), an even larger proportion indicated that they did not find it useful (59\%). Yet, the majority of the respondents (53\%) was willing or very willing to participate in agricultural knowledge training courses. This willingness differed significantly between the household clusters $(P=0.029)$, however, with larger proportions giving a neutral response in all clusters, except cluster 2 (households focusing on high-quality cash crops). Among the factors which would influence the willingness of the respondents to participate in these courses, the highest ranking were the relation of course content to agricultural practice (57\%), the potential to improve agricultural income (56\%), and the provision of guidance in the field rather than lectures in a class room (49\%). When asked about the function of rural technology promotion stations, the major part of the participants thought these stations stimulate farmers to participate in training courses and provide them with guidance on new technologies (29\%). However, the opinion of an almost similar proportion of the respondents was that these stations play practically no role in farmers' practices (26\%). The latter opinion ranked first among respondents in clusters 3 and 4 , both comprising households growing food crops for domestic consumption ( $P=0.001)$, and among respondents of above 60 years old $(P=0.001)$. With respect to the relationship between farmers and technical training personnel, almost half of the respondents favored an interactive learning relationship (49\%). There was a marginally significant effect of education level ( $P=0.059)$, with the largest proportion of respondents with only primary school education favoring a relationship between trainer and farmer as 'to guide and be guided'. Finally, when asked who should take the lead in promoting farmers' acquisition of new agricultural technology and knowledge, the major part of the respondents thought that the government should lead and organize this (37\%). This preference was significantly affected, 
however, by household type $(P=0.064)$ and education level $(P=0.007)$. A relatively large proportion of respondents in cluster 2 (households growing mostly cash crops for the market) and respondents with a college degree held the view that promoting farmers' acquisition of new knowledge should be a cooperative effort of farmers, government, and agricultural experts.

\subsection{DISCUSSION}

The aim of this chapter is to provide insight into the perspectives and practices of farmers in the Guanzhong Plain of Shaanxi Province, China. These perspectives and practices concern economic, social and environmental aspects of farming, and the acquisition and use of agricultural knowledge. Particular attention was paid to the diversity in these perspectives and practices among farmers, and how this is associated with their farm household type, level of education and age. In this section, we first summarize the main findings, compare these with published results from other studies, discuss the implications for policy, and give recommendations for further research.

\subsubsection{Main findings}

On the basis of the responses to the questionnaire that received overall the highest support, the perspectives, practices, and use and acquisition of knowledge of farmers in the Guanzhong Plain can be summarized as follows. Food production for domestic consumption is more important than generation of income, although farmers' satisfaction about agriculture would increase with higher income. Currently, only a minor part of the farmers is satisfied with their income from agriculture, and income from migrant work is generally more important. Modern agricultural methods (machinery, agrochemicals) are seen as efficient, labor-saving, and productivity enhancing, are widely adopted and expected to become even more dominant at the cost of traditional agriculture. A majority of the farmers enjoys the rural life, mainly because there is less pollution than in urban areas, and has a neutral tot positive view on being a farmer. The dominant view is that agriculture and the natural environment are interdependent, but farmers are not willing to reduce the application of agrochemicals, because they are dependent on these for a good yield, and see environmental protection as the government's responsibility. The main consideration of farmers in their decisions, including the application rate of agrochemicals, is the quantity of the production. The impact on the environment does not affect their decisions, and fertilizers and pesticides are applied without paying attention to the instructions concerning the quantity to be used. Although many farmers are positive about ecological modes of agriculture, they are hesitant to adopt these, unless there are clear incentives from the government or the market. Most farmers learned how to farm from older generations, and have a positive view of tradi- 
tional agricultural knowledge. Yet they are not satisfied with their current knowledge and actively acquire new knowledge, e.g., from TV or books, and try to combine this new 'scientific' knowledge with their traditional knowledge. Although they think that the government should take the lead in promoting the acquisition of new knowledge, they do not think the current training courses are useful. They are nevertheless willing to participate, especially when the knowledge would be practically useful, transferred in an interactive way and helpful to raise their income.

It would be misleading however, to summarize the results of the survey by only taking the most favored responses into account, as often these were not even supported by the majority of the respondents. It appears that even in a fairly homogeneous agricultural production area like the Guanzhong Plain, there is a large diversity in farmers' perspectives and practices, with many significant differences between respondents depending on their farm household type, age and level of education. In terms of farm household types, the perspectives and practices of two clusters clearly stand out from the 'mainstream'. First of all there is the large cluster 2, with 39\% of the respondents. This concerns a group of farm households that mostly grows perennial cash crops for the market, and for whom income from agriculture is more important than from migrant work. These farmers are interested in learning about new technologies, prepared to switch to another type of crop when they see better income opportunities, and participate in farmers' cooperatives to improve their market competitiveness. They focus on quality rather than quantity of production, use relatively more non-chemical types of fertilizer and apply agrochemicals strictly in accordance with the instructions. The farmers in this cluster have a relatively high level of education. The other group of households that stands out and contrasts rather sharply with cluster 2 , is the small cluster 4 with $18 \%$ of the respondents. This concerns farm households that grow food crops for domestic consumption using traditional farming methods, e.g., manure instead of chemical fertilizers. The farmers are relatively old and have a low level of education. Many of them do not like rural life, because they find it difficult and tiresome. In their decisions, they just follow the example of previous generations, without giving it too much thought. Rural technology promotion stations play no role in their practices, and new knowledge is not acquired in a structured way. Although they believe that modern agricultural methods have a negative environmental impact, they do not support the view that farmers should take responsibility for the environment. A final remarkable effect of farm household type was that the respondents in clusters 1 and 3, which focus on income from migrant work rather than from agriculture, mostly indicated not to enjoy rural life. Many of the effects of education level and age coincided with effects of household type 2 and/or 4, but a notable additional effect of age was that younger respondents tended to have a negative view on being a farmer and especially valued the role of modern agricultural technology in reducing the need for labor input. 


\subsubsection{Comparison with previous studies}

Surveys of Chinese farmers' perspectives and practices taking an integrative approach and considering economic, social as well as environmental aspects, are quite rare. We could identify only three published studies that allow for a comparison with our findings. These concern the work of Zhen et al. (2015), a survey of 270 farm households from Ningjin County in Shandong Province, Ma et al. (2009), a survey of 98 farm households from Hailun County in Heilongjiang Province, and Yang et al. (2016), a survey of 91 households from Jiangsu Province and Shandong Province. Concerning the economic dimension, an interesting finding of $\mathrm{Ma}$ et al. (2009) was that prices of agricultural inputs and products played a major role in farmers' decision making, and that the large majority of the farmers was interested in investing more when prices would be more favorable. The authors explain this by the labor-extensive system of grain production and the lack of opportunities to generate off-farm income in that region. This contrasts with our finding that most farmers in the Guanzhong Plain are more focused on income from migrant work and invest in agricultural inputs to reduce the need for labor. With regard to the environmental dimension, also these three studies conclude that farmers overuse chemical fertilizers, and see environmental protection as the government's responsibility (Ma et al., 2009). Both Zhen et al. (2005) and Yang et al. (2016) also studied farmers' use and acquisition of knowledge, and their findings are similar to ours. Farmers generally considered their current knowledge to be adequate and relied mostly on TV, books and fellow farmers to obtain new knowledge. The majority of the farmers did not make use of the agricultural knowledge extension services, as they were dissatisfied with the quality. According to Zhen et al. (2005) and Yang et al. (2016), the information provided by these services was mainly restricted to the use of agrochemicals and livestock production, and did not include knowledge about health risks and adverse effects of these technologies on the environment.

\subsubsection{Policy implications}

The implications of our findings for Chinese agricultural development policy are two-fold. First, the governmental development strategy as well as major critical alternatives match poorly with the dominant perspectives and practices of our respondents. Moreover, even within a fairly homogeneous region like the Guanzhong Plain, there is a large diversity in farmers' perspectives and practices which these high-level strategies tend to ignore. Second, the current top-down system of transferring new scientific agricultural knowledge and technologies to farmers does not reach the major part of the farmers or satisfy their needs. Elaborating the first issue with respect to the three strategies for sustainable agricultural development distinguished in the previous chapters, the governmental strategy of scale-enlargement and technological modernization addresses the needs and objectives of only a part of the farmers. The strategy applies in particular to the farmers in household cluster 2, which grow mostly perennial cash crops. This group focusses on income from 
agriculture and is interested in learning about new technologies. However, a major part of the farmers is not, as they grow crops for domestic consumption and/or income from offfarm work is more important for them. The proponents of the strategy focusing on conservation of small-scale agriculture should be worried about the finding that a large part of the respondents indicated not to enjoy rural life, in particular those from households where migrant work was the major source of income, and that especially the younger respondents do not like to be farmers. Finally, the strategy to develop ecological agriculture is faced with large contradictions in farmers' perspectives and practices. On the one hand, the majority has a positive attitude towards this mode of agriculture and beliefs that agriculture and nature are partly interdependent. On the other hand, most decisions are determined by the goal to maximize productivity while minimizing labor input, and negative environmental impacts do not play a role. Moreover, a large part of the farmers sees important barriers to actual adoption of ecological agriculture and would require strong incentives from the government or demand from the market to overcome these. Our conclusion is that a strategy for sustainable development of agriculture in China should address a wide diversity of needs and goals as articulated by Chinese farmers themselves, otherwise it will lack the support it needs to be successful. For the development and transfer of new technologies and knowledge, the current top-down approach with a narrow focus on high inputs must be abandoned with a much more interactive learning approach, for which farmers, government and experts are jointly responsible, and which pays due attention to environmental protection.

\subsubsection{Further research}

To better match high-level strategies for agricultural development and on-the-ground services with the needs of Chinese farmers, more in-depth research is needed into farmers' perspectives and practices. First, more insight is needed into what farmers see as problems and why, how they cope with these problems and what viable prospects they see for themselves and, more generally, for agriculture in their village and region. This requires a different research strategy than the survey approach followed in this chapter. A case study approach, with extensive in-depth interviews with a relatively small number of respondents is more appropriate. Second, more insight is needed into the impact of the agro-ecological context on farmers' perspectives, practices, problems and prospects. However, studies of farmers' perspectives following an integrative approach are extremely rare, and only a few related studies from other regions are available. The study of Ma et al. (2009), for example, made clear that in a labor-extensive grain production system, with a lack of off-farm opportunities, prices rather than labor are a dominant factor. We therefore recommend to conduct a number of case studies in contrasting agro-ecological zones of Shaanxi Province, allowing a comparison between farmers in the Guanzhong Plain and those in agronomically less favorable areas, at greater distance from major urban areas. 


\section{APPENDIX 3.1: SURVEY QUESTIONS AND RESPONSES ${ }^{16}$}

1. Basic information

\begin{tabular}{|c|c|c|c|}
\hline \multicolumn{2}{|c|}{ NumberQuestion } & \multirow{2}{*}{$\begin{array}{l}\text { Answer (options) } \\
\text { A. Below } 40\end{array}$} & \multirow{2}{*}{$\begin{array}{l}\text { Percentage } \\
33.3 \%\end{array}$} \\
\hline 1.1 & What is your age bracket? & & \\
\hline & & B. $40-60$ & $58.2 \%$ \\
\hline & & C. Above 60 & $8.5 \%$ \\
\hline \multirow[t]{2}{*}{1.2} & \multirow[t]{2}{*}{ What is your gender? } & A. Female & $50.3 \%$ \\
\hline & & B. Male & $49.7 \%$ \\
\hline \multirow[t]{4}{*}{1.3} & \multirow[t]{4}{*}{ What is your education level? } & A. No school & $7.3 \%$ \\
\hline & & B. Primary school & $26.1 \%$ \\
\hline & & C. Secondary (middle and high) school & $57 \%$ \\
\hline & & D. College degree or above & $9.7 \%$ \\
\hline \multirow[t]{6}{*}{1.4} & \multirow{6}{*}{$\begin{array}{l}\text { What is the main source of } \\
\text { income in your household? }\end{array}$} & A. Farming & $35.2 \%$ \\
\hline & & B. Migrant work & $50.3 \%$ \\
\hline & & C. Industrial or commercial operations & $7.3 \%$ \\
\hline & & D. Property (lease of premises or land) & $2.4 \%$ \\
\hline & & E. Income from government's land requisition & $1.8 \%$ \\
\hline & & F. Other & $3.0 \%$ \\
\hline \multirow[t]{4}{*}{1.5} & \multirow{4}{*}{$\begin{array}{l}\text { Who is doing most of the } \\
\text { farming work in your } \\
\text { household? }\end{array}$} & A. The elderly & $26.1 \%$ \\
\hline & & B. The middle-aged people & $68.5 \%$ \\
\hline & & C. The young people & $3.0 \%$ \\
\hline & & D. Other & $2.4 \%$ \\
\hline \multirow[t]{6}{*}{1.6} & \multirow{6}{*}{$\begin{array}{l}\text { What is main source of } \\
\text { agricultural income in your } \\
\text { household? }\end{array}$} & A. Arable crops (such as wheat) & $52.7 \%$ \\
\hline & & B. Livestock & $7.9 \%$ \\
\hline & & C. Tree crops (such as apple) & $20.0 \%$ \\
\hline & & D. Vegetables & $13.3 \%$ \\
\hline & & E. Aquaculture & $0.6 \%$ \\
\hline & & F. Other & $5.5 \%$ \\
\hline \multirow[t]{4}{*}{1.7} & \multirow{4}{*}{$\begin{array}{l}\text { What is your main mode of } \\
\text { farming? }\end{array}$} & A. Traditional agriculture & $29.7 \%$ \\
\hline & & B. Modern, mechanized agriculture & $55.2 \%$ \\
\hline & & C. The ecological modes of agriculture & $13.9 \%$ \\
\hline & & D. Other & $1.2 \%$ \\
\hline \multirow[t]{2}{*}{1.8} & \multirow{2}{*}{$\begin{array}{l}\text { Which description of the } \\
\text { economic orientation of } \\
\text { agricultural production fits } \\
\text { your situation best? }\end{array}$} & $\begin{array}{l}\text { A. The agricultural production is completely for self- } \\
\text { sufficiency and provides food for domestic } \\
\text { consumption }\end{array}$ & $9.7 \%$ \\
\hline & & $\begin{array}{l}\text { B. The agricultural production is mainly for domestic } \\
\text { consumption and the surpluses will be sold in the } \\
\text { market }\end{array}$ & $32.5 \%$ \\
\hline
\end{tabular}

${ }^{16}$ Translated from the original in Chinese 


\section{Chapter 3}

\begin{tabular}{|c|c|c|c|}
\hline \multicolumn{2}{|c|}{ NumberQuestion } & \multirow{2}{*}{$\begin{array}{l}\text { Answer (options) } \\
\text { C. The majority of agricultural production is for the } \\
\text { market and a small proportion of agricultural } \\
\text { production is for domestic consumption }\end{array}$} & \multirow{2}{*}{$\begin{array}{l}\text { Percentage } \\
55.2 \%\end{array}$} \\
\hline & & & \\
\hline & & $\begin{array}{l}\text { D. The entire agricultural production is sold in the } \\
\text { market }\end{array}$ & $3.6 \%$ \\
\hline \multirow[t]{2}{*}{1.9} & \multirow{2}{*}{\multicolumn{2}{|c|}{ How much arable land does your household have? $\left(\mathrm{mu}^{17}\right)$}} & Mean :4.4 \\
\hline & & & SD:2.9 \\
\hline \multirow[t]{2}{*}{1.10} & \multirow{2}{*}{\multicolumn{2}{|c|}{ How many persons are there in your household? }} & Mean:4.3 \\
\hline & & & SD:1.5 \\
\hline \multirow[t]{2}{*}{1.11} & \multirow{2}{*}{\multicolumn{2}{|c|}{ How many persons in your household work off-farm as migrant workers? }} & Mean:1.3 \\
\hline & & & SD:1.0 \\
\hline \multirow[t]{2}{*}{1.12} & \multirow{2}{*}{\multicolumn{2}{|c|}{ What was your household's income from migrant work last year? (yuan) }} & Mean:28710.5 \\
\hline & & & SD:26743.7 \\
\hline \multirow[t]{2}{*}{1.13} & \multirow{2}{*}{\multicolumn{2}{|c|}{ What was your household's agricultural income last year? (yuan) }} & Mean:15278.9 \\
\hline & & & SD:19668.6 \\
\hline
\end{tabular}

2. Perspectives

\begin{tabular}{|c|c|c|c|}
\hline \multicolumn{2}{|c|}{ NumberQuestion } & \multirow{2}{*}{$\begin{array}{l}\text { Answer (options) } \\
\text { A. Food production for domestic consumption }\end{array}$} & \multirow{2}{*}{$\begin{array}{l}\text { Percentage } \\
72.7 \%\end{array}$} \\
\hline 2.1 & What do you think are the & & \\
\hline & functions of agriculture? & B. Renewal of natural resources & $6.7 \%$ \\
\hline & (multiple response) & C. Conservation of biodiversity & $4.8 \%$ \\
\hline & & D. Providing a beautiful rural landscape & $4.8 \%$ \\
\hline & & E. Income & $58.8 \%$ \\
\hline & & F. Other & $0 \%$ \\
\hline \multirow[t]{3}{*}{2.2} & Are you satisfied with your & A. Very satisfied & $21.2 \%$ \\
\hline & household's agricultural & B. Neutral & $48.5 \%$ \\
\hline & income? & C. Not satisfied & $30,3 \%$ \\
\hline \multirow[t]{6}{*}{2.3} & What do you think about the & A. They save human labor and improve the productivity & $61.2 \%$ \\
\hline & $\begin{array}{l}\text { impact of modern production } \\
\text { tools? }\end{array}$ & $\begin{array}{l}\text { B. They raise the production costs and thereby reduce } \\
\text { farmers' income }\end{array}$ & $10.9 \%$ \\
\hline & & $\begin{array}{l}\text { C. They increase agricultural production and increase } \\
\text { farmers' income }\end{array}$ & $17.6 \%$ \\
\hline & & D. They cause adverse effects on the environment & $7.9 \%$ \\
\hline & & $\begin{array}{l}\text { E. They cause farmers' unemployment, so that farmers } \\
\text { have to work in cities }\end{array}$ & $1.8 \%$ \\
\hline & & F. Other & $0 \%$ \\
\hline
\end{tabular}

\footnotetext{
${ }^{17} 1 \mathrm{mu}=0.067$ hectare
} 


\begin{tabular}{|c|c|c|c|}
\hline \multicolumn{2}{|c|}{ NumberQuestion } & \multirow{2}{*}{$\begin{array}{l}\text { Answer (options) } \\
\text { A. Higher income }\end{array}$} & \multirow{2}{*}{$\begin{array}{l}\text { Percentage } \\
61.8 \%\end{array}$} \\
\hline 2.4 & What influences your & & \\
\hline & satisfaction about farming & B. Reduced involvement of human labor & $18.2 \%$ \\
\hline & most of a & C. Appropriate physical exercise & $2.4 \%$ \\
\hline & & D. More government subsidies & $16.4 \%$ \\
\hline & & E. Improving the environmental conditions of the village & $1.2 \%$ \\
\hline & & F. Other & $0 \%$ \\
\hline \multirow[t]{5}{*}{2.5} & \multirow{5}{*}{$\begin{array}{l}\text { What are in your view major } \\
\text { features of modern agriculture } \\
\text { as compared to traditional } \\
\text { agriculture? (multiple } \\
\text { response) }\end{array}$} & $\begin{array}{l}\text { A. Rationalized production: improved production } \\
\text { efficiency, reduced input of human labor, and increased } \\
\text { production }\end{array}$ & $82.3 \%$ \\
\hline & & B. Increased cost of agricultural production & $15.6 \%$ \\
\hline & & $\begin{array}{l}\text { C. Commercialization of agricultural production, replacing } \\
\text { the traditional self-sufficient farming mode }\end{array}$ & $27.9 \%$ \\
\hline & & $\begin{array}{l}\text { D. The large negative impact on nature and the } \\
\text { environment }\end{array}$ & $10.9 \%$ \\
\hline & & E. Other & $25.2 \%$ \\
\hline \multirow[t]{4}{*}{2.6} & \multirow{4}{*}{$\begin{array}{l}\text { What is your expectation } \\
\text { about the future development } \\
\text { of agriculture? }\end{array}$} & A. The conservation of traditional agriculture & $6.7 \%$ \\
\hline & & $\begin{array}{l}\text { B. More modern agriculture and mechanization of } \\
\text { production }\end{array}$ & $46.1 \%$ \\
\hline & & $\begin{array}{l}\text { C. More ecological modes of agriculture, and more } \\
\text { attention for the protection of the environment }\end{array}$ & $44.8 \%$ \\
\hline & & D. Other & $2.4 \%$ \\
\hline \multirow[t]{2}{*}{2.7} & \multirow{2}{*}{$\begin{array}{l}\text { In general, do you enjoy rural } \\
\text { life? }\end{array}$} & A. Yes, in general, I enjoy it & $65.5 \%$ \\
\hline & & B. No, in general, I do not enjoy it & $39.9 \%$ \\
\hline \multirow[t]{4}{*}{2.8} & \multirow{4}{*}{$\begin{array}{l}\text { What do you like most about } \\
\text { rural life? }\end{array}$} & A. Rural life is slow-paced, relaxed and carefree & $20.7 \%$ \\
\hline & & $\begin{array}{l}\text { B. Compared with urban areas, the environment is of } \\
\text { better quality. There is less pollution in rural areas }\end{array}$ & $46.8 \%$ \\
\hline & & $\begin{array}{l}\text { C. Parents, relatives, and friends live relatively nearby, so it } \\
\text { is easy to take care of each other. }\end{array}$ & $\mathrm{t} 30.6 \%$ \\
\hline & & D. Other & $1.8 \%$ \\
\hline \multirow[t]{5}{*}{2.9} & \multirow[t]{5}{*}{$\begin{array}{l}\text { What do you dislike most } \\
\text { about rural life? }\end{array}$} & $\begin{array}{l}\text { A. Life in rural areas is difficult, and the farming work is } \\
\text { tiresome }\end{array}$ & $14.8 \%$ \\
\hline & & B. The rural income is low & $31.1 \%$ \\
\hline & & C. Rural life is boring and has no vitality & $9.8 \%$ \\
\hline & & $\begin{array}{l}\text { D. Rural infrastructure is poor and the rural life is not } \\
\text { convenient compared to urban life }\end{array}$ & $27.9 \%$ \\
\hline & & $\begin{array}{l}\text { E. The education level of rural schools is not as good as in } \\
\text { urban areas }\end{array}$ & $16.4 \%$ \\
\hline
\end{tabular}




\section{Chapter 3}

\begin{tabular}{|c|c|c|c|}
\hline \multicolumn{2}{|c|}{ NumberQuestion } & Answer (options) & $\frac{\text { Percentage }}{25.5 \%}$ \\
\hline 2.10 & $\begin{array}{l}\text { What do you think about being } \\
\text { a farmer and the farming } \\
\text { profession? }\end{array}$ & $\begin{array}{l}\text { B. I have a neutral attitude toward being a farmer, because } 49.1 \% \\
\text { farmer is a normal profession just like workers, teachers }\end{array}$ & $49.1 \%$ \\
\hline & & $\begin{array}{l}\text { C. I'd rather not be a farmer, because farmers' social } \\
\text { status is low, farmers' work is hard, and agricultural } \\
\text { income is low }\end{array}$ & $24.2 \%$ \\
\hline & & D. Other & $0.6 \%$ \\
\hline \multirow[t]{3}{*}{2.11} & \multirow{3}{*}{$\begin{array}{l}\text { What do you think about the } \\
\text { relationship between } \\
\text { agriculture and the natural } \\
\text { ecosystem? }\end{array}$} & A. They are independent from each other & $21.1 \%$ \\
\hline & & $\begin{array}{l}\text { B. Agriculture is partly dependent on the natural } \\
\text { ecosystem }\end{array}$ & $41.2 \%$ \\
\hline & & $\begin{array}{l}\text { C. Agriculture is completely dependent on the natural } \\
\text { ecosystem }\end{array}$ & $35.2 \%$ \\
\hline \multirow[t]{4}{*}{2.12} & \multirow[t]{4}{*}{$\begin{array}{l}\text { What is your position } \\
\text { concerning the use of chemical } \\
\text { fertilizers and pesticides? }\end{array}$} & $\begin{array}{l}\text { A. I have never considered whether it is good or not to use } \\
\text { chemical fertilizers and pesticides, because I just follow } \\
\text { the example of my father's generation }\end{array}$ & $29.1 \%$ \\
\hline & & $\begin{array}{l}\text { B. I am very dependent on chemical fertilizers and } \\
\text { pesticides because I consider these helpful to increase } \\
\text { production and reduce farmers' workload }\end{array}$ & $52.1 \%$ \\
\hline & & $\begin{array}{l}\text { C. I use as little chemical fertilizers and pesticides as } \\
\text { possible because of environmental pollution }\end{array}$ & $17.0 \%$ \\
\hline & & $\begin{array}{l}\text { D. I never use chemical fertilizers and pesticides, because } \\
\text { they are harmful for people's health. I prefer the } \\
\text { traditional farming methods }\end{array}$ & $1.8 \%$ \\
\hline \multirow[t]{4}{*}{2.13} & \multirow{4}{*}{$\begin{array}{l}\text { What is your attitude toward } \\
\text { environmental degradation } \\
\text { and pollution? }\end{array}$} & $\begin{array}{l}\text { A. Farmers should be aware of the need to protect the } \\
\text { environment and take the initiative }\end{array}$ & $20.0 \%$ \\
\hline & & $\begin{array}{l}\text { B. The government is responsible for environmental } \\
\text { protection. This is not the responsibility of individual } \\
\text { farmers }\end{array}$ & $48.7 \%$ \\
\hline & & $\begin{array}{l}\text { C. Economic development comes first. Environmental } \\
\text { pollution can be dealt with later }\end{array}$ & $7.9 \%$ \\
\hline & & $\begin{array}{l}\text { D. Economic development and environmental pollution } \\
\text { should be given equal attention }\end{array}$ & $22.4 \%$ \\
\hline \multirow[t]{3}{*}{2.14} & \multirow{3}{*}{$\begin{array}{l}\text { What is your attitude toward } \\
\text { ecological modes of } \\
\text { agriculture? }\end{array}$} & A. Positive & $43.0 \%$ \\
\hline & & B. Neutral & $20.6 \%$ \\
\hline & & C. Negative & $36.4 \%$ \\
\hline
\end{tabular}




\begin{tabular}{|c|c|c|c|}
\hline \multicolumn{2}{|c|}{ NumberQuestion } & \multirow{2}{*}{$\begin{array}{l}\text { Answer (options) } \\
\text { A. I am afraid that reduced use of chemical fertilizers and } \\
\text { pesticides will negatively affect agricultural productivity }\end{array}$} & \multirow{2}{*}{$\frac{\text { Percentage }}{30.3 \%}$} \\
\hline 2.15 & $\begin{array}{l}\text { What factors make you } \\
\text { unwilling to adopt ecological }\end{array}$ & & \\
\hline & $\begin{array}{l}\text { modes of agriculture? } \\
\text { (multipleresponse) }\end{array}$ & \multicolumn{2}{|l|}{$\begin{array}{l}\text { B. I am accustomed to the traditional farming mode, while } 40.0 \% \\
\text { sustainable agriculture is a relatively new mode of } \\
\text { farming. It is difficult to accept in a short period of time }\end{array}$} \\
\hline & & \multicolumn{2}{|l|}{$\begin{array}{l}\text { C. I am skeptical about sustainable, ecological, and organic } 41.2 \% \\
\text { agriculture because I have rarely heard about them }\end{array}$} \\
\hline & & $\begin{array}{l}\text { D. I appreciate sustainable, ecological, and organic } \\
\text { agriculture, but I am worried that these new modes of } \\
\text { farming will be accompanied by large market risks }\end{array}$ & $30.3 \%$ \\
\hline \multirow[t]{4}{*}{2.16} & \multirow{4}{*}{$\begin{array}{l}\text { What factors make you willing } \\
\text { to adopt ecological modes of } \\
\text { agriculture? (multiple } \\
\text { response) }\end{array}$} & $\begin{array}{l}\text { A. The more nearby farmers adopt these farming modes, } \\
\text { the easier for me to adopt as well }\end{array}$ & $36.4 \%$ \\
\hline & & $\begin{array}{l}\text { B. The more government policy supports these farming } \\
\text { modes, the easier for me to adopt }\end{array}$ & $57.6 \%$ \\
\hline & & $\begin{array}{l}\text { C. The more popular sustainable, ecological or organic } \\
\text { products are in the market, the easier for me to adopt }\end{array}$ & $55.8 \%$ \\
\hline & & $\begin{array}{l}\text { D. The more environmentally friendly these farming modes } \\
\text { are, the easier for me to adopt }\end{array}$ & s20.6\% \\
\hline
\end{tabular}

3. Farming practices (decision-making and behaviors)

\begin{tabular}{|c|c|c|c|}
\hline \multicolumn{2}{|c|}{ NumberQuestion } & \multirow{2}{*}{$\begin{array}{l}\text { Answer (options) } \\
\text { A. The quantity of agricultural production }\end{array}$} & \multirow{2}{*}{$\begin{array}{l}\text { Percentage } \\
75.8 \%\end{array}$} \\
\hline 3.1 & What is the main & & \\
\hline & consideration in your decisions & ${ }^{S_{B}}$. The quality of agricultural production & $13.9 \%$ \\
\hline & as a farmer? & C. The impact on the environment & $0 \%$ \\
\hline & & D. Other & $10.3 \%$ \\
\hline \multirow[t]{3}{*}{3.2} & \multirow{3}{*}{$\begin{array}{l}\text { Do you take the relationship } \\
\text { between agriculture and } \\
\text { nature into consideration in } \\
\text { your farming practice? }\end{array}$} & $\begin{array}{l}\text { A. I never consider the relationship between agriculture } \\
\text { and nature }\end{array}$ & $24.2 \%$ \\
\hline & & $\begin{array}{l}\text { B. I think about it occasionally, but it does not influence my } \\
\text { farming practice }\end{array}$ & $y 50.9 \%$ \\
\hline & & $\begin{array}{l}\text { C. I often take the relationship between agriculture and } \\
\text { nature into consideration in my farming practice, } \\
\text { because I think that the environment is very important. } \\
\text { We should focus on long-term environmentally } \\
\text { sustainable agricultural development, and not on short- } \\
\text { term economically profitable agricultural development }\end{array}$ & $24.2 \%$ \\
\hline \multirow[t]{6}{*}{3.3} & \multirow{6}{*}{$\begin{array}{l}\text { Which considerations } \\
\text { influence the amount of } \\
\text { fertilizers and pesticides that } \\
\text { you use? (multipleresponse) }\end{array}$} & A. The productivity & $70.7 \%$ \\
\hline & & $\begin{array}{l}\text { B. The cost of inputs and the price of fertilizers and } \\
\text { pesticides }\end{array}$ & $49.4 \%$ \\
\hline & & $\begin{array}{l}\text { C. The practices of other farmers in the village concerning } \\
\text { fertilizers and pesticides }\end{array}$ & $31.1 \%$ \\
\hline & & D. Whether it can reduce the input of labor input or not & $33.5 \%$ \\
\hline & & E. Whether it can cause serious environmental pollution & $12.2 \%$ \\
\hline & & F. Other & $0 \%$ \\
\hline
\end{tabular}




\begin{tabular}{|c|c|c|c|}
\hline \multicolumn{2}{|c|}{ NumberQuestion } & \multirow{2}{*}{$\begin{array}{l}\text { Answer (options) } \\
\text { A. Yes, I would like to participate because it helps small } \\
\text { farmers to improve their market competitiveness }\end{array}$} & \multirow{2}{*}{$\begin{array}{l}\text { Percentage } \\
45.5 \%\end{array}$} \\
\hline 3.4 & $\begin{array}{l}\text { Would you like to participate } \\
\text { in a farmers' cooperative }\end{array}$ & & \\
\hline & organization? & $\begin{array}{l}\text { B. It is not relevant for me. We have only a small piece of } \\
\text { land and the agricultural income in my household is low }\end{array}$ & $45.5 \%$ \\
\hline & & C. No, I don't like to participate in any farmers' cooperative & $9.0 \%$ \\
\hline \multirow[t]{6}{*}{3.5} & \multirow{6}{*}{$\begin{array}{l}\text { What is the main factor that } \\
\text { influences your choice of the } \\
\text { type of agricultural } \\
\text { production? }\end{array}$} & $\begin{array}{l}\text { A. Habit, I will just continue with the same type of } \\
\text { agricultural production as before }\end{array}$ & $32.7 \%$ \\
\hline & & $\begin{array}{l}\text { B. The choice of the majority of the other farmers in my } \\
\text { village }\end{array}$ & $15.2 \%$ \\
\hline & & C. The guidance of the government and agricultural experts & s11.5\% \\
\hline & & D. The opportunity to reduce the workload & $7.3 \%$ \\
\hline & & E. The opportunity to improve my household's income & $32.7 \%$ \\
\hline & & F. Other & $0.6 \%$ \\
\hline \multirow[t]{4}{*}{3.6} & \multirow[t]{4}{*}{$\begin{array}{l}\text { What type of fertilizers do you } \\
\text { use? }\end{array}$} & $\begin{array}{l}\text { A. Chemical compound fertilizers (nitrogen, phosphate, } \\
\text { potash) }\end{array}$ & $87.3 \%$ \\
\hline & & B. Animal manure & $8.5 \%$ \\
\hline & & C. Organic fertilizers bought at the market & $4.2 \%$ \\
\hline & & D. Other & $0 \%$ \\
\hline
\end{tabular}

3.7 Which description fits best your use of fertilizers and pesticides?

A. I use large amounts of fertilizers and pesticides, because $10.3 \%$ I think it increases the production

B. I use fertilizers and pesticides strictly in accordance with $31.5 \%$ the application instructions

C. I never pay attention to the application instructions and $\mathbf{1 5 7 . 0 \%}$ do not really know about the quantity of pesticides and fertilizers I use

D. Other

3.8 To what extent do you use

A. Fully dependent on manpower agricultural machinery in farming?

B. Mainly dependent on manpower

C. Mainly dependent on farm machinery

D. Fully dependent on farm machinery

3.9 Did you take part in a farmers' A. I have never heard of farmers' cooperatives cooperative?

B. I have heard about farmers' cooperatives, but I didn't $54.5 \%$ take part in any of them

C. I took part in a farmers' cooperative, but I thought it was $12.1 \% \%$ not very helpful

D. I take part in farmers' cooperatives and I feel it is very

$6.1 \%$ helpful to improve small farmers' market competitiveness 
4. Practices and perspectives concerning the use and acquisition of knowledge

\begin{tabular}{|c|c|c|c|}
\hline Number & Question & Answer (options) & Percentage \\
\hline \multirow[t]{4}{*}{4.1} & \multirow{4}{*}{$\begin{array}{l}\text { What type of agricultural } \\
\text { knowledge do you use in your } \\
\text { farming work? }\end{array}$} & $\begin{array}{l}\text { A. Traditional agricultural knowledge, which was learned } \\
\text { from older generations, by observation or orally }\end{array}$ & $44.8 \%$ \\
\hline & & $\begin{array}{l}\text { B. Scientific knowledge, which was obtained through } \\
\text { agricultural knowledge and technology training }\end{array}$ & $20 \%$ \\
\hline & & $\begin{array}{l}\text { C. A combination of traditional agricultural knowledge and } \\
\text { scientific knowledge }\end{array}$ & $35.2 \%$ \\
\hline & & D. Other & $0 \%$ \\
\hline
\end{tabular}

4.2 How do you obtain
agricultural knowledge?

A. I obtain agricultural knowledge through government- $\quad 22.4 \%$ organized farmer training in the village

B. I obtain agricultural knowledge very actively. For

$40.6 \%$ example, I gain information by watching TV programs and reading agricultural books

C. I obtain agricultural knowledge not in a structured way. 33.3\% For example, by hearing about some information from relatives and friends

D. Other

4.3 What is your opinion about traditional agricultural

A. Negative, because the efficiency and income of knowledge? traditional agriculture are low

B. Neutral, I haven't considered the issue seriously

C. Positive, traditional agriculture causes has only limited $39.4 \%$ impact on the environment, although the efficiency is low

A. I tend to give up traditional agricultural knowledge and $\mathbf{1 6 . 4 \%}$ agricultural knowledge with fully accept scientific knowledge modern scientific agricultural

B. I tend to use traditional agricultural knowledge knowledge, what is your choice and opinion?

C. I tend to combine the traditional agricultural knowledge $55.2 \%$ and scientific agricultural knowledge

4.5 Are you satisfied with your

A. I am satisfied with my current agricultural knowledge current agricultural

B. Neutral, I have never considered the issue knowledge?
C. I am not satisfied with my agricultural knowledge and looking forward to learning more scientific and technological agricultural knowledge

4.6 Do you think agricultural

A. It is not useful

B. It is very useful, because it helps us to do farming in a modern scientific way and to improve agricultural productivity 


\begin{tabular}{|c|c|c|c|}
\hline Number & Question & Answer (options) & Percentage \\
\hline \multirow[t]{5}{*}{4.7} & \multirow{5}{*}{$\begin{array}{l}\text { Do you want to take part in } \\
\text { agricultural knowledge } \\
\text { training courses? }\end{array}$} & A. Very unwilling to participate & $4.2 \%$ \\
\hline & & B. Unwilling to participate & $20.6 \%$ \\
\hline & & C. Neutral & $21.2 \%$ \\
\hline & & D. Willing to participate & $41.8 \%$ \\
\hline & & E. Very willing to participate & $11.5 \%$ \\
\hline \multirow[t]{6}{*}{4.8} & \multirow{6}{*}{$\begin{array}{l}\text { Which factors will influence } \\
\text { your willingness to } \\
\text { participate in agricultural } \\
\text { knowledge training courses? } \\
\text { (multiple response) }\end{array}$} & $\begin{array}{l}\text { A. When knowledge is provided which relates to my own } \\
\text { agricultural practice }\end{array}$ & $56.7 \%$ \\
\hline & & $\begin{array}{l}\text { B. When the trainers give guidance to farmers in the crop } \\
\text { field instead of just giving a lecture }\end{array}$ & $49.4 \%$ \\
\hline & & $\begin{array}{l}\text { C. When the agricultural knowledge is popularized and } \\
\text { supported by government }\end{array}$ & $31.7 \%$ \\
\hline & & D. When it can help me to improve my agricultural income & $55.5 \%$ \\
\hline & & $\begin{array}{l}\text { E. When there are many surrounding farmers in the } \\
\text { village who also would like to participate }\end{array}$ & $20.7 \%$ \\
\hline & & F. Other & $0 \%$ \\
\hline
\end{tabular}

4.9 What do you think about the A. They play practically no role in farmers' practices $25.5 \%$ function of rural technology $\quad$ B. They stimulate farmers to participate in training courses $28.5 \%$ promotion stations? and provide farmers with agricultural technology guidance

C. They do demonstration tests to promote new $\quad 21.8 \%$ agricultural technology

D. They provide some agricultural information services $\quad 16.4 \%$

E. Other $0.6 \%$

4.10 What do you think about the A. The relationship is 'to guide and to be guided' $32.1 \%$ relationship between farmers $B$. It should be an interactive learning relationship $\quad 49.1 \%$ and technical training personnel?

C. It must be a relationship of cooperation; both farmers $17.6 \%$ and technical trainers are participants in agricultural production
D. Other

4.11 Who should play the main

A. Farmers should learn agricultural knowledge actively by $23.6 \%$ role in promoting farmers' TV and reading

acquisition of new

agricultural technology and knowledge?

B. The government should lead and organize farmers to $37 \%$ obtain new agricultural knowledge

C. Farmers' professional organizations should take the lead $8.5 \%$

D. Agricultural experts and agricultural knowledge trainers $11.5 \%$ should take the lead

E. This should be accomplished by the cooperation of $\quad 19.4 \%$ farmers, government, agricultural experts, and farmers' professional organizations. 


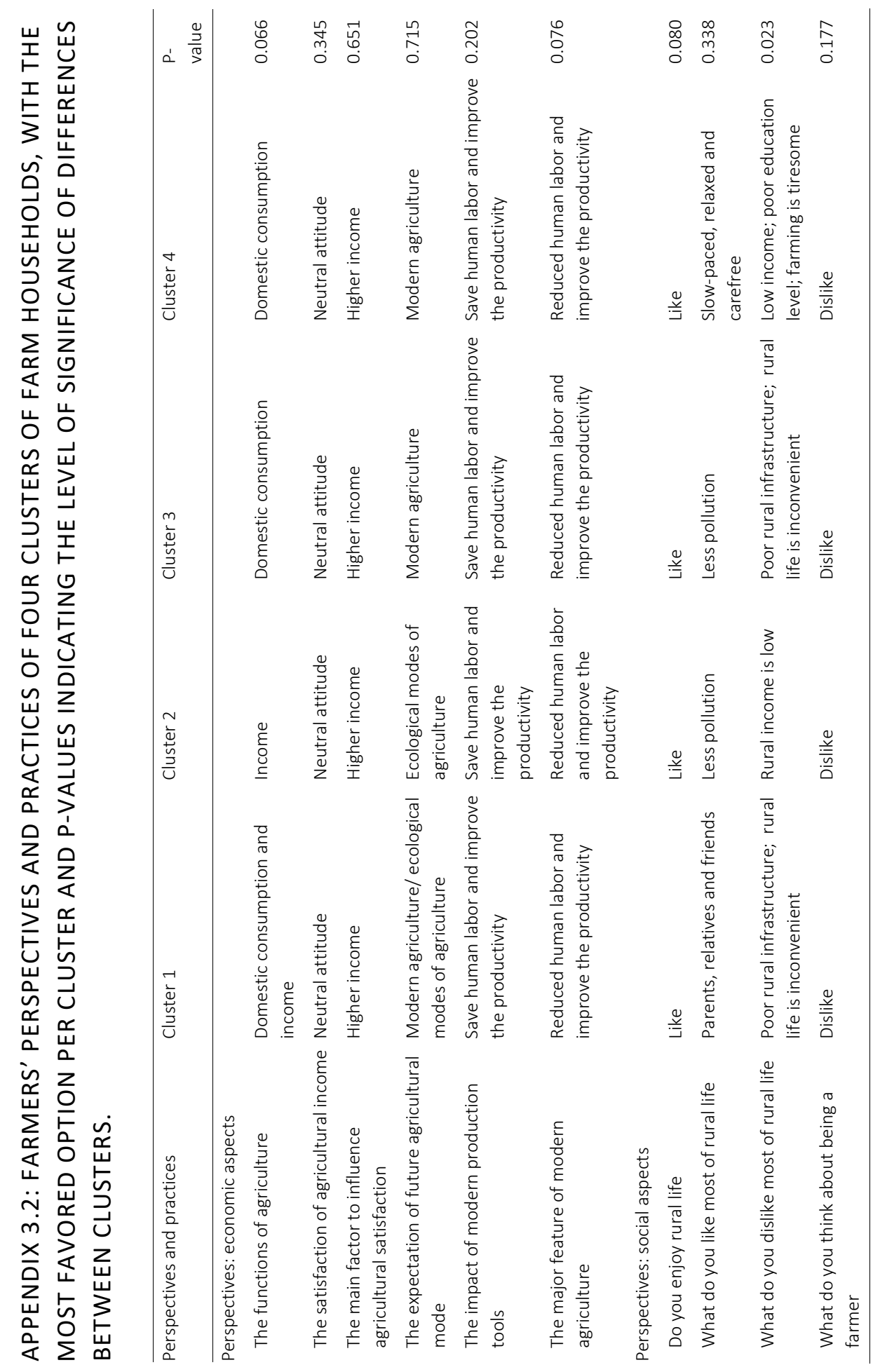




\section{Chapter 3}

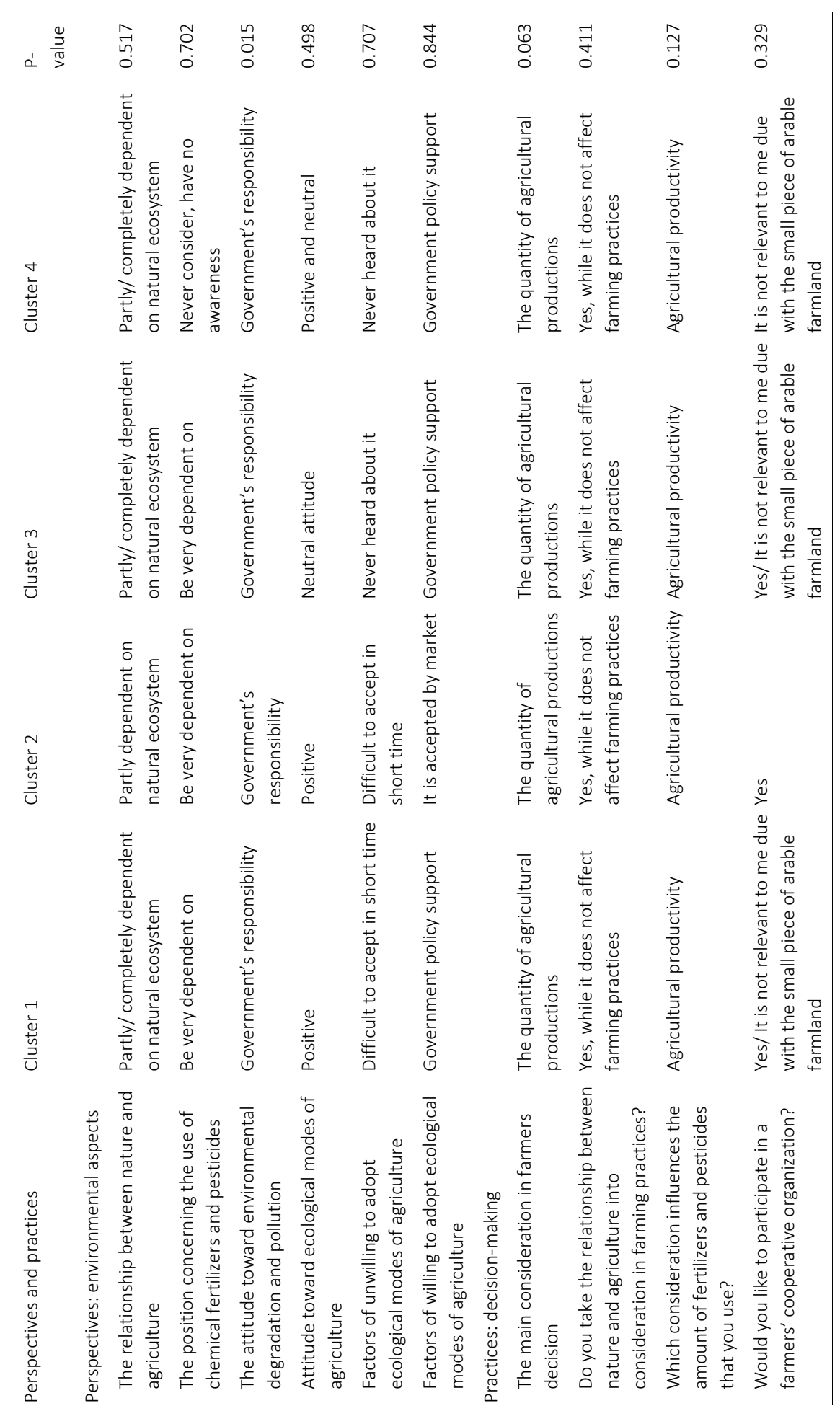


Farmers' perspectives and practices in the Guanzhong Plain of Shaanxi Province, China

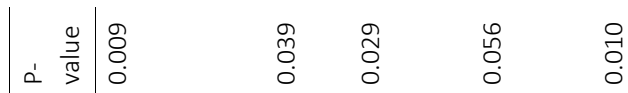

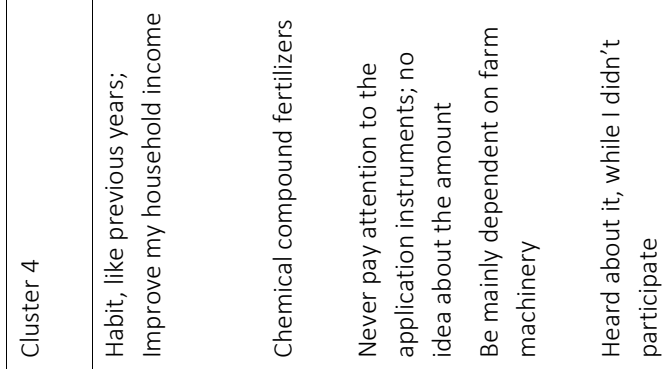

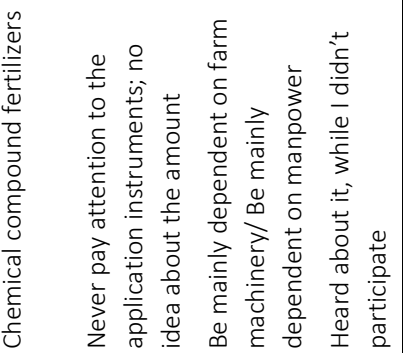

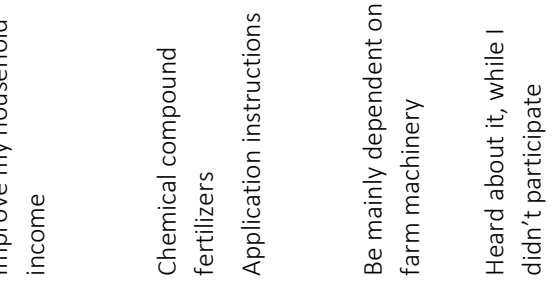

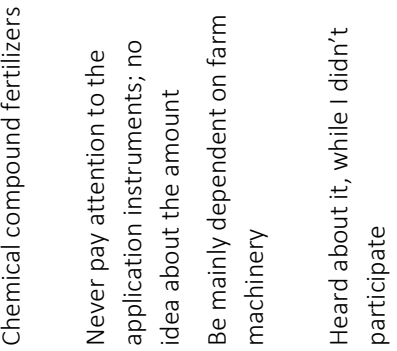
4
|.

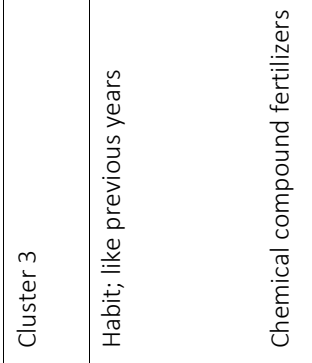

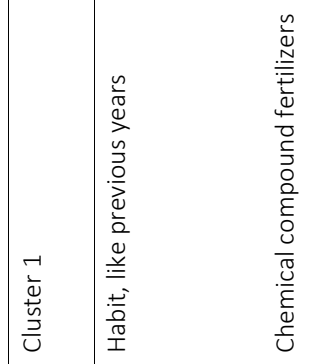

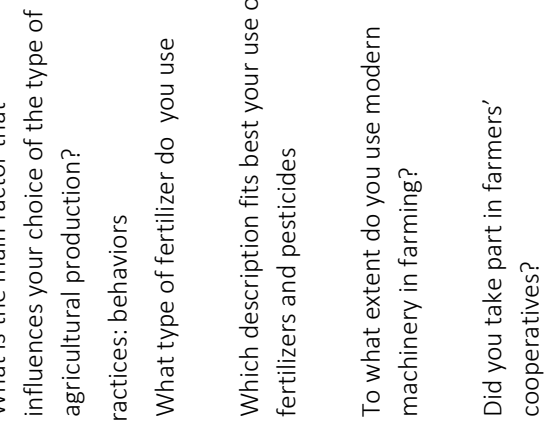



Chapter

\section{4}

Farmers' perspectives in Daijia, a village in the Guanzhong Plain of

Shaanxi Province, China 
Abstract: The perspectives of farmers on the current state and future development of agriculture in Daijia are described based on in-depth interviews with 14 respondents. Diajia is a village located in the Guanzhong Plain of Shaanxi Province. As the dominant system is intensive double-cropping of maize and winter wheat, the area is representative of agriculture in the North China Plain, the major agricultural production region of China. According to the farmers, the major problem is that the net income from grain production is far too low to cover household expenses, which is mainly due to the very small land holdings (0.1-0.7 ha). From an economic perspective, farm households in Daijia address this problem successfully by diversification into apple growing and offfarm employment, both locally and in more distant major cities. The respondents mentioned several of the social problems often associated with rural-urban migrant labor, but these were considered to be relatively moderate due to the presence of a primary school for the children of migrant parents in Daijia and the availability of local off-farm jobs for older, returning migrant workers. Despite the reported intensive use of pesticides and chemical fertilizers in both grain production and apple growing, no major environmental problems were mentioned. Farmers felt that these high input levels were needed to maximize the yields. For the future, respondents expected that most young people would not continue the farming and that agriculture in Daijia would be further mechanized and increase in scale. However, given the current importance of subsistence farming as social safety net for unemployment and old age, the expectation was that these developments would take place slowly. The chapter concludes with a reflection on the sustainability of farming in Daijia and implications for policy. 


\subsection{INTRODUCTION}

Over the past decades, agricultural development in China was characterized by a strong increase in agricultural production and farmer incomes. Major policy goals concerning national food security, access to affordable food and rural poverty alleviation have been reached. However, at the same time environmental, as well as economic and social problems threaten the sustainability of agriculture (Chapter 2). The Chinese government aims to address these problems with a modernization strategy in combination with urbanization. Alternative strategies focus on the conservation of small-scale agriculture or the development of ecological agriculture. However, neither the government's modernization strategy nor the two major alternatives offer a comprehensive and integrated response to the current threats to the sustainability of agriculture. Moreover, all three strategies make unsupported, generic assumptions about the problems and needs of Chinese farmers (Chapter 2). Investigation of farmers' perspectives on agricultural development and how these vary with local conditions is therefore a much needed step towards a comprehensive and broadly supported strategy for sustainable agricultural development in China. A survey of farmers in the Guanzhong Plain (Shaanxi Province) made clear that even in a fairly homogeneous agricultural production area, there is a large diversity in farmers' perspectives and practices, depending on farm household type, age and level of education (Chapter 3).

To better match high-level strategies for agricultural development as well as on-theground services with the needs of Chinese farmers, more in-depth research is required into farmers' perspectives and practices. First, more insight is needed into what farmers see as problems and why, how they cope with these problems and what viable prospects they see for themselves and, more generally, for agriculture in their village. This requires a case study approach, with extensive in-depth interviews with a relatively small number of respondents. Second, more insight is needed into the impact of the agro-ecological context on farmers' perspectives, practices, problems and prospects. We therefore conducted case studies of three villages in contrasting agro-ecological zones of Shaanxi Province, allowing a comparison between farmers in the Guanzhong Plain and those in agronomically less favorable areas, at greater distance from major urban centers.

This chapter reports on the perspectives of farmers in Daijia village in the Guanzhong Plain of Shaanxi Province, where the natural conditions are favorable and agriculture is relatively advanced. As the dominant system is double-cropping of maize and winter wheat, the area is representative of agriculture in the North China Plain, the major agricultural production region of China. The following sections describe the methods used to determine farmers' perspectives on the current state and future development of agriculture in Daijia, the context of Daijia village, and the farmers' perspectives. We 
conclude with summarizing the main findings, comparing these with other studies, and reflecting on the sustainability of farming in Daijia and associated policy options.

\subsection{METHODS}

\subsubsection{Data collection and analysis}

The field work started with a four-week stay in Daijia village in July and August 2014, to become familiar with village life and to gain a better understanding of the village context. In April and May 2015, 14 farmers were interviewed. A former village leader was interviewed first, and thereafter the other interviewees were identified by walking through the village and requesting people for interviews until a sufficiently large and balanced selection was obtained. The target was to interview people from all teams of Daijia village (including Renqu village) ${ }^{18}$, in total about 15 persons from different households, with a 50/50 gender balance and a representative distribution of age groups. The interviews were semi-structured, addressing a limited set of predefined topics detailed below. The duration of a single interview ranged from 1 to 3 hours, and the interviewees were given ample opportunity to tell their stories.

All interviews were audio-recorded, transcribed in full in Chinese, and then translated into English. After reading all transcripts, a qualitative content analysis was conducted by coding the text with the MAXQDA software program. The main codes were predefined and related to the three dimensions of agriculture: economic, social and environmental. For each main code, several sub-codes were predefined or determined after reading all transcripts. Sub-codes for economic aspects were 'grain crops', 'apples', 'labour input and mechanization', 'migrant and off-farm work as income source', 'importance of agriculture', and 'scale-enlargement'. With respect to the grain crops and apples, data on inputs and outputs were identified in the interviews to calculate the net income from wheat, maize, and apples. Sub-codes for social aspects were 'social security', 'problems of migrant workers', and 'return of migrant workers'. Finally, sub-codes for environmental aspects were 'application of agrochemicals', and 'environmental problems'.

\footnotetext{
${ }^{18}$ Due to the small population of Daijia proper (765 people) and Renqu (approximately 597 people), the two villages were merged into one administrative village in 2010. The combined village is called Daijia village. The government policy of merging small villages aims at reducing the amount of village officials in order to decrease the costs of rural administration.
} 


\subsubsection{Characteristics of the respondents}

The characteristics of the respondents in Daijia village are presented in table 4.1. The 14 respondents included 8 males and 6 females. Due to the clan characteristic of the village, the majority of the male respondents' surname is Dai or Ren whereas the surnames of the female respondents are more diverse. In terms of age, there were two 'young' (less than 40 years old), seven 'middle-aged' (40-60 years old), and five 'old' interviewees (more than 60 years old). This age distribution reflected the situation in Daijia village, with mainly middle-aged and old farmers doing the farming work, and the majority of the young people staying in cities for migrant work. Concerning the two young interviewees, one interviewee (Ren, 27 years old, male) had returned to the village due to unemployment in urban construction work and marriage plans. The other (Song, 39 years old, female), had to stay in the village to take care of her two children. The majority of middle-aged and old respondents were taking care of their grandchildren in addition to the farming work, and some also had temporary off-farm jobs nearby. The size of the land-holdings is small in Daijia, and ranged among the interviewees from 1 to 10 mu per household. The respondents are referred to as 'farmers ${ }^{19}$ in this chapter. As explained in Chapter 1, due the Household Registration System (hukou) and the Household Responsibility System, everyone who is formally a rural resident in China has the right of use of a piece of the collective farmland of the village (see also section 4.3.4).

\footnotetext{
${ }^{19}$ The Chinese word is nongmin, which can be translated as farmer or peasant (Schneider, 2015).
} 


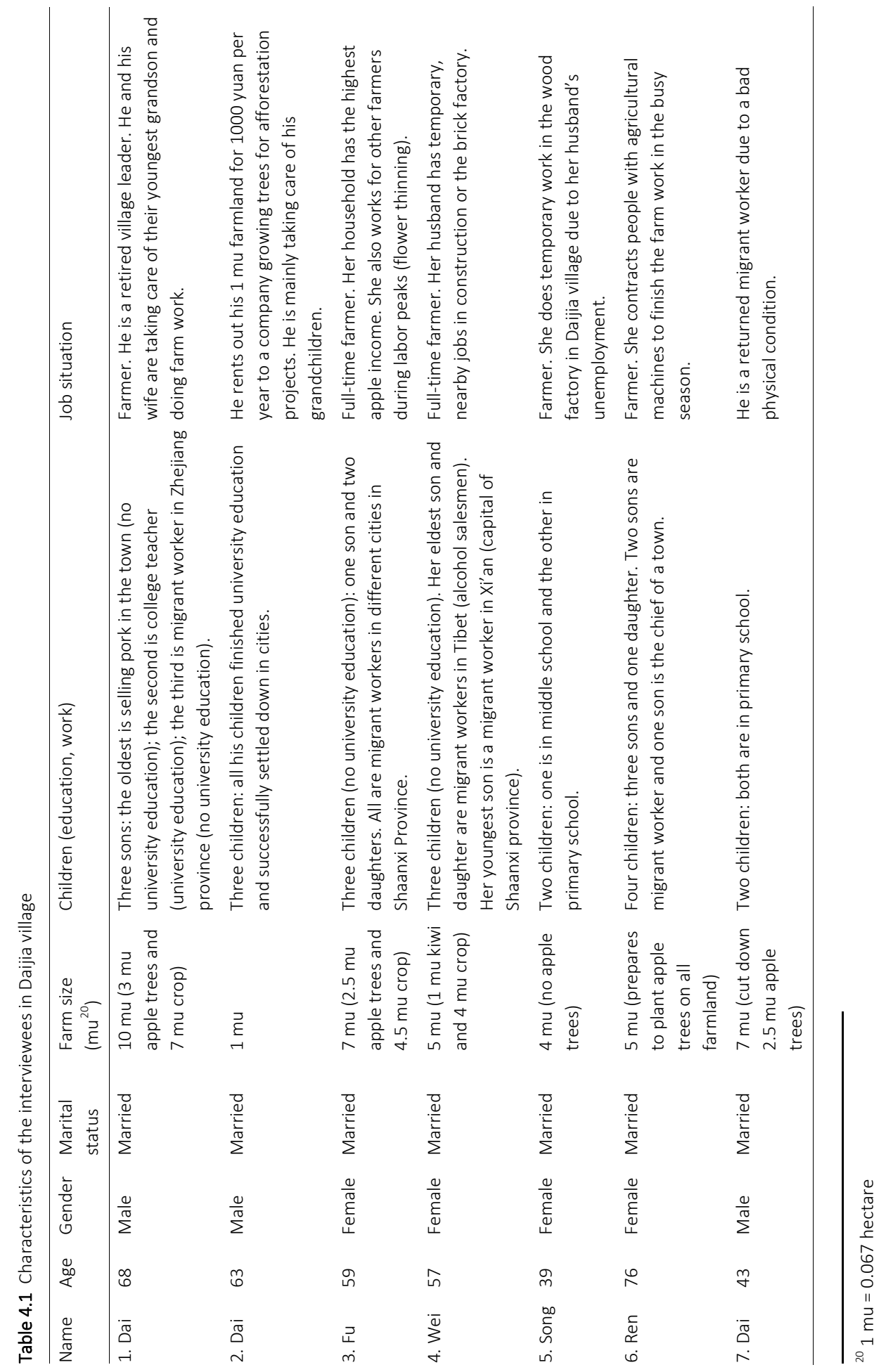




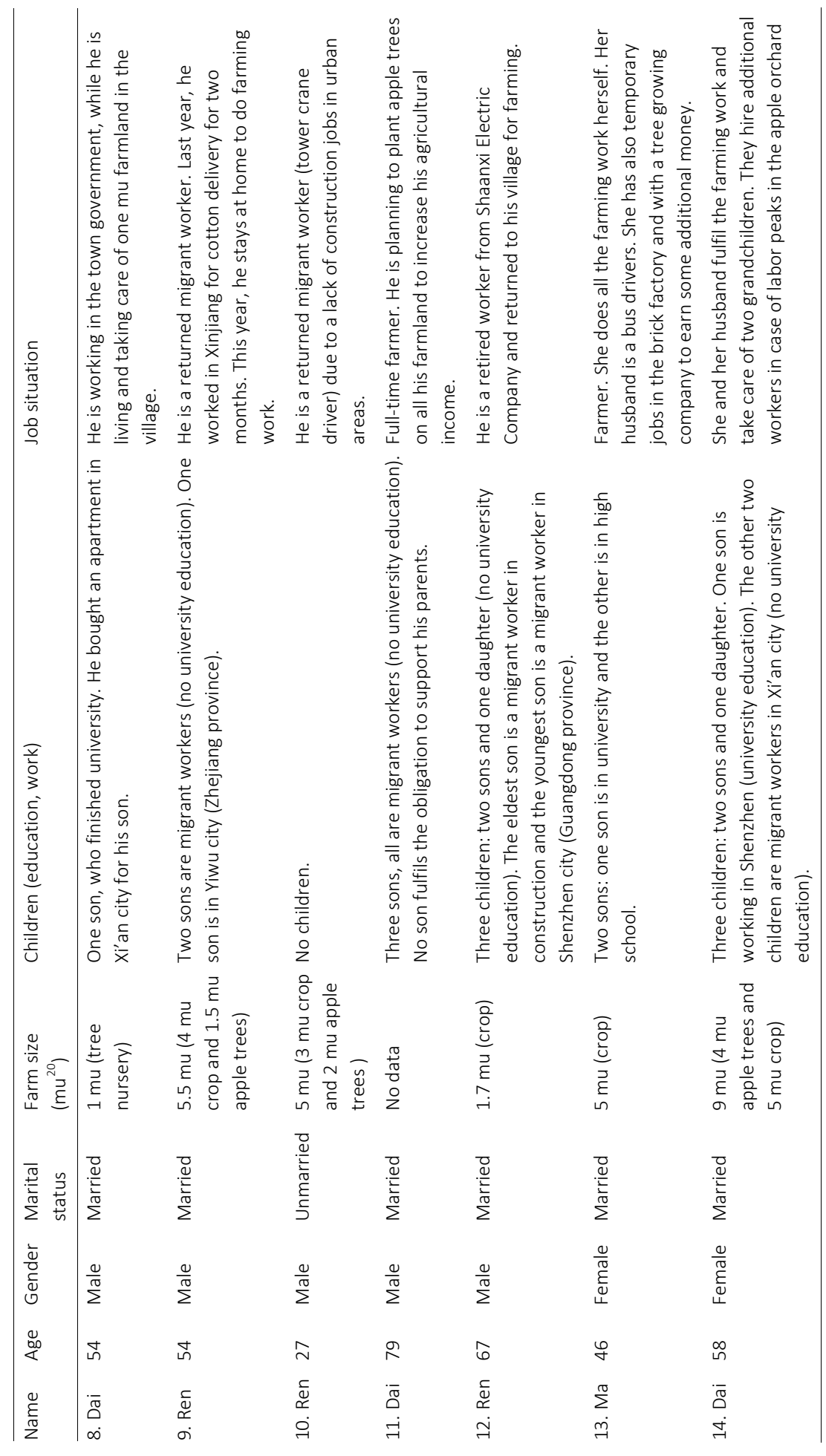




\subsection{THE CONTEXT OF DAIJIA VILLAGE}

In this section the context of Daijia village is briefly described, with respect to the physical and social geographic conditions, farming system, administrative organization of the village, and the implementation of policies concerning farmland reallocation and rural welfare in Daijia. The description is based on local sources, unless indicated otherwise.
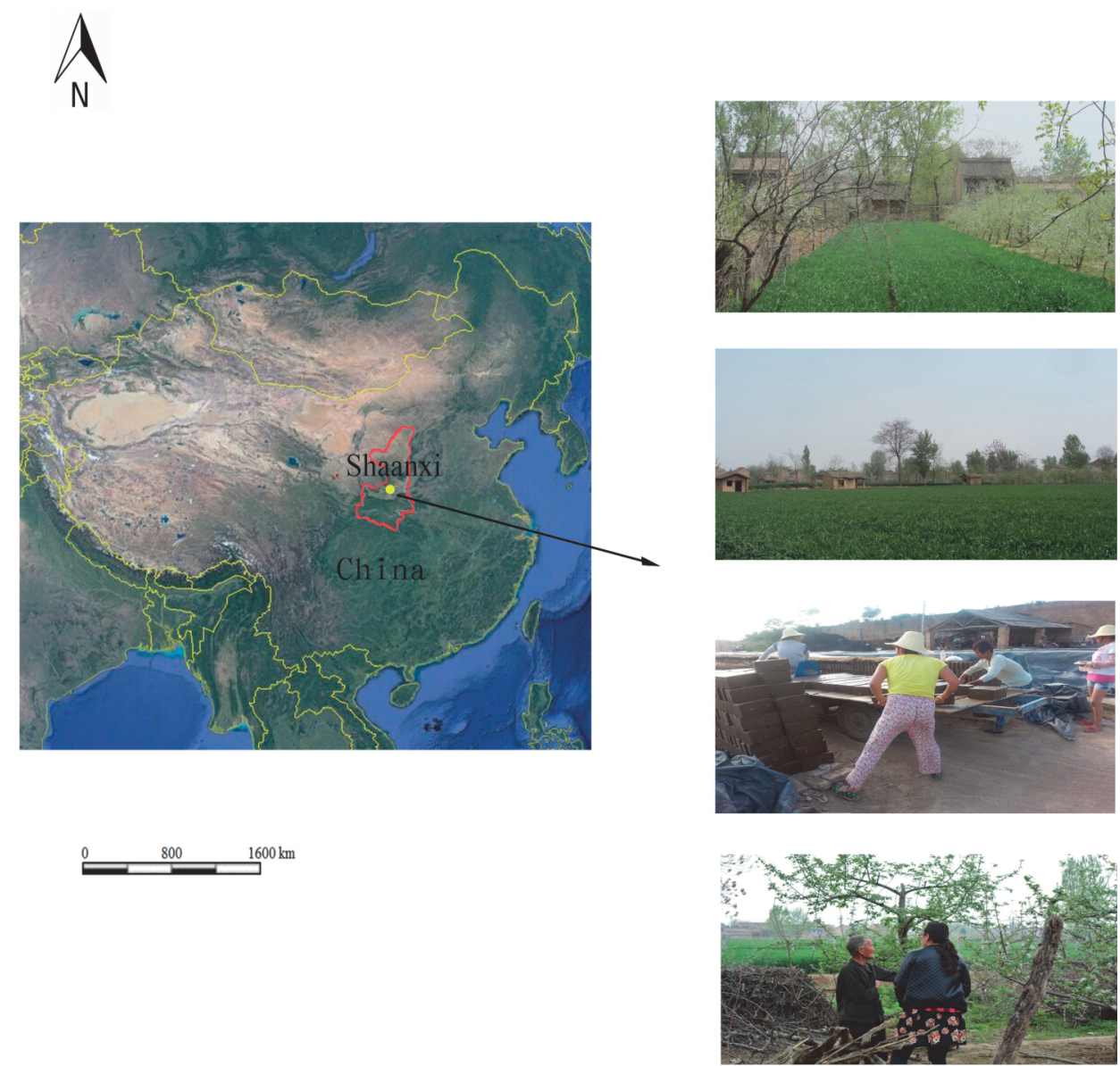

Figure 4.1 Daijia village: geographic location; wheat field and apple orchard; intercropping of apples and wheat; brick factory in Renqu village; interviewing an old farmer 


\subsubsection{Geography ${ }^{21}$}

Daijia village is located in the Guanzhong Plain, in the middle part of Shaanxi Province (figure 4.1). Administratively, it belongs to Sufang town, Wugong county of Xianyan city. The Guanzhong Plain is the most developed area of Shaanxi province, both with respect to agriculture and industry. The land is fertile due to its location in the fluvial plain of the Wei River. The average altitude is approximately 500 meter. The annual amount of precipitation varies between 500 and $800 \mathrm{~mm}$. The natural conditions are favourable for agriculture, and the Guanzhong Plain is one of the main wheat producing areas of China.

Daijia village is adjacent to major urban areas, such as Wugong county, Qian county, Xianyang city and Xi'an city. This geographic position offers several advantages to local development in terms of agriculture and off-farm employment. First, due to the proximity of Northwest Agriculture \& Forrestry University in the Yangling agricultural high-tech zone, Daijia is often visited by agricultural technology extension officers and, as a consequence, is relatively well-developed in terms of agricultural mechanization and modern farming techniques. Agricultural technicians and experts visit the village each year and inform the farmers about the latest knowledge and technology to help them increase their production and income. Second, the location nearby urban centres gives the farmers good and stable access to the markets for their products. Third, it also offers the villagers relatively abundant employment opportunities for temporary work nearby. This allows for instance middle aged farmers to combine the farm work with odd jobs in the surroundings of the village.

\subsubsection{Farming system}

The crop rotation of winter wheat and summer maize ${ }^{22}$ is the most common cropping system in the Guanzhong Plain, as in most grain producing areas in the northern part of China. With the introduction of new varieties, agrochemicals and agricultural machinery in Daijia, the yields of these crops have been raised substantially over the past decades. For instance, the average yield of maize has increased from $150 \mathrm{~kg}$ per mu in the 1970s to $500 \mathrm{~kg}$ per mu in recent years. Due to the flat terrain, the degree of mechanization is high, which has resulted in a reduced need for human labor and enhanced labor productivity.

In addition to grain crops, many farmers in Daijia also grow apples as a cash crop. Planting of apple orchards was encouraged in the early 1990s by the county government to

\footnotetext{
${ }^{21}$ Information on soil, altitude and precipitation is obtained from Baidu Baike (Chinese encyclopedia): http://baike.baidu.com/view/718190.htm.

${ }^{22}$ The growing season of maize is from June till October; and of wheat from October to the end of May.
} 
improve farmers' incomes. After visits of village leaders to Liquan county ${ }^{23}$, local farmers started to plant apple trees. Initially however, this was an economic failure. The main reason was that many different apple varieties were planted, each produced in small quantities, which made it difficult to attract apple traders and to compete in the market. The village leaders then invited experts from Northwest Agriculture \& Forrestry University, who concluded that the natural condition were most suitable for Fuji apples and advised the farmers to concentrate on this variety. With the larger scale of production and the relatively high price for Fuji apples, the income from apples has been stable in recent years.

\subsubsection{Administrative organization}

Daijia (including Renqu village) counts 1362 inhabitants and 326 households. Administratively, Daijia village proper and Renqu village were combined into one village named "Daijia village" in 2010. These two villages share the same village leadership, three officals are from Daijia village proper and one is from Renqu village. According to some respondents, the two villages are economically separated because of the brick factory in Renqu village. However, villagers from both Daijia proper and Renqu village have temporary jobs in the brick factory and with respect to agriculture, they grow the same crops (grains and apples). Also the situation with regard to migrant work and income is similar. Generally, the people living in the village can be divided into three groups: older farmers (male and female), middle aged female farmers, and children. The children attend the primary school in Daijia village rather than moving with their migrant-worker parents to the cities. Daijia village has a tradition in emphasizing the importance of education and therefore there are more children who entered university than in surrounding villages. Both the high level of education and the strong communication ties between the village and the outside world provided by the migrant workers, promote an open mind among the farmers concerning the development of Daijia village.

Farmers in Daijia village proper frequently made a distinction between the three teams $^{24}$ in the village. These teams were formed in the period of agricultural collectivization with initially 108 villagers per team and the same amount of farmland. Currently, there are approximately 200 people in team 1 and over 300 people in team 3 (see table 4.2; numbers based on household registrations). The main reason is that more people

\footnotetext{
${ }^{23}$ Liquan county is located in Guanzhong plain, which is the middle part of Shaanxi province. It is a nationally famous apple-producing county. Available from: http://baike.baidu.com/view/4892465.htm

${ }^{24}$ In the administrative hierarchy, the production team was the lowest level, the next higher levels being the production brigade and people's commune. Within each production team, famers were divided into smaller teams to organize agricultural production and collect agricultural tax. Since 1984, with the liberalization of the rural economy and the establishment of the Household Responsibility System, the production teams have been replaced with villages as administrative units. In some rural areas, the division over the smaller teams is maintained even though they do not play a role anymore in the organization of agricultural production. Available from: https://en.wikipedia.org/wiki/Production_team_(China).
} 
from team 1 entered university and now work in cities. As a consequence, per capita farmland in team 1 is more than that in team 3. In Daijia village proper, the farmers follow their own traditional farmland reallocation norms at team level (see section 4.3.5), which is the major reason why it still matters to which team a farmer belongs. However, in most rural areas in China, including Renqu village, "team" no longer has an important meaning or function. In Renqu village, the 597 people are formally divided over two teams (Rennan and Renbei), but farmers from Renqu seldomly referred to these teams. In Renqu village, the farmers follow the national policy with respect to farmland reallocation in which team membership does not play a role.

Table 4.2 Three teams in Daijia village proper

\begin{tabular}{lllll}
\hline Team & Population & Households & Farmland & Housing sites $^{25}$ \\
\hline Team 1 & 205 & 50 & 350 & 22 \\
Team 2 & 240 & 65 & 350 & 30 \\
Team 3 & 320 & 80 & 350 & 30 \\
\hline
\end{tabular}

\subsubsection{Farmland reallocation policy}

Nationally, the duration of the contracts which transferred the right of use of the collective farmland to individual households, was initially set at 15 years (from 1983 to 1997) and extended to 30 years after 1997 (Hu, 2014; Ren, 2004; Zhou, 2014a; see also Chapter 1). This national farmland policy is normally strictly followed and therefore it is remarkable that the farmers in Daijia village proper follow their own, local policy ${ }^{26}$ (土 政策). In this policy, the village farmland distribution is adjusted by minor reallocations every 5 years. According to the villagers, their policy is motivated by considerations of equity and was collectively agreed upon when the Household Responsibility System came into force in the 1980s. It works as follows: when people pass away or girls marry boys from outside the village, their farmland rights will be reclaimed by the village committee; and when children are born or girls from outside marry a boy from Daijia village, the reclaimed farmland rights will be allocated to them.

Each team in Daijia proper has its own "flexible farmland" buffer to enable these reallocations. There is in total approximately 100 mu of "flexible farmland", about 30 mu per team. However, in 2014 only team 1 and 3 followed the local reallocation norms. The reason why team 2 did not adjust the distribution of farmland was that apple trees were planted on the "flexible farmland", which is not in agreement with the formerly agreed policy. The farmers in team 2 felt that farmland reallocation every 5 years discouraged

\footnotetext{
${ }^{25}$ Rural land in China is divided into farmland and housing sites. A housing site is the parcel of land given to an individual household to build their house.

${ }^{26}$ According to the Property Law (2007) and the Law on Mediation and Arbitration of Rural Land Contract Disputes (2009), the land reallocation policy in Daijia proper is not legal (Ma et al., 2015).
} 
longer-term investments in agricultural production to improve farmers' income, and therefore decided to break with the local reallocation policy. Moreover, the farmers from team 2 also question the fairness of the local policy, as it is based on formal household registrations (hukou) rather than the true numbers per household. For instance, there are some girls who married and settled down in other places, but kept their household registration in Daijia village. Therefore, they are still allocated farmland, even though they are no longer living in the village. Given these developments, several farmers doubted whether their local farmland reallocation policy would be continued in the future for long.

\subsubsection{Rural welfare policies}

Nowadays, the government has a poverty reduction policy to improve farmers' living standards. Between 2007 and 2010, Daijia village was designated as "poverty village" by the provincial government and therefore qualified for additional investments from the government. During this period, local farmers built five wells in the village, representing an investment of 350,000 yuan, and in 2007, the village leaders organized the farmers to construct a road in the village. Both the wells and the road significantly improved the level of the local infrastructure.

The rural policy of minimum living security ${ }^{27}$ (nong cun di bao 农村低保) has been implemented nationally since 2003, but cannot yet guarantee a basic living for the farmers. In Daijia, there are 57 villagers receiving subsidies under this policy, which is 89 yuan per month. In addition, on the eve of Spring Festival, officials from the Wugong County Bureau of Civil Affairs visit low-income families to deliver them goods for the celebration of the festival.

\subsection{FARMERS' PERSPECTIVES IN DAIJIA VILLAGE}

This section presents the perspectives of the interviewed farmers in Daijia. The 14 interviewees were asked about the current situation and future development of farming, sources of income and security, migrant work, and environmental issues. Below, their perspectives are described and structured according to the economic, social and environmental aspects. The descriptions are based exclusively on the answers of the respondents, sometimes with reference to specific interviewees, and are illustrated with quotes from the interviews to give additional detail and an impression of the "farmers' voice".

\footnotetext{
${ }^{27}$ Rural residents whose income is below the local average are entitled to subsidies from the local government. This group includes disabled people, long-term poor, and old people who have no child to support them. Available from: http://baike.baidu.com/view/3671477.htm
} 


\subsubsection{Economic aspects}

The economic aspects addressed by the respondents concerned in the first place the various sources of income of the households, including the different roles of household members in income generation. In Daijia, grain crops and apples are the main sources of agricultural income. Based on information from the respondents, the net yearly income from both sources was calculated. Income from salaries is also very important in Daijia, and the sources include migrant work in cities as well as temporary jobs in the surroundings. Other aspects addressed concerned the current and future importance of agriculture and the issue of scale-enlagement.

\subsubsection{Income from grain crops $^{28}$}

According to the majority of the respondents, grain production is not very profitable due to the high costs of inputs, such as chemical fertilizers, pesticides and machinery, and the low market price of the outputs. Detailed information about the inputs of maize and wheat to determine the net income per mu farmland is provided in table 4.3 and 4.4. Most of the work is done with machines, saving many hours of manual labor. Farmers need to spend only several days to manage the crop, and rather do the work themselves than hiring laborers. The price of maize fluctuates annually around 2 yuan per kilo. The majority of the respondents mentioned a price of 2.1 yuan per kilo in 2014. Thus, with an average yield of $500 \mathrm{~kg}$ per mu, the gross income from $1 \mathrm{mu}$ maize is 1050 yuan. After deducting the cost of inputs, the net income from maize is about 300 yuan per mu. When the labor costs are not considered, because the farm work is done by the household and does not require cash investment, the net income from maize is about 600 yuan per mu. Similarly, with a price of 2.4 yuan per kilo and an average yield $450 \mathrm{~kg}$ per mu, the net income from wheat is calculated at 330 yuan per mu, or 630 yuan per $\mathrm{mu}$ if the labor costs are not considered. Thus, the total net income from one mu farmland on which maize and wheat are grown in rotation, is about 1230 yuan per year when the cost of labor is not considered. When this cost is included, the total net income will be only about 630 yuan per mu per year.

\footnotetext{
${ }^{28}$ In the terminology of agricultural economics: gross income = revenues; input costs = variable costs; net income [excluding labor] = gross margin
} 
Table 4.3 Inputs and input costs of maize per mu in Daijia village

\begin{tabular}{ll}
\hline Input & Cost (yuan) \\
\hline Seeds & 20 \\
Seeding (tractor) & 30 \\
Fertilizer (compound): 2x & $100-120$ \\
Irrigation: $2 \times$ & $120-150$ \\
Pesticides (herbicide and fungicides) & 20 \\
Harvesting & 80 \\
Threshing & 10 \\
Delivery of harvest (tractor): $1.5 \times$, average & 45 \\
Labor (60 yuan per day, female worker): 5 days & 300 \\
Total & $725-775$ \\
\hline
\end{tabular}

Table 4.4 Inputs and input costs of wheat per mu in Daijia village

\begin{tabular}{ll}
\hline Input & Cost (yuan) \\
\hline Land preparation & 80 \\
Seeds & 30 \\
Seeding (tractor) & 30 \\
Fertilizer (compound) & 150 \\
Pesticide (insecticide) & 20 \\
Pesticide (herbicide) & 10 \\
Irrigation & 80 \\
Harvesting & 80 \\
Delivery of harvest (tractor): 1× & 30 \\
Labor (80 yuan per day, male worker): 3 days & 240 \\
Total & 750 \\
\hline
\end{tabular}

\subsubsection{Income from apples}

Apple growing has been introduced in Daijia village in the 1990s. According to the respondents, the crop has provided a stable profit for over two decades, which has enhanced their enthusiasm for apple cultivation. However, growing apples is quite laborintensive and involves manual labor for thinning apple flowers (two times), thinning young apple fruits, covering apples with bags, removing the bags, spraying of pesticides (eight times), applying fertilizer (three times), harvesting the apples and pruning the trees in winter. Therefore, the total area of apple orchards in Daijia is determined by the available labor in the village. The large majority of farmers who grow apples are elderly farmers and middle aged female farmers. The young people are generally not interested in apple cultivation. The main reason is that the labor-intensive management of an apple orchard cannot be combined with a job outside as migrant worker. 
Apple growing is more profitable than growing grain crops, but it also requires more inputs. According to the respondents, the price of apples fluctuates around 4 yuan per kilo and the average yield is nearly $2500 \mathrm{~kg}$ per mu. This results in a gross income from apples of about 10,000 yuan per mu. When external labor inputs are kept to a minimum, about $40 \%$ of the gross income must be deducted for inputs (table 4.5 ), and the net income is about 6,000 yuan per mu per year. The actual net income differs between households depending on internal availability of labor and the amount of chemical fertilizers and pesticides applied. In particular thinning and harvesting are normally fulfilled by the households themselves to maximize their cash income.

Due to the higher profits from apple growing, the farmers in Daijia village tend to expand their apple orchards and reduce the area of farmland for grain crops. As part of this expansion strategy, several respondents (interviewee 1, 5, 6, 10, 11 and 12) have started to intercrop grains with apple trees. As long as the trees are small (and not yielding much), wheat and maize can still be grown on the strips in between the trees. After several years the apple trees have grown too tall to be combined with the grain crops, but are providing a good yield themselves.

Table 4.5 Inputs and input costs of apple per mu in Daijia village *

\begin{tabular}{ll}
\hline Input & Cost (yuan) \\
\hline Thinning apple flowers: $2 \times$ & 200 \\
Covering apples with bags & 200 \\
Chemical fertilizer: $3 \times$ & 2340 \\
Pesticides & 320 \\
Pesticide application: $8 \times$ & 200 \\
Irrigation (sprinkler) & 60 \\
Total & 3320 \\
\hline
\end{tabular}

* Thinning young apple fruits, removing the bags, harvesting and pruning are not included because many households perform these tasks with own labor, so no cash investment is required. When external labor is hired for these tasks the additional labor cost would be at least 4000 yuan.

\subsubsection{Farming labor requirements}

In Daijia, the farming work in grain crops (wheat and maize) is almost completely mechanized. This has resulted in a strong decrease in need for human labor according to the respondents. Nowadays, almost all young and some middle aged male villagers are migrant workers and not involved in the farming work in the village. Agriculture in Daijia clearly has the character of "old-age agriculture" and "women agriculture", but even the labor investment of old and female farmers is decreasing as for the grain crops the work mainly consists of contacting the contractors that own and operate the agricultural machinery. However, apple growing is labor intensive and this work is done by the old 
and middle aged farmers. This means that when labor is not available, e.g., in case of physical disability, the apple orchard may be converted back to grain fields.

We depend on agricultural machinery, such as rotary cultivators, seeding machines, and harvesting machines. We can do all farming work now within a very short time, about 2 or 3 days. [Ren, 54 years old, male]

My mother did all the farming work in our household. I have no experience with farming work myself. Now, everything is mechanized, such as rotary cultivators and harvesters, resulting in a much lower labor requirement. After harvesting, we can rent a vehicle to transport the wheat to our household. [Ren, 27 years old, male]

People who are over 60 years old can still fulfil all farming work due to machines. In the past we had to harvest the wheat by ourselves while now it can be done by machines. [Ma, 46 years old, female]

We got altogether $2.5 \mathrm{mu}$ of apples, but we cut them down because I was in a bad physical situation. I got cerebral hemorrhage. My wife couldn't attend to all the crops, so we converted the apples to grain crops. [Dai, 43 years old, male]

\subsubsection{Income from migrant work and local off-farm work}

In Daijia, at least one person from each household works as a migrant in urban areas. The majority of these rural-to-urban migrants are young people who work in industry or the services sector. They are relatively long-term migrants and return to the village only occasionally. For the majority of the households, the main source of income is from migrant work rather than from farming. According to the respondents, the large expenditures of the household, such as children's education and old people's medical treatment, are mainly dependent on young people's migrant salaries. Migrant work is generally more remunerative than apple growing. However, the salary of young migrant workers is low compared to the high cost of living in the cities. Construction workers earn relatively more, but the risk of (temporary) unemployment is high. Most migrants are engaged in unskilled, physically demanding labor.

The farm work is mainly the women's duty. Those who can work outside would never do it. So generally, the men in the family would work out. You know, the farm work is not cost-effective. Even if you can attend to $20 \mathrm{mu}$, you can't earn more than the people working outside. [Ren, 54 year old, female]

The young people work outside, such as in the southern cities of China, Beijing, Tibet, Xinjiang, Xi'an, and Xianyang. Work in the factory is easy to find for young people, but the salary is low, only 3000 yuan per month. They have to rent an apartment in the city, which is very costly. My husband worked on construction 
sites, but as fewer buildings are established, he was laid off. [Song, 39 year old, female]

It is not easy to find a job at a construction site. I used to drive the tower crane on the construction sites in Harbin. I didn't work nearby because the salary was not as high as in the other provinces. For example, I could earn 10,000 yuan a month in the northeast of China, but here only several thousand yuan. As far as I known, the majority of my friends who are tower crane drivers are unemployed now. [Ren, 27 years old, male]

I worked in Xinjiang, physical work. I worked as coolie, carrying the cotton. I think "no physical effort, no money". I have no specialized skills, so what I can do is to force myself to work very hard. I am just a farmer. Someone recruited me to work in Xinjiang for 160 yuan per day. The place is remote with few opportunities to spend money. So it is a good place to save money. But my wife doesn't want me to go anymore. We have two grandsons and no one does the farm work. It would be too busy for my wife, because generally speaking I would have to stay in Xinjiang for at least 2 months. [Ren, 54 years old, male]

Another source of off-farm income is from middle aged farmers having temporary, lowpaid jobs in or nearby the village during the slack season in farming. The contribution of these temporary jobs to the household income is not comparable to the contribution of young migrants' salaries, but at least it provides some cash to cover small expenditures. Some female middle aged farmers referred to the income from their temporary jobs as "pocket money".

I temporarily work in the brick factory in the village to carry bricks, and my daily salary is just 50 yuan. I also occasionally work at the Senmiao Company to weed or spray pesticides. [Ma, 46 years old, female]

\subsubsection{Current and future importance of agriculture}

Generally, the old and middle aged farmers emphasized the importance of agriculture. Young people tended to be less interested. Their main reason is the much lower profit from agriculture compared with migrant work. Moreover, for young people it is relatively easy to find employment in the urban areas.

The farm work is not profitable. The elderly who have nothing else to do can attend to the fields. However, young people can find jobs which are more profitable than agriculture. I don't think agriculture is important for us. Anyone who is a capable person will not fulfil farming work. The chemical fertilizers and pesticides are expensive, and therefore the net income is extremely meager. We would rather do any other job than farming. [Ren, 27 years old, male] 
The old and some middle aged returned farmers do most of the farming work in the village. The importance of agriculture to this group is determined by two main factors. First, they are dependent on grain crops for self-sufficiency in food and on growing apples to generate cash for other basic needs. When there are no other sources of income in the household, agriculture plays a crucial role in rural livelihoods. In Daijia, with apple as a profitable cash crop, farming also contributes to the cash income of the household. Second, the self-sufficiency of the older generation alleviates the economic burden of the younger members of the household. For young migrant farmers, it is often difficult to save a substantial part of their salary due to the high cost of living in the urban areas.

Agriculture is very important for me. Otherwise, where does my food come from? We need vegetables and food, and now we don't need to buy these in the market and we can even sell the extra production. [Dai, 79 years old, female]

Farm work is better than nothing. I didn't work outside for a whole year, but I am not starving. At least we have something to eat. [Ren, 54 years old, male]

I think agriculture is very important for us. Young people are not paid well and they need the money to support themselves in the cities. Farming can at least make me and my husband self-sufficient. We don't have other sources of income. Thus, we can live a reasonable life from farming and reduce our children's burden. [Fu, 59 years old, female]

The respondents were generally optimistic concerning the question "who will fulfil the farm work in the future?". Although young people have no farming experience, they could hire contractors with machinery to do the work for the grain crops. For the laborintensive cultivation of apples, the respondents thought that young people could hire farm laborers, or even rent out the apple orchard to other farmers or companies to form large-scale apple orchards. Even if the young people would permanently settle down in urban areas they could subcontract their farmland to other people interested in enlarging their farms. Overall, the respondents did not expect that the farmland in Daijia village would be abandoned in the future.

\subsubsection{Farmland transfer and scale-enlargement}

Transfer of the right of use of farmland by subcontracting, or "farmland circulation", is still in an embryonic stage in Daijia village. According to the respondents, about $150 \mathrm{mu}$ farmland is subcontracted to an agricultural company (Senmiao Company) and to one individual farmer, in both cases for large-scale growing of trees for afforestation projects. The land rent is approximately 1000 yuan per year, which is higher than the net income from growing grains (wheat and maize).

I am the only one who possesses farmland in my household, but I subcontracted all the farmland (1.4 mu) to Senmiao Company. They use my farmland for the 
growing of sapling trees. I have done it already for 7 years, receiving 1000 yuan per mu per year. [Dai, 63 years old, male]

Some of the villagers rented out farmland to Senmiao Company for the cultivation of flowers and landscape trees. They can get 1000 to 1200 yuan per mu, which is cost-effective compared to the net income from grain crops. [Song, 39 years old, female]

According to the town government official (interviewee 8), the Wugong county government is promoting a large land transfer project involving 1000 mu farmland elsewhere in the county to stimulate mechanization and sprinkler irrigation. Most respondents expressed their interest in subcontracting their land and predicted that subcontracting and development of large-scale, modern agriculture would be the trend of the future in Daijia as well. Neverheless, they thought it would be a long-term process. In particular the elderly farmers want to keep the land to grow their food and growing apples is still profitable.

If you ask the villagers in our team to quit with the farm work, I am sure 8 out of 10 would say no. If you want to reclaim all the fields and contract them out to only a few households, the others would definitely reject the proposal, even if you were the county magistrate. [...] Most of the families in Henan work outside with no one left in the hometown. They know it is better than doing the farm work. Those people are smart and farsighted and the people of my generation agree with them, but the elderly here won't. There is an old expression that "never give your homestead and fields to the others", which means that the farmland is very important. Besides, the soil here is good and we generally have good harvest. [Ren, 54 years old, male]

\subsubsection{Social aspects}

The social aspects addressed by the respondents concerned the role of the rural welfare system, the problems of migrant workers, and whether they return (or not) to the village.

\subsubsection{The rural social security system}

In China, the rural social security system is developing, but it is not comparable to the social security system in the urban areas and does not (yet) provide a guaranteed basic living. In Daijia village, both the old age pension and health insurance systems have been implemented. However, according to the respondents, the role of the social security system is to provide them, especially the old farmers, with some "pocket money". China's small-scale agriculture, in which every rural household can farm a piece of land, plays the role of social security system guaranteeing a basic living for the rural residents. 
In some areas, the government provided subsidies for farmers to subcontract their fields. [...] However, it was problematic. If farmers have no skills and only live on the subsidy, they even cannot make ends meet, so it is not a real alternative for the farmers. For example, in our village, of many people who are over 60 years old the children are working outside. Without farmland, these parents would have no financial resource. They cannot just live on social security benefits or subsidies, these are just pocket money. [Dai, 54 years old, male]

\subsubsection{Problems of migrant work}

Migrant workers from Daijia are confronted with various problems. First of all, migrant work is by definition temporary. There are strong age-related limitations. It is relatively easy for young people to find a job in urban areas, but middle aged (about 40 to 50 years old) farmers are increasingly confronted with unemployment (interviewees 3, 5, 10, and 12). Second, the factories have strict requirements. People who are approximately 20 years old can find work in a wide range of labor-intensive factories. They are long-term migrant workers and only return to the village for Spring Festival. However, according to the respondents some factories do not like to hire married young people as they might be distracted by household affairs. To some degree, marriage and maternity are the moments at which especially female migrant workers have to terminate their jobs. In addition, rural-to-urban migrants are in a marginalized postion in the cities, with poor social conditions: low salaries for physically demanding jobs and delays in the payment of wages. Third, employment opportunities in urban areas are decreasing. For example, several migrant workers from Daijia village were engaged in construction. However, in recent years, many construction workers have lost their job.

It is relatively easy for young people, but for people who are 40 to 50 years old, it is difficult to find a job. [Fu, 59 years old, female]

My son works in Suzhou Telecom and my daughter-in-law works in a factory in Suzhou. They had a baby last year, so my daughter-in-law stayed here for a year. They don't have vacation usually, so they can only come back every Spring Festival. [Dai, 58 years old, female]

The situation for people who are engaged in construction jobs is bad. Besides, the contracts are not meeting the official standards. Delays in payment happen frequently. [Ren, 67 years old, male]

In addition to the problems in the cities making it hard to find and keep a job as a migrant worker, there may also be reasons at home to quit the migrant work. For example, several middle aged villagers had to quit because there was a shortage of farming labor in their household, especially in the management of the apple orchards. Others had to quit due to responsibilities in the household, notably to take care of their grandchildren. 
My wife doesn't want me to go outside for migrant work. We have two grandchildren and there are no others in my household that could help in farming. Especially in the apple orchard, there is a lot of work needed. My wife cannot do all the farming work and at the same time take care of two grandchildren. Otherwise, I would work in Xinjiang to carry cotton for about 2 months, which is more beneficial than agriculture [Ren, 54 years old, male].

\subsubsection{Return of migrant workers to the village}

The majority of migrant workers cannot afford to rent an apartment in the city, let alone to buy one. Thus, permanent settlement in urban areas is not an option for them. According to the retired village leader, this is different for young people with good educational qualifications. In Daijia village, there are 5 or 6 young people who bought an apartment in the city. However, the level of education of the large majority of migrant farmers is low and therefore they will have to return to the village when they are over 40 or 50 years old. During their stay in urban areas, they try to provide their children with the best educational opportunities they can afford.

In Daijia, the returned middle aged migrants often use their savings from migrant work to build new houses in the village for their children to occupy when they get married. After this, their responsibility will be to take care of the grandchildren. At the same time, many returned migrants engage in farming again, especially in the more profitable cultivation of apples. In addition, they often try to find temporary jobs in the surroundings that do not conflict with the farm work. A small group uses the savings from their migrant salaries to start a new business or expand their agricultural activities. For instance, villager Dai used his savings to rent 50 mu farmland to grow trees for afforestation projects.

\subsubsection{Environmental aspects}

The environmental aspects of agricultural development addressed by the respondents concerned the application of agrochemicals, and the presence and awareness of problems caused by overuse of agrochemicals.

\subsubsection{Application of agrochemicals}

The increase in crop yields in Daijia village is largely due to the application of agrochemical inputs, such as pesticides and fertilizers. According to the respondents, since four years the local government (of Wugong county) provides free pesticides for wheat cultivation. The amount of the pesticides per household is determined by the size of the farmland. However, most interviewees indicated that this amount was not enough and that they had to buy additional pesticide in the market. Farmers' pesticide application 
practices in Daijia are determined by the recommendations from the pesticide dealers, but also by their own observations and perception of the degree of pest infestation.

I normally follow the instructions on the pesticide package. However, if I feel the pests are increasing faster than I expected, I will apply more pesticide. [Wei, 57 years old, female]

My household has 7 mu wheat. However, the pesticide issued by the local government is only enough for $2 \mathrm{mu}$. So we have to buy pesticides for the remaining $5 \mathrm{mu}$. [Dai, 43 years old, male]

Concerning pesticide application, the people who sell us pesticide set up an archive for us to record the amount of pesticides applied. If the pesticide is not effective or causes some damage to the crop, we can hold them responsible. [Ren, 67 years old, male]

Overapplication of chemical fertilizers appears to be more widespread than misuse of pesticides. The farmers in Daijia have the deep-rooted idea that the more fertilizer they apply, the higher the yield will be. Another reason for applying chemical fertilizer is that the alternative, animal manure, is hardly available in Daijia.

There is a saying in my village "farming work needs no skills but fertilizers". Only few people in the village use manure as fertilizer, because only few raise pigs or chickens. We found the livestock not to be cost-effective. I do know that the manure can improve the quality of soil, but formerly I thought that "the more chemical fertilizers I apply, the more crop yield I get". Now I know that it is not scientific and also a waste of money. [Ren, 67 years old, male]

We are used to the chemical fertilizer, because it guarantees the yield. Yield is the foremost thing. We also have to use the pesticides to kill the pests. Although the chemical fertilizers and pesticides are not good for our health if applied frequently, we have no other choice. [Song, 39 years old, female].

The villagers of Daijia grow grains for domestic consumption and for the market. One respondent (interviewee 1 ) told that he used less agrochemicals on crops for domestic consumption than on crops for the market. However, the other respondents indicated that the purpose did not affect their application of chemical fertilizers and pesticides and that they are dependent on agrochemicals for both domestic consumption and for the market. Moreover, they do not divide their fields into a part for domestic consumption and a part for the market.

\subsubsection{Environmental problems}

According to the respondents, the intensive application of agrochemicals is causing adverse effects to the environment. For instance, the farmers had observed that the major part of the chemical fertilizer they apply is not taken up by the grain crops or the 
apple trees, but is lost to the envrionment. This results in hardening of the topsoil, especially in the apple orchards. To illustrate concerns about water pollution, the respondents told that the wells for drinking water in Daijia village are drilled deeper and deeper to assure the supply of unpolluted ground water.

We apply fertilizer based on experience or we observe how our neighbors use it. Most of the villagers use excessive amounts of chemical fertilizer, especially too much nitrogenous fertilizer, and thus have problems with hardening of the soil. After my daughter-in-law applied fertilizer, I checked in the apple orchard and found that there were some white fertilizer deposits. The trees only absorbed part of the fertilizer while the rest was wasted. [Ren, 67 years old, male]

Someone who sells purifier in Qianxian tested our water and found it seriously polluted. The water of our village exceeded the standard 20 times. You know, pesticide is used everywhere, for the wheat, the maize and the apples. We have to do it to kill the pests. [Dai, 43 years old, male]

No one here takes the environment into consideration [...] so the water may be polluted. The well in our yard is $40 \mathrm{~m}$ deep but we stopped using it. There is a deep well of $100 \mathrm{~m}$ in the village, but it is under repair because the pipe is broken. So we have no well for drinking water to use in the past two years. [Song, 39 years old, female]

\subsection{DISCUSSION}

In this section, we present the main findings by summarizing the problems of farmers in Daijia from the perspective of the respondents, and how these are addressed, as well as the respondents' views on the future development of agriculture in Daijia village. We then compare the main findings with those of previous studies, and end with an outlook by reflecting on the sustainability of farming in Daijia and the implications for policy.

\subsubsection{Main findings}

\subsubsection{Problems and solutions}

The major economic problem is the low profitability of the traditional maize-wheat cropping system in Daijia. Despite high yield levels, the net income is low due to the high cost of inputs, the relatively low grain price, and, above all, the small land holdings. With a net income of 600-1200 yuan per mu per year, depending on labor costs, and a farm size between 1 and 10 mu per household, the potential income from grain crops is by far not enough to guarantee a basic living. In Daijia, this problem is addressed mainly in two ways. First, part of the farmland is used for the cultivation of apples, which is 
much more profitable: up to 6,000 yuan per mu, depending on labor costs. The natural conditions in Daijia are favorable for apple growing and due to the high degree of mechanization in the cultivation of wheat and maize, there is sufficient labor available for the time-intensive management of the apple orchards. Second, the income from farming is supplemented by income from rural-urban migrant work. In each household, at least one person works as a long-term migrant in major cities of the province or elsewhere in China (Table 4.1). The income from migrant work is the major component of the household income in Daijia and is essential to cover large expenditures for education and medical care. As there is a primary school in Daijia, most migrant workers leave their children with the grandparents in the village, to minimize the cost of living in the cities and to maximize savings. Major social problems are the poorly developed rural social security system and the insecure employment situation of the migrant workers. Social security benefits in case of old age or health problems are low and insufficient for a basic living. The education level of most migrant workers from Daijia is low, hence the jobs they can find mostly concern unskilled and physically demanding work. For migrant workers of 40 to 50 years old it gets quite difficult to find permanent employment in the cities and they have to return to the village, at least part of the year. In both cases, the farmland is important as a last resort, so that the people can at least grow their own food. Due to the high degree of mechanization and use of contractors, farmers in Daijia can continue the farm work even at an advanced age. In addition, due to the proximity of Daijia to major urban areas, middle-aged farmers can relatively easy find temporary off-farm jobs in the surroundings of the village, or work for other farmers in the apple orchards. The farmers in Daijia are aware of the environmental problems caused by their intensive application of agrochemicals, such as pollution of ground water with pesticides and soil degradation due to overuse of chemical fertilizers. However, the farmers feel that they do not have a choice and must continue the intensive use of agrochemicals to maximize yields.

\subsubsection{The future development of agriculture in Daijia village}

The views of the respondents on the future development of agriculture in Daijia were fairly optimistic. In the more immediate future, the major development is the expansion of the more profitable cultivation of apples at the expense of the grain crops, initiated mainly by middle-aged farmers. Subcontracting of land to form large-scale farms was considered to be a likely, but longer term development. Many farmers, in particular the elderly, rather keep the land to be able to grow their own food as a last resort. However, the expectation was that most of the young people would not be interested to continue the farming and would prefer to hire others to do the work or to rent out the farmland. The possibility that in the future not many migrants would return to the village to do the farming was therefore not considered a problem. As the conditions in Daijia are favourable for labor-extensive mechanized production of grain crops and for 
the production of high-value crops such as apples, the problem of land abandonment are was not expected to occur.

\subsubsection{Comparison with previous studies}

The development of farming in Daijia can be interpreted with the concept of livelihood strategies. Dixon et al. (2001), distinguish five main strategies followed by farm households to improve livelihoods: (1) intensification of the existing production system, (2) diversification of the production system, (3) expansion of the production system in size or area, (4) increasing off-farm income, both agricultural and non-agricultural, and (5) a complete exit from the agricultural sector. These options are not mutually exclusive and households with multiple members often pursue a mix of strategies. In Daijia, the dominant strategy was initially the intensification of the grain production, resulting in the current high level of mechanization, agrochemical inputs and yields. As described in Chapter 2 and 3, this path was followed in all major grain producing areas in China, including the Guanzhong Plain where Daijia is located. As the income from grain production is low given the small land holdings of farm households in Daijia, and labour is available for other sources of income, two other livelihood strategies have become important, often combined within one household but in different ways (cf. Table 4.1). The first is diversification into labor-intensive high-value crops, mainly apples, and the second is increased generation of off-farm income from local jobs and migrant work in major cities. For the future, a combination of the strategies of expansion (larger farms) and exit (complete transfer of land rights) is expected to gain importance, but is currently still rare. The diversification strategy of including cash crops and the strategy to focus on migrant work were also found to be important in 24 other villages in the Guanzhong Plain (Chapter 3 ), as well as in villages in comparable grain producing regions, such as the North China Plain (Zhen et al., 2005; Huang et al., 2015).

In Daija, almost all farm households continue to use part of their land to grow food for domestic consumption, including households that focus on cash crops or off-farm work. In this way they can reduce the spending of scarce cash resources, alleviate the burden of the younger members ${ }^{29}$ working as migrants, and compensate for the lack of social security in case of old age or unemployment. The income from migrant work on the other hand is essential to cover major expenditures, including health care costs. This combination of subsistence farming, production for the market and urban employment, is characteristic of Chinese agriculture (Wang et al., 2013), and observed in many other case studies (e.g., Van der Ploeg \& Ye, 2010). As in Daijia, migrant work involving a longterm stay away from home is usually done by younger members of the household and local off-farm jobs by middle-aged members (Qiao et al., 2014). The literature is inconclusive regarding the question whether the income from migrant work is mainly spent

\footnotetext{
${ }^{29}$ In China, children are expected to take care of their parents when these grow old.
} 
for consumptive purposes, including house construction and health costs (De Braauw \& Rozelle, 2008) or whether it also substantially contributes to labor-saving productive investments in agriculture, such as agrochemical inputs and machinery (Taylor et al., 2003). In the latter case there would be a positive feedback loop between rural labor surplus and rural-urban labor migration. From our interviews, this cannot be concluded, and the productive investments mentioned by the respondents referred the returning migrants starting an off-farm business.

As mentioned, the combination of, on the one hand, rural households completely giving up on farming (exit strategy), and, on the other hand, the remaining farms growing larger (expansion strategy) was only observed at a limited scale in Daijia. Also at national or provincial level, this is hardly observed till now (Ji et al., 2016). Between 2007 and 2013, the average farm size in China increased from 0.59 ha to 0.62 ha and even decreased from 0.48 ha to 0.47 ha in Shaanxi Province. Similarly, at national level the percentage of rural households that did not engage in farming rose only slightly from $7.8 \%$ to $9.2 \%$, whereas it did not change in Shaanxi Province. Finally, although Ji et al. (2016) conclude that there is an emerging class of middle-sized and larger-sized farms, their data show that this is not the case in Shaanxi Province. These data correspond with the perspective of our respondents that scale-enlargement and exit from agriculture are not rapidly growing, widespread developments.

The various livelihood strategies followed by the farmers in Daijia have solved problems, but also created new ones, most notably the difficult social conditions of the migrant workers in the cities and the environmental problems caused by intensive farming methods in the village. Both types of problems appear to be relatively moderate in Daijia as compared to other villages. The possibility for migrant parents to leave their children in the village and the relatively favourable opportunities for local off-farm employment alleviate several of the most pressing problems rural-urban migrants are facing in China (Li, 2006). High input levels of agrochemicals in grain crops and cash crops as in Daijia are also often reported for comparable systems (e.g., Zhen et al., 2005; Huang et al., 2015). None of the respondents mentioned health problems due to environmental pollution, however. Neither did they mention problems of water depletion, which is an urgent and wide-spread problem in other grain producing areas in Northern China, such as the North China Plain (Zhen et al., 2005; Liu et al., 2007). Nevertheless, the farmers reported cases and visible impacts of overuse of agrochemicals, and the current absence of major problems does not mean that their farming methods are sustainable in the long run. 


\subsubsection{Outlook}

In this final section we reflect on the long-term sustainability of the strategies followed by the farmers in Daijia and how policy could support a more sustainable development of agriculture in this village and other villages with similar conditions.

Farm households in Daijia are heavily dependent on income from migrant labor. This important source of income is quite vulnerable, however, especially because most of the migrant workers do unskilled work and have insecure jobs. Investment in rural education would be necessary to improve the salaries and job-security of the migrant workers on the longer term (Hu et al., 2011). Another strategy households in Daijia are following is to increase the agricultural income by replacing grain crops by apples as a cash crop. Local farmland reallocation rules, such as described for Daijia proper, can cause tenure insecurity and prevent longer-term investments (Ma et al., 2015). Yet, it seems unlikely that this will be a major barrier to the expansion of apple orchards in Daijia, as according to the respondents support for the local policy is diminishing. The scope for a substantial improvement of household income through a further expansion of apple growing is limited, however, by the availability of labor during peak periods and the very small size of the farms. To enable households to specialize in apple growing as the main livelihood strategy, an integrated policy would be required combining investments in farmer training, subsidies for less labor-intenstive cultivation methods including mechanization, and facilitation of scale-enlargement (cf. Hengsdijk et al., 2005; Van den Berg et al., 2007).

At present, the opportunity for rural residents to grow their own food functions as a social safety net, and is used to justify the differences in social security benefits for rural and urban residents (Wang et al., 2013). However, with a growing urban-rural gap in many respects, young members of rural households, also in Daijia, are less and less willing to return to the villages and farming after a long stay as migrant worker in the cities. The governmental policy is to address this problem through a combination of urbanization and scale-enlargement in agriculture (Chapter 2). However, as argued by $\mathrm{He}(2013,2014)$, there is currently only half-urbanization, as the Household Registration System (hukou) results in a very disadvantaged position of migrant workers in the cities and also prevents them to settle there permanently. Yet, changing the current hukou system, e.g., by giving equal rights to urban and rural residents in exchange for the land rights of rural residents, creates the risk of development of slums in the cities and a class of landless poor in the villages (Ye, 2015; Tian et al., 2016). Wang et al. (2013) listed three key requirements that should be met before a large-scale transfer of land use rights from rural residents can be considered as part of a sustainable agricultural development policy: the domestic market should be big enough to guarantee a stable demand for migrant labor, migrant workers should be given the same level of social 
security as urban residents, and the major part of the Chinese labor force should be fully engaged outside the agricultural sector.

Finally, the current intensive production of both grains and apples in Daijia is not environmentally sustainable. As indicated by the respondents, the input levels of fertilizers and pesticides in both production systems are high, and most probably too high (Min \& Han, 2008). Sooner or later, there will be health problems due to pollution of the ground water and soil degradation due to the impacts of long-term overuse of chemical fertilizers (Chapter 2). Moreover, even though the farmers in Daijia did not report problems with falling ground water levels, Min and Han (2008) reported that this problem is spreading in the Guanzhong Plain due to excessive exploitation of ground water for agricultural, domestic and industrial use. Similar to farmers in comparable production systems in the North China Plain (Ma et al., 2009), farmers in Daijia are aware of the problems, but feel compelled to continue using high levels of inputs to maximize yields, whereas they see environmental protection as the government's responsibility. Furthermore, it appears that overuse of agrochemicals is more common in households with higher off-farm income, presumably because this income is used to buy time-saving agricultural inputs (Zhen et al., 2005). However, Ha et al. (2015) found that in grain production systems in the North China Plain there was no positive relationship between input level and crop yields. When all farmers would follow their neighbours' best practice, this could result in a reduction of greenhouse gas emissions due to reduced input use by $7-21 \%$ for wheat and maize, respectively, and higher yields at the same time. Researchers have developed even far more efficient grain production methods (Shen et al., 2013), but the current agricultural extension system appears to be highly inadequate to transfer this knowledge to farmers (Zhen et al., 2005; Yang et al., 2016). Moreover, most farmers in the Guanzhong Plain and other areas have a negative view on the quality of the agricultural extension services (Chapter 3 ). To be effective in stimulating the adoption of more sustainable production methods, these services should change to a much more interactive and adaptive way of working with farmers. 
Chapter

Farmers' perspectives in Chiniuwa, a village in the Loess Plateau area of

Shaanxi Province, China 
Abstract: The perspectives of farmers on the current state and future development of agriculture in Chiniuwa are described based on in-depth interviews with 14 respondents. Chiniuwa is a village located in the Loess Platea region, in the north of Shaanxi Province. The Chinese Loess Plateau is highly prone to soil erosion due to the combination of steep slopes and a semi-arid climate. The dominant crop in Chiniuwa is jujube, a drought-tolerant fruit tree planted on terraced hillsides. According to the farmers, the cultivation of jujube was a highly successful way to deal with the difficult conditions for agriculture in the Loess Plateau region. The terraces and trees prevented soil erosion, the dry climate was favorable for high quality fruits, and due to the high market price the cash income from jujubes was even higher than from migrant salaries. However, after three years of failed harvests, a loss in market share and a steep drop in prices, the income from jujube is now almost nil. In response, farmers have strongly reduced their investments in jujube production. At the same time, a slow-down in construction activity in China has severely limited the off-farm employment opportunities of the farmers, and many are forced to stay in the village. Unfortunately, due to the unfavorable growing conditions, the households in Chiniuwa are not self-sufficient in food production. As the farmers believe that the harvest failures of jujube are due to a permanent change in climate, several have started to replace the jujube trees with annual food crops, such as millets. The farmers showed no awareness of the risk that this change in land use may result in the re-emergence of severe soil erosion problems. The respondents were generally quite uncertain and rather pessimistic about the future development of agriculture in Chiniuwa. Many did no longer see a future for jujube as the main cash crop. Some of the villagers were experimenting with alternative cash crops, but whether these would be successful in providing sufficient cash income was still highly uncertain. A structural shift towards off-farm sources of income and exit from farming in combination with scale-enlargement by remaining farmers was not seen as a likely future direction, given decreasing off-farm employment opportunities and the limited opportunities for commercial agriculture in Chiniuwa. The chapter concludes with a reflection on the sustainability of farming in Chiniuwa and implications for policy. 


\subsection{INTRODUCTION}

Over the past decades, agricultural development in China was characterized by a strong increase in agricultural production and farmer incomes. Major policy goals concerning national food security, access to affordable food and rural poverty alleviation have been reached. However, at the same time environmental, as well as economic and social problems threaten the sustainability of agriculture (Chapter 2). The Chinese government aims to address these problems with a modernization strategy in combination with urbanization. Alternative strategies focus on the conservation of small-scale agriculture or the development of ecological agriculture. However, neither the government's modernization strategy nor the two major alternatives offer a comprehensive and integrated response to the current threats to the sustainability of agriculture. Moreover, all three strategies make unsupported, generic assumptions about the problems and needs of Chinese farmers (Chapter 2). Investigation of farmers' perspectives on agricultural development and how these vary with local conditions is therefore a much needed step towards a comprehensive and broadly supported strategy for sustainable agricultural development in China. A survey of farmers in the Guanzhong Plain (Shaanxi Province) made clear that even in a fairly homogeneous agricultural production area, a large diversity exists in farmers' perspectives and practices, depending on farm household type, age and level of education (Chapter 3).

To better match high-level strategies for agricultural development as well as on-theground measures and services with the needs of Chinese farmers, more in-depth research is required into farmers' perspectives and practices. First, more insight is needed into what farmers see as problems and why, how they cope with these problems and what viable prospects they see for themselves and, more generally, for agriculture in their village. This requires a case study approach, with in-depth interviews of a relatively small number of respondents. Second, more insight is needed into the impact of the agro-ecological context on farmers' perspectives, practices, problems and prospects. We therefore conducted case studies of three villages in contrasting agro-ecological zones of Shaanxi Province, allowing a comparison between farmers in the Guanzhong Plain and those in agronomically less favorable areas, at greater distance from major urban centers (Chapters 4, 5 and 6).

This chapter reports on the perspectives of farmers in Chiniuwa village in the Loess Plateau area of Shaanxi Province. The Loess Plateau of North China, which covers an area of 0.64 million $\mathrm{km}^{2}$, is characterized by steep sloping lands and a semi-arid climate, with most rainfall concentrated in summer. Over $60 \%$ of the land in the Loess Plateau region has had severe soil erosion. In addition, the yields of food crops are low and rural poverty is widespread (Guo, Liu, Wen, \& Li, 2014). The dominant crop in Chiniuwa village is jujube, a Chinese fruit tree that is tolerant to drought and is widely cultivated in the Loess Plateau region, currently covering about one million hectares of land (Liu et al., 2013). 
The following sections describe the methods used to determine farmers' perspectives on the current state and future development of agriculture in Chiniuwa, the context of Chiniuwa village, and the farmers' perspectives. We conclude with summarizing the main findings, comparing these with other studies, and reflecting on the sustainability of farming in Chiniuwa and associated policy options.

\subsection{METHODS}

\subsubsection{Data collection and analysis}

The field work started with a two-week stay in Chiniuwa village in August 2013, to become familiar with village life and to gain a better understanding of the village context. In April and May 2015, 14 farmers were interviewed. A retired village leader was interviewed first, and thereafter the other interviewees were identified by walking through the village and requesting people for interviews until a sufficiently large and balanced selection was obtained. The target was to interview people about 15 persons from different households, with a 50/50 gender balance and a representative distribution of age groups. The interviews were semi-structured, addressing a limited set of predefined topics detailed below. The duration of a single interview ranged from 1 to 3 hours, and the interviewees were given ample opportunity to tell their stories.

All interviews were audio-recorded, transcribed in full in Chinese, and then translated into English. After reading all transcripts, a qualitative content analysis was conducted by coding the text with the MAXQDA software program. The main codes were predefined and related to the three dimensions of agriculture: economic, social and environmental. For each main code, several sub-codes were predefined or determined after reading all transcripts. Sub-codes for economic aspects concerned the various sources of income: 'income from jujube', 'jujube yields', 'market price for jujube', 'investments in jujube production', 'food crops', and 'migrant and local off-farm work'. Sub-codes for social aspects were 'problems of migrant workers', 'food production as a last resort', and the 'accumulation of problems in Chiniuwa village'. Finally, sub-codes for environmental aspects were 'changes in weather patterns and natural environment' and 'changes in land use'.

\subsubsection{Characteristics of the respondents}

The characteristics of the respondents in Chiniuwa village are presented in table 5.1. The 14 respondents included 9 males and 5 females. Due to the clan characteristic of the village, the majority of the male respondents' surname is Gao. The surnames of the female respondents are more diverse, as they originated often from other villages. A 
balance between male and female respondents could not be achieved because in Chiniuwa village, most of the middle-aged male farmers stayed in the village rather than working outside, due to the limited off-farm employment opportunities. When entering a household, we normally found both the male and female farmer at home. The male farmers commonly took the lead in the conversation while the female farmers just listened or sporadically joined in. In terms of age, there were three 'young' (less than 40 years old), six 'middle-aged' (40-60 years old), and five 'old' interviewees (more than 60 years old). This age distribution reflected the situation in Chiniuwa village, with mainly middle-aged and old farmers undertaking the farming work, and the majority of the young people staying in cities for migrant work (most commonly in Yulin, the nearest major city in Shaanxi Province). The majority of middle-aged respondents were returned migrants. In terms of education, the large majority of the respondents' children did not have a university degree. The size of the land-holdings ranged from 5 to 20 mu per household. The respondents are referred to as 'farmers' in this chapter. As explained in Chapter 1, due the Household Registration System (hukou) and the Household Responsibility System, everyone who is formally a rural resident in China has the right of use of a piece of the collective farmland of the village. 


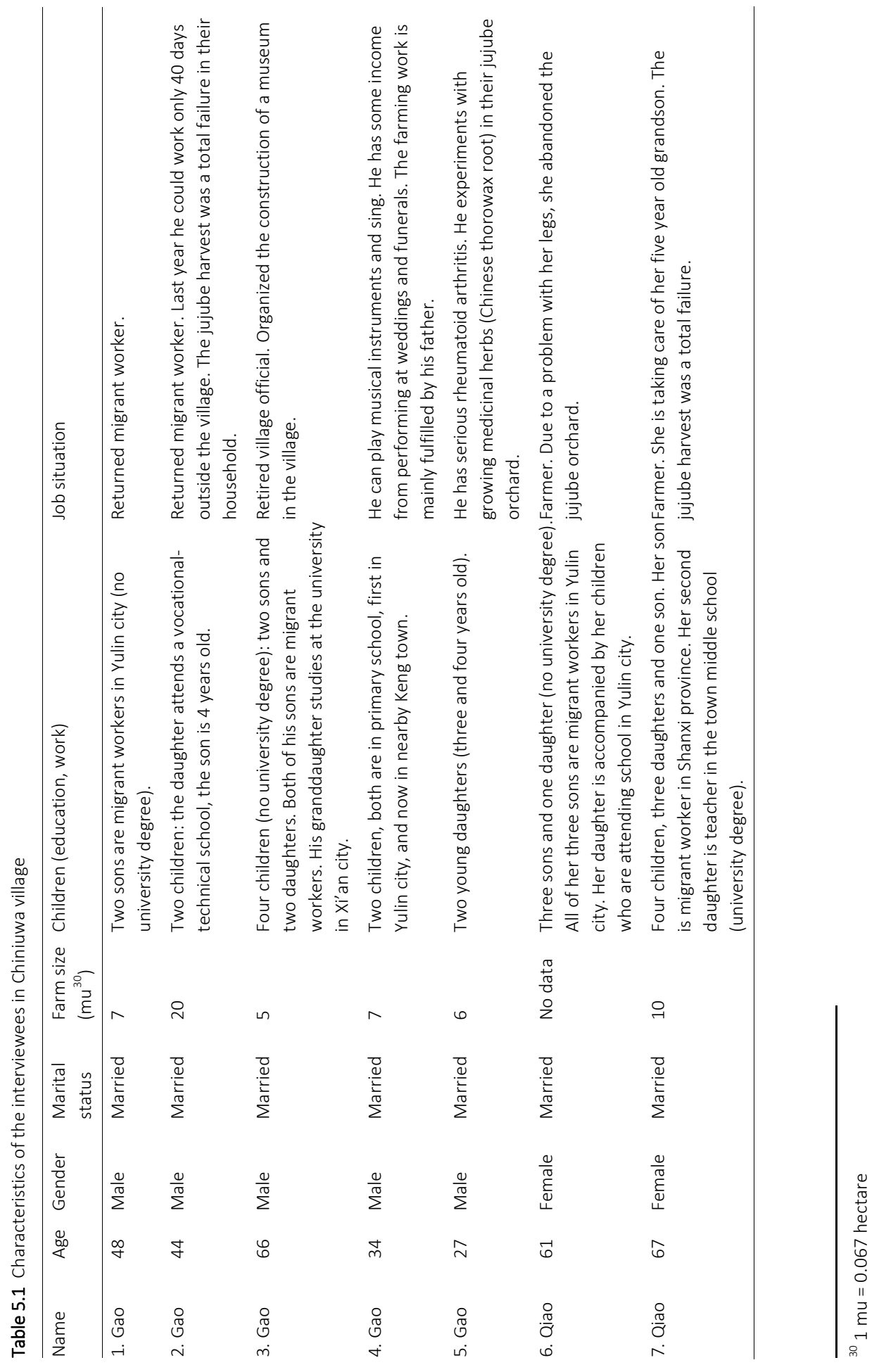




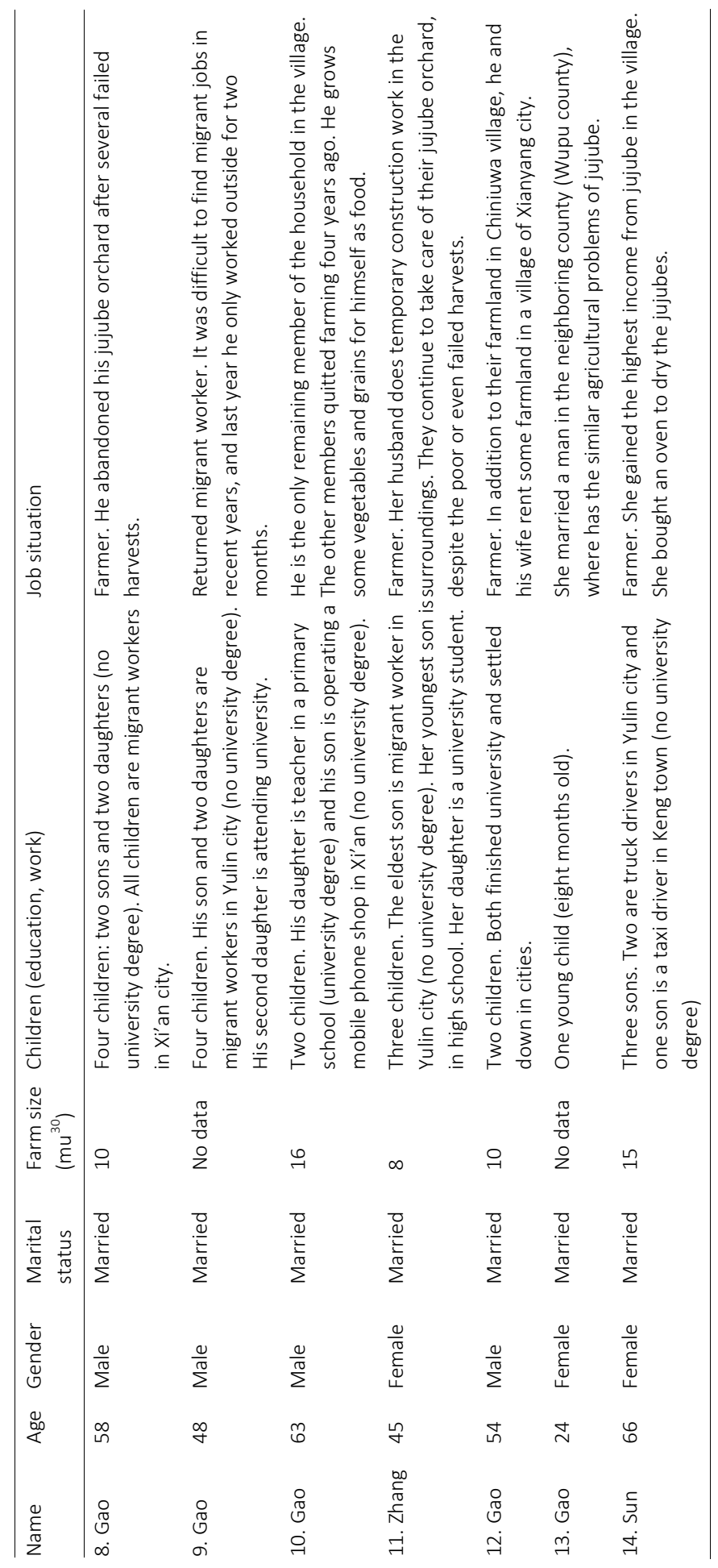




\subsection{THE CONTEXT OF CHINIUWA VILLAGE}

In this section the context of Chiniuwa village is briefly described, with respect to the physical and social geographic conditions and developments. The description is based on local sources, unless indicated otherwise.
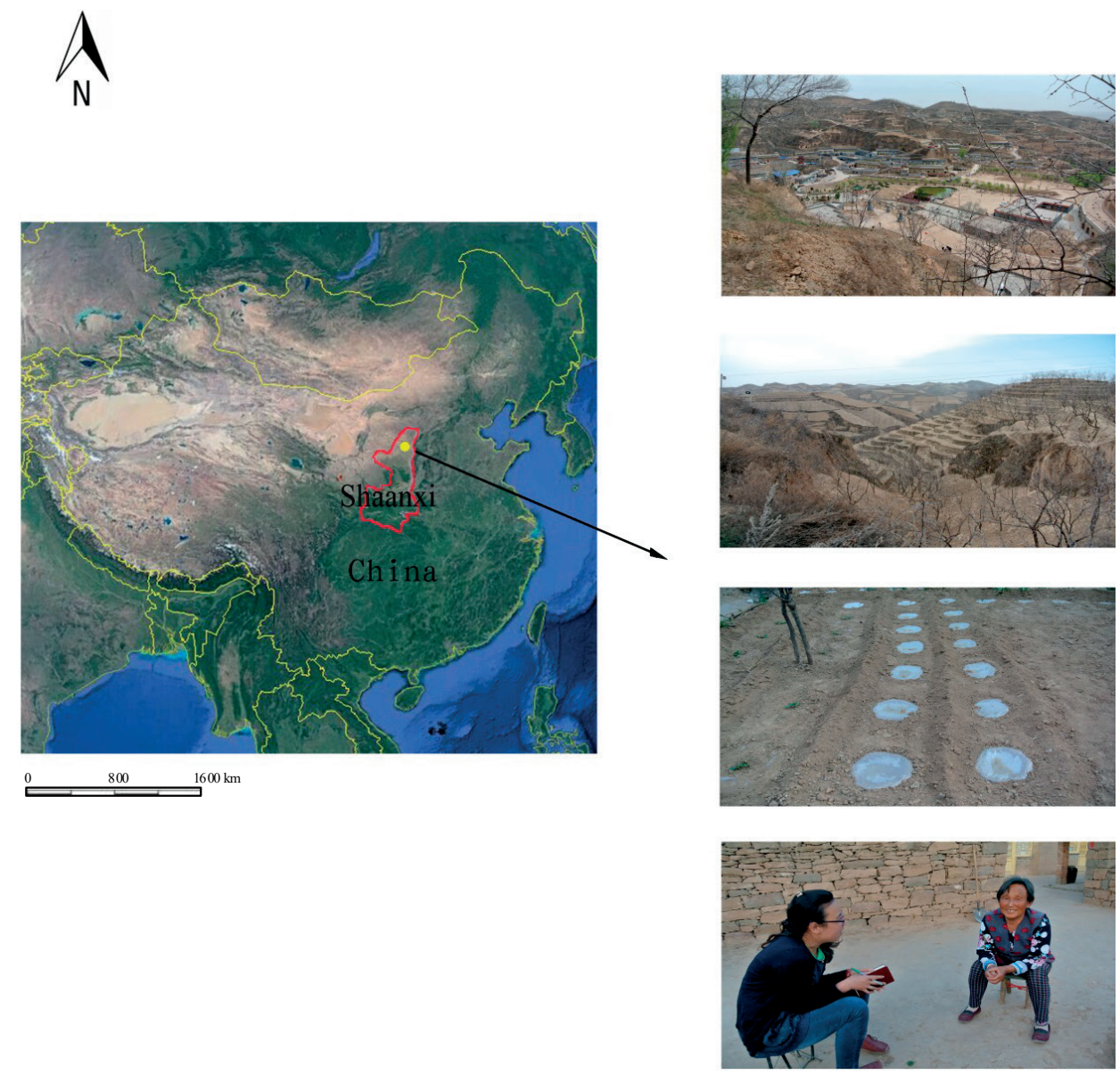

Figure 5.1 Chiniuwa village: geographic location; overview of the village; terraces planted with jujube trees; plastic covers after sowing maize to preserve moisture for the seeds; interviewing a female farmer

\subsubsection{Geography ${ }^{31}$}

Chiniuwa village is located in the northeast of Shaanxi province, in the middle reach of the Yellow River. Administratively, it belongs to Keng town, Jia county of Yulin city. The

\footnotetext{
${ }^{31}$ Information on geography and climate is mainly obtained from Baidu Baike (Chinese internet-encyclopedia): http://baike.baidu.com/view/603990.htm
} 
altitude of Jia county ranges from 650 to $1350 \mathrm{~m}$ above sea level. The village is located on the Loess Plateau of Shaanxi, which is the central part of the Chinese Loess Plateau, covering almost $20 \%$ of its total area (Min \& Han, 2008). As the name indicates, this region is mostly covered with a loess layer of $50-100 \mathrm{~m}$ thick, at some locations even up to $200 \mathrm{~m}$. The landscape is characterized by hills and gullies. On average, there are 33 gullies per square kilometer, with the depth from top to bottom ranging from 30 to $200 \mathrm{~m}$. Due to intensive cultivation and destruction of the natural vegetation, the area has long suffered from very severe soil erosion and water loss (Min \& Han, 2008).

The climate is semi-arid, with an average precipitation of less than $400 \mathrm{~mm}$ per year. Moreover, the annual amount of rain and its distribution over the growing season is highly variable, which poses severe constraints on agriculture in Jia county. As the villagers indicated, they feel to be "dependent on the mercy of the forces of nature" (Kao Tian Chi Fan 靠天吃饭). One of the worst problems is prolonged drought in spring when crops are sown. It is common that farmers have to postpone sowing due to the lack of rain in spring. In three recent years (2012, 2013 and 2014), another problem occurred, which was prolonged periods of heavy rain in September, badly affecting the harvest. Traditionally, agriculture in this region is characterized by single cropping systems with grain crops, such as millets which are relatively drought resistant.

\subsubsection{The construction of terraced farmland, dams, roads and wells in} Chiniuwa ${ }^{32}$

Before the founding of the People's Republic of China in 1949, no major efforts to conserve water and soil were made in Chiniuwa village. Access to drinking water was a major challenge for the villagers. The main way to provide for drinking water was by storage of rainwater by each household individually. At the same time, soil erosion was serious, especially when there were prolonged and heavy rains. After 1949, collective water and soil conservation was increasingly emphasized in the Loess Plateau region. In the early 1960s, the construction of hill-side terraces started in Chiniuwa to cope with water run-off and soil erosion. In the slack farming season (from the end of autumn till spring), the villagers were organized and gathered to construct terraced farmland. For instance, 200 mu of terraced farmland was constructed by approximate 200 villagers in autumn and winter of 1966. Between 1964 and 1974, all the terraced farmland in Chiniuwa village was constructed.

Another means to tackle the problem of water loss and soil erosion is the construction of dams. Over a period of about 20 years (from 1964 to 1984), the villagers of Chiniuwa constructed many dams, which fulfill multiple functions. First, the dams decrease the amount of soil ending up in the Yellow River. Second, the dams store the soil lost from

\footnotetext{
${ }^{32}$ Based on local sources and the website of Chiniuwa village: http://www.chiniuwa.com/
} 
the hill-sides to form new fertile land which can be used for agricultural production. Third, the dams control floods and thus ensure the safety of people living at the lower reaches of the Yellow River. Fourth, the dams serve to store water locally and help to alleviate the shortage of drinking and irrigation water. However, according to the respondents, in recent years maintenance has not been organized and several dams are in poor condition.

Chiniuwa village is located in the northern part of Keng town. It is a remote and relatively isolated village, which constrains the development of the local economy. At the end of the 1970s, the village leaders organized the residents to build a road from Chiniuwa village to Keng town. More recently, this road was broadened in the winter of 2012 and surfaced with concrete in 2013, which was beneficial for the connections with the outside world.

To effectively solve the problem of drinking water shortages in Chiniuwa village, the local government invested in the construction of five water wells. In 1991 and 1992, the first two wells were constructed, the third (deep) well was constructed in 1999, the fourth in 2003 and the fifth in 2009.

\subsubsection{Agricultural development since 1978}

Before the reform of China's agricultural policy in 1978 (Chapter 1), 90\% of the farmland in Chiniuwa village was used to produce food crops for self-subsistence. Since then, there has been a transition from food crops to cash crops, notably to jujube, a perennial fruit crop (Ziziphus jujuba Mill.). Currently, 2100 mu of the total farmland area of 2500 mu in Chiniuwa are planted with jujube trees (85\%). Jujube is highly drought tolerant and economically much more profitable than food crops. To maximize the area of the jujube orchards, the farmers intercrop jujube with food crops, such as potato, millets and soybean ${ }^{33}$. Over the past 30 years, jujube has become the main source of agricultural income in Chiniuwa. The transition from annual food crops to jujube trees has not only improved farmers' agricultural income, but also greatly reduced water loss and soil erosion. This is also the goal of the large national "Grain for green" program, which has the Loess Plateau as one of its focal areas in China, and stimulates the replacement of cropland by trees through a system of subsidies (Chapter 1 ). Chiniuwa village participated in the program in 2010, and several farmers now receive an annual subsidy of 105 yuan per mu, which includes grain subsidies (70 yuan), a compensation for operational

\footnotetext{
${ }^{33}$ Potato and millet are the main types of food in Chiniuwa. Most households have a cellar to store potatoes for consumption during winter and spring. Although relatively monotonous in terms of food type, the local people developed a variety of preparations, such as potato noodles and millet wines. In summer and autumn, different types of vegetables are available. In addition, the villagers buy wheat flour at the market, especially to prepare steamed buns and noodles. Farmers in Chiniuwa rarely keep livestock due to the lack of water and grain crops for feed. For instance, none of the 14 households we interviewed were raising pigs or cattle.
} 
costs (20 yuan) and an "ecological benefits" compensation (15 yuan) ${ }^{34}$. However, since the majority of the jujube trees in Chiniuwa were planted during the 1980s, long before the start of the "Grain for green" program in 1999, only 200 mu farmland was converted to trees under this subsidy scheme.

\subsubsection{Work, leisure and culture in Chiniuwa village}

Chiniuwa village has about 1000 inhabitants and approximately 400 villagers are migrant workers, working mostly in Yulin, which is the nearest major city. Due to the absence of a primary school in the village, young migrant parents have to bring their children with them to attend school in the city, which restricts their employment choices. The old and middle-aged people mostly remain in the village and take care of the jujube orchards. This is labor-intensive, but with a good harvest, the household income from jujube can be higher than from migrant work.

As many old and middle aged villagers do not work off-farm, they have leisure time and come to the village square to sit and chat. In addition, Chiniuwa has an active cultural life. An example of a cultural activity is the yangko opera. From the 1950s to the 1970s, the time of the communes, yangko operas were collectively organized, and Chiniuwa was very famous for this in the wide surroundings. As Chiniuwa village is located in one of the homebase areas of the communist revolution, the yangko opera was mainly used to promote the "red culture" of the Communist Party. In the 1980s, after the communes were disbanded, no-one organized the rehearsal of yangko operas anymore. However, since 2009, the village leaders organize traditional cultural activities again and have even been successful in attracting regional media to cover the spring festival activities in Chiniuwa village.

In 2009, the transformation of an old abandoned school in Chiniuwa to an agricultural and folk customs museum was initiated. The construction work was completed in 2013, including the building of supporting facilities, such as the cave hotel, and the restoration of the village temple. The museum has three floors, with a total area of about $1000 \mathrm{~m}^{2}$. The majority of the items on display were collected from households in the village or surrounding areas, and include traditional farming tools, daily utensils, and specimens of crops grown in the area. The exhibitions relate to different aspects of local farmers' life, especially the traditional farming culture. A major goal of the museum is to provide the villagers with additional income from tourism. Local farmers can be trained, for example as a tour conductor to tell about the history of the village in the museum, or to give cultural performances for tourists, such as the yangko opera.

\footnotetext{
${ }^{34}$ Based on local sources and website of Jia County government: http://www.sxjiaxian.gov.cn/gk/zfwj/jzf/ 8308.htm
} 


\subsection{FARMERS' PERSPECTIVES IN CHINIUWA VILLAGE}

The section presents the perspectives of the farmers we interviewed in Chiniuwa. The 14 respondents were asked about the current situation and future development of farming, sources of income and social security, migrant work and environmental issues. Their perspectives are described below, and structured according to the economic, social and ecological aspects. The descriptions are based exclusively on the answers of the respondents, sometimes with reference to specific interviewees, and are illustrated with quotes from the interviews to give additional detail and an impression of the "farmers' voice".

\subsubsection{Economic aspects}

The economic aspects addressed by the respondents concerned in the first place the production of jujube, a very important source of income. Recently, however, the profitability of jujube production has come under severe pressure. Other ways to support households in Chiniuwa, growing food crops and working off-farm, are nowadays fraught with difficulties as well. According the respondents, the economic situation in the village is very difficult with no immediate prospects for improvement.

\subsubsection{Income from jujube}

Until recently, household income in Chiniuwa from jujube was relatively high and comparable to income from migrant work. However, in recent years, the income from jujube has dropped dramatically. In three consecutive years (2012, 2013, and 2014), the farmers were confronted with failed harvests (see explanation in section 5.4.1.2). At the time of the interviews (April and May 2015), the majority of the respondents was quite negative about the production of jujube and it was rather difficult to obtain more precise information from them about the income earned from jujube. When asked to calculate the net income per mu farmland, most respondents made a comparison, either between the income from jujube before 2012 and the current income, or between the current income from jujube and income from migrant work. Both ways of comparing made clear that the current income from jujube is poor.

The income from jujube was considerable three or four years ago, and I could gain about 10,000 yuan each year. However, last year I just gained 1700 yuan. [Gao, 27 years old, male]

The jujube has not been so profitable. In the past, my household earned about 10,000 yuan, while now it is just about 500 to 600 yuan. [Qiao, 67 years old, female] 
Several years ago, we could earn 40 to 50 yuan per day for working outside while we could gain 7,000 to 8,000 yuan from jujube each year. Currently, if we can find migrant jobs, we can earn 200 yuan per day, while we just can gain several hundred yuan from jujubes each year. In the past few years, the jujube was not economical and we almost earned nothing from it. [Gao, 48 years old, male]

\subsubsection{Jujube yields}

According to respondents, the maximum yield of jujube was approximately $500 \mathrm{~kg}$ per mu before 2012. In three recent years, however, the farmers suffered a nearly complete loss of the jujube harvest. All of the 14 respondents ascribe this to rains that continued for several days during the harvest time in autumn, which had a very negative impact on the quality of the fruit. In 2012, there was in addition even a hail storm, which almost completely destroyed the harvest.

In former years, the precipitation was little in autumn. However, it heavily rained in the past three autumns, which has caused serious rotting of the jujube berries. The mountains in Jia County are nearly all covered by jujube orchards, and farmers were confronted with serious economic loss. [Gao, 48 years old, male]

Jujube yield was bad due to the rainy weather in autumn. When the jujube berries were ripe, it just kept raining and sometimes we had even hailstone. The ripe jujubes could not survive in the rain, so the yield dramatically decreased. And sometimes we gained nothing. All the jujubes were just rotting on the trees. [Gao, 44 years old, male]

The respondents expressed jujube yields in bags of jujube fruit rather than in the precise weight ${ }^{35}$. The majority mentioned that they only harvested several bags of jujube in 2012, 2013 and 2014. Even the respondent who gained the highest income from jujube mentioned the serious reduction in jujube yield.

I gained 170 bags of jujubes three years ago while just 6 bags of jujubes last year. [Gao, 63 years old, male]

I had the highest income from jujube in my village, because I bought an oven to dry the jujube berries when it was rainy in autumn. However, I also suffered a serious decrease in jujube yield. For instance, I could harvest several hundred bags of jujube in former years, while I just had no more than one hundred bags of jujubes last year. [Sun, 66 years old, female]

\subsubsection{The market price for jujube}

In addition to failed harvests, the farmers in Chiniuwa are now confronted with problems in the marketing of jujube. Jia county is one of the main jujube producing areas in

\footnotetext{
${ }^{35}$ According to local farmers, one bag of jujubes weighs no more than $50 \mathrm{~kg}$.
} 
Shaanxi Province ${ }^{36}$. In China, the jujube fruits from this region are famous and known as "the Yellow River beach date". Before 2012, part of the harvest was even exported and farmers received a good price. However, since 2012, both the quantity and the quality of jujubes have decreased due to the autumn rains in Jia county. As a result, their place on the jujube market has been taken over by jujubes from Xinjiang, in the western part of China, and the local market price has sharply decreased. The current price is about 2.5 yuan per $\mathrm{kg}$, while it was 4 to 6 yuan per $\mathrm{kg}$ in former years. In 2013, when the market price was 2.4 yuan per $\mathrm{kg}$, some farmers decided not to harvest and sell their jujube fruits because the price was too low in their opinion. However, in 2014, the jujube price was even lower at about 1.2 yuan per kg.

\subsubsection{Reduced investment in jujube}

The investments in jujube orchards in Chiniuwa village are decreasing due to the recent harvest failures, the low market price, and, as a result, the poor income from jujube. According to the respondents, the normal level of investment in inputs per mu jujube orchard is approximately 200 yuan. The main input cost is for chemical fertilizer, because pesticides are offered for free by the local government. Although some respondents mentioned that the provided amount of pesticide was usually not sufficient and that farmers need to buy additional pesticide in the market, it does reduce their input costs substantially. Recently however, only few farmers bought the additional amount of pesticide and many even did not use the pesticide provided by the local government. The reason is that the farmers did not want to invest the labor required for applying the pesticides.

The production of jujube is labor intensive, especially weeding and harvesting. For instance, seven or eight rounds of weeding are required each year, and it takes a farmer an entire day to weed one mu of jujube orchard. If farmers hire other villagers to assist them in weeding, they will have to pay 150 yuan per person per day. Therefore, the majority of the households do the weeding themselves. Due to the recent failures of the jujube harvest, some farmers even have abandoned their jujube orchards or weed it just one or two times.

A household with sufficient hands can do weeding as much as needed, while a household with a shortage of hands can just do it once or twice a year. People in the village are not willing anymore to do the farming work in jujube orchards. We invested so much but gained too little; it is not economical. [Zhang, 45 years old, female]

\footnotetext{
${ }^{36}$ The nine main producing counties of jujubes in Yulin city are Fuguu, Shenmu, Jia, Wupu, Suide, Qingjian, Mizhi, Zizhou and Yuyang. Available from: http://tianqi.cncn.com/sxyulin/news-183791. The situation of jujube in Chiniuwa village is probably representative of the other counties. For instance, we interviewed a young woman (interviewee 13), whose husband is from neighbouring Wupu County, and she indicated that in this county the situation is similar, with failed harvests of jujube.
} 


\subsubsection{Production of food crops}

For farmers in Chiniuwa village self-sufficiency in food production is difficult to achieve, and most households have to buy (part of) their food in the market. The natural conditions in Chiniuwa village are not favorable for the cultivation of food crops. Due to spring droughts, sowing often has to be postponed, with low yields as a result. After the large-scale transition to jujube production in the past decades, most farmers only plant some millets, potatoes and soybeans in between the jujube trees. However, in recent years, these crops suffered severe damage from wild animals. For instance, some people in the village have quit planting soybeans because they expect it will be consumed by pheasants and hares.

There is not enough food produced in my village. We farmers are dependent on the mercy of nature. We need to buy some food in the market. What we gain from the crops each year is not enough for domestic consumption due to the spring drought and because most of the farmland is planted with jujube trees. The vegetables in spring and summer give a better yield than the grain crops, because we can water them by hand. [Gao, 44 years old, male]

We have 4 to 5 mu jujube orchard, and 0.5 mu farmland for potato and millet. We do not plant soybeans anymore because it will be eaten by pheasants and hares. [Gao, 66 years old, male]

I planted 0.5 mu potato and then I was confronted with a total failure of the harvest due to wild pheasants. [Gao, 58 years old, male]

\subsubsection{Migrant and local off-farm work}

Due to their low level of education and lack of professional training, most migrant workers from Chiniuwa village, especially the middle-aged, can only do unskilled and physically-demanding work. The majority has jobs in the construction sector. However, due to the recent reduction in construction projects in the cities, it is more difficult to find employment and the contribution of migrant salaries to the household income has decreased. At the time of the interviews (April-May 2015), almost all middle-aged migrant workers had returned to stay in the village, awaiting new employment opportunities.

In the village, there are so many people just staying at home, especially the middle-aged people, between 40 and 50 years old. It is not easy to find a job outside now, because the construction projects in the cities are becoming less and less. Unfortunately, we mainly look for jobs at the construction sites to do stone- or brick-laying. Our choices are very limited. [Gao, 44 years old, male]

Local off-farm employment opportunities (odd jobs) for middle-aged farmers are also very limited in Chiniuwa, as a result of the remote location of the village and the low 
level of economic development in the surroundings. The establishment of the agricultural and folk customs museum and the associated cultural performances were meant to provide local employment and income from tourism for middle-aged and older farmers in Chiniuwa. However, the majority of the respondents indicated that the contribution to the household income is negligible, because the numbers of visitors and tourists are (still) rather low. Most middle-aged farmers are therefore no longer cash earners. For those who have children attending middle school or university this presents a serious problem. The income from migrant work, especially construction work, is irregular and uncertain, which means that there is no income security.

The employment opportunities are extremely poor nowadays, and last year I only worked no more than two months outside. I have to support my children's education. My third daughter studies in university in Xi'an. My second daughter had to give up university and became a migrant worker in Yulin city due to the economic difficulties. My youngest son has just finished his junior school and became a lorry driver at a construction site. He earns 3000 to 4000 yuan, but he even cannot balance his own expenditures in Yulin city. [Gao, 48 years old, male]

Generally, it is more easy for young people to find a job and stay for a relatively long time in the urban areas. However, these young migrant workers are confronted with low salaries on the one hand and high costs of living on the other.

It is not easy to find a suitable job for young migrant workers. And the salary is low, but if they ask for a higher salary, no one would employ them in the cities. [Gao, 34 years old, male]

Compared with the middle-aged migrant workers, it is relatively easy for young people to find a job. However, the living expenditures in the city are very high. They even cannot maintain a balance of payment. Especially after the payment of the rent, there is almost nothing left for them. Thus, it is also not easy for young people. [Gao, 63 years old, male]

I have four children and all of them are migrant workers. My sons' work mainly concerns the installation of central air conditioning equipment. They can earn 3000 to 4000 yuan per month at best, and 1000 to 2000 yuan at the worst. Currently, it is difficult for them to find work. And even when they find jobs, the salary is low. [Gao, 58 years old, male]

A young couple together can earn 4000 to 5000 yuan, which is not a lot to maintain their own subsistence. [Zhang, 45 years old, female] 


\subsubsection{Social aspects}

The social aspects addressed by the respondents concerned the various problems the households in Chiniuwa village are facing. The combination of problems in off-farm employment and agricultural production makes the situation in the village particularly difficult.

\subsubsection{The problems of migrant workers}

As described above, it is relatively easy for the younger members of the households in Chiniuwa to find a job as migrant worker. However, they are confronted with many difficulties, which include not only low salaries and high living expenditures, but also long working hours, limited access to public services, and delays in salary payments.

The migrant work is difficult. It pays poorly and we have to work long time a day. This year, the salary level decreased everywhere. My husband has worked for more than 4 months this year without knowing the monthly salary. In fact, he did not receive his salary for the last whole year. [Gao, 24 years old, female]

The absence of elementary education in Chiniuwa village negatively affects the employment opportunities for young migrant parents in terms of places to work. The majority of young people from Chiniuwa work in Yulin, the nearest major city, where their children can attend the primary schools. According to the respondents, before the children are old enough for middle school ${ }^{37}$, the parents cannot work in other urban areas. In addition to this limitation in finding migrant jobs, their economic burden is made heavier because in cities schools are more costly than in rural areas.

Our village has no primary school. Nearly ten years ago, there was still a school in the village. However, teaching quality was poor, and parents were not satisfied with the school. So they just took their kids with them to the city, mainly in Yulin city. And then, we had no school anymore due to the dramatic decrease in the number of pupils. However, the life is not easy for young migrants in the city. Now that they have kids attending school in the city, they cannot save any money after a whole year of migrant work. [Gao, 63 years old, male]

\subsubsection{Food production as a last resort}

With the current problems in finding outside employment and the harvest failures of the jujube, there is almost no cash income for the households in Chiniuwa village. Therefore, all old and middle-aged respondents emphasized the importance of agriculture for subsistence, even though the land can only provide a part of the required food, such as potato, millet, and some vegetables.

\footnotetext{
${ }^{37}$ At middle school level there are boarding school facilities, so children can live in the school without the need for parental care.
} 
Although the agriculture is not economical, I and my husband rely on it for our daily life. Each year we grow vegetables for ourselves. [Qiao, 67 years old, female]

Agriculture is important. If people cannot find a job, they still can make a living with farming work. At least, they will not starve. That is why I continue with the farming work, regardless of the harvest failures. [Gao, 44 years old, male]

Agriculture is of significant importance. In the rural areas, you can do farming for a basic living, even when there is only little money. Agriculture offers us some food to some degree. In the cities we cannot survive if we don't have money. [Gao, 54 years old, male]

The opinion of the younger respondents about the importance of agriculture was directly related with their migrant work situation. In case they were able to find migrant work, agriculture was not so important to them, mainly because of the low profitability. However, when agriculture was the only opportunity left to support themselves, also younger respondents acknowledged the importance of agriculture.

I am not sure whether I will do agricultural work. It will depend. Who knows, maybe I will come back to do farming activities. It is hard to find a job outside. If we can't subsist in the city, we have to come back to the village. [Gao, 24 years old, female]

I am ill, and have no other income source. Agriculture is important for me. Without agriculture, I and my family will have nothing to eat. [Gao, 27 years old, male]

\subsubsection{The accumulation of problems in Chiniuwa village}

Whereas rural households in China often combine various livelihood strategies to secure their income and subsistence (e.g., Chapter 4), the households in Chiniuwa village face difficulties in either direction. First, the local conditions are unfavorable for subsistence agriculture. Second, due to the harvest failures of the jujube, households have almost no cash income from agriculture. Third, many farmers, such as the majority of the middle-aged farmers, are confronted with a lack of off-farm employment opportunities. According to respondents, the majority of the villagers do not have longer-term plans of how to cope with this combination of problems in farming and migrant work.

The farming is not profitable. We have to rely on working outside. However, there are less migrant employment opportunities. I think the life of farmers is getting harder. [Gao, 54 years old, male]

The jujube is not that profitable and simultaneously it is hard to find a suitable job outside. So, many of us are really going through hard times. [Zhang, 45 years old, female] 
There is no solution for my village. The job situation is bad, the yield of food crops is low, and the jujubes are not marketable. [Gao, 66 years old, male]

\subsubsection{Environmental aspects}

The environmental aspects of farming in Chiniuwa addressed by the respondents concerned the changes in weather patterns, natural environment and land use.

\subsubsection{Changes in weather patterns and natural environment}

In September, when the jujube fruits are ripening, the weather in Chiniuwa is normally dry and sunny ${ }^{38}$, which is favorable for a high quality of jujubes. The respondents therefore described the unusual and disastrous rainy weather in autumn over the past three years (2012, 2013, and 2014), in terms of “climate change" (气候变化 qi hou bian hua). Some were uncertain about the causes of these changes in weather patterns, while others attributed the "climate change" to the extensive coverage of the region with jujube trees. In addition, some farmers attributed the increasing number of wild animals to the large coverage with jujube orchards as well.

I guess the main reason for the continuous rainy days in autumn is the large coverage of jujube orchards. Because there are more trees and the area has been greened, it rains more often, which negatively affects the output of the jujube trees. [Gao, 48 years old, male]

There were wild animals also before, but they never destroyed the crops due to their small numbers. Now there are more because of the jujube orchards and they do great harm to the crops. [Qiao, 67 years old, female]

The natural environment has improved because of the jujube orchards, and the pheasants can reproduce more rapidly. [Gao, 48 years old, male]

\subsubsection{Current changes in land use}

In the 1980s and 1990s, a very large proportion of the farmland was planted with jujube trees in Jia County. Although farmers in Chiniuwa continued to grow some food crops as an intercrop in the jujube orchards, they also indicated that crop yields are low due to shading by the trees. After three years of failed jujube harvests, the majority of respondents (interviewee 1, 2, 5, 6, 7, 8, 9, 10, 12, 13) have started to replace the jujube trees with other crops. Three types of alternatives were mentioned. First, part of the villagers replaced the jujube orchards with food crops, mainly millet. As millet is drought-resistant, the yield is relatively stable compared to other crops.

\footnotetext{
${ }^{38}$ According to the China Meteorological Administration: http://www.cma.gov.cn/kppd/kppdkpdt/201301/ t20130108_200834.html
} 
I think maybe no one will continue to attend to the jujube trees, and everyone will cut them down to replace them with crops. [Qiao, 67 years old, female]

Many people already have started to replace jujube trees with millets due to the poor or zero profit from the jujubes. [Gao, 63 years old, male]

The jujubes are really not profitable anymore. Thus, my parent-in-law who are living in the neighboring Wupu County cut down the jujube orchard and focused more on millet which is more profitable. [Gao, 34 years old, female]

Second, a few people started to replace the jujube trees with walnut trees. These farmers expect walnuts to be less sensitive to rainy weather in autumn and more profitable in the market.

Some people in the village replaced jujube trees with walnut trees. Once people (farmers) find something profitable, the others just swarm to do it too. However, once too many people do it, it will not be profitable. [Gao, 58 years old, male]

Third, there was one farmer (interviewee 5) who started to explore the opportunities to grow traditional Chinese medicinal herbs (thorowax) as an intercrop in jujube orchards. He obtained information about this option from a friend in Weinan city (in the middle part of Shaanxi province), where he lived as a migrant worker. Whether this works is still highly uncertain, as the growing cycle of the herb takes three years, and at the time of the interview, there were two more years to go.

Large-scale replacement of jujube trees with crops such as millets or medicinal herbs may result in the re-emergence of major environmental problems, such as water loss and soil erosion. However, none of the respondents made a reference to this risk.

\subsection{DISCUSSION}

In this section, we present the main findings by summarizing the problems of farmers in Chiniuwa from the perspective of the respondents, and how these are addressed, as well as the respondents' views on the future development of agriculture in Chiniuwa village. We then compare the main findings with those of other studies, and end with an outlook by reflecting on the sustainability of farming in Chiniuwa and the implications for policy.

\subsubsection{Main findings}

\subsubsection{Problems and solutions}

Over the past decades, the farmers of Chiniuwa village have increasingly specialized in the production of jujube fruit. The income from this cash crop represented until very 
recently the major share of their household income, and was even more important than income from migrant work. However, after three years of failed harvests, a loss in market share and a steep drop in the price of jujube, the dependence of the local economy on jujube has become Chiniuwa's largest problem. Most farmers seem disoriented and still do not know how to respond to this crisis. A few, however, are trying different solutions in order to maintain a substantial cash income from agriculture: investing in a drying oven to prevent the jujubes from rotting, replacing jujube with walnut trees, or growing thorowax, a medicinal herb. Shifting towards more off-farm labor nearby or as migrant workers in the cities, is not an option. On the contrary, due to a slow-down in China's economic growth, construction activity has recently decreased, which has severely limited the off-farm employment opportunities for the farmers of Chiniuwa, in particular the middle-aged who are mostly active as unskilled workers in construction. The opportunities for younger villagers to find migrant work in China's major cities are constrained by the absence of a primary school in Chiniuwa. This forces them to take their young children with them to the cities, limiting their choice to nearby Yulin city, and reducing their contribution to the household cash income in Chiniuwa to almost nil due to the high costs of education in cities. In many Chinese villages, the land holdings of the rural residents function as a source of social security in case of unemployment and lack of cash income, by allowing the villagers to provide for their own food (Chapter 1,2 , and 4). However, even food production for self-subsistence is problematic in Chiniuwa. The agro-climatic conditions are unfavourable, crops suffer heavily from damage by wild animals, and most land is planted with jujube trees whereas intercropping gives low yields. As a consequence, farmers in Chiniuwa have started to cut down their jujube trees to make way for food crops, in particular millet, a traditional grain crop which is well-adapted to the semi-arid climate. In terms of environmental problems, the Loess Plateau where Chiniuwa is located is notorious for large-scale soil erosion. However, in Chiniuwa this problem was successfully addressed already decades before the large national forestation programs started around 2000, by terracing the hill slopes and planting jujube trees. Remarkably, the farmers attributed their current problems with unusual rainfall during autumn and increased crop damage from wild herbivores to this large-scale planting of jujube in the area. However, what they started to pursue as a solution (cutting down jujube orchards), may result in the re-emergence of the old problem of soil erosion. The farmers showed no awareness of this risk, but were focused on solving urgent problems of food and income.

\subsubsection{The future development of agriculture in Chiniuwa village}

The respondents were generally quite uncertain and rather pessimistic about the future development of agriculture in Chiniuwa. As they believed that the three years of failed jujube harvests were caused by "climate change", many did no longer see a future for jujube as the main cash crop and had stopped investing time and resources in jujube production. Some of the villagers had already started to replace the jujube trees with 
alternatives, cash crops as well as food crops. However, at the time of the interviews the respondents were highly unsure about whether these alternatives would be successful in providing sufficient cash income or food for the households in Chiniuwa. A structural shift towards off-farm sources of income and exit from farming in combination with scale-enlargement by remaining farmers was not seen as a likely future direction. First, because it was the respondents' experience that the off-farm employment opportunities were decreasing rather than growing. Second, because apart from jujube production the conditions in Chiniuwa were not deemed particularly favourable for other types of (large-scale) agricultural production. Third, the respondents stressed the importance of their land as a last resort, despite of the difficulties in local food production.

\subsubsection{Comparison with other studies}

A major finding in our case study of Chiniuwa was the crisis in the production of jujubes, the crop on which most villagers relied for cash income. Although the respondents indicated that the problem of harvest failures due to prolonged rainy weather in autumn was widespread in the jujube-producing counties of the region, the scientific literature does not mention it. On the contrary, when climate change in the Loess Plateau region and adaptation of jujube cultivation are discussed, it is about the problem of water scarcity and enhancing the water use efficiency of jujube production (e.g., Gao et al., 2014; Chen et al., 2015). We therefore contacted researchers from Northwest Agriculture \& Forestry University who operate an experimental station in Mizhi county, which is adjacent to Jia county, and monitor the precipitation in the area. The researchers confirmed that the amount of precipitation in 2012, 2013 and 2014 was much higher than the long-term average of the Loess Plateau area, especially in 2012 and 2013 (pers. comm., prof. Wang Youke, 30 October 2015). According to the researchers, the failed harvests of jujube in 2012 and 2013 could well be due to the rainy autumn, but they attributed the poor harvest of 2014 rather to frost damage in spring and high temperature during summer. Moreover, they indicated that the amounts of precipitation in these three years were not the highest measured during the past decades for the Loess Plateau area, and that rainfall was even relatively low in the autumn of 2015. Contrary to the perception of the interviewed farmers, the researchers therefore concluded that there is no change of climate in the Loess Plateau area where Chiniuwa village is located.

Another major finding is this case study was that in Chiniuwa, where conditions for food production are not favorable, land does not function properly as a source of social security for rural residents. Scholars often mention this social security function of land (e.g., Wang et al., 2013), and the Chinese sociologist He advocates to conserve the current system of land rights of rural residents for this purpose (He, 2013a, 2014a, 2014b). 
However, no attention is paid in the literature to the problem that in many areas in China, the agro-climatic conditions may be too unfavorable for the land to produce the amount of food required to fulfill this function. This will be even more problematic when most members of the household are forced to return to the village due to the lack of outside employment.

The severe lack of secure off-farm employment opportunities for the villagers of Chiniuwa, both local and migrant, is commonly observed for rural residents across China (He, 2014a, 2014b; Wang, 2011). In particular the construction sector, which employs the large majority of rural-urban migrant workers, is notorious for a lack of job security. Construction in China is driven by a combination of economic growth and the urge of local governments to generate revenues from urban land expansion (Ye \& Wu, 2014), which is also known as "the Movement of Building Cities" (Sun, Song, Xiu, \& Liang, 2013). This combination of drivers easily results in alternate phases of acceleration and deceleration in construction activity, with concomitant effects on employment of rural workers. Our case study of Chiniuwa not only confirms that off-farm, urban employment is temporary, irregular and uncertain (Wang, 2011), but also indicates that urban employment opportunities may often simply be largely insufficient for the rural labor surplus from the villages.

\subsubsection{Outlook}

In this final section we reflect on the long-term sustainability of the strategies followed by the farmers in Chiniuwa and how policy measures could support a more sustainable development of agriculture in this village and other villages with similar conditions.

The Loess Plateau in China is a region known for its widespread problems of soil erosion, unfavourable climatic conditions for food crop production and low agricultural incomes (Liu et al., 2011). The transition to jujube cultivation in the region of Chiniuwa village appeared for a long time to be a successful solution strategy. The large-scale planting of jujube trees effectively controlled soil erosion and the semi-arid conditions were suitable for the production of high-quality jujube fruits. Combined with a good market price, the jujube became the most important source of cash income for the households in Chiniuwa. With the cash from the jujubes, the villagers could buy their food in the market. However, the three recent harvest failures have shown the vulnerability of rural communities that specialize in a single cash crop. A partial conversion of jujube orchards to cropland, especially to cultivation of the well-adapted millet, can therefore be viewed as a positive development from a sustainability perspective, as it makes the system more resilient (cf. Liu et al., 2011). However, care should be taken that the replacement of trees by annual crops is only partial and in small parcels, in order to prevent soil erosion after harvesting the crops. In addition to support in making 
sustainable adjustments in the production system, the farmers should also be supported in the marketing of their jujube fruits or other cash crops.

The case of Chiniuwa village shows that two common livelihood strategies to deal with a crisis in the production of a major cash crop may not work well. The first strategy, a shift to production of food crops for self-sufficiency as described above, is not adequate in areas with unfavourable conditions for food crops, such as the Loess Plateau. This indicates that the land holdings of rural residents are no full substitute for the social security system of urban residents, and that there is an urgent need for further development of the rural social security system. The second strategy, a shift toward off-farm employment neither worked well in the case of Chiniuwa, as most farmers could only access low-skilled, highly insecure jobs, mainly in construction, and young migrant parents were facing high costs of primary education in the cities due to the absence of an elementary school in the village. From a sustainability policy perspective, this indicates the need for an improvement of the rural education system to enhance the capabilities and off-farm employment opportunities of the rural work force (Tian et al., 2016), and for measures to maintain primary schools in the villages or to reduce the costs of primary education in the cities for rural-urban migrants.

Finally, Chiniuwa provides a strong case for the need for close collaboration between farmers and agricultural experts in the development of sustainable farming systems, and makes clear that neither scientists nor small-scale farmers alone have all the answers. In the case of Chiniuwa, the isolation of farmers and experts resulted in an overreaction of the farmers to disastrous weather anomalies perceived as a permanent and unfavourable change in climate, and a complete lack of awareness of the farmers' urgent problems on the side of the agricultural experts. This situation has created the risk that the farmers in Chiniuwa in their panic will make drastic, very unsustainable decisions, such as large-scale cutting of jujube trees. In contrast, frequent interaction between farmers and researchers, combining the more objective, long-term knowledge of scientists and the detailed knowledge about local conditions of farmers, could result in the co-production of a more balanced diagnosis and more sustainable responses to the jujube crisis. 
Chapter

Farmers' perspectives in Donghe, a village in the Qinba Mountains,

Shaanxi Province, China 
Abstract: The perspectives of farmers on the current state and future development of agriculture in Donghe are described based on in-depth interviews with 17 respondents. Donghe is a village located in in the Qinba Mountains of Shaanxi Province. In this region, the climatic conditions are favorable for agriculture, but the steep slopes make the fields less accessible and hinder mechanization. The dominant system is doublecropping of rice and oilseed rape, a cropping system which is common and widespread in southern China. According to the farmers, rice is their major source of agricultural income, but due to the very small land holdings the profits are not sufficient to cover household expenses. Off-farm migrant work in cities by young and middle-aged farmers is nowadays the main source of household income. The rural-urban migrant work is temporary and short-term, however, and does not provide social security. Beyond the age of 35 , it is increasingly difficult for the farmers to find employment as migrant worker. As most households in Donghe are self-sufficient in food production, farming plays an important role as social safety net. However, the younger generation has no or little experience with farming and prefers to settle down in cities. Although this is very difficult where it concerns the large cities, settling down in nearby smaller cities and towns appears a feasible compromise. Major environmental risks such as soil erosion and agrochemical pollution are effectively managed according to the farmers, by conversion of sloping dryland fields to forest under the national "Grain for green" program and by an ongoing transition to organic rice production. For the future, the farmers expected a rapid expansion of organic rice production. However, given the importance of land as a social safety net for the households, farmers did not expect a short-term shift from the current system of production contracts with a private company to a system in which the land rights are transferred to the company to allow large-scale farming. The chapter concludes with a reflection on the sustainability of farming in Donghe and implications for policy. 


\subsection{INTRODUCTION}

Over the past decades, agricultural development in China was characterized by a strong increase in agricultural production and farmer incomes. Major policy goals concerning national food security, access to affordable food and rural poverty alleviation have been reached. However, at the same time environmental, as well as economic and social problems threaten the sustainability of agriculture (Chapter 2). The Chinese government aims to address these problems with a modernization strategy in combination with urbanization. Alternative strategies focus on the conservation of small-scale agriculture or the development of ecological agriculture. However, neither the government's modernization strategy nor the two major alternatives offer a comprehensive and integrated response to the current threats to the sustainability of agriculture. Moreover, all three strategies make unsupported, generic assumptions about the problems and needs of Chinese farmers (Chapter 2). Investigation of farmers' perspectives on agricultural development and how these vary with local conditions is therefore a much needed step towards a comprehensive and broadly supported strategy for sustainable agricultural development in China. A survey of farmers in the Guanzhong Plain (Shaanxi Province) made clear that even in a fairly homogeneous agricultural production area, there is a large diversity in farmers' perspectives and practices, depending on farm household type, age and level of education (Chapter 3).

To better match high-level strategies for agricultural development as well as on-theground measures and services with the needs of Chinese farmers, more in-depth research is required into farmers' perspectives and practices. First, more insight is needed into what farmers see as problems and why, how they cope with these problems and what viable prospects they see for themselves and, more generally, for agriculture in their village. This requires a case study approach, with in-depth interviews of a relatively small number of respondents. Second, more insight is needed into the impact of the agro-ecological context on farmers' perspectives, practices, problems and prospects. We therefore conducted case studies of three villages in contrasting agro-ecological zones of Shaanxi Province, allowing a comparison between farmers in the Guanzhong Plain and those in agronomically less favorable areas, at greater distance from major urban centers (Chapters 4, 5 and 6).

This chapter reports on the perspectives of farmers in Donghe village in the Qinba Mountains of Shaanxi Province. In this region, the climatic conditions are favorable for agriculture, but the steep slopes make the fields less accessible and hinder mechanization. The dominant system is double-cropping of rice and oilseed rape, a cropping system which is common and widespread in southern China. The following sections describe the methods used to determine farmers' perspectives on the current state and future development of agriculture in Donghe, the context of Donghe village, and the farmers' perspectives. We conclude with summarizing the main findings, comparing 
these with other studies, and reflecting on the sustainability of farming in Donghe and associated policy options.

\subsection{METHODS}

\subsubsection{Data collection and analysis}

The field work started with a two-week stay in Donghe village in August 2013, to become familiar with village life and to gain a better understanding of the village context. In April and May 2015, 17 farmers were interviewed. The village leader was interviewed first, and thereafter the other interviewees were identified by walking through the village and requesting people for interviews until a sufficiently large and balanced selection was obtained. The target was to interview people at least 15 persons from different households, with a 50/50 gender balance and a representative distribution of age groups. The interviews were semi-structured, addressing a limited set of predefined topics detailed below. The duration of a single interview ranged from 1 to 3 hours, and the interviewees were given ample opportunity to tell their stories.

All interviews were audio-recorded, transcribed in full in Chinese, and then translated into English. After reading all transcripts, a qualitative content analysis was conducted by coding the text with the MAXQDA software program. The main codes were predefined and related to the three dimensions of agriculture: economic, social and environmental. For each main code, several sub-codes were predefined or determined after reading all transcripts. Sub-codes for economic aspects were 'income from rice', 'agricultural income from other sources', 'income from migrant work', and 'importance of agriculture'. With respect to rice production, data on inputs and outputs were identified in the interviews to calculate the net income from conventional and organic rice. Subcodes for social aspects were 'problems of migrant workers', and 'return of migrant workers'. Finally, sub-codes for environmental aspects were 'organic production methods' and the 'Grain for green program'.

\subsubsection{Characteristics of the respondents}

The characteristics of the respondents in Donghe village are presented in table 6.1. The 17 respondents included 10 males and 7 females. The surname of the majority of the male interviewees is Feng. According to respondents, the members of the Feng clan established Donghe village during the Qing dynasty, approximately 400 years ago. The surnames of the female interviewees are more diverse. In terms of age, there were five 'young' (less than 40 years old), seven 'middle-aged' (40-60 years old), and five 'old' interviewees (more than 60 years old). The majority of the younger interviewees had 
returned to the village to wait for new employment opportunities as migrant worker in the cities, or to fulfil their household responsibilities (e.g., construction of a new house, marriage, pregnancy, or taking care of children and the elderly). The farming work in Donghe is mostly done by the middle-aged and old members of the household. The size of the land-holdings is small in Donghe, and ranged among the interviewees from 3 to 8 mu per household. Concerning the respondents' children, many of them are rural-tourban migrants who do low-skilled, physical work in major cities in other provinces. The majority does not have a university degree. The respondents are referred to as 'farm$\mathrm{ers}^{39}$ in this chapter. As explained in Chapter 1, due the Household Registration System (hukou) and the Household Responsibility System, everyone who is formally a rural resident in China has the right of use of a piece of the collective farmland of the village.

\footnotetext{
${ }^{39}$ The Chinese word is nongmin, which can be translated as farmer or peasant (Schneider, 2015).
} 


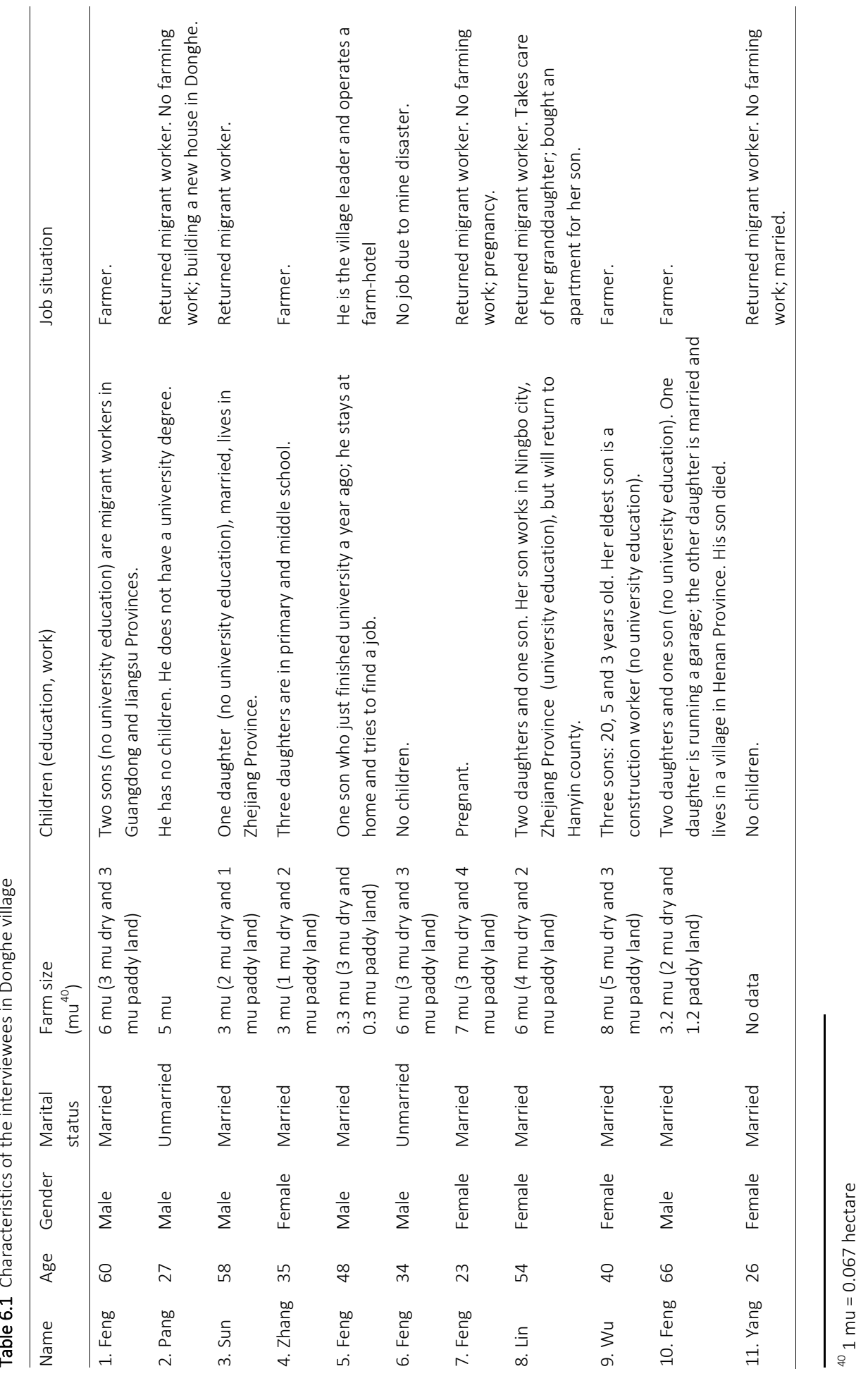


Farmers' perspectives in Donghe, a village in the Qinba Mountains

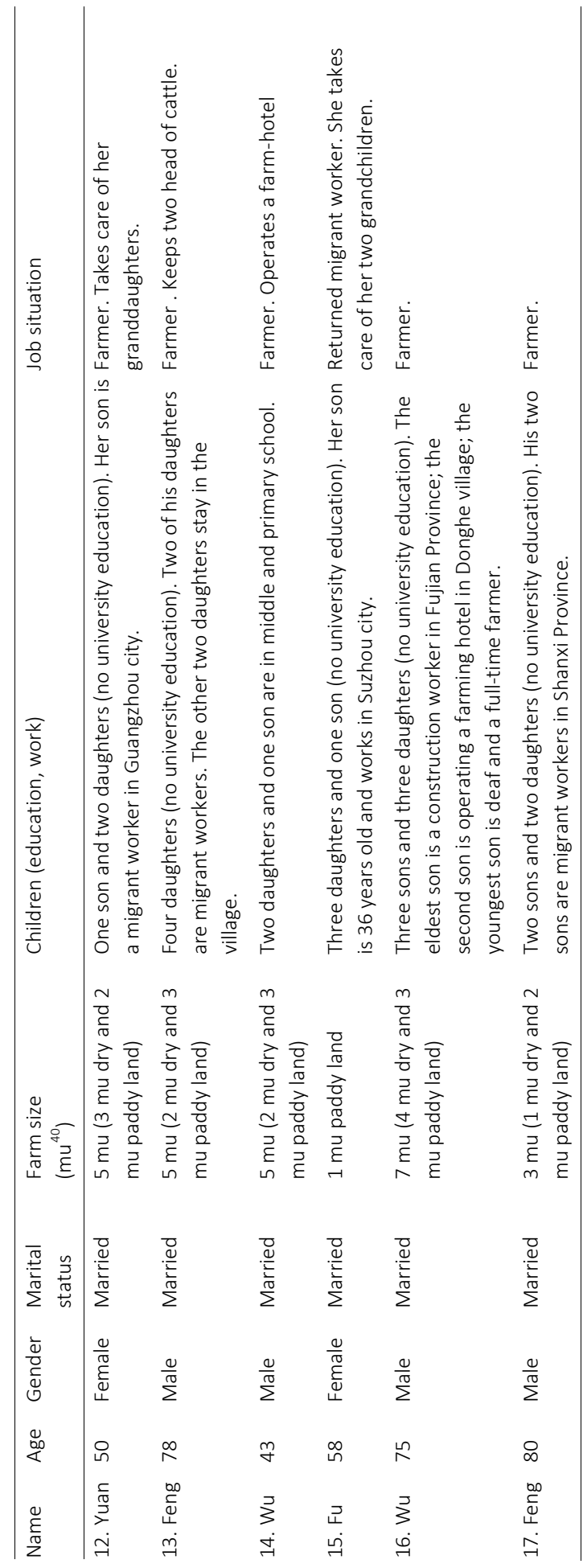




\subsection{THE CONTEXT OF DONGHE VILLAGE}

In this section the context of Chiniuwa village is briefly described, with respect to its geography, economy and people. The description is based on local sources, unless indicated otherwise.
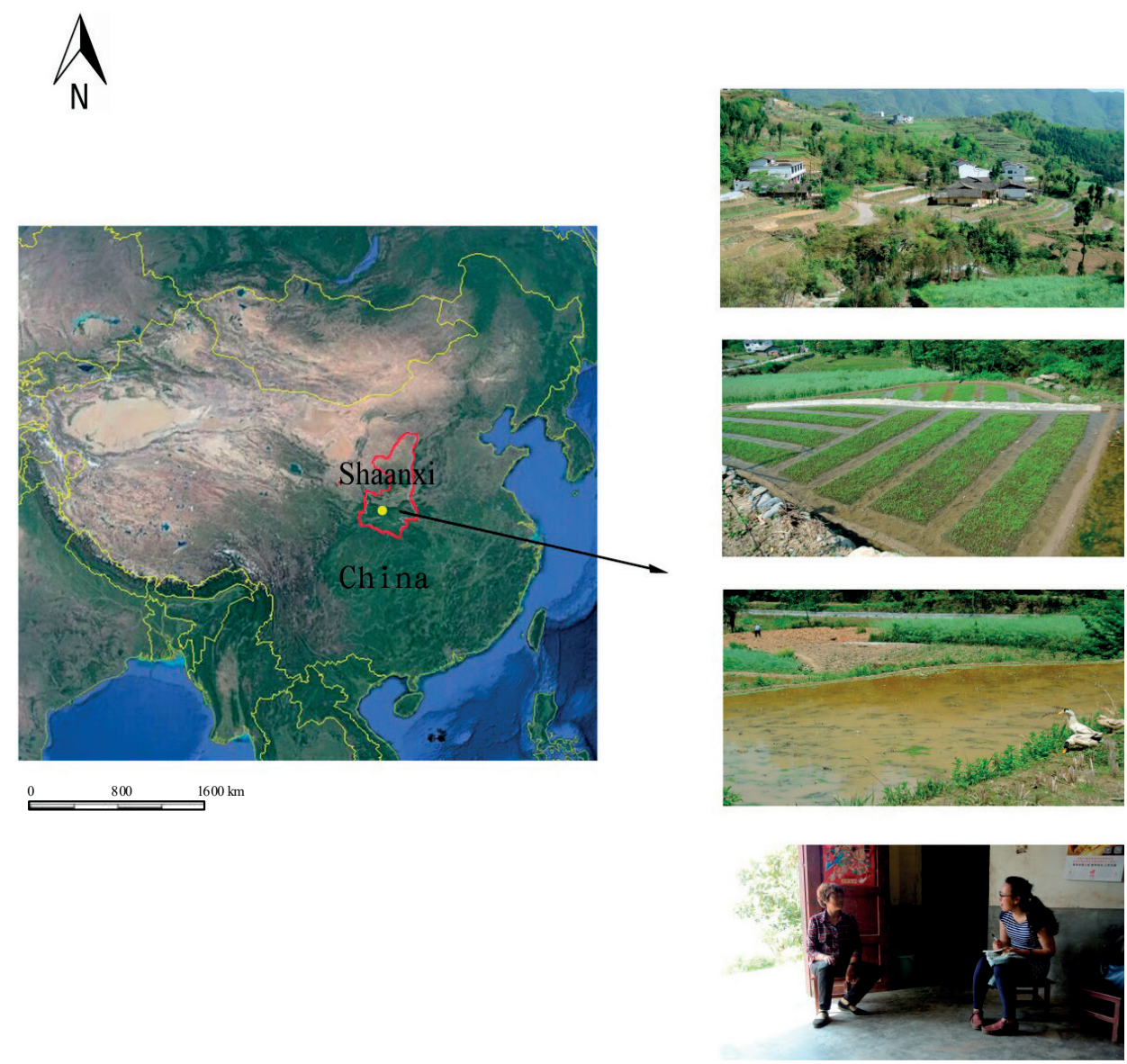

Figure 6.1 Donghe village: geographic location; overview of the village; rice seedlings in the nursery before transplanting; ducks near a flooded paddy field; interviewing a female farmer

\subsubsection{Geography ${ }^{41}$}

Donghe village is located in the Qinba Mountains, in the south of Shaanxi Province. Administratively, it belongs to Xuanwo town, Hanyin county of Ankang city. The distance from Donghe to Ankang is about $110 \mathrm{~km}$. The Qinba Mountains are mostly between

\footnotetext{
${ }^{41}$ Information on geographic location, landform and climate is obtained from http://baike.baidu.com/view/ 708400.htm
} 
1,500 to 3,000 $\mathrm{m}$ in height and form an important natural east-west boundary between the northern and southern part of China. Another important geographical characteristic is the proximity of the Han River, which runs from west to east through the Qinba mountains and which is an important tributary of the Yangtze River. The climate is humid subtropical: the average temperature of coldest month is above $0 \stackrel{\circ}{C}$ and the annual amount of precipitation in Xuanwo town is over $1300 \mathrm{~mm}$. The warm and humid climate provides favourable conditions for the cultivation of paddy rice (Min \& Han, 2008).

Donghe village and the surrounding areas are locally famous for their ancient terraced paddy land. The history of these paddy terraces goes back 400 years, to the Qian Long period (Qing dynasty). In Donghe, the surname of the majority of the male farmers is Feng. The ancestors of the Feng clan migrated from Hubei and Hunan Provinces and settled down at the site of Donghe village to cultivate rice. They constructed terraces on the steep mountain slopes to increase the area of farmland and to secure sufficient food. The sticky soil in this area prevents the water in the terraced fields from draining away. On some slopes there are up to 300 terrace layers, the height of each layer ranging from 0.3 to $1 \mathrm{~m}$, the width from 3 to $15 \mathrm{~m}$, and the average length is about $600 \mathrm{~m}$. The ancient paddy terraces are listed in the "Top 10 of Archaeological Sites of Shaanxi Province" and are considered to be the most beautiful ancient paddy terraces in Shaanxi Province.

\subsubsection{Sources of income in Donghe village}

In Donghe, there are two major sources of income: agriculture and the salaries of migrant workers in cities. With the rapid urbanization and industrialization, the salary income is becoming the main source of income for the households in the village. For the major expenditures, such as the construction of new houses, education, and medical treatment of the elderly, the households rely on the salaries of the young and middleaged members who work as migrants in urban areas. Agriculture provides the households with a basic and secure supply of food, such as grains, oil, vegetables and meat.

There are two types of farmland in the village, dryland fields and paddy fields. Many of the more remote dryland fields are currently abandoned. The dryland fields which are closer to the farmers' homes are planted mainly with corn, potato and some vegetables for domestic consumption. Corn is mostly used for feeding livestock, such as pigs, ducks and chickens. Middle-aged female farmers and old farmers usually feed two pigs: one to sell for cash income and one for domestic consumption ${ }^{42}$ to reduce the living expenditure. The paddy fields are used for double-cropping of rice (from May-September) and

\footnotetext{
${ }^{42}$ The farmers preserve the meat by smoking. The houses have a room to smoke the pork, which takes nearly one month. The smoked pork of one pig provides the household with meat for a whole year.
} 
oilseed rape (from October-April). In contrast to the dryland, the paddy fields are rarely abandoned. There are various reasons for this difference: (1) the farmers sell most of the rice to increase their agricultural income; (2) rice is their traditional staple food; (3) the county government encourages the farmers to take part in organic rice production; and (4) the village committee strictly requires the farmers to plant all their paddy farmland to maintain the landscape for which Donghe is famous.

Another important reason for the decreasing amount of cultivated dryland is the "Grain for green" program (see Chapter 1). Between 2002 and 2009, approximately 1200 mu dry farmland was converted to forest, under the slogan that "the mountains need blankets (forests), and the farmers need money". The subsidies for this conversion were based on an estimated yield of $150 \mathrm{~kg}$ corn per mu. With a corn price of 1.4 yuan per kg, plus 20 yuan per mu management fee, this resulted in a subsidy of 230 yuan per mu per year. After 2009, in the second phase of the "Grain for green" program, the subsidy has been halved to 125 yuan per mu per year. This subsidy is the same throughout the region of Ankang city. The "Grain for green" program is effective in preventing soil erosion and water run-off in mountainous areas, and provides an alternative use for sloping land with low agricultural output at remote locations from the farmers' homes.

The double-cropping of rice and oilseed rape as practiced in Donghe is representative of the cropping system in large parts of southern China. In Donghe, the cultivation of oilseed rape is promoted by the government providing seeds of high-quality varieties and an annual subsidy of about 70 yuan per mu. Each year, in March, when the oilseed rape is flowering and the terraces on the mountain slopes are bright-yellow, the Hanyin county government and the Xuanwo town government organize a "flower festival" to attract tourists. In this way, the villagers of Donghe can gain some additional income by accommodating tourists for several days.

\subsubsection{The organic rice project}

Since 2013, farmers in Donghe village are engaged in an organic rice project, in cooperation with a privately-owned enterprise (Xinxin Rice Company). Each year, the company and interested farmers sign a contract for organic rice production. The company issues free organic rice seeds, organic fertilizer, pest-killing lamps and ducks to the farmers. In return, the farmers are obliged to sell their organic rice to the company. In the first year (2013), the yield of organic rice was about $150 \mathrm{~kg}$ per mu lower than the yield of conventional rice. Since then, farmers were provided with seeds of an improved variety of rice and in 2014 the difference in yield was reduced to 50-100 kg per mu.

Ducks and pest-killing lamps (PV-powered light-traps) are the main approach to control pests and weeds, as organic alternatives to synthetic biocides. The use of ducks is based on the concept of "rice-duck mutualism", which was already developed 400 years ago 
(Suh, 2015). This mutualism works as follows. First, the ducks are allowed to roam freely in the paddy fields and eat weeds and pests. Second, the feeding activities of the ducks loosen the soil and improve the absorption of fertilizer. Third, the duck manure provides additional fertilizer and enhances the organic matter content of the soil.

The total area of paddy fields in Donghe is about $1000 \mathrm{mu}$. The final goal of the organic rice project is to include all paddy fields in the village. As a first step the company aimed to contract 500 mu of farmland in Donghe, but in 2015, this was still not more than 200 mu because many farmers are still hesitant and afraid of potential risks. According to the village leader, it would be better to replace the current system of contract farming by a system of farmland transfer. In that case, the farmers would transfer the right of use to the company, which could then manage the total area of paddy fields as a single, large-scale farm. The advantage would be that the company will bear the risks of, for instance, natural disasters and harvest failures. A neighboring village (Yanping) has adopted this system. The farmers rent out their land to the company for 450 yuan per mu per year, and the company hires the farmers as workers for 1000 to 1200 yuan per year. In total, the farmers can gain 1400 to 1600 yuan per mu per year.

\subsubsection{The people in Donghe village}

According to the Chinese household registration system, Donghe village counts 1730 residents and 453 households. Formally, the village is divided into seven teams, with about 200 persons per team. The majority of the teams does not have a leader, as there are no salary or subsidies available for this function. In fact, as elsewhere in China since the 1980s, teams do no longer play an important role in the social and economic life of the villagers in Donghe.

Almost all households in Donghe have at least one member working as rural-to-urban migrant in large cities. The majority of young people (20-40 years old) have no experience in farming and work in cities in Shaanxi Province, but also in other provinces, such as Hebei Province, Guangdong Province, Zhejiang Province, Jiangsu Province and Beijing. The farming work is done by the old and middle-aged farmers. It is difficult for most of the migrant workers to permanently settle down in cities due to the high costs of living and the high prices of apartments. In addition, they are reluctant to change their rural household registration (hukou) to urban hukou due to their farmland rights and the increasing subsidies for rural households (see Chapter 1). According to the village leader, approximately $10 \%$ of the local households have bought apartments in Hanyin, the local county capital, and roughly $4 \%$ have bought apartments in Xuanwo town. The large majority of migrant workers use their savings to build a house in Donghe village. 
The people actually living in Donghe village are mainly female middle-aged farmers (4060 years old), old farmers (over 60 years old), and children. As there is no school in the village, the children attend the primary school in the neighbouring village (Yanping). Due to the distance and the mountainous road, the parents make use of a private minibus pick up service to transport their children to school together. The fee for one child is 1800 yuan per year. The female middle-aged farmers remain in the village to attend to their young grandchildren, so that their own children can work outside. They do the farming work when their grandchildren are in primary school. When their grandchildren are at middle school age, these female farmers even no longer have a choice but to remain in the village, because they are too old to find employment in the cities. The period that women work outside as migrants is shorter than for men, because they are confronted with household responsibilities, such as taking care of the young children and the elderly. The old male farmers are the ones that fulfil most of the more physically-demanding farming activities in the village. As the fields are located on steep slopes, the farming work is labor-intensive and time-consuming, and mechanization is not an option. Even mini-tillers cannot be used under these conditions. Several of the older interviewees (over 70 years old) keep one or two cattle to assist them in the farming work.

\subsection{FARMERS' PERSPECTIVES IN DONGHE VILLAGE}

This section presents the perspectives of the farmers we interviewed in Donghe. The 17 respondents were asked about the current situation and future development of farming, sources of income and social security, migrant work and environmental issues. Their perspectives are described below, and structured according to the economic, social and ecological aspects. The descriptions are based exclusively on the answers of the respondents, sometimes with reference to specific interviewees, and are illustrated with quotes from the interviews to give additional detail and an impression of the "farmers' voice".

\subsubsection{Economic aspects}

The economic aspects addressed by the respondents concerned the major sources of income of the households: agriculture and migrant work. The latter is the main source of household income, but different groups of respondents varied in the significance they attach to agriculture for rural households. 


\subsubsection{Income from rice ${ }^{43}$}

According to the respondents, the income from rice is low due to the small land holdings and the high costs of inputs. Due to the steep slopes, no agricultural machinery can be employed and farming is labor-intensive. In case there are two or three farming laborers available in the household, the majority of the work will be done by the farmers themselves rather than by hiring "helpers" ${ }^{44}$. Otherwise, the input costs will be much higher, because the price of "helpers" has substantially increased in recent years. Due to the different numbers of farming laborers in their households and therefore the different need for "helpers", the net income calculated by respondents varied. However, they all concluded that agriculture is not cost-effective in Donghe.

I, my wife and my daughter-in-law are the main farming laborers in our household, and the majority of farming work is fulfilled by ourselves rather than by hiring helpers. As for the net income, if we do the farming work by ourselves, it is ok; while if we hire others, it will be not cost-effective. [Feng, 60 years old, male]

I am the only one doing the farming work in my household. I have to hire farm cattle to plow, at a price of 200 yuan per day. I also need to hire people to construct and fix the bunds of the paddy fields, which will cost 100 yuan per day. In addition, for rice transplanting, I need to hire a helper to finish in two days, at 100 yuan per day. There may not be much left for a net income. [Zhang, 35 years old, female]

Detailed information about the inputs for conventional rice production is provided in table 6.2. The yield of conventional rice is about $600 \mathrm{~kg}$ per mu, and the price is 2.6 yuan per $\mathrm{kg}$. Thus, the gross income is about 1560 yuan, and the net income 370 yuan per mu. However, the real net income may be higher, because some of the work listed in table 6.2 is done by the farmers themselves to save the costs of hiring "helpers", for example, the weeding and clearing of the fields before transplanting. In addition, the second and third plowing are usually less labor-demanding compared with the first plowing, which decreases the labor costs.

\footnotetext{
${ }^{43}$ In the terminology of agricultural economics: gross income = revenues; input costs = variable costs; net income [excluding labor] = gross margin

44 "Helpers" is the word the farmers used for persons from outside their household, usually other villagers, who are hired to assist in the farming work during the busy season. Due to the usually close relationship (relatives, neighbors), the farmers called them "helpers" rather than "farm workers".
} 
Table 6.2 Inputs and input costs of conventional rice per mu in Donghe village

\begin{tabular}{lc}
\hline Input & Cost (yuan) \\
\hline First plowing (after the harvest, to level the field) & 200 \\
Second plowing (after draining the field) & 200 \\
Third plowing (before transplanting) & 200 \\
Repairing the terraces and bunds of the paddy fields & 100 \\
Weeding and clearing the field (before transplanting) & 100 \\
Transplanting & 100 \\
Seeds & 50 \\
Fertilizers & 100 \\
Pesticides & 40 \\
Harvesting (including reaping and threshing) & 200 \\
Total & 1,190 \\
\hline
\end{tabular}

Interestingly, despite the lower yield of organic rice, the net income per mu is higher. This is due to the lower input costs and higher price for organic rice. The total input costs of organic rice are 1000 yuan per mu, based on table 6.1 and after deducting the costs of seeds, pesticides and fertilizers, as these are provided for free by the contractor (Xinxin Rice Company, see section 6.3.3). The yield of organic rice is 400 to $450 \mathrm{~kg}$ per $\mathrm{mu}$ and the price is 3.6 yuan per $\mathrm{kg}$, which results in a gross income of 1440 to 1620 yuan per mu. Thus, the net income from organic rice ranges from 440 to 620 yuan per mu.

The yield of organic rice is lower than that of conventional rice. However, due to the improvement of organic rice seeds, the yield of organic rice has substantially increased in 2014 compared with 2013. Concerning the price, the conventional rice was 2.6 yuan per kilo while the organic rice was 3.6 yuan per kilo. Thus, organic rice is more profitable. [Feng, 48 years old, male, village leader]

\subsubsection{Income from other crops and livestock}

In Donghe, rice is grown in rotation with oilseed rape. The cultivation of oilseed rape is relatively simple compared with rice and dryland crops. Farmers appreciate this crop, because it requires less labor and other inputs and the price is relatively high. A disadvantage is that the harvest period overlaps with the preparation of the seedbeds and seedlings of rice. Therefore, not all farmers do double-cropping of oilseed rape and rice in Donghe.

We harvested $150 \mathrm{~kg}$ rape seed from one mu of good quality field, and we could sell it at 6 yuan per $\mathrm{kg}$. [Wu, 43 years old, male] 
Oilseed rape is easy to cultivate and the price is good, except that the time of harvest overlaps with the time of the cultivation of the rice. At that time we will be very busy. [Zhang, 35 years old, female]

Corn (or maize) is the major dryland crop in Donghe. According to the respondents, the corn yield per mu ranges from 350 to $400 \mathrm{~kg}$. The average price per kilo is approximately 2 yuan, but the majority of households do not earn much cash income from corn, as most of it is used to feed the livestock. Livestock breeding is very popular in Donghe village. In addition to pigs, ducks and chickens, some old farmers also keep one or two cattle to assist them in the farming work. Compared with rice, the production of corn is less profitable and more time-consuming. Therefore the farmers tend to plant just enough corn to satisfy the needs of the household.

The corn is only for feeding pigs, I fed two pigs last year. Some pork was to sell, about 1000 yuan in total, but the majority of the pork was for our own use. I preserve and smoke the meat every year and we can eat it for the whole year. [Zhang, 35 years old, female]

I raise cattle and pigs. The livestock is important for farming. Without cattle, I cannot do the farm work. I just keep one pig, because I cannot provide enough feed for more livestock. [Wu, 75 years old, male]

\subsubsection{Income from migrant work}

To increase their economic income, households in Donghe rely on migrant salaries rather than income from agriculture. Migrant work is more remunerative than farming, and a large part of the young farmers and middle-aged male farmers are rural-to-urban migrant workers in large cities. In all the respondents' households there was at least one member working as a rural-to-urban migrant. According to the respondents, the income from migrant salaries is the main source of household income. However, they also mentioned several problems relating to migrant work. For instance, the migrant salary is not regular and stable. In addition, due to the high expenditure in urban areas, it is difficult for migrant workers to save money.

I have two sons. One son works in a hardware factory and the other son in an insulation board factory in Guangdong Province. My eldest son can bring home 7000 to 8000 yuan per year, and the second son can bring back 5000 to 6000 yuan each year. It is more profitable than farming, but it is not a long-term plan because the income is not stable. [Feng, 60 years old, male]

I worked in a bar in Beijing for three years. It was not a career, just a job, earning 7000 to 10000 yuan per month. The income was not stable, but based on how much wine I sold. The expenses were extremely high in Beijing. What I earned 
was only to cover my own expenditures rather than to save money for buying a flat. [Pang, 27 years old, male]

My son works in a printing factory in Suzhou, earning 3000 yuan per month. He cannot save money because the living expenses are high. [Fu, 58 years old, female]

\subsubsection{The importance of agriculture to different groups}

All old respondents indicated that agriculture is important for them. Out of the five old interviewees in Donghe village, four $(60,66,78,75$ years old) are doing most of farm work in their household. All these four farmers keep cattle to assist them in the farming work and to save the cost of "helpers" for plowing. In addition, when they have finished their own plowing, they can rent out their cattle to other villagers for a small fee. The fifth old interviewee, who was 80 years old, is too old to attend to much farmland, so he just kept one mu to grow some vegetables. The old respondents gave several reasons for continuing the farm work. First, they are too old to find a job in urban areas. By farming they can be self-sufficient in food and earn some cash income. Second, by farming they relieve their children's economic burden. Rural pensions are meager (not more than 100 yuan per month) and insufficient for the living expenses of old farmers. Instead, according to Chinese traditions the children are expected to take care of the elderly. However, the younger generation itself already suffers from many economic difficulties as rural-to-urban migrant workers. Third, the old farmers have a deep-rooted conviction that it is the natural calling of farmers to attend to the land. The majority of the old people has suffered from famine, and therefore farming the land provides them with a sense of security. Fourth, the government promotes the development of agriculture, and has cancelled agricultural taxes while simultaneously increasing agricultural subsidies. This combination of policies (惠民政策) stimulates farmers to continue their agricultural activities.

Since I can't find a job outside and I have not enough money to start my own business, I have no choice but to do farm work, whether I like it or not. I can at least earn something from the crops and it is enough for the food consumption of my family. Agriculture is therefore important for me. [Feng, 60 years old, male]

My family depends on agriculture. My wife and I have to live from our crops. [Wu, 75 years old, male]

As a farmer, it is my duty to do farm work. Many young people say it is not costeffective and have little enthusiasm to fulfil farming activities. Where do we get food if no one wants to do the farming work? It would not be a problem that money can solve. When I was young, the collective commune system was adopted. When there was a natural disaster, no one had food and many people were 
starving during that period. [...] Although we are old, we should do what we can do, because young people are also under big pressure. What I can get from the fields is enough for my living and it reduces the burden on my children. [Feng, 78 years old, male]

The government policy is favorable and we can have subsidy for doing farm work. I and my wife can do some farm work and reduce our daily expenses. [Feng, 66 years old, male]

Within the middle-aged group of respondents there were diverging views on the importance of agriculture for the rural households. Most of the male middle-aged farmers held the opinion that agricultural income is not so important, while the majority of the female middle-aged respondents indicated that agriculture is quite important to them. According to the latter, it is more difficult for them to continue working outside as migrant workers. Often they are forced to return to the village due to limited employment opportunities in the cities and the strong traditional household hierarchy structure in the rural areas. The female farmers who are between 40 to 60 years old, are expected to run the household and take care of their young grandchildren and old parents. In addition, they are doing a major part of the farming work in Donghe village. For male middle-aged farmers it is also difficult to find employment in the cities as long-term migrant workers, but it is possible for them to do temporary jobs, for example, in construction. As such they still make an important contribution to the household income. As they can earn cash income from temporary work, they find farming relatively unimportant. In contrast, much of the female farmers'contribution to the household is invisible in terms of income. According to female farmers, they rely on farming to prove and make visible their value to the household.

I only grow some vegetables on farmland that is close to my house. Many people don't do farm work, and I am not going to do it either. The agricultural income is poor. Rarely people can make a fortune from doing farm work. Anything else would be more profitable. [Sun, 58 years old, male]

Although agriculture is important, cash income is more important. Thus, we should do whatever is more profitable. [Wu, 40 years old, male]

I have nothing to do but farm work. I don't care how much I can earn, as long as it is enough for what my family needs. At least it can provide food for us. [Wu, 43 years old, female]

Agriculture provides us food. In fact, I feel anxious that I could not do farm work in recent years because I have to take care of my grandchildren. Agricultural income is very important for me since I can't work outside. [Yuan, 50 years old, female] 
Out of the five young interviewees, only one (Zhang, 35 years old, female) fulfilled farming activities, whilst the other four even had no farming experience at all. Concerning the importance of agriculture, the young respondents stressed two aspects. On the one hand, for the household as a whole, agriculture is important for being self-sufficient in food and decreasing the living expenditures of the older generation. On the other hand, for young people personally, agriculture is not so important due to the low profitability. For them it is relatively easy to find employment as a rural-to-urban migrant worker. Their migrant work is much more remunerative than farming would be.

I think purely doing farm work is not even enough for a household's subsistence. Agriculture also needs investments, such as plowing, seeds and chemical fertilizers and pesticides. Sometimes, people in the village need the migrant workers in their household to remit money to them to maintain a basic living. [Pang, 27 years old, male]

Young people don't attach the same importance to agriculture as our parents do. We find it not profitable. The monthly income of working outside is perhaps higher than the annual income of farm work. However, agriculture can guarantee the basic life expenses, such as food, for rural people, although the income is not profitable. [Feng, 34 years old, male]

My father-in-law grows some crops and vegetables. The fields can at least satisfy the food demand of the family. And if young people work outside, the income can be improved. [Yang, 26 years old, female]

\subsubsection{Social aspects}

The social aspects addressed by the respondents concerned the problems encountered in rural-urban migrant work, and whether the migrant workers will return to the village or not.

\subsubsection{The temporary nature of migrant work}

A main characteristic of rural-to-urban migrant work is its temporary nature, which has two aspects. First, there is an (informal) age limit for migrant workers. According to the respondents, young farmers who are between 20 to 40 years old, and in particular people who are younger than 35 , easily find jobs in the cities, for example, in construction, in labor-intensive factories (shoes, clothing, electronics) in the south of China, or in bars and restaurants. In contrast, farmers who are over 40 years old are usually not hired by factories or the service industry. Their employment opportunities are largely restricted to working in construction or the mines. However, due to the stagnation in real estate development in China, the employment opportunities for migrant workers over 40 have sharply decreased. As old farmers (above 60 years old) are concerned, for them it is 
impossible to find a job in the cities. The second temporary aspect of migrant work is that many jobs are only short-term. Construction workers for instance, only have a job for several months per year. A large proportion of the migrant farmers from Donghe village are working outside as construction workers. When they finish a project, they have to return to the village to wait for the next job opportunity. Some even can only work for several days in a construction project and then have to wait in the city (with high costs of living) for many days to find another project.

Migrant work is not a long-term plan because it is hard to find a job when people are not young. It is quite common that migrant workers have to return to the village. [Sun, 58 years old, male]

It is not easy to find a job in urban areas. There is an age limit everywhere. Some factories will not employ people who are over 35 years old. But people who are 20 years old can easily find a job in factories. [Feng, 23 years old, female]

Construction workers do not have work every day. My son-in-law even cannot earn 100 yuan per day on average. It is maybe not that profitable. If he had a regular job, the income would not be bad. He has to wait for a new construction job in the cities, and the expenditure in the cities is high. [Feng, 78 years old, male]

Many people working at a construction site just return to the village every October. They stay at home until the next February or March. [Lin, 54 years old, female]

\subsubsection{Poor rights and decreasing migrant employment opportunities}

The rights of migrant workers are not well protected. The employment relationship is completely dominated by the employers, and migrant workers are easily fired. For instance, in the service industry, some employers hire new people each year. The reason is that new employees are more obedient and receive an internship salary, which is lower than a regular employee's salary.

I worked in a bar in Beijing for three years. The competition in Beijing is fierce, and we are easily fired. The company likes new employees because they are more obedient. The people who are not obedient or work there for a long time, generally one year, the company will just fire them because they think the experienced staff will be difficult to manage. You know, this is common in bars. So most people only work for a bar for at the most one year. [Pang, 27 years old, male]

Due to a lack of education and skills, a large proportion of the migrant workers from Donghe village are engaged in simple, physically-demanding work, such as jobs at construction sites and in mines. With the slow-down in real estate development in China, 
the employment prospects for migrant workers are grim. Construction workers are confronted with unemployment, and opportunities in the mining industry and some labor-intensive factories have decreased as well.

It's getting difficult to find a job at construction sites. By now there are enough buildings in the urban areas. And the mining work will eventually be mechanized. If farmers have no skills, it will be harder and harder to find a job outside. [Feng, 66 years old, male]

The employment situation this year is bad. People who used to go out in January went out in February this year. And some people just couldn't find a job at the mining sites. [Zhang, 35 years old, female]

\subsubsection{Migrant workers returning to the village}

Most migrant workers from Donghe do not remain in the cities but return to the village. Out of 17 interviewees, 15 respondents expected that in the end the migrant workers from their household would come back to the village. Only one of the respondents bought a flat in Hanyin, the county capital, for her son who is currently a migrant worker in Ningbo city (in the south of China). The other respondent wants to settle down in the city if she manages to establish her own business there, but she admitted that this will be difficult. Only few villagers can save enough money from migrant work to buy an apartment in the nearby county capital, although the majority of respondents considered this to be the ideal situation. In that case, the younger generation could live there and try to start their own business, whereas the older people could attend to their young grandchildren in the county capital, but at the same time keep their house in the village so that they could easily return to do farming work.

I saved money from working outside and bought a flat for my son. I and my husband worked very hard to save some money. I hope my son can run his own business in the county capital. As for me, I plan to cultivate crops in the village, and simultaneously help my son to attend to their children in the city. [Lin, 54 years old, female]

The majority of the interviewees indicated that for them migrant work is a "job" rather than a "career". Therefore, most migrant workers try to save money for a future "career" in the village or the local county capital. For the middle-aged returned migrant workers this means continuing the farming work to provide them and their families with food. The young migrant workers often have the ambition to use their savings to start their own business, but they haven't figured out yet what types of business to run, where and how. It is difficult for young migrant workers to settle down in urban areas, but it is also challenging for them to return to the rural areas to have a "career". Although all young interviewees expressed their preferred choice of settling down in either the urban areas or the rural areas, concrete plans for the future were lacking. 
I have some savings from working outside when I was young. And in the village, we can produce food and vegetable. The living expenses in my village are lower. Settling down in the city is hard. Most of us have to come back. The houses and living in the city are too expensive. Most people just earn enough money and come back to the village. [Sun, 58 years old, male]

Most migrant workers are people who dropped out from middle or high school, so they have a poor educational background. The development opportunities for them are very limited. Many people want to open their own business. For instance, my elder brother plans to have a livestock farm in the village. [...] The income from working outside is not sufficient to settle down in the city, and they have to come back. [Feng, 23 years old, female]

\subsubsection{Environmental aspects}

The environmental aspects of farming addressed by the respondents concerned the organic production of rice and application of agrochemicals, and the respondents' opinion about the "Grain for green" program, which aims to reduce soil erosion on sloping lands.

\subsubsection{Organic rice production and agrochemical use}

Since 2013, the organic rice project has rapidly expanded in Donghe village. The majority of the respondents were participating, and all interviewees expressed their preference for organic rice production. Several factors contributing to the popularity of organic rice were mentioned: the higher price compared to conventional rice, and the free seeds, organic fertilizer and ducks provided by the company. In addition the farmers also appreciated the opportunity to abandon agrochemicals in rice production, which they considered more healthy for people and friendly for the environment. The importance of a healthy environment was frequently stressed, and also in conventional production the level of application of chemical fertilizers and pesticides seemed to be low. Problems of overuse or misuse of agrochemicals were not mentioned by the respondents.

During the cultivation process, no pesticide is needed, which is more environment-friendly. The cultivation of conventional rice requires pesticide, which is harmful for people's health. Although we don't apply pesticide, there are not many pests in the paddy field, because we use ducks and pest-killing lamps. [Feng, 60 years old, male]

My parents-in-law plant organic rice, and they also use farm manure instead of chemical pesticide to spray the vegetables. [Yang, 26 years old, female] 
I would like to plant organic rice. Then we don't have to spray pesticides and use chemical fertilizer, which is safer for the environment and healthier for the local residents. [Yuan, 50 years old, female]

Although chemical fertilizer is more efficient, we need to apply manure-based fertilizer in the long run. At least, we should combine chemical fertilizers with manure-based fertilizers. The sole application of the chemical fertilizer would harden the soil. [Feng, 66 years old, male]

\subsubsection{Farmers' perspectives on the "Grain for green" program}

Most respondents were positive about the "Grain for green" program. They provided three reasons for this. First, due to mountainous landscape, a large proportion of the dryland fields is located on remote mountain slopes, which is inconvenient for farming and time-consuming. In addition, the soil quality of these fields is relatively low, which results in low yields. Second, the "Grain for green" program is profitable for the farmers in Donghe. Farmers receive annual subsidies from the local government according to the size of their land holding and the price of the crops. Moreover, the saved farming labor can be shifted to more remunerative sectors, such as rural-to-urban migrant work. A third reason is the ecological function of the "Grain for green" program. According to the farmers, there were severe problems with water loss and soil erosion in Donghe due to the steep sloping land, whereas the conversion to forest has reduced these problems.

The "Grain for green" project is a good policy. Planting more trees can prevent the loss of soil and water. And fewer fields to farm mean less labor, which saves time to fulfil more remunerative work. In addition, we receive subsidies from the government. [Feng, 66 years old, male]

The dryland up the mountain slopes is not fertile and the work is hard. With the "Grain for green" project at least we get some subsidy from the government. [Wu, 43 years old, female]

Local farmers don't want to keep the fields far away from their home. If we don't change the farmland into forest land, it is not beneficial. But if we join "Grain for green", we can have some subsidy. [Lin, 54 years old, female]

\subsection{DISCUSSION}

In this section, we present the main findings by summarizing the problems of farmers in Donghe from the perspective of the respondents, and how these are addressed, as well as the respondents' views on the future development of agriculture in Donghe village. We then compare the main findings with those of other studies, and end with an out- 
look by reflecting on the sustainability of farming in Donghe and the implications for policy.

\subsubsection{Main findings}

\subsubsection{Problems and solutions}

From an economic point of view, the major problem of agriculture in Donghe is that the income that can be generated from farming is largely insufficient to cover household expenses. For example, the net income from one mu of rice ranges between 350 and 650 yuan, and with 1 to 4 mu paddy land per household, the household income from rice is only a few thousand yuan at best. The difference in net income per mu between conventional and organic rice does not translate in large differences in household income in absolute terms, because the land holdings are small and a substantial part of the rice harvest is for domestic consumption. The common solution for the low agricultural income in Donghe is to engage in off-farm work. In almost every household, one or more members work as rural-urban migrants, often in the major cities of South- and East-China. Overall, migrant work is the dominant source of household income in Donghe. The problem with migrant work, however, is that it does not provide social security. For low-skilled migrants above 35 , it is difficult to find permanent employment in urban areas, and for migrants older than 60 working outside the village is no longer an option. For the people of Donghe, their land therefore functions as a social safety net. It provides sufficient and diverse food (rice, oil, vegetables, meat) for those that have returned to the village, temporarily or permanently. The older generation prefers village life over life in the city, but many of the younger generation have no experience with farming, and would rather settle down in urban areas and start a business. Due to the Chinese household registration rules (hukou, Chapter 1), permanent settling in the larger cities is very difficult for villagers. A solution, as indicated by the respondents, may be to settle in the county capital, a relatively nearby, smaller city, which at least offers more business opportunities than Donghe village. Concerning environmental problems, the situation in Donghe appeared to be rather favorable. Although chemical fertilizers and pesticides are used in conventional rice farming, the farmers showed awareness of the environmental and health problems associated with intensive use of these agrochemicals and it seemed that the application rates were not excessive. Moreover, many farmers had switched or planned to switch to organic rice production, which excludes the use of agrochemicals. Another risk of intensive farming, in particular on sloping lands, is soil erosion and water run-off. In Donghe this risk was effectively managed by cultivating the rice on terraced paddy fields and by converting the more remote dryland fields, higher up the mountain slopes, into forest by participating in the national "Grain for green" program. 


\subsubsection{The future development of agriculture in Donghe village}

All respondents indicated a preference for organic rice production given its economic and environmental benefits, and expected that in Donghe the area of organic rice would rapidly expand in the near future. Whether or when this would also involve an enlargement of scale is uncertain. The middle-aged and old farmers appreciated that the current system of production contracts with the private company allowed them to combine market-oriented and subsistence farming, and thus to use their land as a social safety net. However, as the younger generation showed little enthusiasm for farming, on the longer term many households in Donghe may prefer to transfer their land rights and rent out their land to the company. In that case, most of the paddy land would then be managed as a single farm, and the villagers have the option to be hired as farm workers or to work off-farm. In fact, respondents indicated that many of the younger returning migrants intended to start a business in the village, rather than continuing farming in the same way as the older generation. Although these plans were still rather vague, it can be expected that household livelihoods in Donghe will become more diversified in the future.

\subsubsection{Comparison with other studies}

The importance to rural households of urban migrant salaries on the one hand, and of land as a social safety net on the other, is a commonly observed phenomenon in China (e.g., Van der Ploeg \& Ye, 2010; Wang et al., 2013; Tian et al., 2016). Also the related phenomenon of "circular migration" is well-known, i.e., young people move to the cities to work, but return to the villages when they get older and have increasing difficulty in finding employment (Hu et al., 2011). A more remarkable finding is the relatively fast and wide adoption of organic farming in Donghe. Over the past 15 years, 'Westernstyle' certified organic agriculture has been rapidly expanding in China (Kuehl \& Liu, 2014; Scott et al., 2014). By 2015, there were already 1.6 million hectares of land under organic production or in conversion, although this still represents less than $1 \%$ of the total agricultural land (Willer \& Lernoud, 2017). The expansion of organic production was first mainly fueled by the export market, but due to a series of food scandals the demand for organic, completely "pollution-free" food has increased strongly in China (Qiao, 2011; Scott et al., 2014; Willer \& Lernoud, 2017). Currently, the Chinese domestic market for organic food is the third largest in the world, after the USA and EU, and China has become globally the largest producer of organic cereals, including rice (Willer \& Lernoud, 2017). As also was observed in Donghe, the Chinese organic food sector is organized in a top-down manner and driven by the market and local governments rather than by the central government. Typically, a large trading company with good access to the market subcontracts a local company which selects farmers and coordinates the production activities (Sanders \& Xiao 2010; Kuehl \& Liu, 2014). The large company also takes care of the costly certification process, which is the major barrier for small- 
holder farmers to engage in organic agriculture independently from these large companies (Chen 2014; Kuehl \& Liu, 2014). Whereas the central government is reluctant to promote organic agriculture as it fears that the lower yield levels conflict with its goal of national food security, regional and local governments are often strong supporters (Scott et al., 2014). Not only do they see organic agriculture as a way to increase farmers' income and boost local economic development, they can also obtain commission by acting as broker in negotiating land transfers from the farmers to the private companies (Scott et al., 2014). This may have been a reason for the village leader in Donghe to favor the transfer of farmers' land rights to Xinxin Rice Company, in addition to the advantages for the farmers he mentioned (see section 6.3.3).

Recent publications have listed several factors that may either hinder or promote the adoption of ecological or organic production methods by Chinese farmers (Wang et al., 2007; Li et al., 2011; Qiao, 2011; Scott et al., 2014). In Donghe, the conditions are favorable with respect to at least five of these factors. First, farmers in Donghe appeared well aware of the health and environmental risks of intensive use of agrochemicals. Second, the organic rice production methods are not complicated and/or not very different from what farmers are familiar with, thus minimizing the need for additional training. For example, the rice-duck mutualism used in Donghe builds on a well-known Chinese tradition (Suh, 2011). Third, the organic alternative is more profitable than conventional rice production. This is important, because environmental and health benefits alone are not enough for most farmers to change their production methods (Ma et al., 2009). Fourth, other ways to make farming more profitable, e.g., by making it less labor-intensive through mechanization, are not an option due to the steep slopes in Donghe. Fifth, organic farming can be combined with other local, high-value added economic activities. In Donghe these activities are primarily associated with the development of agritourism, based on its attractive landscape with rice terraces.

\subsubsection{Outlook}

In this final section we reflect on the long-term sustainability of the strategies followed by the farmers in Donghe and how policy measures could support a more sustainable development of agriculture in this village and other villages with similar conditions.

For the near future, a nearly full-scale transition to organic rice production can be expected for Donghe. The long-term economic sustainability of this transition can be questioned, however. In China, the major driver in the development of organic agriculture is public concern about food safety rather than about the environmental impacts of intensive use of chemical fertilizers and pesticides in food production (Kuehl \& Liu, 2014; Scott et al., 2014). More directly, expansion of organic production is not driven by governmental policies stimulating a bottom-up transition, but top-down by large commercial companies looking for the most profitable opportunities for production (Kuehl 
\& Liu, 2014). It is not unlikely that Donghe will be outcompeted in that respect, given the mountainous terrain preventing mechanization of farming. In addition, Donghe is rather remotely located which enhances the transportation costs and limits access to the largest domestic market for organic food, formed by the rising middle class in China's big cities (Sanders \& Xiao 2010). As for the farmers in Donghe, organic production is something more or less "imposed" on them, without much attention for training and internalization of the associated values. Therefore, they may easily switch back to conventional farming when the price advantage and other assets offered by the contracting company disappear.

These developments might be counteracted by stronger promotion of the currently underdeveloped agri-tourism in Donghe and integrating this with organic production, for example, by conservation of the cultural heritage landscape and selling high-quality, local organic food products to tourists. This type of development path has been frequently suggested by scholars (e.g., Wang et al. 2007; Li et al. 2011), and is also popular with local governments (Scott et al., 2014). Although at national scale this will remain a niche market, it appears that Donghe with its very scenic agricultural landscape and acceptable travelling distance to major urban areas such as Ankang city, is wellpositioned in this respect. The development and marketing of local specialty products may also provide interesting business opportunities for migrant workers returning to the village.

Another element to make ecological agriculture more sustainable, is to pay farmers for ecosystem services (Li et al. 2011). The subsidies for converting sloping fields to forest that farmers in Donghe receive from the "Grain for grain" program are an example of this. It is uncertain, however, what will happen in case the program ends. Research conducted in the Loess Plateau region in the north of Shaanxi Province, showed that just like in Donghe, farmers mostly held a positive attitude towards the "Grain for green" programme and its effectiveness in environmental protection, but also that part of the farmers considered to reconvert their fields in case the subsidies would stop ( $\mathrm{Hu}$ et al., 2006; Lian et al., 2007).

Finally, the current system of "circular migration", with young people moving to the cities to work, but returning to the villages and farming when they get older, does not seem to be sustainable in the long run. Currently, it is still popular among the migrant workers from Donghe to use their savings to build a new house in the village, but many of the younger generation do not want to engage in farming anymore and prefer to start a self-employed business in the city. Moreover, the opportunity to return to farming diminishes as households in the villages may gradually transfer their land rights to a few other households or to private companies, such as the Xinxin Rice Company in Donghe. However, as pointed out before, settling down in the large cities is very difficult for people with a rural hukou. A sustainable compromise could be to settle in the small- 
er county capital, as some of the migrant workers from Donghe were preparing to do. A policy of relaxing the hukou rules for smaller cities would support this, and in addition to stimulating local economic development, it would also remove some of the urbanization pressure from the major cities (Tian et al., 2016). 

Chapter

Comparing high-level strategies for agricultural development with the perspectives of Chinese farmer 
Abstract: In China, the direction of agricultural development is subject to intensive debate. The central government aims at "modernization", which includes technologybased intensification and increased farm size to improve both land and labor productivity. In the scholarly literature, the government's modernization strategy is criticized mainly from two sides. From a social point of view, it is stressed that rural households need their land as a social safety net. As an alternative strategy, these scholars therefore propose to conserve small-scale agriculture. From an environmental point of view, the long-term unsustainability of current agriculture is emphasized. As an alternative to the high input - high output modernization strategy, these scholars promote a transition to Chinese Ecological Agriculture. All three strategies described above aim at sustainable agricultural development, but strategies developed at a high-level level by policymakers and scientists will only work when they are accepted and supported by the key decision makers "on the ground", the farmers. The probability of farmer acceptance and support is greatly enhanced when their perspectives and diverse local conditions have been taken into account. In this chapter, we assess the extent to which the three strategies for sustainable agricultural development address the problems and solutions as perceived by Chinese farmers from different agricultural contexts. We first map the assumptions underlying these three strategies concerning farmers' key problems and the preferred ways to solve these problems. We then present our findings on farmers' perspectives on problems and solutions, based on in-depth interviews in three villages located in contrasting agro-ecological regions in Shaanxi Province, and assess how these match with the assumptions underlying the three strategies. We conclude by summarizing the main findings and identifying ways how a high-level strategy for sustainable agricultural development could take farmers' perspectives into account. 


\subsection{INTRODUCTION}

In China, the direction of agricultural development is subject to intensive debate. The central government aims at "modernization", which includes technology-based intensification and increased farm size to improve both land and labor productivity (Huang, 2011; 2014). Agricultural development is high on China's political agenda: ever since 2004, the Central Document No.1 ${ }^{45}$ has focused on "the triple problem of agriculture, farmers and villages" (三农问题 san nong wen ti), with telling titles, such as “Speeding Up the Modernization of Agriculture and Further Strengthening the Vitality of Rural Growth" (2013), "Deepening Rural Reform and Developing a Modern Agriculture" (2014), and "Strengthening the Reform and Innovation, and Accelerating the Construction of Modern Agriculture" (2015). National policies to support farmers and promote agricultural development have included the removal of agricultural tax ${ }^{46}$ in 2006, direct subsidies to grain growers and subsidies for the procurement of agricultural machinery in 2004, and subsidies for seeds of improved varieties in 2009. The governmental strategy for agricultural development aims to address the combined problem of low economic profitability of small-scale farming and rapid urbanization (He, 2014b). This combination of factors has already resulted in the phenomenon of farmland abandonment, and aroused fears about "who will plant the land and who will feed the large Chinese population?" (Guan \& Wang, 2013).

In the scholarly literature, the government's modernization strategy is criticized mainly from two sides: from a social and from an environmental perspective. From a social point of view, it is stressed that the current urbanization process is actually a form of "half-urbanization", meaning that rural-urban migrants cannot settle down permanently in cities and also do not have the same social rights as urban residents (Hao, 2014; Ong, 2014; Sun, et al., 2013; Wang \& Weaver, 2013; Wang \& Wan, 2014; Zhang, 2008). As a consequence of the insecure employment and poor social position of rural-urban migrant workers and the absence of a well-developed social security system for rural residents, the land and the food it can provide function as a social safety net for rural households. As an alternative strategy, these scholars therefore propose to conserve small-scale agriculture and to stop promoting rapid urbanization (He, 2013a, 2014a, 2014b; Hebel, 2003; Ma, et al., 2015; Schneider, 2014; Zhang, 2013). From the environmental point of view, the long-term unsustainability of current agriculture is emphasized. Pollution of land and water is widespread due to large-scale overuse of agrochemicals, ground water resources are rapidly being depleted for irrigation and large areas of sloping farmland are degraded due to soil erosion (Ren, et al., 2009; Wang,

\footnotetext{
${ }^{45}$ Central Document No.1 is the first policy statement released at the start of each year by the CPC Central Committee and the State Council. It addresses what are considered the most significant policy issues in China. See for more details [in Chinese]: http://baike.baidu.com/subview/1391355/19008501.htm

${ }^{46}$ Agricultural tax had a history in China of about 2600 years.
} 
2013; Zhou, 2014a). As an alternative to the high input - high output modernization strategy, these scholars promote a transition to ecological agriculture. Chinese Ecological Agriculture (CEA) focusses on quality rather than quantity of production and aims to maximize the internal recycling of inputs and outputs, thus minimizing both the need for external inputs and the level of harmful emissions from agriculture (Li et al., 2011; Wang et al., 2007; Ye, et al., 2002).

All three strategies described above aim at sustainable agricultural development, but strategies developed at a high-level level by policymakers and scientists will only work when they are accepted and supported by the key decision makers "on the ground", the farmers (Pimbert, 2004; Ma et al., 2009). The probability of farmer acceptance and support is greatly enhanced when their perspectives and diverse local conditions have been taken into account (Fujisaka 1989, 1994; Grudens-Schuck, 2000). In this chapter, we assess the extent to which the three strategies for sustainable agricultural development address the problems and solutions as perceived by Chinese farmers from different agricultural contexts ${ }^{47}$. We first map the assumptions underlying these three strategies concerning farmers' key problems and the preferred ways to solve these problems (section 7.2). We then present our findings on farmers' perspectives on problems and solutions, based on in-depth interviews in three villages located in contrasting agroecological regions in Shaanxi Province (section 7.3), and assess how these match with the assumptions underlying the three strategies (section 7.4). In the final section (7.5), we summarize the main findings and discuss how a high-level strategy for sustainable agricultural development could take farmers' perspectives into account.

\subsection{ASSUMPTIONS CONCERNING FARMERS UNDERLYING HIGH-LEVEL STRATEGIES}

In this section, we map the assumptions underlying three high-level strategies for sustainable development of agriculture in China. This concerns the governmental modernization strategy and the two prominent alternatives: conservation of small-scale agriculture and transition to Chinese Ecological Agriculture. An extensive description and assessment of these strategies can be found in Chapter 2. Here, we concentrate on the generic assumptions made concerning farmers' key problems and the preferred way to solve these problems. For this purpose, we follow the common definition of a problem as a gap between the current and the desired situation, and of a solution as the preferred option (or combination of options) from the set of options available to solve the problem (Enserink et al., 2010). We therefore distinguish for each of the strategies

\footnotetext{
${ }^{47}$ In this chapter, we use the term 'farmers' as synonymous to 'rural residents'. As explained in Chapter 1, due to the Household Registration System (hukou) and the Household Responsibility System, everyone who is formally a rural resident in China has the right of use of a piece of the collective farmland of the village.
} 
between assumptions concerning (1) farmers' current situation, (2) farmers' desired situation, (3) options available to farmers, and (4) farmers' preferred solution. These assumptions are described below per strategy and summarized in Table 7.1.

\subsubsection{Modernization strategy: assumptions}

Farmers' current situation is most prominently characterized by income issues. Due to the very small land holdings per household, income from agriculture is low and insufficient to cover household expenses. Rural households increase their income by engaging in migrant work in cities, which is usually a far more profitable activity than farming. However, the gap between rural and urban incomes is still widening, and farmers would like to increase their household income and raise their standard of living. Most farmers prefer to transfer their land rights to other farmers or private companies, quit farming, and (continue to) work in urban areas. A minority of farmers is interested to continue with agriculture and to further develop their farm, both in scale and in modern production methods. This is possible because there are sufficient urban employment opportunities for all those wishing to exit from farming, and for those continuing with agriculture, 'modern', larger-scale farms can be formed that rovide an adequate hoiusehold income, at least comparable to urban incomes. The preferred solution is therefore a combination of scale-enlargement and technological development in agriculture, and urbanization providing employment for the rural labor surplus.

\subsubsection{Conservation of small-scale agriculture: assumptions}

The most prominent characteristics of farmers' current situation concern the lack of social rights and income security. In the cities, rural-urban migrant workers face a highly insecure employment situation and their social rights position, e.g., concerning access to education and health services, is very poor. At the same time, the rural social security system is much less developed than the urban system. The monthly pension benefits, for example, are very low. Amidst all this insecurity, farmers want at least to have a guaranteed and suffient supply of food to feed their families, independent of off-farm employment. In the city, you may starve if you don't have money, but in the village you can grow your own food. Therefore, farmers prefer to live in the rural area, and use at least part of their land for self-subsistence. This is possible, because the current farm size is small but large enough to provide enough food for the household members in the village and to function as a social safety net in case of unemployment and old age. Without changing the current scale of agriculture, labor productivity can still be substantially enhanced through farmland consolidation, i.e., merging of scattered plots into single fields by exchange between households. The preferred solution is therefore the conservation of small-scale agriculture, where possible combined with farmland consoldation, and return of middle-aged migrant workers to farming. 


\subsubsection{Transition to Chinese Ecological Agriculture: assumptions}

Farmers' current situation is characterized by severe and urgent environmental problems. Due to the intensive use of agrochemicals, the health of rural residents is negatively affected by high levels of pollution of soil, water and food. The productivity of the land is increasingly reduced by soil and water pollution, loss of biodiversity, and loss of arable land due to soil erosion. As many farmers prefer to stay in the rural areas, and continue with farming or start a business in the village, they highly value a clean and healthy environment and production methods that minimize the use of agrochemicals and conserve the natural resources. These methods are available and feasible, and also acceptable, because the yield is only slightly lower than in conventional farming, whereas the better quality results in a higher price. Farmers are willing to spend time and effort in learning the skills required for the transition to these ecological farming methods. The market for high-quality, ecologically-produced food and related services is large enough to provide all farmers who want to switch with an adequate agricultural income. An additional source of income are payments to the farmers for ecosystem services and conservation of natural resources, e.g., in the form of subsidies for converting arable land to forest. The preferred solution is therefore a transition to Chinese Ecological Agriculture, which not only includes the adoption of ecological farming methods but also the development of rural agri-businesses, involving local processing and marketing of high-quality, "pollution-free" products and agritourism. 
Table 7.1 Assumptions concerning farmers underlying three strategies for agricultural development

\begin{tabular}{|c|c|c|c|}
\hline Questions & Modernization & $\begin{array}{l}\text { Conservation of small-scale } \\
\text { agriculture }\end{array}$ & Chinese Ecological Agriculture \\
\hline $\begin{array}{l}\text { Farmers' } \\
\text { current } \\
\text { situation }\end{array}$ & $\begin{array}{l}\text { - Low agricultural income, } \\
\text { mainly due to small-scale } \\
\text { agriculture } \\
\text { - Migrant work in urban areas - } \\
\text { more profitable than } \\
\text { farming }\end{array}$ & $\begin{array}{l}\text { - Insecure employment and lack of - } \\
\text { basic social rights in the cities for } \\
\text { rural-urban migrant workers } \\
\text { - Insufficient social security system } \\
\text { for rural residents in case of } \\
\text { illness, unemployment and old age }\end{array}$ & $\begin{array}{l}\text { - Pollution of soil, water and } \\
\text { food products by } \\
\text { agrochemicals negatively } \\
\text { affect health } \\
\text { - Pollution and depletion of } \\
\text { soil and water resources, and } \\
\text { loss of biodiversity reduce } \\
\text { agricultural productivity and } \\
\text { provision of food }\end{array}$ \\
\hline $\begin{array}{l}\text { Farmers' } \\
\text { desired } \\
\text { situation }\end{array}$ & $\begin{array}{l}\text { - Higher household income } \\
\text { and standard of living } \\
\text { - Most farmers prefer to } \\
\text { transfer land rights, exit } \\
\text { from farming and work in } \\
\text { the urban areas } \\
\text { - Few farmers prefer to stay } \\
\text { in rural areas, expand farm } \\
\text { size and improve agricultural } \\
\text { income }\end{array}$ & $\begin{array}{l}\text { - Secure source of food and income,- } \\
\text { and a decent life } \\
\text { - Farmers, especially the middle- } \\
\text { aged and old, prefer to live in the } \\
\text { rural areas } \\
\text { - Farmers prefer to keep their land - } \\
\text { and use it to provide their } \\
\text { household with food }\end{array}$ & $\begin{array}{l}\text { - Pollution-free agricultural } \\
\text { - Lonvironment and food } \\
\text { natural resources for a } \\
\text { productive agriculture } \\
\text { - Many farmers prefer to live } \\
\text { in the rural areas and } \\
\text { continue farming or start } \\
\text { rural business }\end{array}$ \\
\hline $\begin{array}{l}\text { Options } \\
\text { available to } \\
\text { farmers }\end{array}$ & $\begin{array}{l}\text { - Sufficient urban } \\
\text { employment opportunities } \\
\text { for farmers exiting } \\
\text { agriculture } \\
\text { - Sufficient household income } \\
\text { for farmers focussing on } \\
\text { 'modern' (larger-scale, high - } \\
\text { input) agriculture }\end{array}$ & $\begin{array}{l}\text { - Farmers' land holdings provide } \\
\text { enough food for the household } \\
\text { members staying in the village } \\
\text { - Labor productivity can be } \\
\text { improved considerably through - } \\
\text { farmland consolidation } \\
\text { - Sufficient household income and } \\
\text { social security by combining } \\
\text { farming and migrant work }\end{array}$ & $\begin{array}{l}\text { - No or strongly reduced use } \\
\text { of chemical fertilizers and } \\
\text { pesticides, without strong } \\
\text { reduction in yields } \\
\text { - Production methods that } \\
\text { maximize internal recycling } \\
\text { and conserve resources are } \\
\text { available, feasible, } \\
\text { acceptable and transferrable } \\
\text { - Large market for high- } \\
\text { quality, ecologically- } \\
\text { produced food and related } \\
\text { services } \\
\text { - Farmers receive payments } \\
\text { for ecosystem services and } \\
\text { conservation of natural } \\
\text { resources }\end{array}$ \\
\hline $\begin{array}{l}\text { Farmers' } \\
\text { preferred } \\
\text { solution }\end{array}$ & $\begin{array}{l}\text { - Larger-scale and } \\
\text { technologically-modern } \\
\text { farms, for a few farmers } \\
\text { - Exit from farming and urban } \\
\text { employment in industry and - } \\
\text { service sectors, for most } \\
\text { farmers }\end{array}$ & $\begin{array}{l}\text { - Conservation of small-scale } \\
\text { agriculture, where possible } \\
\text { combined with farmland } \\
\text { consolidation } \\
\text { - Return to farming (for middle- } \\
\text { aged and old farmers) when off- } \\
\text { farm work is not available }\end{array}$ & $\begin{array}{l}\text { - Transition to Chinese } \\
\text { Ecological Agriculture } \\
\text { - Stimulating rural } \\
\text { employment by local } \\
\text { processing and marketing of } \\
\text { high-quality, "pollution-free" } \\
\text { products and agritourism }\end{array}$ \\
\hline
\end{tabular}




\subsection{FARMERS' PERSPECTIVES ON PROBLEMS AND SOLUTIONS}

In this section, we present the perspectives of respondents on problems and solutions of farming households in three villages in Shaanxi Province: Daijia, Chiniuwa and Donghe (Figure 7.1). These perspectives are based on in-depth interviews of about 15 farmers per village and represent the situation of 2015 (see Chapters 4, 5 and 6 for extensive descriptions). To enable a comparison with the assumptions concerning farmers underlying the high-level strategies, we distinguish between farmers' perspectives on their current situation, desired situation, available (or not available) options, and preferred solution. These perspectives are described below per village and summarized in Table 7.2.

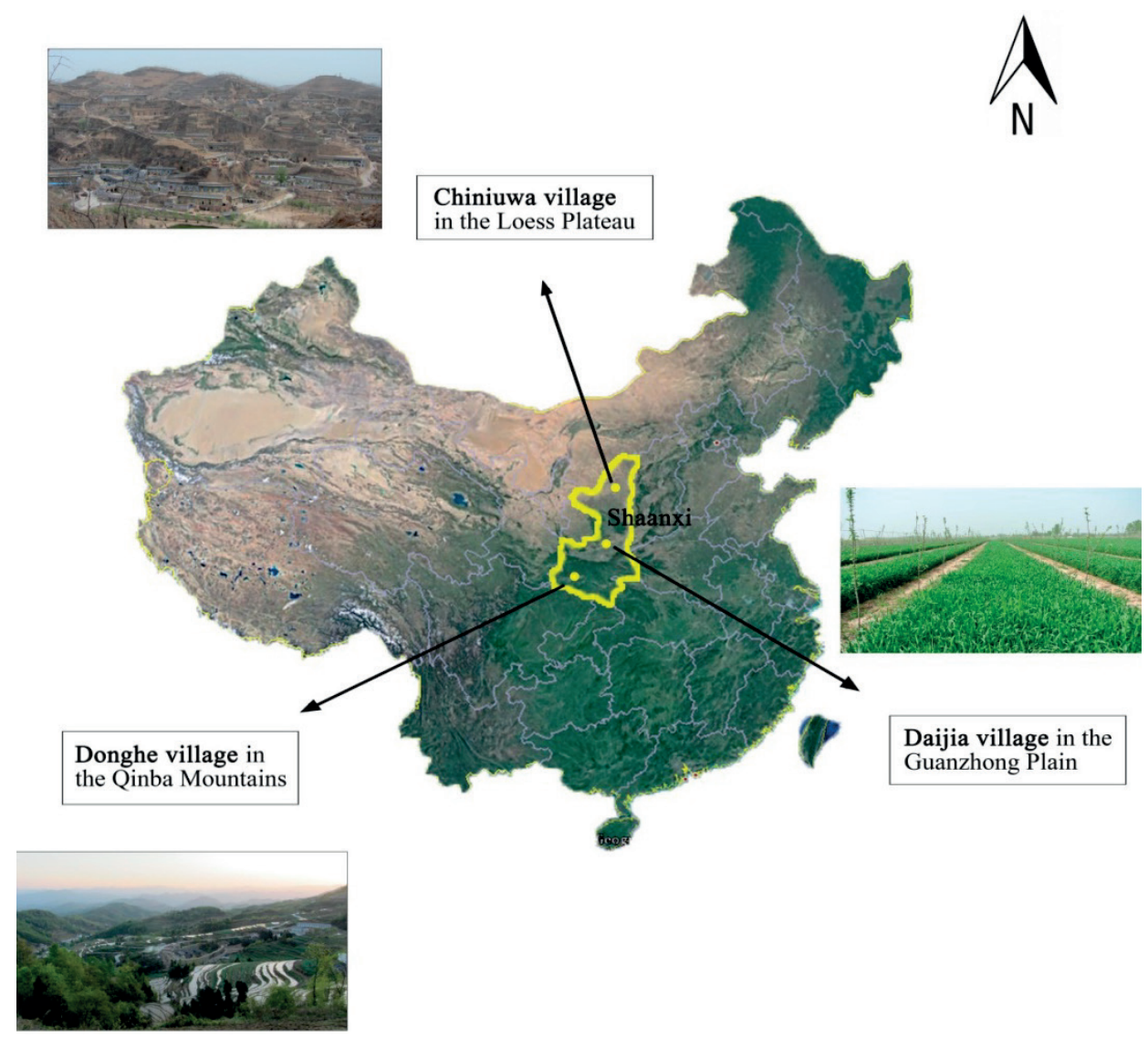

Figure 7.1 Location of Daijia, Chiniuwa and Donghe villages in Shaanxi Province, China 


\subsubsection{Farmers'perspectives in Daijia village}

Diajia is a village located in the Guanzhong Plain in the central part of Shaanxi Province. The conditions are favorable for farming, with fertile soil, flat terrain, and good water supply. The dominant system is double-cropping of maize and winter wheat. The grain yields are high due to use of improved varieties and intensive use of chemical fertilizer and pesticides. As the grain production is largely mechanized, there is sufficient labor available for the cultivation of time-intensive fruit crops, mainly apples. Due to the high input of agrochemicals in both grains and apples, some problems with pollution of soil and water occur. Although the income from apples is much higher than from grain crops, off-farm work is considered necessary to cover major household expenditures and is the main source of income in Daijia. Young farmers work as rural-urban migrants in major cities, whereas middle-aged farmers do temporary local off-farm work. The farming work is mostly done by middle-aged and old farmers. Two larger-scale farms (tree nurseries) have developed in the village, but only a few farmers rent out their land as the farmland is considered important to provide the household with food. Given the high costs of, for example, education and medical care, farmers would like to improve their household income, and, connected to that, have better and more stable off-farm employment opportunities. However, migrant work in urban areas is poorly paid and insecure, whereas the opportunities for local off-farm employment are decreasing due to a slow-down in the construction sector. The farmers worry about the pollution, and would rather have a healthy and clean agricultural environment, but reducing the input of agrochemical inputs is not considered as an option, because this will result in lower yields. Middle-aged and old farmers prefer to live in the village and be self-sufficient in food production, but most young farmers prefer to settle down permanently in the cities, and exit from farming. For the near future, in particular middle-aged farmers intend to increase their agricultural income by expanding the more profitable cultivation of apples at the expense of grain production. For the more distant future, the farmers expect that many migrant workers will not return to the village and farming, and would rather rent out the land. Given the favorable conditions for agriculture and the proximity of major urban centres, they expect that there will be people interested in developing modern, larger-scale farms in Daijia.

\subsubsection{Farmers' perspectives in Chiniuwa village}

Chiniuwa is a village located in the Loess Plateau region in the north of Shaanxi Province. The Chinese Loess Plateau is highly prone to soil erosion due to a combination of soil type, steep slopes, and a semi-arid climate with a highly uneven temporal distribution of precipitation. The dominant crop in Chiniuwa is jujube, a drought-tolerant fruit tree planted on terraced hillsides. According to the farmers, the cultivation of jujube was a highly successful way to deal with the difficult conditions for agriculture in the 
Loess Plateau region. The terraces and trees prevented soil erosion, the dry climate was favorable for high quality fruits, and due to the high market price the cash income from jujubes could be even higher than from migrant salaries. However, since 2012, the jujube harvest failed for three consecutive years and the prices dropped, reducing the income from jujube to almost nil. In response, farmers have strongly reduced their investments in jujube production. At the same time, a slow-down in construction activity in China has severely limited the off-farm employment opportunities for unskilled work, and many migrant workers are forced to stay in the village. Due to the absence of a primary school in Chiniuwa, young migrant parents have to bring their children along and can save little money due to the high costs of education in the city. It also restricts their employment opportunities to nearby cities. Unfortunately, due to the unfavorable growing conditions, the households in Chiniuwa are not self-sufficient in food production. As the farmers believe that the harvest failures of jujube are due to a permanent change in climate, several have started to replace the jujube trees with annual food crops, such as millets, to improve self-sufficiency. The farmes are generally quite uncertain and rather pessimistic about the future development of agriculture in Chiniuwa. Many do no longer see a future for jujube as the main cash crop. One of the villagers bought a drying oven to prevent rotting of the jujube fruits and some other farmers started to experiment with alternative cash crops (walnuts, thorowax), but whether these will be successful in providing sufficient cash income is still highly uncertain. A structural shift towards off-farm sources of income and exit from farming in combination with scale-enlargement by remaining farmers is not seen as a likely future direction, given decreasing off-farm employment opportunities and the limited opportunities for commercial agriculture in Chiniuwa.

\subsubsection{Farmers' perspectives in Donghe village}

Donghe is a village located in the Qinba Mountains in the south of Shaanxi Province. In this region, the climatic conditions are favorable for agriculture, but the steep slopes make the fields less accessible and hinder mechanization. The dominant system is double-cropping of rice and oilseed rape. According to the farmers, rice is their major source of agricultural income, but due to the very small land holdings the profits are not sufficient to cover household expenses. Off-farm migrant work in cities by young and middle-aged farmers is nowadays the main source of household income. The ruralurban migrant work is temporary and short-term, however, and does not provide social security. Beyond the age of 35 , it is increasingly difficult for the farmers to find employment as migrant worker. As most households in Donghe are self-sufficient in food production, farming plays an important role as a social safety net. However, the younger generation has no or little experience with farming and prefers to settle down in cities. Although this is very difficult where it concerns the large cities, settling down in nearby smaller cities and towns appears a feasible compromise. Major environmental 
risks such as soil erosion and agrochemical pollution are effectively managed according to the farmers, by conversion of remote, sloping dryland fields to forest, subsidized by the national "Grain for green" program, and by an ongoing transition to organic rice production by contract farming for a private company. The local and regional governments are promoting Donghe as a tourist destination because of its beautiful ancient rice terraces. However, with currently two farm-hotels in the village, (agri)tourism is at an early stage of development. For the future, the farmers expect a rapid full-scale transition to organic rice production, because it is more profitable than conventional rice production and because the farmers think it is better for their health and the environment. However, a short-term shift from the current system of production contracts with a private company to a system in which the land rights are transferred to the company to allow large-scale farming is not expected. Middle-aged and old farmers prefer to live in the village, and to keep their land for self-sufficient food production. The younger generation prefers to exit from farming and start a business, probably at first in the village, as they are not allowed to settle down in the large cities. At the longer term, the farmers expect that most young migrants will settle down in smaller cities, such as the local county capital, and would prefer to transfer their land to the company. 


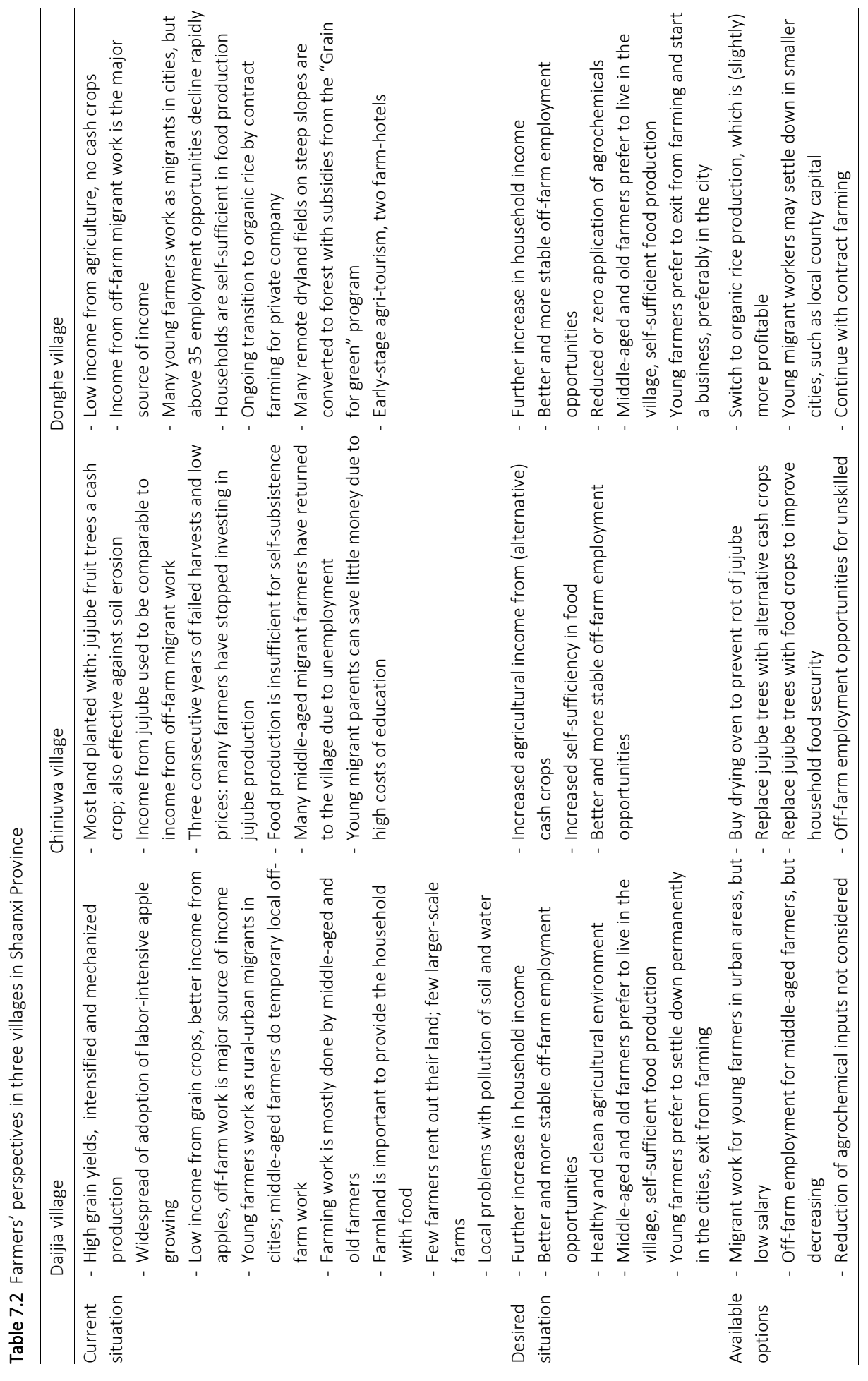


Comparing high-level strategies for agricultural development

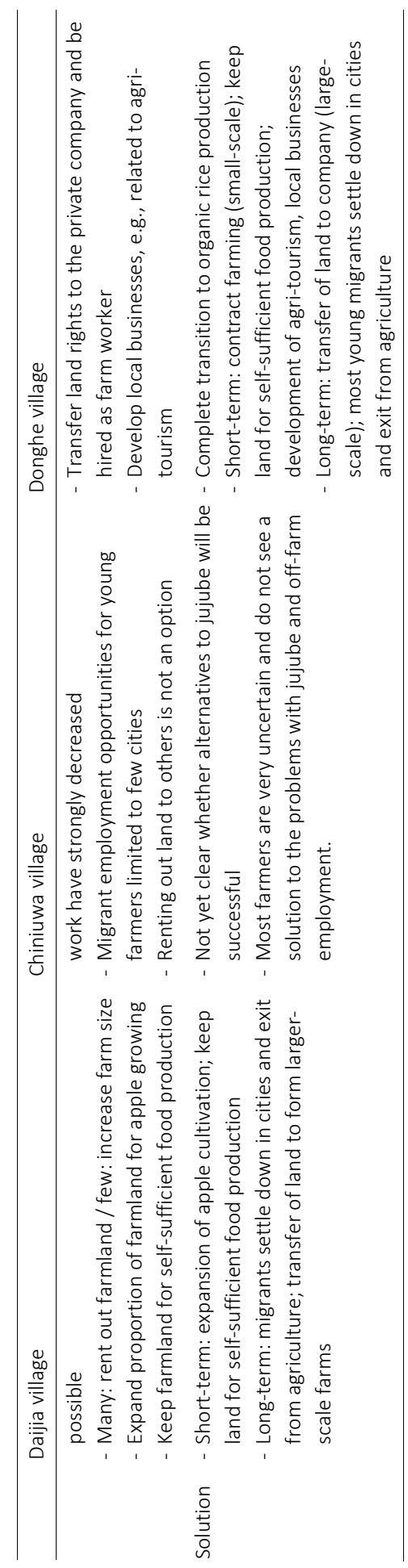




\subsection{CORRESPONDENCE BETWEEN ASSUMPTIONS CONCERNING FARMERS AND FARMERS' PERSPECTIVES}

In this section, we assess how the perspectives and realities of the farmers from the three villages match with the assumptions underlying the three strategies concerning farmers' current situation, desired situation, options and preferred solution.

\subsubsection{Modernization strategy}

The assumption that the income from agriculture is insufficient to cover the living expenses of farm households, mainly due to the small land holdings, was confirmed by the farmers in all three villages. In Daijia and Donghe, income from off-farm work was the major source of income. In Chiniuwa, the income from jujubes used to be higher or comparable to income from off-farm work. However, due to the "crisis" in jujube cultivation, this has changed dramatically in recent years. The assumption that to further improve their household income, most farmers would be willing to exit from farming and transfer their land rights was not confirmed. Most middle-aged and old farmers in the three villages wanted to keep their land as a social safety net, for food provision. The younger generation mostly preferred to settle down in cities, but in Chiniuwa, where farmers were facing both a strong decrease in agricultural cash income and in off-farm employment opportunities, even several young farmers acknowledged the importance of being able to produce your own food. The assumption that there are also farmers that prefer to focus on agricultural income by expanding their farm size and adopting modern technology, was not confirmed by our respondents personally. In Chiniuwa, with the current problems in jujube production and the generally unfavorable conditions for agriculture, clearly no one was interested. However, in Daijia there were already two large farms, one operated by a farmer and another by a private company, and in Donghe, the private organic rice trading company was interested in taking over the land rights from the farmers. A major discrepancy between the assumptions underlying the modernization strategy and the farmers' perspectives concerned the urban employment opportunities. In the most remote village, Chiniuwa, there was a dramatic lack of opportunities for off-farm work, and even in Daijia, in close proximity to major urban centres, off-farm employment was insufficient and insecure according to the farmers. The assumption that agricultural income alone can be sufficient in case of a transition to larger-scale, modern farming, appeared to apply only to Daijia, where the agro-climatical conditions are favorable, a high degree of mechanization is possible and large markets are nearby. Both in Chiniuwa and Donghe, the prospects for profitable large-scale farming are poor, due to unfavorable agro-climatic conditions and steep slopes, respectively. For the short term, the assumption that the preferred solution to the problem of low agricultural incomes lies in scale-enlargement on the one hand and exit from farming on the other, clearly was not confirmed by the farmers in the three 
villages. On the long term, this solution strategy may apply to Daijia, provided urban employment opportunities and social security will improve. However, for the farmers in Chiniuwa and Donghe, alternatives to the modernization strategy are needed.

\subsubsection{Conservation of small-scale agriculture}

Farmers in all three villages confirmed the assumptions underlying the strategy to conserve small-scale agriculture concerning the problematic situation of rural-urban migrant workers and the lack of social security for rural residents. In accordance with the assumptions, middle-aged and old farmers generally preferred to keep their land for household food security, as a social safety net. However, young farmers, currently working as rural-urban migrants, prefer to settle down in cities and exit from farming. In Daija and Donghe, the land per household was sufficient to provide the household members staying in the village with food, but in Chiniuwa this was not the case due to the unfavorable conditions for crop production and the large proportion of the land planted with jujube trees. At the same time, many households in Chiniuwa were facing an alarming drop in cash income, due to the failed jujube harvests and the strongly decreased opportunities for off-farm work, whereas in Daijia and Donghe most households were coping rather well according to the farmers, by combining agricultural and off-farm sources of income. Land consolidation was not mentioned by the farmers as an important issue. In Donghe, this had been addressed already by government policies of village concentration (moving farm houses to the central village) and conversion of remote fields to forest under the "Grain for green" program. The assumption that the preferred solution to the problem of the lack of social security lies in the conservation of small-scale agriculture, was confirmed by the farmers in Daijia and Donghe, at least for the short term. For the long-term, the preferred solution is different, as most of the young farmers in Daijia and Donghe do not want to return to farming after having worked as migrants in the cities. In Chiniuwa, the land was insufficient to provide food security for the households, and an alternative social safety net is needed, already on the short term.

\subsubsection{Transition to Chinese Ecological Agriculture}

The assumptions that environmental problems are widespread, urgent, and negatively affecting agricultural productivity and health, were not confirmed by the farmers in the three villages. Only in case of Daija, farmers reported some problems with environmental pollution. In Chiniuwa and Donghe, former problems with soil erosion and water runoff were effectively dealt with by terracing and tree planting. In Chiniuwa, the farmers were too much absorbed by the jujube crisis to be concerned about environmental problems, but in Daijia and Donghe the farmers showed awareness of the problems caused by high inputs of agrochemicals. However, in these two villages, the farmers' 
perspectives on the available options differed strongly. In Daijia, farmers felt that they could not reduce the input of agrochemicals as it would negatively affect the yields, and they were not interested in ecological production methods. In Donghe, farmers had a positive attitude towards organic rice production and either had switched already from conventional production or were considering a switch in the near future, mainly because the organic alternative is more profitable. In Donghe, farmers also still received subsidies from the "Grain for green" program after converting their sloping dryland fields to forest. The Chinese Ecological Agriculture strategy also emphasizes the development of rural businesses, assuming that on the one hand farmers prefer to stay and live in the rural areas and on the other hand that there is a large market for products and services based on ecological farming. These assumptions were not confirmed for Daijia and Donghe, where young farmers had a clear preference to settle down in cities and exit farming. However, in Donghe there are clearly possibilities to develop agritourism and related products, and for the short-term, young returned migrants were interested in starting a business in the village. In Chiniuwa, there were some modest successes in developing tourist attractions based on the local culture (the museum, the yangko opera performances), but according to the farmers their contribution to income was minimal and the potential severely limited by the remote location of the village. The assumption that environmental problems are urgent and need to be addressed by a transition to ecological agriculture was not confirmed by the farmers in the three villages. In Daijia, the farmers did not consider ecological farming a feasible option. In Chiniuwa, the farmers were in the survival mode and ecological farming was not even considered. In Donghe, a full-scale transition to organic agriculture in the near future was considered to be quite likely according to the farmers, but this was mainly motivated by economic motives. Whether the potential for agritourism and related products would be developed was unsure, as the younger generation prefers urban living and employment.

\subsection{DISCUSSION}

In this final section, we summarize the main findings and discuss how a high-level strategy for sustainable agricultural development could take farmers' perspectives into account.

\subsubsection{Main findings}

The assumptions concerning farmers' current and desired situation, the options available to them, and their preferred solution underlying the three strategies did not match completely with farmers' perspectives in any combination of strategy and village. It is also important to note that in case assumptions of one of the strategies concerning the 
current situation of farmers corresponded with their perspectives, these assumptions only concerned a part of farmers' reality, for example the economic or social dimension, which does not exclude that the assumptions of the alternative strategies apply as well.

The modernization strategy's assumptions concerning farmers apply only to areas with favorable conditions, both for 'modern' farming and urban employment. Daijia village approximates this situation most closely, but for the other two villages this was clearly not the case. Moreover, even with favorable conditions, a transition to larger-scale farms will be slow due to the preference of middle-aged and old farmers to keep their land for self-sufficiency in food, due to the current lack of social security. For the strategy of conservation of small-scale agriculture, the assumptions apply to the current situation and short-term future in Daijia and Donghe, but conflict with the strong, general preference of the younger generation to settle down in cities and exit farming. This strategy also does not consider that conservation of the current land distribution is insufficient to provide a social safety net in areas with unfavorable conditions for food production, such as in Chiniuwa village. The assumptions underlying the Chinese Ecological Agriculture strategy generally did not apply in any of the three villages. Environmental problems were not seen as urgent or had been addressed already, e.g., by the national "Grain for green" program. A transition to ecological farming was not considered by the farmers in Daijia because they feared lower yields and in Chiniuwa because they had other, more pressing concerns. In Donghe, farmers were very positive about a transition to rice production methods that excluded the use of agrochemicals, but mainly because this was the most profitable alternative to their current mode of farming. Perhaps even more interesting, this transition did not concern Chinese Ecological Farming (CEA), but "Western style" organic agriculture. As the demand for ecological farming products in China is driven by the export market and, after several food scandals, by concerned urban consumers, the rather vaguely defined "green food" products from CEA face increasing competition from certified organic products (Scott et al. 2014). It is therefore not unlikely that certified "Western style" organic farming will replace CEA as a major alternative to the governmental modernization strategy. Finally, the assumption of the CEA strategy that many farmers would be interested in rural, agribusiness-based employment, conflicts with the preference of young urban-rural migrants to settle down permanently in cities.

\subsubsection{Accounting for farmers' perspectives in a strategy for sustainable agricultural development}

As stated in the Introduction (section 7.1), strategies developed at a high-level level by policymakers and scientists will only work when they are accepted and supported by the key decision makers "on the ground", the farmers, and the probability of farmer acceptance and support is greatly enhanced when their perspectives and diverse local 
conditions have been taken into account. Based on the comparison of the assumptions concerning farmers underlying three strategies for agricultural development and the perspectives of farmers as identified in three villages in Shaanxi Province, we aim to identify here how a high-level development strategy could better address the diverse needs and conditions of Chinese farmers. In this respect, it is important to note that the three villages were deliberately chosen for their representative character for major farming systems and agro-ecological regions in China and that our findings on the perspectives of farmers in these villages thus have a more general significance. Daijia village in the Guanzhong Plain with its favourable conditions for agriculture and intensive double-cropping system of maize and winter wheat, is representative of agriculture in the North China Plain, the major agricultural production region of China. Chiniuwa village is located in the Loess Plateau, a vast region in the north of China covering an area of 0.64 million $\mathrm{km}^{2}$, characterized by severe soil erosion problems, low yields of food crops, and widespread rural poverty. In Donghe village in the Qinba Mountains, the favorable climatic conditions and the steep slopes have resulted in a system of irrigated rice production on small, terraced fields, nowadays double-cropped with oilseed rape. These conditions and this cropping system are common and widespread in southern China. As our point of departure in accounting for farmers' perspectives, we take the central government's modernization strategy and its three major components: increasing the size of Chinese farms to improve agricultural incomes through enhanced labor productivity, developing and transferring technologically advanced, intensive production methods to improve land productivity and agricultural incomes, and promoting a shift towards urban employment for farmers exiting agriculture. The additional policy goals we identified based on the analysis of farmers' perspectives are summarized in table 7.3.

\subsubsection{Increasing the size of Chinese farms}

The major barrier to farm-scale enlargement in China, is that most middle-aged and old farmers are not willing to transfer their land rights because they want to be able to grow their own food. This makes clear that scale-enlargement will only be possible, when accompanied by policies that effectively address the current lack of social security of rural residents. Only when social benefits in case of illness, old age or unemployment are sufficient to buy food in the market and to cover other essential needs, farmers will be willing to give up their land. Another important barrier to scale-enlargement is that it often does not match with the agro-ecological conditions. For example, in Donghe, the steep slopes and small terraced fields make mechanization almost impossible, and in that case an increase in farm size will not result in a much higher labor productivity. In Chiniuwa, the conditions for agriculture are so unfavorable, that there is no interest at all in expanding the farm size. This means that for many regions in China, alternatives to scale-enlargement are needed to enhance labor productivity and household incomes in the rural areas. As proposed by CEA, this could be the development of local, off-farm 
employment and (agri)businesses. In Donghe and Chiniuwa, some initiatives were already taken to develop tourism, but for this to become a substantial source of income, much stronger support and promotion by governments would be needed.

\subsubsection{Developing and transferring technologically advanced, intensive production methods}

The current approach in China to develop and transfer new agricultural technology and production methods has produced both successes and failures. These successes include high yields of grain crops, such as maize and wheat in Daijia and rice in Donghe, and wide adoption of profitable cash crops, such as apples in Daijia and jujubes in Chiniuwa. The village case studies also showed notable failures, however. The focus on high yields has led to overuse of agrochemicals and associated prolbems of environmental pollution in Daijia, and the specialization on a single cash crop has rendered the farming system in Chiniuwa extremely vulnerable to harvest failures and price falls. The root cause of these failures appears to be a lack of communication between farmers and agricultural experts. In the case of Daijia, farmers were not aware and convinced of the possibilities to produce high grain yields with strongly reduced inputs of agrochemicals (Shen et al., 2013). In the case of Chiniuwa, agricultural experts were unaware of the crisis in jujube production the farmers experienced and their perception of weather anomalies as a permanent change of climate. This shows that for the development and adoption of more economically, socially and environmentally sustainable production methods, the governmental strategy should aim at an interactive, locally adaptive and trustful relationship between farmers and agricultural experts and scientists. Such an approach could also successfully anticipate and address future problems with labor shortages and productivity in time-intensive crops, such as apples in Daijia. This is needed, because without new, labor-saving production methods, the farmers' strategy to expand apple production is unlikely to be successful in the long run. Finally, the case of jujube makes clear that governmental support should not only focus on agricultural production, but also on marketing if it is to improve farmers' incomes, and on compensation for farmers' efforts to conserve natural resources, when these are not costeffective.

\subsubsection{Promoting a shift toward urban employment}

Perhaps the most striking contrast between the assumptions underlying the governmental modernization strategy and the realities of the farmers in the three villages we studied, concerned the availability and quality of urban employment. Due to a lack of education, the rural-urban migrant workers are dependent on unskilled, physical work, e.g., in the construction sector. These jobs are not only poorly paid, but also quite insecure, as the demand can fluctuate strongly with developments in the Chinese economy. Therefore, if urban employment is to fully replace employment in agriculture for most Chinese farmers, an improvement of the rural education system is urgently needed to 
enhance the capabilities and off-farm employment opportunities of the rural work force (Tian et al., 2016). Another barrier to urban employment, as identified in Chiniuwa, is the absence of primary schools in villages, resulting in high costs and restricted employment opportunities for rural-urban migrant parents. This indicates a need for policy measures that aim to either support and maintain primary schools in the villages or to reduce the costs of primary education in the cities for rural-urban migrants. Finally, a major constraint to a shift toward urban employment is the current Household Registration System (hukou), which makes it nearly impossible for rural-urban migrants to settle down permanently in the cities and also puts them in a socially very disadvantaged position during their temporary stay in the urban areas. However, abolishing the current hukou system may result in completely unmanageable urbanization, including the development of slums (Ye, 2015). As the growing interest of farmers from Donghe to settle in local towns and cities already indicated, a more sustainable compromise could be a policy of relaxing the hukou rules for smaller cities only, which would also result in a better balance in demographic and economic development between the large and smaller cities (Tian et al., 2016).

Table 7.3 Additional policy goals for a sustainable agricultural development strategy based on an analysis of farmers' perspectives

\begin{tabular}{ll}
\hline Strategy component & Additional policy goals \\
\hline Increasing the size of Chinese farms & improve the rural social security system to replace small land \\
& holdings as the social safety net \\
& - support and promote the development of rural businesses, e.g., \\
& agritourism \\
Developing and transferring technologically- & develop an interactive, locally adaptive and trustful relationship \\
advanced, intensive production methods & between farmers and agricultural experts and scientists \\
& - support farmers in the marketing of cash crops \\
& - compensate farmers' efforts to conserve natural resources, \\
& when these are not cost-effective \\
Promoting a shift toward urban & improve the rural education system to enhance the capabilities \\
employment & and off-farm employment opportunities of the rural work force \\
& support primary schools in the villages or to reduce the costs of \\
& primary education in the cities for rural-urban migrants \\
& - relax the hukou rules for smaller cities \\
\hline
\end{tabular}


Chapter

\section{General discussion}




\subsection{SUMMARY OF MAJOR FINDINGS}

Agricultural development is a central concern for many in China, not only for national policy makers, but also for many scholars who are critical about the government's modernization strategy. This thesis starts from the assumptions that agricultural development must include economic viability, social equity and protection of the environment and the natural resource base to be sustainable, and that, to be effective, a strategy for sustainable agricultural development must account for farmers' perspectives and diverse conditions. Here, we summarize our main findings with respect to the three key objectives of this dissertation, namely, to assess how comprehensive the Chinese governmental strategy for agricultural development and major alternatives are; to determine the perspectives of Chinese farmers on problems and possible solutions in agricultural development; and to assess whether the strategies take farmers' perspectives into account and how this can be improved.

China's agricultural development is characterized by a strong increase in agricultural production and the income of farmers. Major policy goals concerning national food security and rural poverty alleviation have been reached, but at the same time environmental, as well as economic and social problems threaten the sustainability of agriculture. The government aims to address these problems with a modernization strategy in combination with urbanization. Alternative strategies focus on the conservation of small-scale agriculture or the development of ecological agriculture. We conducted an integrated assessment of these three strategies for agricultural development to determine in how far the current sustainability problems of Chinese agriculture are addressed in a comprehensive way, i.e., whether the economic, social and environmental dimensions of sustainable development are taken into account. We found that neither the government's modernization strategy nor the two major alternatives offer a comprehensive and integrated response to the current threats to the sustainability of agriculture. The modernization strategy neglects the need for rural migrant workers to maintain their small land holdings as a fallback option, and measures to control agrochemical pollution are ineffective due to its emphasis on enhancing agricultural production. The alternative strategy to conserve small-scale agriculture does not offer a solution for the widening urban-rural gap and the current environmental problems. The weak spot of the strategy promoting ecological agriculture lies in the difficulty to create an effective market for high added value products and ecosystem services. Moreover, all three strategies neglect the huge variation in local conditions across China and make unverified key assumptions about the needs and preferences of Chinese farmers. We concluded that investigation of farmers' perspectives on agricultural development, and how these vary with local conditions, is therefore a much needed step towards a comprehensive and broadly supported strategy for sustainable agricultural development in China. 
The perspectives and practices of Chinese farmers were first studied following a quantitative survey approach. The focus was on the Guanzhong Plain (Shaanxi Province), where the natural conditions are favorable and agriculture is relatively advanced. The dominant system is double-cropping of maize and winter wheat, as in the North China Plain, the major agricultural production region of China. The survey covered 165 farm households from 24 villages. The dominant trend in the responses was that food production for domestic consumption is more important than generation of income. Only a minor part of the farmers was satisfied with their income from agriculture, and income from migrant work is generally more important. Modern agricultural methods (machinery, agrochemicals) were seen as efficient, labor-saving, and productivity enhancing, are widely adopted and expected to become even more dominant at the cost of traditional agriculture. A majority of the farmers enjoys the rural life, mainly because there is less pollution than in urban areas, and has a neutral to positive view on being a farmer. The dominant view was that agriculture and the natural environment are interdependent, but farmers are not willing to reduce the application of agrochemicals, because they are dependent on these for a high yield, and see environmental protection as the government's responsibility. The main consideration of farmers in their decisions, including the application rate of agrochemicals, is the quantity of the production., and the impact on the environment does not affect their decisions. Although many farmers were positive about ecological modes of agriculture, they are hesitant to adopt these, unless there are clear incentives from the government or the market. Most farmers were interested in the acquisition of new knowledge and technologies, but, they found the agricultural training courses currently offered not useful. They wanted the knowledge to be practically useful, transferred in an interactive way and helpful to raise their income. Apart from the dominant trend, there were many significant differences between respondents depending on their farm household type, age and level of education. For instance, the largest cluster of households, with $39 \%$ of the respondents, concerned farm households that mostly grow perennial cash crops for the market, and for whom income from agriculture is more important than from migrant work. These farmers are interested in learning about new technologies, prepared to switch to another type of crop when they see better income opportunities, and participate in farmers' cooperatives to improve their market competitiveness. The farmers in this cluster have a relatively high level of education. Many of the effects of education level and age coincided with effects of household type, but a notable additional effect of age was that younger respondents tended to have a negative view on being a farmer and especially valued the role of modern agricultural technology in reducing the need for labor input. It appears that even in a fairly homogeneous agricultural production area like the Guanzhong Plain, there is a large diversity in farmers' perspectives and practices. The governmental agricultural development strategy as well as the two critical alternatives match poorly with the dominant perspectives and practices of the respondents and with the large diversity in these perspectives and practices. Our conclusion was that a strategy for sustainable 
development of agriculture in China should address a wide diversity of needs and goals as articulated by Chinese farmers themselves, otherwise it will lack the support it needs to be successful.

To gain a more in-depth understanding of what farmers see as problems and why, how they cope with these problems and what viable prospects they see for agriculture in their village, we applied a case study approach, with extensive interviews with a relatively small number of respondents. We conducted these interviews in three villages in contrasting agro-ecological zones of Shaanxi Province, including one village (Daijia) in the relatively prosperous Guanzhong Plain and two villages in agronomically less favored areas, at greater distance from major urban centers (Chiniuwa and Donghe).

Daijia is a village located in the Guanzhong Plain of Shaanxi Province. As the dominant system is intensive double-cropping of maize and winter wheat, the area is representative of agriculture in the North China Plain, the major agricultural production region of China. According to the farmers, the major problem is that the net income from grain production is far too low to cover household expenses, which is mainly due to the very small land holdings (0.1-0.7 ha). From an economic perspective, farm households in Daijia address this problem successfully by diversification into apple growing and offfarm employment, both locally and in more distant major cities. The respondents mentioned several of the social problems often associated with rural-urban migrant labor, but these were considered to be relatively moderate due to the presence of a primary school for the children of migrant parents in Daijia and the availability of local off-farm jobs for older, returning migrant workers. Despite the reported intensive use of pesticides and chemical fertilizers in both grain production and apple growing, no major environmental problems were mentioned. Farmers felt that these high input levels were needed to maximize the yields. For the future, respondents expected that most young people would not continue the farming and that agriculture in Daijia would be further mechanized and increase in scale. However, given the current importance of subsistence farming as social safety net for unemployment and old age, the expectation was that these developments would take place slowly.

Chiniuwa is a village located in the Loess Platea region, in the north of Shaanxi Province. The Chinese Loess Plateau is highly prone to soil erosion due to the combination of steep slopes and a semi-arid climate. The dominant crop in Chiniuwa is jujube, a drought-tolerant fruit tree planted on terraced hillsides. According to the farmers, the cultivation of jujube was a highly successful way to deal with the difficult conditions for agriculture in the Loess Plateau region. The terraces and trees prevented soil erosion, the dry climate was favorable for high quality fruits, and due to the high market price the cash income from jujubes was even higher than from migrant salaries. However, after three years of failed harvests, a loss in market share and a steep drop in prices, the income from jujube is now almost nil. In response, farmers have strongly reduced their 
investments in jujube production. At the same time, a slow-down in construction activity in China has severely limited the off-farm employment opportunities of the farmers, and many are forced to stay in the village. Unfortunately, due to the unfavorable growing conditions, the households in Chiniuwa are not self-sufficient in food production. As the farmers believe that the harvest failures of jujube are due to a permanent change in climate, several have started to replace the jujube trees with annual food crops, such as millets. The respondents were generally quite uncertain and rather pessimistic about the future development of agriculture in Chiniuwa. Many did no longer see a future for jujube as the main cash crop. Some of the villagers were experimenting with alternative cash crops, but whether these would be successful in providing sufficient cash income was still highly uncertain. A structural shift towards off-farm sources of income and exit from farming in combination with scale-enlargement by remaining farmers was not seen as a likely future direction, given decreasing off-farm employment opportunities and the limited opportunities for commercial agriculture in Chiniuwa.

Donghe is a village located in the Qinba Mountains, in the south of Shaanxi Province. In this region, the climatic conditions are favorable for agriculture, but the steep slopes make the fields less accessible and hinder mechanization. The dominant system is double-cropping of rice and oilseed rape, a cropping system which is common and widespread in southern China. According to the farmers, rice is their major source of agricultural income, but due to the very small land holdings the profits are not sufficient to cover household expenses. Off-farm migrant work in cities by young and middle-aged farmers is nowadays the main source of household income. The rural-urban migrant work is temporary and short-term, however, and does not provide social security. Beyond the age of 35 , it is increasingly difficult for the farmers to find employment as migrant worker. As most households in Donghe are self-sufficient in food production, farming plays an important role as social safety net. However, the younger generation has no or little experience with farming and prefers to settle down in cities. Although this is very difficult where it concerns the large cities, settling down in nearby smaller cities and towns appears a feasible compromise. Major environmental risks such as soil erosion and agrochemical pollution are effectively managed according to the farmers, by conversion of sloping dryland fields to forest under the national "Grain for green" program and by an ongoing transition to organic rice production. For the future, the farmers expected a rapid expansion of organic rice production. However, given the importance of land as a social safety net for the households, farmers did not expect a short-term shift from the current system of production contracts with a private company to a system in which the land rights are transferred to the company to allow largescale farming.

As a final step, we assessed the extent to which the Chinese governmental strategy for agricultural development and the two alternative strategies address the problems and solutions as perceived by farmers in the three villages with their diverse and contrasting 
contexts (Daijia, Chiniuwa and Donghe). We first mapped the assumptions underlying the three strategies concerning farmers' key problems and the preferred ways to solve these problems. We then assessed how these matched with farmers' perspectives on their current and desired situation, the problems and solutions found in the three villages, and aimed to identify ways how a high-level strategy for sustainable agricultural development could take farmers' perspectives into account. We found that the assumptions concerning farmers' current and desired situation, the options available to them, and their preferred solution underlying the three strategies did not match completely with farmers' perspectives in any combination of strategy and village. Moreover, in case assumptions of one of the strategies concerning the current situation corresponded with the farmers' perspectives, these assumptions only concerned a part of farmers' reality, for example the economic or social dimension. Based on the comparison between assumptions of strategies and farmers' perspectives, we identified additional policy goals by which the government's strategy for agricultural development could take the diversity of farmers' needs and preferences into account. This strategy consists of three major components: increasing the size of Chinese farms, developing and transferring technologically advanced, intensive production methods, both meant to improve productivity and agricultural incomes, and promoting a shift towards urban employment for farmers exiting agriculture. The major barrier to farm-scale enlargement in China, is that most middle-aged and old farmers are not willing to transfer their land rights because they want to be able to grow their own food. This makes clear that scaleenlargement will only be possible, when accompanied by policies that effectively address the current lack of social security of rural residents. Another important barrier to scale-enlargement is that it often does not match with the agro-ecological conditions, for example, in Donghe and Chiniuwa. This means that for many regions in China, alternatives to scale-enlargement are required to enhance labor productivity and household incomes in the rural areas, and policies are needed to promote the development of local, off-farm employment and (agri)businesses. The current approach in China to develop and transfer new agricultural technology and production methods has produced both successes and failures. These successes include high yields of grain crops and wide adoption of profitable cash crops. The failures concern the overuse of agrochemicals and associated problems of environmental pollution (e.g., Daijia), and the vulnerability of specialization on a single cash crop (e.g., Chiniuwa). The root cause of these failures appears to be a lack of communication between farmers and agricultural experts. For the development and adoption of more economically, socially and environmentally sustainable production methods, the governmental strategy should therefore aim at an interactive, locally adaptive and trustful relationship between farmers and agricultural experts and scientists. Perhaps the most striking contrast between the assumptions underlying the governmental modernization strategy and the realities of the farmers in the three villages we studied, concerned the availability and quality of urban employment. Therefore, if urban employment is to fully replace employment in 
agriculture for most Chinese farmers, an improvement of the rural education system is urgently needed to enhance the capabilities and off-farm employment opportunities of the rural work force. Finally, a major constraint to a shift toward urban employment is the current Household Registration System (hukou), which makes it nearly impossible for rural-urban migrants to settle down permanently in the cities and also puts them in a socially very disadvantaged position during their temporary stay in the urban areas. However, abolishing the current hukou system may result in unmanageable urbanization, including the development of slums. As the growing interest of farmers from Donghe to settle in local towns and cities already indicated, a more sustainable compromise could be a policy of relaxing the hukou rules for smaller cities only, which would also result in a better balance in demographic and economic development between the large and smaller cities.

\subsection{DISCUSSION}

This thesis is part of a broader discussion and on-going research efforts concerning the sustainable future of Chinese agriculture. In this section, we first reflect on the strengths and weaknesses of our methodology as compared to the approaches taken by other studies on the sustainability of Chinese agriculture. Thereafter, we compare our major findings with those other studies. Finally, we provide recommendations for further research and agricultural policy in China.

\subsubsection{Reflections on methodology}

The choice of methodology is a process of compromise. Researchers are dependent on methodologies to answer their research questions and to fulfill different research objectives (Moses \& Knutsen, 2007). Given the different objectives of their research, researchers have to make a balance relating to the strengths and weakness of the methodology. We addressed the central issue of sustainable agricultural development in China at three levels: at the national level, we focused on the comprehensiveness of governmental policy strategy and critical alternatives, at the regional level (Guanzhong Plain), we studied the diversity of farmers' practices and their perspectives on agricultural development in dependence of selected context variables, and at the local level, we aimed to gain a deeper understanding of farmers' perspectives under contrasting agro-ecological conditions. To obtain a better insight into the strengths and weaknesses of our methodology, we make as comparison with other studies on the sustainability of Chinese agriculture that followed very different approaches.

At the national level, the study by Xu et al. (2006), presents an example of a different approach. As in this dissertation, these researchers acknowledge the need to account in 
a national strategy for sustainable agricultural development for the wide heterogeneity of conditions in China. To this end, they aimed to identify a relatively small number of more homogeneous zones within China. Based on an index system of sustainable development with 95 indicators at provincial level and mapping of geographical patterns in these variables, the whole country is divided into nine agricultural development regions (first-level), and 22 sub-regions (second-level). The first-level zones reflect each region's direction for future sustainable agricultural development and management. The second-level zones reflect their level of development, and whether or not each subregion has reached the basic criteria for sustainable agricultural development. As compared to our study, the data these researchers used are similar (government reports, bulletins, statistical yearbooks, and academic literature), but their data collection was more extensive with 95 indicators and accounted for the heterogeneity between provinces. The major weakness of their approach, however, is that the sustainability of agriculture is assessed in isolation. Concerning the economic aspects, the focus is on the profitability of farming and ignores the importance of non-agricultural sources of income. Concerning the social aspects, no comparison is made between the position of rural and urban residents. Thus, the strong dependence of rural households on income from migrant labor is missing in their assessment, just as the large and widening ruralurban gap. Furthermore, the directions and criteria for sustainable agricultural development in the study by $\mathrm{Xu}$ et al. (2006) are established in a top-down manner by experts, without interaction with farmers. For these reasons, we do not expect that this approach will be very helpful in developing a national strategy that comprehensively addresses the economic, social and environmental dimensions of agricultural development and that will receive broad support from Chinese farmers.

At the regional level, an example of a different approach is offered by Wang et al. (2015). To support the implementation of sustainable development at the provincial level, several eastern provinces of China started at the end of 1990s with the so-called "Ecological Province Construction" (EPC). In the case of Shandong Province, a leading group of policy makers and experts formulated a long-term regional development plan and predefined a set of indicators to monitor progress towards sustainability. These indicators focus on eco-efficiency (economic added value per unit of environmental impact) and decoupling to measure resource and environmental efficiency. In their paper, Wang et al. (2015) apply the indicator set to evaluate the current state of "Shandong Ecological Province Construction" and to identify improvements of the indicator set for policy development. The strength of this approach is that with a limited number of indicators, based on "hard" data, regional sustainability can be measured and assessed. In comparison, in our survey of farmers' practices and perspectives, we collected also quantitative, but mainly "soft" data, and no "hard" conclusion on the sustainability of agriculture in the Guanzhong Plain can be derived from it. Yet, we believe that this produced information that is at least complementary to data on the eco-efficiency 
of agriculture. First of all, because our approach paid attention to the social dimension, income from other sectors and the interaction between rural and urban areas. Second, and perhaps even more important, because our assessment is not based on regionallevel statistics but on the diversity of lived experiences of the farmers.

Finally, at the village level, an example of a different approach is presented by the EUChina SUCCESS project (Dumreicher, 2008). This project involved transdisciplinary action research on sustainable development in seven Chinese villages, located across China in six different provinces. Researchers from different disciplines engaged with villagers to jointly develop a sustainable future scenario for each village. Subsequently, concrete development opportunities were identified and implemented as a first step for each village. A strength of this approach is that all aspects of development were covered by the multidisciplinary team of researchers and the interaction with the villagers with their local knowledge. Another strength is the visibility of the results, which is crucial for villagers' awareness, their self-confidence and their experience with a successful participation in decision-making processes. A final strength are that the consortium could provide concrete examples in their recommendation to policy makers "to cherish the human and natural potential of the rural economy and environment" (Dumreicher, 2008). A weakness of this project in our view, is that the focus on what can be achieved locally, accepts the constraints imposed by the current higher-level policies. In contrast, whereas our approach did not produce any tangible results for our case study villages, it allowed us to identify adaptations to the governmental strategy for sustainable agricultural development that are essential for substantial improvements towards sustainability in these villages. Furthermore, the focus of the SUCCESS project on concrete local improvements resulted in a very diverse and disparate range of initiatives from which it appears difficult to derive recommendations for other villages. Although China counts more than 800,000 villages, and we only studied three, these villages represented a broad range of conditions and we feel that our in-depth analysis of farmers' perspectives in these villages uncovered major policy issues that apply to many other villages as well. A final weakness of the focus on local improvements is that for implementation a village level consensus was needed, which limits the choice to the largest common denominator, which does not necessarily coincide with the most urgent issues that individual households are facing. In our approach, it became clear that within villages, households and even individuals can have very different concerns and perspectives with respect to sustainable development, which conflicts with trying to implement the same solution for everyone. A high-level strategy allowing for and enabling individual variation in solutions is probably more appropriate. 


\subsubsection{Comparing the major findings with the literature}

This thesis seeks to contribute to the debate about the future of Chinese agriculture and the prospects for sustainability. It is appropriate, therefore, to compare and contrast our findings with other positions in the debate. In the last decades, the Chinese government and economic elites had the political and economic goals to promote largescale modernized agriculture by replacing traditional small-scale agriculture (He, 2013a; He, 2014a, 2014b; Huang, 2011, 2014). However, in recent years, China's farming sector has also been dominated by small-scale farms which are operated by the form of households rather than the form of enterprises (Ji, Rozelle, Huang, Zhang, \& Zhang, 2016). Ji et al conducted research relating to the changes of farm size in 60 villages from five provinces. They found that the average operational size of farms increased marginally (Ji et al., 2016). Although small-scale agriculture is the main characteristics of the current farming sector, there are some new non-household farming entities (Ji et al., 2016), such as agricultural firms. In terms of household-operated farms, farmers are old and low educated; whilst, young farmers have the tendency to operate relatively largescale farms (Ji et al., 2016). The changes from the type of peasant household agriculture to the type of enterprise agriculture will be far-reaching (van der Ploeg \& Ye, 2010). In our research, we found the small-scale household agriculture occupied the most weight in all of our cases villages. In addition, we found the new class of farms (enterprises) in Daijia village and Donghe village, whilst there are no new agricultural entities emerging in Chiniuwa village due to the remote geographical position and the failure of jujube output. However, the forms of new classes are different in the budding stage of the large-scale farm. For instance, farmers directly contract their farmland use right to agricultural firms in Daijia village; whilst farmers just sign the contract with an agricultural firm to only allowed to sell their organic agricultural production to the firm without circulating their farmland in Donghe village. In terms of the preference of the size of farms, according to our field research in three villages, farmers of different ages indicated different perspectives. Generally, young farmers have the preference of largescale of agriculture. The main reason for the preference of large-scale of farms is the meager net income of agriculture comparing with their rural-urban migrant income. In contrast, old and middle-aged farmers prefer small-scale agriculture of their own generation. Generally, the old and middle-aged generation believe that the next generation will return to the village to fulfill an agricultural job in the future due to the temporary characteristics of rural-urban migrant work.

Our research thus confirms that smallholding farmland is still of importance for farmers. In terms of the rural household organization, there is a tight three-generation structure and the circularity of agricultural labor and migrant labor (van der Ploeg, Ye, \& Pan, 2014). In China, villagers' lifetime can generally be divided into three periods. In the children period, their parents work outside the village to afford the main expenditure of 
the family while their grandparents fulfill agricultural work to "feed the family"; after their marriage, it is their turn to work to leave their parents and children to outside to take the responsibility to support the main expenditure of the household; in their middle-aged stage, they have to retreat back to their sending village and fulfill the agricultural work due to the unemployment in urban areas (van der Ploeg et al., 2014). It is the general circle for the majority of villagers in their lifetime. During this circle, farmland plays central role to "feed left-behind people" in the rural areas and provide migrant people with the last "fall-back position" (van der Ploeg et al., 2014). In addition, the smallholding farmland is cared well by farmers so as to benefit the next generation. Our in-depth interviews and observations confirms the predominance of the three generations structure. The family is of utmost importance for villagers, which makes that different generations are tightly interrelated and interdependent for the sake of their family. In the villages we studied, the majority of young people (both male and female) and some middle-aged male farmers work outside. The majority of middle-aged farmers and almost all old farmers are left behind to take care of farmland and young children. However, there are some exceptions. For instance, several households have bought an apartment in the county or in the town for the young generation by the migrant savings from middle-aged generation. In addition, some people achieved the permanent settlement in urban areas by accepting high education. In such situations, the possibility that young generation will return to the village to fulfill agricultural work becomes meager. As a result, their farmland will be reallocated within the village.

According to many scholars, the current pattern of "half worker and half cultivation" will continue to exist for a long period of time in China (He, 2013a; He, 2014a, 2014b; Huang \& Gao, 2013). In general, there is a tight relationship between industrial sector and agricultural sector (van der Ploeg \& Ye, 2010). Much more than in other countries, there is an interaction between industrialization and agricultural development (van der Ploeg \&Ye, 2010). The cheap rural-urban migrant labor from rural areas, for instance, is beneficial to China's industrialization. No new slums are created in urban areas because smallholding agriculture provides unemployed migrant workers with a fall-back position in rural areas (van der Ploeg \&Ye, 2010). In return, the fast development of industrial sector guarantees the further robust development of agricultural sector. For instance, migrant workers invest their wages in agricultural input (Huang \& Gao, 2013; van der Ploeg \&Ye, 2010). However, in addition to the synergetic relationship, there are also tensions between agricultural sector and industrial sector. For instance, due to the high remuneration of industrial sector, the development of agriculture tends to be ignored. In our research, many farmers complain about the high agricultural input and the low agricultural income. The farmers in our study are involved in struggles both from the agricultural and industrial sector. The meager agricultural income renders it impossible for them to afford the household expenditure, which makes the rural household split. At the same time, migrant workers are confronted with regular unemployment, short- 
age of social insurance, marginalized life, the drudgery of coolie jobs with low salaries, unaffordable apartments (high housing rental fee), and the final fate of being forced back to their sending rural areas. To sustain basic life, rural households need the diversity of livelihoods from farming in rural areas as well as from migrant work in urban areas.

In the literature it has been reported that in the current early stage of urbanization and industrialization, Chinese farmers are confronted with multifaceted constraints and solutions to find viable livelihoods (Tian, Guo, \& Zheng, 2016 ). The low-income from agriculture, makes the diversity of rural livelihoods needed (Tian et al., 2016 ). Undoubtedly, agriculture development plays a pivotal role to eradicate poverty and hunger and various ways of solving the problems of rural livelihoods have been suggested. The FAO, for instance lists five possible strategies: the intensification of agriculture, the diversification of agriculture, the expansion of farm size, increased off-farm income, and the complete exit of agriculture (Dixon, Gibbon, \& Gulliver, 2001). In our field research, we found different strategies. Firstly, intensification of agriculture as the main way to increase agricultural output with less involvement of human labors, especially in Daijia and Chiniuwa villages. Secondly, the diversification of agricultural production as the main way to increase farmers' agricultural income. In general, there is a tendency to develop high-valued "new agriculture", such as fruit, vegetables, meat (Huang \& Gao, 2013). In our research, we indeed encountered the strategy of "new agriculture", such as apple orchards in Daijia village, jujube orchards in Chiniuwa village and organic rice in Donghe village. Thirdly, we found that off-farm income is the main source of rural household in all three villages.

Agriculture also plays the role of social security (Wang, Weaver, \& You, 2013). Chinese urbanization is in the early stage, and the industrial sector is not large enough to provide adequate employment opportunities for rural-urban migrants (Wang et al., 2013). In developing countries, it is difficult to build a social security system for rural dwellers (Wang et al., 2013). Under such situation, agriculture and smallholding farmland itself play the function of social security in rural areas. The farming labor is called "extra labor", for those who have no ability to find jobs in urban areas. When migrant workers are in their middle-aged stage, it is easy for them to be fired by industrial sector due to their diminishing physical power. Agricultural sector absorbs the extra labor and provides them with a self-sufficient lifestyle in rural areas. In our field research, farmers from all three case villages reflected the temporary migrant work and their regular unemployment in urban areas. In addition, farmers from these three villages also indicated the extreme difficulty to buy an apartment and to achieve the permanent settlement in urban areas because of their low wage. Secondly, local farmers who did receive social security (such as a pension) referred to it as "pocket money", stressing that it is too meager to guarantee their basic life in rural areas. Under the condition of inadequate urbanization and imperfect social security, local farmers have to depende on small-scale agriculture as their last leeway. However, in our research, we also found the 
case that it is difficult to dependent on agriculture for a self-sufficient life, such as the failure of agriculture in Chiniuwa village (Loess Plateau area). Then the rural social security should be the solution for local farmers. In China, in terms of the social insurance system, there is a huge gap between urban and rural areas. To begin with, the duality household registration system is one main reason to cause the widened disparity between rural and urban areas, which should be reformed. Chinese citizens should not be labeled rural people and urban people. In addition, the new cooperative medical scheme and the new rural pension system were just adopted in 2008 and 2009, which is also in the initial stage. The government should accelertate the development of rural social insurance systems.

Note that 'farmer' (peasant) in China not just refers a profession, but also to a social category (social rank) (Schneider, 2014). In China, a farmer is someone to "be looked down upon", and has the image of "low-qualified, poor"; and it is common for "rural areas" to have the image of being "backward and outmoded" (Schneider, 2014). Chinese government and economic elites have the goal to build state-led agro industrialization by replacing small-scale traditional agriculture. It is a common discourse (government, scientists, and common people) to attribute the rooted reason of agricultural problems to small-scale traditional agriculture. However, actually, farmers have made and still make a great contribution to Chinese development. Firstly, since the beginning of China's industrialization, agriculture has the role of "feeding" industry (see chapter 2). There is a priority to develop industry in urban areas. Secondly, rural-urban migrant workers are educated in rural areas without using urban resources, which provides urban areas cheap labors without asking for guarantees from the urban area when they are sick and old (van der Ploeg \&Ye, 2010). Thirdly, farmers themselves rather than states and firms invest most capitals in agricultural development, which easily ignored (Huang \& Gao, 2013). For instance, rural-urban migrants remit their wages to rural household to invest in the reproduction of agriculture. Clearly, it is unfair and unequal to sustain such "images" of farmers. In our research, according to our questionnaire and interview research in three villages, farmers like their rural life, especially old and middle-aged farmers. However, in terms of the profession of "farmers", only few people indicated directly that they like to be a farmer. It is popular amongst farmers to call themselves "grassroots", which symbolize their lowest social rank. In addition, due to the qualification of "looking down upon", it is common that old and middle-aged farmers expect young generations to change to a new profession (not being a farmer); it is also common amongst the young generation to hate being a farmer like the older generations.

The development of agricultural technologies and the dominance of intensification of agriculture, namely high-input and high-output have made agriculture-related ecological problems very serious (Qu, Kuyvenhoven, Shi, \& Heerink, 2011; Yu, 2016). Generally, the land availability, land degradation, water availability and water pollution are the 
main problems (Qu et al., 2011; Yu, 2016). In our research, we found serious ecological problems in Daijia and Chiniuwa village. In Donghe village, the problems were less severe, also due to the tendency to develop the ecological modes of agriculture (organic agriculture). In our field research, some farmers reflect that the ground water table decreased due to the agricultural irrigation in Daijia village. They also know that the high dependency on agriculture-related chemicals will cause ecological problems, while they have to do so to gain high agricultural productivity. In general, their ecological awareness ("ecological thinking") contradicts their ecological activities ("ecological doing"). In addition, the centralized "top-to-down" agriculture related policies affect local areas (Qu et al., 2011). For instance, , we found the implementation of the "grain for green" project (SLCP)in Chiniuwa village and Daijia village. In this project remote areas are chosen by the government where farmland is converted into forest. In Chiniuwa village, farmers plant jujube trees and the same is happening, according to local farmers, in the surrounding counties. In Donghe village, farmers plant ecological trees (one or two types) in the remote areas. Even, the economic compensation way is also similar. Such centralized top-to-down ecological policy also causes other ecological problems (see chapter 1 ). From the ecological perspective, the problems include the more water demand of new trees comparinging with natiave grassland, the high evaporation of afforestation trees, the negative effect on water run-off (the decreased amount for rivers), and the side effect on local biodiversity. From social-economic perspective, the compensation reaching farmers is low, which has the potential risk for farmers to change back from forest to farmlands.

\subsubsection{Reflections on "the best strategy" for agricultural development in China}

According to many, Chinese agriculture is at the crossroads, given the current processes of urbanization and industrialization. The direction of Chinese agriculture development is a hot topic in China and the "best strategy" is disputed. Generally, the government and economic elites in China argue that the large-scale industrialized and modernized agriculture remains the main direction. Their assumption is that small-scale agriculture is tantamount to low efficiency agriculture and, thus, leads to meager incomes of farmers. However, there are also different voices in the struggle for "the best strategy" of Chinese agricultural development. Instead of blaming small-scale agriculture, Huang (2016) brings a new train of thought of "the hidden revolution of Chinese agriculture". There is an apparent transition from "old agriculture" to "new agriculture" (Huang \& Gao, 2013). In other words, there is a switch from grain crops to high-value agricultural products (such as vegetables, poultry-fish, and fruits). Since the 1980s, Chinese people's living standard has increased to a great extent, which also changes the pattern of "agricultural products consumption". In recent years, the sown area of new agriculture has increased (Huang \& Gao, 2013). The main characteristics of "new agriculture" is that it is both labor-intensive and capital-intensive (Huang, 2016). He proposed the strategy of 
"appropriate scale of farms", including 15 mu old agriculture and 3 mu new agriculture (Huang \& Gao, 2013). In addition, Huang strongly argues that it is the rural household (rather than firms and the government) that invest most in agricultural development. After the Green Revolution, the input in "old agriculture" increased several times. In addition, the input in "new agriculture" substantially surpasses the input in "old agriculture". Small-holding farmers even applied their migrant off-farm income in the investment of agriculture production. Thus, he strongly stressed the "great importance of peasant household investment" (Huang \& Gao, 2013). In our research, we found the "new agriculture" in all of three case villages, such as the apple orchards in Daijia village, the jujube orchards in Chiniuwa village, as well as the organic rice in Donghe village. The main purpose of "new agriculture" is to increase farmers' agricultural income. However, we also found that the "new agriculture" is labor and capital-intensive, which makes the scale of "new agriculture" small. As "half worker half cultivator", young farmers are mainly engaged in migrant off-farm work in urban areas while returned middle-aged farmers and old farmers fulfill the agricultural job in their villages. The labor condition thus will not develop to the large-scale of "new agriculture".

Also others have stressed that China' industrialization is accompanied by the revival of peasant economy (van der Ploeg \&Ye, 2010). There is an interaction between industrialization and agricultural development. On the one hand, the cheap labors from rural areas guarantee the role of "the factory of the world"; on the other hand, when these cheap labors are old and sick, the industrial sector pays out nothing because they will retreat from urban areas to their sending villages (van der Ploeg \& Ye, 2010). According to Van der Ploeg and Ye agriculture mainly has two functions for farmers. The first one is that agriculture provides farmers with self-sufficient food; and the second one is that agriculture means "a kind of life guarantee" (van der Ploeg \&Ye, 2010). Currently, due to the absence of equal welfare and insurance systems between urban and rural areas, agriculture provide farmers (especially for unemployment migrant workers) with the last fall-back position. Thus, they argued that the transition from small-scale peasant agriculture to large-scale firm agriculture will be far-reaching(van der Ploeg \& Ye, 2010).

In the same vein, Schneider (2014) directly criticized the government and economic elites' ideas relating to the problems of small-scale agriculture. Inversely, she holds the idea that agro-industrialization is the problem while small holding agriculture is the part of the solution (Schneider, 2014). To reach the goal of large-scale of modernized agriculture, government and economic elites purposely create the image that small holding farmers are "low-quality" people (Schneider, 2014). In Chinese society, the farmer is not just a profession but also a low social rank. In our research, we also found that the radical policy of the construction of large-scale industrialised agriculture will aggravate the phenomenon of inequality in Chinese society. Regarding the direction of Chinese agricultural development, we hold the position that farmers' voices should be paid ade- 
quate attention. In addition, a coordinated urban-rural development is needed to construct sustainable agriculture.

\subsubsection{Further reflections on theories and methodology}

Most of the existing research relating to agricultural development is conducted from a monolithic dimension, such as the agricultural income, social inequity, or agricultural pollution. There is an absence of an integrated assessment of agricultural problems from all of three dimensions of sustainable agriculture (economic, social, and ecological dimensions). This dissertation narrows this gap. We make an integrated review of the literature (Chinese and English literature), governmental reports or bulletins (from different ministries), and secondary data sources from the Chinese Statistical Bureau; and we mainly focus on the integrated assessment of farmers' perspectives of sustainable agriculture by in-depth field research (questionnaire and in-depth interviews). It provides an integrated perspective to the future Chinese agriculture-related research.

This research is mainly based on field research in different rural contexts and the strong narrations of small-holding farmers. Concerning the research on Chinese triple problems (三农问题 San Nong Wen Ti), there is no shortage of theories and methodologies, whilst "common sense" in terms of the reality of agriculture, peasants (farmers' perspectives) and villages is lacking (He, 2013b). The underlying social foundations are more important than agricultural policies themselves to some extent (He, 2013b). Farmers are the most important entities in agricultural development. However, during the process of agricultural policy making, there is an absence of farmers' voices due to their historically weak and marginalized position in Chinese society. Usually, agriculturerelated research questions are formulated by literature analysis and by identifying limitations in the literature. Then the information is sought to prove the question or provide solutions. However, this research is set-up oppositely as this dissertation is rooted in the rural context and includes farmers' perspectives. By analyzing in-depth interviews with small-holding farmers and our observations of the rural contexts, we proposed that the main research question should relate to the (un)-correspondence between agricultural policy proposals and farmers' perspectives in (diverse) rural contexts.

In the process of the interviews in three case villages, we learned some skills to obtain comprehensive and real information. We gave farmers adequate time to tell their own stories before we asked the next question, and we kept asking questions when we did not understand what farmers were saying. In addition, we elaborated on "new" or "remarkable" elements in farmers' stories, and we cross-checked information among different farmers. We never gave moral judgment, and always showed understanding of interviewees' position. It was a valuable experience of doing field research. The concentrated field research is not only to about collecting primary materials, but also to gain a deepened understanding of "experiencing" rural contexts and farmers' perspectives. 


\subsection{RECOMMENDATIONS}

In this part, we make recommendations for future research and agricultural policy in China.

\subsubsection{Recommendations for future research}

\subsubsection{The importance of farmers' perspectives}

First of all, we argue that only agricultural policy proposals that align with farmers' perspectives can be implemented successfully. After all, farmers are the main decision makers in agriculture. Yet they are in marginalized position and their voices are ignored, in agricultural policy proposals of the government, but also in those of critical scholars. Only few studies previous studies have focused on farmers' perspectives on agricultural development in a comprehensive way, and, in this sense, this research narrows a scientific gap. This study shows that the added value of investigating the gap between highlevel strategies and farmers' perspectives of agricultural development, and hopefully stimulates future research emphasizing farmer' perspectives to diagnose farmers' real problems and formulate practical solutions.

Currently, research in China relating to the triple problems of "agriculture, peasants, and villages" is poorly integrated. While Chinese agriculture is going through transformative changes, economically, socially and environmentally, different scientists focus on different aspects, such as rural administration, agricultural economy, farmland policy, rural culture, agricultural production methods and farmers' behaviors. However, all these studies should be built on the understanding of rural reality and farmers' perspectives. In-depth and participatory field research in rural areas is needed to deepen researchers' integrated understanding and interpretation of their results.

\subsubsection{The diversity of farmers' perspectives}

The diversity of farmers' perspectives is another important topic for future research. Our research shows that farmers' perspectives vary significantly based on household characteristics, individual characteristics (age and education), and regional characteristics. China is a large country with a rich diversity of rural contexts, which needs further study. The three investigated villages are representative of different rural contexts, with different types of agricultural production, different farming strategies, different locations (remote or adjacent to urban areas), and different social-economic situations (more and less developed villages). Although these three chosen villages can represent the agricultural development of China to some degree, they will certainly not reflect the whole range of farmers' perspectives in China. For instance, we did not conduct field research in dry areas in remote regions (such as Xinjiang, Inner Mongolia, and Tibet) 
and coastal areas. Neither did we study the full variety of agricultural types, such as vegetables, animal husbandry, and aquaculture.

\subsubsection{The integrated assessment of agricultural development}

The governmental strategy for sustainable agricultural development as well as the alternatives proposed by critical scholars reflected a strong bias towards one or another dimension of agricultural development. However, an emphasis on only one dimension will undermine the achievement of sustainable agriculture. Strategies for sustainable agricultural development should simultaneously address the sustainability of the rural economy, society and environment (Zhao, Luo, Deng, \& Yan, 2008). In this research, we applied the framework of three dimensions (economic, social and ecological) of sustainable agriculture to assess agricultural problems, agricultural policy proposals and farmers' perspectives. Thus far, such an integrated assessment for sustainable agricultural development in China was lacking. This dissertation provides an outlook of integrated assessment of agricultural development, and seeks to inspire further research in terms of the theory and practice of sustainable agriculture.

\subsubsection{Recommendations for agricultural policy in China}

\subsubsection{The direction of Chinese agricultural development}

As we have argued before, the Chinese central government focuses on larger-scale, modernized agriculture, which has spurred an intensive debate about the direction of agricultural development in China (He, 2013a; He, 2014a, 2014b; He, 2013; Huang, 2011, 2014). Our studies show that given the diversity of rural socio-economic and agro-ecological conditions, availability of migrant work, and the degree of urbanization, a strategy for agricultural development in China should not be limited to a single focus on large-scale modernized agriculture. In its agricultural policy, the Chinese central government should have an open attitude toward diversity and support multiple directions of agricultural development in diverse rural contexts.

\subsubsection{Bottom-up development of development strategies}

In China, agricultural policies are typically developed by the government and experts in a top-down manner. The approach of this dissertation - visiting villages and having indepth interviews with individual farmers - provides Chinese agricultural policy makers and experts with another, new manner to make agricultural policy proposals: from the bottom-up.

Top-down agricultural policy will cause the problem of "the last mile ${ }^{48 "}$ in which agricultural policy that is developed and implemented by the government in a hierarchical,

\footnotetext{
${ }^{48}$ The last mile (最后一公里, Zui Hou Yi Gong Li) was created and used in 2001 in China to describe the problem of the agricultural knowledge and information extension system. "The last mile" describes the knowledge
} 
one-way approach, is not necessarily accepted and adopted by farmers. In that case, there is no bottom-up feedback mechanism, and farmers are treated as passive recipients and their voices are largely ignored. Whatever the future direction of Chinese agriculture will be, it will need to take the perspectives of farmers into account.

and information are disseminated from the beginning (agricultural experts) to the end (farmers), from top to down transmission of knowledge. 



\section{References}

Allen, P., van Dusen, D. , Lundy, J. , \& Gliessman, S. (1991). Expanding the definition of sustainable agriculture. Series: Sustainability in the Balance: Issues in Sustainable Agriculture. Center for Agroecology and Sustainable Food Systems, UC Santa Cruz.

Arnstein, S. R. (1969). A ladder of citizen participation. Journal of the American Institute of Planners, 35(4), 216-224.

Bai, L., \& Bai, Y. (2007). Chinese urban-rural duality system: evolution, current status and the coordinated solutions. Productivity Research, 7, 81-83. (in Chinese).

Baker, S. (2006). Sustainable development. London: Routledge.

Bennett, M. T. (2008). China's sloping land conversion program: institutional innovation or business as usual? Ecological Economics, 65(4), 699-711.

Cao, S. (2011). Impact of China's large-scale ecological restoration program on the environment and society in arid and semiarid areas of China: achievements, problems, synthesis, and applications. Critical Reviews in Environmental Science and Technology, 41(4), 317-335.

Cao, S. , Chen, L. , \& Yu, X. (2009). Impact of China's Grain for Green Project on the landscape of vulnerable arid and semi-arid agricultural regions: a case study in northern Shaanxi Province Journal of Applied Ecology 46, 536-543.

CCCPC. (1982). No.1 Central Document: meeting summary on national rural work. Beijing. (in Chinese).

CCCPC. (1983). No.1 Central Document: the notification on some issues regarding current rural economic policy. Beijing. (in Chinese).

CCCPC. (1984). No.1 Central Document: the notification of CPC Central Committee rural work in 1984. Beijing. (in Chinese).

CCCPC. (1985). No.1 Central Document: CPC Central Committee and State Council's ten policies on activating the rural economy. Beijing. (in Chinese).

CCCPC. (1986). No.1 Central Document: arrangements on rural work in 1986. Beijing. (in Chinese).

Chan, K. W., Liu, T., \& Yang, Y. (1999). Hukou and non-hukou migrations in China: comparisons and contrasts. International Journal of Population Geography, 5(6), 425-448.

Chen, A. (2014). China's path in developing organic agriculture: Opportunities and implications for small-scale farmers and rural development. Unpublished PhD thesis, Waterloo University, Canada.

Chen, D., Wang, X., Liu, S., Wang, Y., Gao, Z., Zhang, L., \& Wei, X. (2015). Using bayesian analysis to compare the performance of three evapotranspiration models for rainfed jujube (Ziziphus jujuba Mill.) plantations in the Loess Plateau Agricultural Water Management, 159, 341-357.

Chen, J. C., Zinda, J. A., \& Yeh, E. T. (2016). Recasting the rural: State, society and environment in contemporary China. Geoforum.

Chen, K., \& Brown, C. (2001). Addressing shortcomings in the Household Responsibility System. China Economic Review, 12(4), 280-292.

Chen, X. P., Cui, Z. L., Fan, M. S., Vitousek, P., Zhao, M., Ma, W. Q., . . . Zhang, F. S. (2014). Producing more grain with lower environmental costs. Nature, 514, 486-489.

Cheng, X. , Han, C. R. , \& Donald, C. T. . (1992). Sustainable agricultural development in china. World Development, 20(8), 1127-1144.

De Brauw, A., \& Rozelle, S. (2008). Migration and household investment in rural China. China Economic Review, 19(2), 320-335. 
Démurger, S., \& Xu, H. (2011). Return migrants: the rise of new entrepreneurs in rural China. . World Development 39, 847-1861.

Dixon, J. A., Gibbon, D. P., \& Gulliver, A. (2001). Farming systems and poverty: improving farmers' livelihoods in a changing world. Food \& Agriculture Organization, Rome.

Enserink, B., Kwakkel, J., Bots, P., Hermans, L., Thissen, W., \& Koppenjan, J. (2010). Policy analysis of multiactor systems. Eleven International Publishers, Portland, Oregon, $177 \mathrm{pp}$.

Fan, S., \& Chan-Kang, C. (2005). Is small beautiful? Farm size, productivity, and poverty in Asian agriculture. Agricultural Economics 32, 135-146.

Feng, L. , Bao, H. X. H. , \& Jiang, Y. (2014). Land reallocation reform in rural China: a behavioral economics perspective. Land Use Policy, 41, 246-259.

Frolking, S., Xiao, X., Zhuang, Y., Salas, W., \& Li, C. (1999). Agricultural land-use in China: a comparison of area estimates from ground-based census and satellite-borne remote sensing Global Ecology And Biogeography, 8, 407-416.

Fujisaka, S. (1989). The need to build upon farmer practice and knowledge: reminders from selected upland conservation projects and policies. Agroforestry Systems: an International Journal Incorporating Agroforestry Forum, 9(2), 141-153.

Fujisaka, S. (1994). Learning from six reasons why farmers do not adopt innovations intended to improve sustainability of upland agriculture. Agricultural Systems, 46(4), 409-425.

Gao, X., Wu, P., Zhao, X., Wang, J ., \& Shi, Y. (2014). Effects of land use on soil moisture variations in a semiarid catchment: implications for land and agriculutral water management Land Degradation \& Development, 25(2), 163-172.

Ge, X. R. (2003). The macro analysis of Chinese duality household registration system: the perspective of neoinstitutional economics. Hubei Social Sciences 9, 67-69. (in Chinese).

Golusin, M., \& Munitlak Ivanović, O. (2009). Definition, characteristics and state of the indicators of sustainable development in countries of southeastern Europe. Agriculture, Ecosystems and Environment, 130(1), 67-74.

Goodkind, D., \& West, L. A. (2002). China's floating population: definitions, data and recent findings. Urban Studies, 39(12), 2237-2250.

Gong, P., Liang, S., Carlton, E. J., Jiang, Q.W., Wu, J.Y., Wang, L., \& Remais, J. V. (2012). Urbanisation and health in China. Lancet, 379(9818), 843-852.

Gray, Benjamin J., \& Gibson, Jane W. (2013). Actor-Networks, Farmer Decisions, and Identity. Culture, Agriculture, Food and Environment, 35(2), 82-101.

Grosjean, P., \& Kontoleon, A. (2009). How sustainable are sustainable development programs? the case of the sloping land conversion program in China. World Development, 37(1), 268-285.

Grudens-Schuck, N. (2000). Conflict and engagement: an empirical study of a farmer-extension partnership in a sustainable agriculture program. Journal of Agricultural and Environmental Ethics, 13(1), 79-100.

Guan, S. Q., \& Wang, G. Y. (2013). The farmland abandon and "who will plant the farmland in the future?" Economic Vision(14), 371-372.

Guo, Y. J., Liu, Y. S., Wen, Q., \& Li, Y. R. (2014). The Transformation of Agricultural Development towards a Sustainable Future from an Evolutionary View on the Chinese Loess Plateau: A Case Study of Fuxian County. Sustainability, 6(6), 3644-3668. doi: 10.3390/su6063644.

Ha, N., Feike, T., Angenendt, E., Xiao, H., \& Bahrs, E. (2015). Impact of farm management diversity on the environmental and economic performance of the wheat-maize cropping system in the North China Plain. International Journal of Agricultural Sustainability, 13(4), 350-366.

Hao, H. Y. (2014). Discussion on improving the quality of urbanization and the synchronous development of four modernizations. Probe, 3, 82-87.

He, X. F. (2013a). Reply to professor Zhou Qi-ren on logic of land ownership. Journal of Huazhong Agricultural University (social sciences edition), 3, 1-9. (in Chinese).

$\mathrm{He}, \mathrm{X}$. (2013b). Rural China in the 21 century. Beijing: Beijing University Press. (in Chinese).

He, X. F. (2014a). How to understand Chinese small-scale agricultural economy. China Rural Science \& Technology(3), 15-15. (in Chinese). 
He, X. F. (2014b). The road of Chinese urbanization Dong Fang Press. (in Chinese).

Hebel, J. (2003). Social welfare in rural China. Journal of Peasant Studies, 30(3-4), 224-224.

Hengsdijk, H., Guanghuo, W., Van den Berg, M. M., Jiangdi, W., Wolf, J., Changhe, L., ... \& Van Keulen, H. (2007). Poverty and biodiversity trade-offs in rural development: a case study for Pujiang county, China. Agricultural Systems, 94(3), 851-861.

Hou, R. (2006). The study on China agricultural support policy (doctoral dissertation), Huazhong agricultural university, Wuhan. (in Chinese).

Hou, H. L., Wu, K. M. , \& Wu, T. (2014). The study of the decreasing number of rural college students: from the perspective of employment pressure. Higher Agricultural Education, 5, 11-15.

Hu, A. G. (2014). Chinese featured agricultural road from 1949 to 2012 Contemporary China History Studies, 3, 24-37. (in Chinese).

Hu, C. X., Fu, B. J., Chen, L. D., \& Gulinck, H. (2006). Farmer's attitudes towards the Grain-for-Green programme in the Loess hilly area, China: A case study in two small catchments. The International Journal of Sustainable Development and World Ecology, 13(3), 211-220.

Hu, F., Xu, Z., \& Chen, Y. (2011). Circular migration, or permanent stay? Evidence from China's rural-urban migration. China Economic Review, 22(1), 64-74.

$\mathrm{Hu}$, Y. (2010). The average life expectancy analysis on China's current population in urban and rural. Population and Development, 16(2), 41-47.

Huang, C., Liu, Q., Heerink, N., Stomph, T., Li, B., Liu, R., ... \& van der Werf, W. (2015). Economic performance and sustainability of a novel intercropping system on the north China plain. PloS One, 10(8), e0135518.

Huang, P. C. C, \& Gao, Y. (2013). The Dynamics of Capitalization in Chinese Agriculture: Private Firms, the State, or Peasant Households? . Rural China,, 10(1), 36-65.

Huang, P. C. C. (2016). China's hidden agricultural revolution, 1980-2010, in historical and comparative perspective. Modern China 42,(4), 339 - 376.

Huang, P. C. C. (2011). China's new-age small farms and their vertical integration: agribusiness or co-ops? Modern China, 37(2), 107-134.

Huang, P. C. C. (2014). Is "Family Farms" the Way to Develop Chinese Agriculture? . Rural China, 11(2), 189221.

Ji, X., Rozelle, S., Huang, J., Zhang, L., \& Zhang, T. (2016). Are China's farms growing?. China \& World Economy, 24(1), 41-62.

Jiang, Y. . (2009). China's water scarcity. Journal of Environmental Management, 90(11), 3185-3196.

Khan, S. , Hanjra, M. A., \& Mu, J. X. (2009). Water management and crop production for food security in China: a review. Agricultural Water Management, 96(3), 349-360.

Krusekopf, C. C. (2002). Diversity in land-tenure arrangements under the household responsibility system in China. China Economic Review, 13(2-3), 297-312.

Kuehl, A.G., \& Liu, Y. (2014). Analytical overview of the Chinese organic sector with the focus on rural development. Building Organic Bridges, 1, 141-144.

Kung, J. K.-S. (2000). Common property rights and land reallocations in rural China: evidence from a village survey. World Development, 28(4), 701-719.

Li, B. (2006). Floating population or urban citizens? Status, social provision and circumstances of rural-urban migrants in China. Social Policy \& Administration, 40(2), 174-195.

Li, G. Q. , Fan, J. , Liu, J. , Wang, W. , Wang, M. , Qi, Y. X. , . . Zhao, D. . (2014). Impact of cerebrovascular disease mortality on life expectancy in China. Biomed Environ Sci, 27(3), 169-175.

Li, H. G. , Liu, J. , Li, G. H. , Shen, J. B. , Bergström, L. , \& Zhang, F. S. (2015). Past, present, and future use of phosphorus in Chinese agriculture and its influence on phosphorus losses. Ambio, 44(S2), 274-285.

Li, N. , Mu, H. L. , Li, H. N. , \& Gui, S. S. . (2012). Diesel consumption of agriculture in China. Energies, 5(12), 5126.

Li W, Liu M, Min Q (2011) China's Ecological Agriculture: progress and perspectives. Journal of Resources and Ecology 2: 1-7.

Lichtenberg, E. , \& Ding, C. (2008). Assessing farmland protection policy in China. Land Use Policy, 25(1), 5968. 
Liu, G., Liu, P. L., Warrington, D. N., Ju, T., Zhang, Q., \& Xu, W. (2011). Resolving ecological and economic challenges: An application of sustainable ecological agriculture on the Chinese Loess Plateau. Journal of Food, Agriculture \& Environment, 9(1), 575-582.

Liu, H., Han, X., Xiao, Q., Li, S., \& Feldman, M. W. (2015). Family structure and quality of life of elders in rural China: the role of the new rural social pension. Journal of aging \& social policy, 27(2), 123-138.

Liu, J. , \& Raven, P. H. . (2010). China's environmental challenges and implications for the world. Critical Reviews in Environmental Science and Technology 40, 823-851.

Liu, J., \& Diamond, J. . (2005). China's environment in a globalizing world. Nature 435, 1179-1186.

Liu, P. X. . (2010). Educational equity and the choice of educational policy. Hubei Social Sciences, 2, 157-160.

Liu, S. , Wang, Y. , Wei, X. , Wang, X. , \& Zhang, L. (2013). Measured and estimated evapotranspiration of jujube (ziziphus jujuba) forests in the loess plateau, china. International Journal Of Agriculture And Biology, 15(5), 811-819.

Liu, W., Wu, W., Wang, X., Wang, M., \& Bao, Y. (2007). A sustainability assessment of a high-yield agroecosystem in Huantai County, China. International Journal of Sustainable Development \& World Ecology, 14(6), 565-573.

Liu , X. J. , \& Zhang, F. S. (2011). Nitrogen fertilizer induced greenhouse gas emissions in China. Current Opinion in Environmental Sustainability, 3(5), 407-413.

Liu, Y. H. , Duan, M. C. , \& Yu, Z. R. . (2013). Agricultural landscapes and biodiversity in China. Agriculture, Ecosystems \& Environment, 166, 46-54.

Liu, Z. (2005). Institution and inequality: the hukou system in China. Journal of Comparative Economics, 33(1), 133-157.

Liu, Z. , \& Henningsen, A. (2016). The effects of China's sloping land conversion program on agricultural households. Agricultural Economics, 47(3), 295-307.

Long, H. , Liu, Y., Li, X. , \& Chen, Y. (2010). Building new countryside in China: A geographical perspective. . Land Use Policy 27, 457-470.

Lu, X. C. , \& Zhu, Q. Z. . (2011). The value of the existence of village from the perspective of agricultural production. Rural economy(10), 99-102.

Lü, Y. , Fu, B., Wei, W. , Yu, X. , \& Sun, R. . (2011). Major ecosystems in China: dynamics and challenges for sustainable management. Environmental Management, 48, 13-27

Ma, X. L., Heerink, N., Feng, S. Y., \& Shi, X. P. (2015). Farmland tenure in China: Comparing legal, actual and perceived security. Land Use Policy, 42, 293-306.

Ma, Y. , Chen, L. D. , Zhao, X. F. , Zheng, H. F. , \& Lu, Y. H. (2009). What motivates farmers to participate in sustainable agriculture? Evidence and policy implications. International Journal of Sustainable Development \& World Ecology, 16(6), 374-380.

MEP. (2014). China's Fifth National Report on the implementation of the Convention on Biological Diversity. In M. o. E. P. o. China (Ed.). Beijing.

MEP, \& MLRC. (2014). Report on the investigation of soil pollution in China. Beijing: Ministry of Environmental Protection of China and Ministry of Land Resources of China.

MFAC. (2015). Report on China's Implementation of the Millennium Development Goals (2000-2015). Beijing: Ministry of Foreign Affairs of People's Republic of China and United Nations System in China.

Min, A., \& Han, Q. (2008). Situation analysis of Shaanxi Province. Northwest Agriculture and Forestry University, Yangling, Shaanxi, China, $89 \mathrm{pp}$.

MLRC. (2002, 2006, 2009, 2014 and 2015). The bulletin of the Chinese land resources. Beijing: Ministry of Land and Resources of China. (in Chinese).

MLRC. (2015). The bulletin of the Chinese land resources. Beijing: Ministry of Land and Resources of China. (in Chinese).

MLRC. (2001, 2005, 2008 and 2013). The bulletin of the Chinese land resources. Beijing: Ministry of Land and Resources of China.

Mu, H. Z. , \& Fan, H. M. . (2015). The influence mechanism for the recognition of income inequality: Social structural status and mobility expectation Journal of Guangdong University of Finance \& Economics 30(1), 12-22. 
Mu, S. L. , Zhang, Y. F. , Wang, K. Y. , \& G.C, Dhruba Bijaya. (2012). Agricultural land contract and management rights: Transferring price and countermeasures in typical agricultural areas of China. Journal of Resources and Ecology, 3(3), 262-268.

MWRC. (2013). The first national bulletin of soil and water conservation. Beijing: The Ministry of Water Resources of China.

MWRC. (2014). China water resources bulletin. Beijing: The Ministry of Water Resources of China.

Nayak, D., Saetnan, E., Cheng, K., Wang, W., Koslowski, F., Cheng, Y. F., . . . Smith, P. (2015). Management opportunities to mitigate greenhouse gas emissions from Chinese agriculture. Agriculture Ecosystems \& Environment, 209(Journal Article), 108-124.

NBSC. (2006, 2011 and 2014). China rural statistical yearbook. Beijing: China statistics press. (in Chinese).

NBSC. (2008). The report of Chinese second agricultural census 2006. Beijing National Bureau of Statistics of China. (in Chinese).

NBSC. (2014). China statistical yearbook. From http://www.stats.gov.cn/tjsj/ndsj/2014/indexch.htm (in Chinese).

NBSC. (2015). China statistical yearbook. from http://www.stats.gov.cn/tjsj/ndsj/2015/indexeh.htm (in Chinese).

OECD. (2001). China's agriculture in the international trading system Retrieved from http://www.sourceoecd.org/.

OECD. (2004). Income Disparities in China: OECD Publishing.

Oelofse, M., Høgh-Jensen, H., Abreu, L. S., Almeida, G. F., El-Araby, A., Hui, Q. Y., ... \& de Neergaard, A. (2011). Organic farm conventionalisation and farmer practices in China, Brazil and Egypt. Agronomy for Sustainable Development, 31(4), 689-698.

Oi, J. C. (1989). Market reforms and corruption in rural China. Studies In Comparative Communism, 22(2), 221-233.

Ong, L. H. (2014). State-Led Urbanization in China: Skyscrapers, Land Revenue and "Concentrated Villages". CHINA QUARTERLY, 217(217), 162-179.

Ongley, E. D., Zhang, X. L., \& Tao, Y. . (2010). Current status of agricultural and rural non-point source Pollution assessment in China. Environmental Pollution, 158, 1159-1168.

Painter, M. (2008). From comm and economy to hollow state? Decentralisation in Vietnam and China. Australian Journal of Public Administration, 67(1), 79-88.

Park, A., \& Rozelle, S. (1998). Reforming state-market relations in rural China. Economics of Transition, 6(2), 461-480.

Pfeffer, M. J. (1992). Sustainable agriculture in historical perspective. Agriculture And Human Values : Journal Of The Agriculture, Food, And Human Values Society, 9(4), 4-11.

Pimbert, M. (2004). Natural resources, people and participation. Participatory Learning and Action, 50, 131139.

Prandl-Zika, V. (2008). From subsistence farming towards a multifunctional agriculture: sustainability in the Chinese rural reality. Journal of environmental management, 87(2), 236-248.

Pretty, J. N. (1995). Participatory learning for sustainable agriculture. World Development, 23(8), 1247-1263.

Qiao, F., Rozelle, S., Huang, J., Zhang, L., \& Luo, R. (2014). Road expansion and off-farm work in rural China. The China Quarterly, 218, 428-451.

Qiao, Y. (2011). Organic agriculture development in China. In: Willer, H. \& Kilcher, L. (Eds.), The world of organic agriculture. Statistics and emerging trends 2011. IFOAM, Bonn \& FiBL, Frick.

Qu, F. , Kuyvenhoven, A. , Shi, X. , \& Heerink, N. (2011). Sustainable natural resource use in rural China: Recent trends and policies. China Economic Review, 22(4), 444-460.

Quheng, D. , \& Gustafsson, B. (2014). The hukou converters-China's lesser known rural to urban migrants. Journal Of Contemporary China, 23(88), 657-679.

Raedeke, A. H. , \& Rikoon, J. S. (1997). Temporal and spatial dimensions of knowledge: Implications for sustainable agriculture. Agriculture And Human Values : Journal Of The Agriculture, Food, And Human Values Society, 14(2), 145-158.

Rao, N. H. , \& Rogers, P. P. (2006). Assessment of agricultural sustainability. Current Science, 91, 439-448. 
Reed, M. S. . (2008). Stakeholder participation for environmental management: A literature review. Biological Conservation, 141(10), 2417-2431.

Ren, J. M. , Yu, Y. X. , \& Wang, R. S. (2009). Preliminary analysis of the environmental impact of Chinese agricultural policy. Chinese Agricultural Science Bulletin, 25(15), 223-229. (in Chinese).

Ren, Y. (2004). Population urbanization and the deconstruction of rural-urban duality system. Exploration and Free Views, 3, 24-25. (in Chinese).

Rigby, D. , Woodhouse, P. , Young, T. , \& Burton, M. (2001). Constructing a farm level indicator of sustainable agricultural practice. Ecological Economics, 39(3), 463-478.

Robertson, G. P. (2015). A sustainable agriculture? . Daedalus, 144(4), 76-89.

Rosset, P. M. , \& Altieri, M. A. (1997). Agroecology versus input substitution: A fundamental contradiction of sustainable agriculture. Society \& Natural Resources, 10(3), 283-295.

Sanders, R., \& Xiao, X. (2010). The sustainability of organic agriculture in developing countries: lessons from China. The International Journal of Environmental, Cultural, Economic and Social Sustainability, 6(6), 233243.

Scott S, Si Z, Schumilas T, Chen A (2014) Contradictions in state-and civil society-driven developments in China's ecological agriculture sector. Food Policy 45: 158-166.

Schneider, M. (2015). What, then, is a Chinese peasant? Nongmin discourses and agroindustrialization in contemporary China. Agriculture and Human Values, 32(2), 331-346.

Shao, J. , Zhang, S. , \& Li, X. (2016). Effectiveness of farmland transfer in alleviating farmland abandonment in mountain regions. Journal of Geographical Sciences, 26(2), 203-218.

Shen, J. B., Cui, Z. L., Miao, Y. X., Mi, G. H., Zhang, H. Y., Fan, M. S., . . . Zhang, F. S. (2013). Transforming agriculture in China: From solely high yield to both high yield and high resource use efficiency. Global Food Security, 2, 1-8.

Shi , T. . (2002 ). Ecological agriculture in China: bridging the gap between rhetoric and practice of sustainability. Ecological Economics, 42, 359-368.

Sicular, T. , Yue, X. M. , Gustafsson, B. , \& Shi, L. . (2007). The urban-rural income gap and inequality in China Review of Income and Wealth, 53(1), 93-126.Sillitoe, P. , \& Marzano, M. (2009). Future of indigenous knowledge research in development. Futures, 41(1), 13-23.

Silverman, D. (2004). Qualitative research : Theory, method and practice (2nd ed.).

Smith, C. S., \& McDonald, G.T. ( 1997 ). Assessing the sustainability of agriculture at the planning stage. Journal of Environmental Management 52(15-37).

Suh, J. (2015). An institutional and policy framework to foster integrated rice-duck farming in Asian developing countries. International Journal of Agricultural Sustainability, 13(4), 294-307.

Sun, B. , Zhang, L. X. , Yang, L. Z. , Zhang, F. S., Norse, D. , \& Zhu, Z. L. . (2012). Agricultural non-point source pollution in China: Causes and mitigation measures. Ambio, 41(4), 370-379.

Sun, T. H. , \& Song, X. Y. (2008). Problems on Chinese agricultural environment and countermeasures. Research of Agricultural Modernization, 29(6), 646-648,652.

Sun, P. J., Song, W., Xiu, C. L., \& Liang, Z. M. (2013). Non-coordination in China's Urbanization: Assessment and Affecting Factors. Chinese Geographical Science, 23(6), 729-739.

Taylor, J. E., Rozelle, S., \& De Brauw, A. (2003). Migration and incomes in source communities: A new economics of migration perspective from China. Economic Development and Cultural Change, 52(1), 75101.

Tian, C., Song, Y. , \& Boyle, C. E. (2012). Impacts of China's burgeoning rural land rental markets on equity: a case study of developed areas along the eastern coast. Regional Science Policy \& Practice, 4(3), 301-315.

Tan, Q. C. (2011). Greenhouse gas emission in China's agriculture: situation and challenge. China Population Resources and Environment, 21(10), 69-75.

Tian, Q., Guo, L., \& Zheng, L. (2016 ). Urbanization and rural livelihoods: A case study from Jiangxi Province, China. Journal of Rural Studies, 47, 577-587.

Trauger, A. (2009). Social agency and networked spatial relations in sustainable agriculture. Area, 41(2), 117128.

Tso, T. C. (2004). Agriculture of the future. Nature, 428(6979), 215-217. 
Urech, P. (2000). Sustainable agriculture and chemical control: opponents or components of the same strategy? Crop Protection, 19(8), 831-836.

UN. (1992). United Nations Conference on Environment \& Development. In U. N. D. f. S. Development (Ed.), Agenda 21. Rio de Janerio, Brazil.

UN. (2015). The millennium development goals report 2015. New York: The Department of Economic and Social Affairs of the United Nations Secretariat.

Van der Ploeg, J.D. (2003). The virtual farmer: Past, present and future of the Dutch peasantry: Uitgeverij Van Gorcum.

Van den Berg, M. M., Hengsdijk, H., Wolf, J., Van Ittersum, M. K., Guanghuo, W., \& Roetter, R. P. (2007). The impact of increasing farm size and mechanization on rural income and rice production in Zhejiang province, China. Agricultural Systems, 94(3), 841-850.

Van der Ploeg, J. D., \& Ye, J. Z. (2010). Multiple job holding in rural villages and the Chinese road to development. The Journal of Peasant Studies, 37(3), 513-530.

van der Ploeg, J. D, Ye, J, \& Pan, L. (2014). Peasants, time and the land: The social organization of farming in China. Journal Of Rural Studies, 36(5), 172-181.

Wang, L. J., \& Béland, D. (2014). Assessing the financial sustainability of China's rural pension system. Sustainability, 6(6), 3271-3290.

Wang, Q. . (2014). Rural students are being left behind in China. Nature, 510(7506), 445-445.Wang, X. , Liu, W. , \& Wu, W. (2009). A holistic approach to the development of sustainable agriculture: application of the ecosystem health model. International Journal of Sustainable Development \& World Ecology, 16(5), 339-345.

Wang, R. Z. (2008). The gap of urban-rural compulsory education from the perspective of educational equity. Journal of Fujian Provincial Committee Party School of CPC(5), 32-36.

Wang, X., \& Weaver, N. (2013). Surplus Labour and Urbanization in China. Eurasian Economic Review, 3(1), 8497.

Wang, X, Weaver, N, \& You, J. (2013). The social security function of agriculture in China. Journal of International Development, 25(1), 1-10.

Wang, X. L., \& Wan, G. H. (2014). China's Urban Employment and Urbanization Rate: A Re-estimation. CHINA \& WORLD ECONOMY, 22(1), 30-44.Wang, H., Qin, L., Huang, L., \& Zhang, L. (2007). Ecological agriculture in China: principles and applications. Advances in Agronomy, 94, 181-208.

Wang, Z. (2013). Research of China agri-environmental policy based on the perspective of agricultural support: Chinese academy of agricultural sciences.

Wang, Z. K. (2011). Social security for China's migrant workers. International Labour Review, 150(1-2), 177187.

Watson, A. (1983). Agriculture looks for 'shoes that fit': The production responsibility system and its implications. World Development, 11(8), 705-730. (in Chinese).

WB. (2006). China water quality management : policy and institutional considerations East Asia and Pacific environmental and social development discussion paper. Washington, DC: World Bank Webber, M. (2008). The places of primitive accumulation in rural China. Economic Geography, 84(4), 395-421.

Wei, G .P. (2014). The pollution of rural remnant farming plastic sheetings and the controlling technology. Gan Su Agriculture, 17, 47-48.

Weigelin-Schwiedrzik, S. . (2008). The distance between state and rural society in the PRC. Reading Document No 1 (February 2004). Journal of Environmental Management, 87(2), 216-225.

Wen, D. , Tang, Y. , Zheng, X., \& He, Y. (1992). Sustainable and productive agricultural development in China. Agriculture, ecosystems \& environment 39, 55-70.

Whalley, J. , \& Zhang, S. (2007). A numerical simulation analysis of (Hukou) labour mobility restrictions in China. Journal of Development Economics, 83(2), 392-410.

Wiggins, Steven. (2013). Reflections on the global food crisis: How did it happen? How has it hurt? And how can we prevent the next one? JOURNAL OF PEASANT STUDIES, 40(2), 450-452.

Willer, H. \& Lernoud, J. (Eds.) (2017). The world of organic agriculture. Statistics and emerging trends 2017. IFOAM, Bonn \& FiBL, Frick. 
Wu, R. C. (2011). The revolution of household registration system: based on the modern country construction. Inner Mongolia Social Sciences, 32(6), 15-20. (in Chinese).

Wu, Q. (2014). Understand the importance of farmers' social security right. Journal of Fujian Party School(6), 81-86.

Xin, Y., \& Gao, J. (2009). "Offer More, take Less, and allow Flexibility"--On evolution of agriculture reform and development theories presented in six CPC national congress reports since the implementation of reform and open-up policies. Teaching and Research, 2, 12-18. (in Chinese).

Xu, H. G., Tang, X. P. , Liu, J. Y., Ding, H. , Wu, J. , Zhang, M. , . . Liu, Y. . (2009). China's progress toward the significant reduction of the rate of biodiversity loss BioScience, 59, 843-852.

Xu, X. G. , Hou, L. S. , Lin, H. P. , \& Liu, W. Z. . (2006). Zoning of sustainable agricultural development in China. Agricultural Systems, 87(1), 38-62.

Yan, H. R. , \& Chen, Y. Y. (2015). Agrarian capitalization without capitalism? Capitalist dynamics from above and below in China. Journal of Agrarian Change, 15(3), 366-391.

Yang, L., Huang, B., Mao, M., Yao, L., Niedermann, S., Hu, W., \& Chen, Y. (2016). Sustainability assessment of greenhouse vegetable farming practices from environmental, economic, and socio-institutional perspectives in China. Environmental Science and Pollution Research, 23(17), 17287-17297.

Yang, P. , Zhu, Y. J. , Xu, X. , Ma, H. Y. , \& Wang, J. M. . (2013). The challenge for China to achieve synchronous development of four modernizations: goal vs. institution. Issues in Agricultural Economy 34(11), 87-96.

Yang, X. P. , \& Fang, S. B. . (2015). Practices, perceptions, and implications of fertilizer use in East-Central China. Ambio, 44, 647-652.

Ye, J. Z. (2015). Land transfer and the pursuit of agricultural modernization in China. Journal of Agrarian Change, 15(3), 314-337.

Ye, L., \& Wu, A. M. (2014). Urbanization, land development, and land financing: Evidence from Chinese cities. Journal of Urban Affairs, 36(s1), 354-368.

Ye, X. (2009). China's urban-rural integration policies Journal of Current Chinese Affairs, 38, 117-143.

Ye, X. J. , Wang, Z. Q., \& Li, Q. S. (2002). The ecological agriculture movement in modern China. Agriculture, Ecosystems and Environment 92, 261-281.

Yep, R. (2015). Filling the institutional void in rural land markets in southern China: Is there room for spontaneous change from below? Development \& Change, 46(3).

Yin, R. S. , Liu, C. , Zhao, M. J. , Yao, S. B. , \& Liu, H. (2014). The implementation and impacts of China's largest payment for ecosystem services program as revealed by longitudinal household data. Land Use Policy, 40, 45-55.

You, X., \& Kobayashi, Y. (2009). The new cooperative medical scheme in China. Health Policy, 91(1), 1-9.

Yu, W. (2016). Agricultural and agri-environment policy and sustainable agricultural development in China: IFRO Report 247. Department of Food and Resource Economics, University of Copenhagen.

Zeng, G. A. , \& Hu, J. J. . (2007). Research on the trend and the reasons of Chinese urban rural economic income gap. Contempary Economic Research, 142(6), 26-30.

Zhang, J. F. , Mauzerall, D. L., Zhu, T. , Liang, S. , Ezzati, M. , \& Remais, J. V. (2010). Environmental health in China: progress towards clean air and safe water. The Lancet, 375(9720), 1110-1119.

Zhang, K. , Dearing, J. A., Dawson, T. P., Dong, X. , Yang, X. D. , \& Zhang, W. G. (2015). Poverty alleviation strategies in eastern China lead to critical ecological dynamics. Science of the Total Environment, 506507, 164-181.

Zhang, L. (2008). Conceptualizing China's urbanization under reforms. Habitat International, 32(4), $452-470$. doi: 10.1016/j.habitatint.2008.01.001

Zhang, N. (2013). Rural women migrant returnees in contemporary China. The Journal of Peasant Studies, 40(1), 171-188.

Zhao, G., Liu, J. , Kuang, W., Ouyang, Z., \& Xie, Z. . (2015). Disturbance impacts of land use change on biodiversity conservation priority areas across China: 1990-2010. . Journal of Geographical Sciences 25, 515-529 
Zhao, J., Luo, Q., Deng, H., \& Yan, Y. (2008). Opportunities and challenges of sustainable agricultural development in China. Philosophical Transactions of the Royal Society B: Biological Sciences, 363(1492), 893-904.

Zhen, L. , \& Routray, J. K. (2003). Operational indicators for measuring agricultural sustainability in developing countries. Environmental Management 32, 34-46.

Zhen, L. , Routray, J. K., Zoebisch, M. A., Chen, G. B. , Xie, G. D. , \& Cheng, S. K. (2005). Three dimensions of sustainability of farming practices in the North China Plain. Agriculture, Ecosystems \& Environment, 105(3), 507-522.

Zheng, H. , \& Cao, S. (2015). Threats to China's biodiversity by contradictions policy. Ambio 44:, 23-33.

Zhong, X. M. . (2013). Research on the current situation, problems and measures of rural land use circulation in the coastal areas of China. Journal of Applied Sciences, 13(19), 3883-3889.

Zhou, J. (2014). Sustainable agricultural and rural development: the integration of environmental and agricultural policies. Journal of the Party School of CPC of Changchun Municipal Committee, 5, 67-71,76. (in Chinese).

Zhou, Q. R. . (2014). The routine map of land entering into market. Land \& Resources Herald(9), 16.

Zhu, Y. (2007). China's floating population and their settlement intention in the cities: Beyond the hukou reform. Habitat International, 31(1), 65-76.

Zhu, Q. Z., \& Lu, X. C. (2011). On the value of the existence of village. Journal of Nanjing Agricultural University (Social Sciences Edition), 11(1), 7-12. 



\section{Summary}

China's agricultural development over the past decades is characterized by a strong increase in agricultural production and the income of farmers. Major policy goals concerning national food security and rural poverty alleviation have been reached, but at the same time environmental, as well as economic and social problems threaten the sustainability of agriculture. The direction of agricultural development has therefore moved to the center of attention of both the Chinese government and many scholars. However, the voices of Chinese farmers are generally absent in this debate and in the strategies for sustainable agricultural development proposed by government and scholars. The point of departure of this dissertation is that agricultural development must include economic viability, social equity and protection of the environment and natural resource base to be sustainable, and that, to be effective, a strategy for sustainable agricultural development must account for the perspectives and diverse conditions of Chinese farmers. The research objectives were:

1. to assess in how far the Chinese governmental strategy for agricultural development and major alternative strategies address the sustainability problems of China's agriculture in a comprehensive way, i.e., whether the economic, social and environmental dimensions of sustainable development are taken into account.

2. to assess the perspectives on economic, social and environmental problems and solutions of Chinese farmers from different ages, levels of education, farm household types, and agro-ecological contexts.

3. to assess the extent to which the Chinese governmental strategy for agricultural development and major alternative strategies address the problems as experienced by farmers from a broad range of contexts, and to determine how such strategies better could account for farmers' perspectives.

A mixed methods research approach was followed to achieve these objectives, analyzing and synthesizing data obtained from desk research, a survey covering 24 villages, and case studies of three villages located in contrasting agro-ecological regions.

The first objective is addressed in chapter 2, with an integrated assessment of problems and solution strategies for sustainable agricultural development in China. The assessment is based on an analysis of scientific literature and secondary data from statistical yearbooks and governmental reports. Three distinct solution strategies were assessed: the governmental strategy aiming at modernization in combination with urbanization, and two alternative strategies focusing on the conservation of small-scale agriculture and the development of ecological agriculture, respectively. The conclusion is that nei- 
ther the government's modernization strategy nor the two major alternatives offer a comprehensive and integrated response to the current threats to the sustainability of agriculture. The modernization strategy neglects the need for rural migrant workers to maintain their small land holdings as a fallback option, and measures to control agrochemical pollution are ineffective due to the strategy's emphasis on enhancing agricultural production. The alternative strategy to conserve small-scale agriculture does not offer a solution for the widening urban-rural gap and the current environmental problems. The weak spot of the second alternative strategy, to promote ecological agriculture, is the difficulty to create an effective market for high-added-value products and ecosystem services. Moreover, all three -strategies neglect the huge variation in local conditions across China and make unsupported, generic assumptions about the needs and wants of Chinese farmers. Investigation of farmers' perspectives on agricultural development and how these vary with local conditions is therefore a much needed step towards a comprehensive and broadly supported strategy for sustainable agricultural development in China.

The second objective is addressed in chapters 3, 4, 5, and 6. First, the perspectives and practices of Chinese farmers were studied following a quantitative survey approach (Chapter 3). The focus was on the Guanzhong Plain (Shaanxi Province), where the natural conditions are favorable and agriculture is relatively advanced. As the dominant system is double-cropping of maize and winter wheat, the area is representative of agriculture in the North China Plain, the major agricultural production region of China. Questionnaires were administered face-to-face in 24 villages and the results from 165 respondents were analyzed statistically. Using cluster analysis, four types of households could be distinguished and compared with respect to their practices and perspectives on economic, social and environmental aspects of agriculture and future development. The results made clear that even in a fairly homogeneous area as the Guanzhong Plain, there is considerable diversity in farmers' practices and perspectives, which in this study was associated with farm household type, age, and level of education. For example, significant differences were found with respect to what was considered the major function of farming, expectations about the future development of agriculture, whether and why farmers enjoyed rural life or not, their views on farmer identity and profession, the relationship between agriculture and natural environment, the use of agrochemicals, and perception of environmental problems. In chapter 4, 5, and 6 a qualitative case study approach was followed to gain in-depth insights into farmers' perspectives. For the case studies, three villages were selected, located in agro-ecologically very distinct parts of Shaanxi Province. Daijia is a village located in the Guanzhong Plain, in the central part of Shaanxi Province (Chapter 4). As in the villages included in the survey, the dominant system is double-cropping of maize and winter wheat, with apples as a cash crop. The two villages contrasting with Daijia are Chiniuwa in the north and Donghe in the south of Shaanxi Province. Chiniuwa village is located in the erosion-prone, semi- 
arid Loess Plateau region, where the farmers specialize in the cultivation of jujube fruit (Chapter 5), and Donghe village is situated in the Qinba Mountains, where the dominant system is a rotation of oilseed rape and rice (Chapter 6 ). In each village, semi-structured interviews were conducted with about 15 residents, focusing on the economic, social and environmental aspects of farming, the problems the respondents experienced and their ways of coping (including off-farm migrant work), and their outlook on the future. The prospects for agricultural development and many of the major problems perceived by the farmers differed widely between the three villages. However, there were also important commonalities: most farmers considered their land an important and necessary social safety net, and although off-farm work was generally the major source of household income, the employment opportunities were decreasing in recent years.

The third objective is addressed in chapter 7. The assumptions concerning farmers' problems and preferred solutions underlying the three strategies for agricultural development, were compared with the findings about farmers' perspectives from the three case study villages in Shaanxi Province. These assumptions did not match completely with farmers' perspectives in any combination of strategy and village. Moreover, in case assumptions of one of the strategies concerning the current situation corresponded with the farmers' perspectives, these assumptions only concerned a part of farmers' reality, for example the economic or social dimension. Based on the comparison between the assumptions underlying the strategies and farmers' perspectives, additional policy goals were identified by which the government's strategy for agricultural development could better take farmers' needs and preferences into account. These additional policy goals included: improving the social security of rural residents and the rural education system, promoting an interactive, locally adaptive and trustful relationship between farmers and agricultural experts and scientists, and relaxing the rules of the Household Registration System. 



\section{总结}

近几十年来, 中国的农业发展特点主要包括农产品产量和农民收入的大幅度增加。 关于国家粮食安全与农村扶贫的农业政策目标基本实现。同时, 农业的环境问题 和经济、社会问题威胁着农业的可持续性。因此, 中国农业的发展方向得到了政 府和学术界的密切关注。但是, 在政府和学术界的政策主张与争辩中, 小农的声 音在很大程度上被忽略了。这部博士论文的出发点是农业可持续发展必须包括农 业经济的可行性、社会的公正性、农业环境与资源的保护性。为了达到政策的有 效性, 农业可持续发展策略必须把农民的视角以及农民视角的多样性考虑进来。 本论文的研究目的主要包括:

1. 评估政府的农业发展策略以及学术界中提出的不同的发展策略, 在多大的程 度上全面地解决了中国农业发展的问题。例如农业发展的经济、社会、环境 维度是否被全方位的考虑进来。

2. 从不同的年龄阶段, 受教育层次, 农户类型和农业生态环境等角度, 去衡量 农民对农业的经济, 社会, 环境问题的看法, 以及农民解决农业问题的办法 的偏好。

3. 衡量中国主要农业政策和学术界提出的不同农业政策是否把农民经历的不同 农业问题考虑进来。并且提出农业政策如何能够更好的考虑农民视角。

为了实现研究目标, 本论文应用了不同的研究方法, 主要包括: 数据的分析和整 合等第二手资料研究工作、包含 24 个村子的问卷调查和三个不同农业生态地域 的案例研究等第一手数据研究。

第二章实现了第一个研究目标, 即对中国农业可持续发展的问题和解决办法的综 合评估。这些评估主要是对科学文献, 统计年鉴以及政府报告等第二手资料进行 分析与整合。三种不同的农业策略被评估: 政府的农业现代化与城镇化策略, 小 农学派的继续保存和发展小规模农业策略, 以及发展生态农业的策略。我们得到 的结论是三种农业策略都没有全面和综合的解决当前农业问题。政府的农业现代 化策略忽略了外出务工者对小规模土地的需要。农民工需要农村的小规模土地作 为他们退回农村的退路。此外, 农业现代化策略主要强调农产品产量的提高, 农 业化学药品引起的环境污染问题没有得到有效的控制。第二种不同农业策略主张 来自于小农学派。他们主张继续发展小规模的农业。但是, 事实上, 他们并没有 提出切实的办法去解决当前的城乡差距问题和农业生态环境问题。第三种不同农 业策略是发展生态农业。但是, 它的主要弱点是很难建立一个关于高附加值以及 高生态系统服务的生态农产品市场。此外, 这三种策略都忽略了中国农业的地区 差异性, 从而对农民需要和偏好做出了没有支持的、一般性的假设。因此, 对农 
民关于农业发展的视角以及对农业当地情况的调查是非常有必要的。从而形成一 个全面的，受到广泛支持的中国可持续农业发展策略。

第二个研究目的主要是在第三, 四, 五, 六章中实现。首先, 通过定量问卷调查 方法, 研究农民的视角与行为 (第三章)。问卷调查是在陕西省关中平原地区进 行。关中平原具有有利的农业发展的自然条件。关中平原地区是一年两熟的玉米 与小麦轮耕模式。这个地区的耕作模式在北方平原地区具有代表性。北方平原地 区是中国最主要的粮食产地之一。问卷研究在 24 个村子中展开, 主要是采取面对 面发放问卷的方式。共有 165 个受访对象。应用聚类分析方法, 对四组不同类型 的农户进行对比。研究农民的经济、社会和生态视角和行为。并且对农业未来发 展的视角进行对比。结论如下：在同质性很强的地区（关中地区）, 农民的意识 和行为存在着很大的差异。在本研究中, 这种差异主要受农户类型, 农民年龄, 受教育层次等因素影响。例如, 关于农业主要功能、对农业未来发展的期待、农 民是否喜爱农村生活、对 “农民” 职业的态度、农业与自然的关系、农业药品的 使用、对农业环境问题的认知等, 四组受访者的看法和行为都存在着显著的差异 性。为了更深层次的了解农民视角, 我们在第四, 五, 六章采用定性的案例分析 方法。在陕西省的农业生态存在显著差异的三个地区中选择出来三个村子作为案 例。代家村位于陕西省中部的关中平原地区, 它主要是一年两熟的玉米与小麦的 轮耕制, 苹果是当地主要的经济林作物。另外的两个村子是位于陕西北部的赤牛 洼村和南部的东河村。赤牛洼村地处土壤易受侵蚀的半干旱地区---黄土高原。 在赤牛洼村, 农民主要种植大東（第五章）。东河村地处秦巴山区, 主要的农作 物是水稻和油菜（第六章）。在这三个村子中, 对受访者进行半结构化的访谈。 每个村子有 15 个左右的受访者进行了深度访谈。访谈的内容主要集中在农民经 历的经济、社会、生态方面的问题, 以及农民自身对这些问题的应对方法（包括 外出务工）。其次, 访谈的内容还提及农民对未来农业发展的展望。在不同的村 子中，农民对农业问题的视角和对农业未来的展望是非常不同的。但是，不同的 农业地区还是存在着明显的共性: 大多数农民认为小规模的土地起到社会保障的 作用; 外出务工是农户的最主要的收入来源, 然而就业机会在近些年减少等。

第三个研究目标在第七章中实现。本章将三种农业发展策略的基本的假设与陕西 省三个案例村子中农民视角进行对比。这些策略的基本假设没有完全和农民的视 角相匹配。此外, 每一个农业策略都基本与其中的一个案例村庄相对应。例如, 农 业现代化和城镇化策略与代家村案例相对应。但是, 我们发现, 这些假设也只是与 农民的一些实际情况相对应（例如经济、社会维度上相对应）。基于农业策略假 设与农民视角的对比, 本章提出附加的农业政策目标---即农业发展政策应该很好 的了解并考虑农民的需要和选择倾向。这些附加的农业政策目标主要包括: 提高农 村居民的社会保障以及教育水平; 农业专家和农民之间建立并适应本地区的互信 关系; 改革并完善户籍制度。 


\section{Valorisation}

\section{INTRODUCTION}

China is a country with a vast population but with limited farmland. Therefore, for the Chinese government the goal of national food security, known as "taking control of our own bowl", is very important. By now, the goals of food security and a strong increase in agricultural productivity and farmers' income have been achieved. However, these achievements have come at a cost, economically, socially, and environmentally. "Which direction should Chinese agriculture take?" is a question receiving much attention from both the government and scientists. and different strategies have been proposed.

Farmers are the most important actors in agricultural development. However, in China, farmers' voices are absent in the process of agricultural policy development, due to their historically weak and marginalized position in Chinese society. Much research has been done on the triple problem of agriculture, farmers and rural development (三农问 题 San Nong We Ti), using sophisticated theories and methods, but "common sense" in terms of the lived experience of the farmers is lacking. However, agricultural policies that are not rooted in the rural realities and widely supported by farmers are unlikely to be effective.

The main aims of this dissertation were (1) to assess the Chinese governmental strategy for agricultural development and two major alternatives vis-a-vis the range of economic, social and environmental sustainability problems of Chinese agriculture; (2) to determine the perspectives of Chinese farmers on problems and possible solutions in agricultural development; and (3) to assess whether the assumptions underlying the three high-level strategies correspond with farmers' perspectives and how this can be improved. These three main objectives have been achieved in this dissertation, which is novel in combining an integrated and farmer-oriented approach. It provides relevant scientific and social contributions by stressing the importance of considering smallholding farmers' voices in the process of agricultural policy development. In addition, this dissertation provides recommendations for research and policy. 


\section{RELEVANCE}

Most of the research on agricultural problems in China is conducted from narrow, monodisciplinary perspective focussing on isolated issues, such as agricultural income, social inequity, or agri-environmental pollution. There is a lack of an integrated view on agricultural problems consideringall three (economic, social, and ecological) dimensions of sustainable agriculture. This dissertation aims to narrow this gap. We conducted an integrated assessment of agricultural development strategies based on the scientific literature (both Chinese and English), governmental reports and bulletins from different ministries, secondary data sources from the Chinese Statistical Bureau, and surveys and case studies of farmers' perspectives. As such, it adds an integrated perspective to Chinese agricultural research.

In regard to agricultural policy, we provide a historical overview to help readers understand the background of China's agricultural development. Especially, the various issues of the so-called Central Document No. 1 that related to the triple problem of "agriculture, peasants, and rural development" played an important role in directing the agricultural development in China. However, in the English scientific literature it is rarely mentioned, maybe because the No.1 documents are in Chinese and just three of them have been translated into English. We made a content analysis of these Central Documents No. 1 based on the three dimensions of sustainable agriculture. The analysis provides useful insights to researchers who are interested in the Central Documents No. 1 , and fills a gap in the study of Chinese agricultural policy.

The most important contribution of this dissertation is the field research on farmers' perspectives on agricultural development. In China, 'farmers' (peasants) not just refers to a profession, but also to a social category (or even social rank). A farmer is someone to "be looked down upon", and has the image of "low-qualified, poor"; and it is common for "rural areas" to have the image of being "backward and outmoded". Even though farmers are the most important actors in agricultural development, their voices are ignored due to their marginalized position in Chinese society. Through our field research, we let small-holding farmers' voices and their stories be heard. The descriptions of farmer' perspectives (including their experiences, needs, options and preferences) concerning agricultural development provides insight into the meanings farmers in different rural contexts give to current and expected developments. . Finally, we also provide a novel approach by comparing the assumptions underlying agricultural policy proposals with the perspectives of farmers from three villages with very different farming systems and conditions. The results stress the importance of letting small-holding farmers be "insiders" in the process of policy making rather than "outsiders". 


\section{TARGET GROUPS AND ACTIVITIES}

This dissertation provides an integrated study of agricultural problems, policies, and farmers' perspectives. It appeals both to policy makers and scholars to consider farmers' perspectives on agricultural problems and possible solutions, and to take the wide diversity of rural contexts in China into account.

\section{Policy makers}

The Chinese government emphasizes the goal of sustainable agricultural and rural development and incorporated this in China's Agenda 21. As farmers are the main decision makers in agriculture, we argue that only agricultural policy proposals that align with farmers' perspectives can be implemented successfully. High-level policy makers should therefore understand very well "the human foundation" of agricultural development in diverse rural areas. Farmers have an experiential understanding of agricultural problems and possible solutions and it will thus be beneficial for agricultural policy when "farmers' voices" are policy makers' first consideration .

China is a large country with a huge diversity of rural and agricultural contexts in which farmers are confronted with different problems. Even in a fairly homogeneous agricultural production area, we found a large diversity in farmers' perspectives and practices depending on their farm household type, age, and level of education. Strategies for sustainable development of agriculture in China should thus address a wide diversity of needs and goals as articulated by Chinese farmers from different rural contexts.

Typically, agricultural policies are developed by the government and experts in a topdown manner in China. The main approach of this dissertation - field research in villages and with in-depth interviews with local farmers - provides Chinese agricultural policy makers with another, new way to inform agricultural policy development: from the bottom up. This bottom-up approach can help agricultural policies to be more widely accepted and adopted by farmers.

\section{Science Community}

Knowledge influences how people understand the world around them. Knowledge is heterogeneous. Diversified knowledge can provide people with multiple perspectives on problems. Different types of knowledge are needed to solve the current range of of agricultural problems.

According to our research, most farmers learned how to farm from older generations, and have a positive view of traditional agricultural knowledge. Yet they are not satisfied with their current knowledge and actively acquire new knowledge, e.g., from TV or 
books, and try to combine this new 'scientific' knowledge with their traditional knowledge (indigenous knowledge). Although they think that the government should take the lead in promoting the acquisition of new knowledge, they do not think the current training courses are useful. They are nevertheless willing to participate, especially when the knowledge would be practically useful, transferred in an interactive way and be helpful to raise their income.

However, the current agricultural knowledge extension system is one-way, and topdown. Farmers are treated as passive followers, but based on their rich experiences, farmers have the wisdom to fulfill agricultural activities. Experts should therefore draw lessons from farmers' indigenous knowledge. Indigenous knowledge is one important part of the culture and tells people what happened and worked in the past, which provides people with experience to draw on. Sustainable agricultural needs heterogeneous knowledge: both indigienous knowledge and scientific knowledge.

\section{Small-holding farmers and farmers' organizations}

The field research was conducted in three very different agricultural contexts in Shaanxi Province. To a large extent, these case studies are representative of agricultural systems that are wide-spread in China. Chinese farmers can learn from the similarities and the differences between agricultural problems in different rural contexts. In addition, the dissertation shows that farmers from different rural contexts developed their own strategies to cope with their agricultural problems. Farmers can draw some lessons from other rural areas which are also suitable for their own local areas.

Due to the household responsibility system in China, in which each rural resident has the right of use over a small piece of land, the farm size in Chinese agriculture is very small, and there are many farmers. These farmers are independent in their decision making, and only loosely organized, which makes it difficult to let their voices be heard by the high-level actors, such as government, policy makers, and scientists. Farmers' organizations could unite individual small-holding farmers and give them more influence. Currently, there are some farmers' organizations emerging in China. However, according to the interviewed farmers and studies by other researchers, the current farmers' organizations play only a limited role in organizing individual small-holding farmers.

\section{Schedule and implementation}

After her PhD study, the researcher will continue to work in the field of rural sociology at a Chinese University. In the first place, the findings of this PhD study will be incorporated in teaching. The researcher will communicate and discuss the findings with young bachelor and master students. Second, Chinese universities have responsibilities with 
respect to public service. University faculty have the obligation to strengthen the connection with communities (villages) and local governments. Finally, we plan to publish some chapters of this dissertation to let more readers know about our research findings. 



\section{Acknowledgements}

Five years ago, I left my home, husband and relatives to pursue my academic dream in the Netherlands. It was a long journey, but it made my whole life colorful. I really think that pursuing a doctoral degree abroad is one of the best decisions I have made. It has brought me many unique experiences. Whereas the majority of my Chinese peers followed the traditional paths in life, my inner voice told me to follow the road of knowledge. Immersing myself in PhD research made me feel happy and lucky. However, in the process of completing my dissertation, I was confronted with many challenges. Without the kind support, patient suggestions, critical comments, and enlightened guidance from many persons, this dissertation could not have been completed. Therefore, I would like to express my gratitude to them.

My deepest thanks go to my two supervisors, prof. dr Harro van Lente and dr Joop de Kraker. Harro, thanks for giving me this valuable and life-changing opportunity by accepting me as one of your PhD candidates. I still vividly remember our first Skype meeting and the first version of the research proposal. During the first year, we discussed many difficulties in my daily life and research, and you always listened patiently and encouraged me. Now, in my heart, I always remind myself that "I can do it". I would like to tell you that I have become more confident to overcome any kind of difficulty. Also, thanks for always being willing to join our regular progress meetings to discuss my research with me and Joop. Joop, you are the person who understands me and my research best. You are the person who provided me with the most support and guidance in the process of thesis writing. I really learned a lot from you, including a critical academic attitude and different research methods. You have been a good teacher and a helpful friend to me. Especially when you joined me in the final research visits to the three case study villages in April 2015, you taught me a lot about formulating interview questions and interviewing skills. We gave farmers ample time to tell their own stories before we asked the next question, and we kept asking questions when we did not understand what farmers were saying. In addition, we elaborated on "new" or "remarkable" elements in farmers' stories, and we cross-checked information among different farmers. We never gave moral judgement, and always showed understanding of the interviewees' position. It was a valuable experience that improved my ability to do field research. I really hope that we can continue to work together on topics relating to rural development and farmers' perspectives. 
Furthermore, I would like to thank professor He Xuefeng (贺雪峰) who is one of the Chinese professors I respect most. Between July and August of 2014, I joined professor He Xuefeng's field research group. Each day I conducted interviews with farmers, together with other PhD fellows. Every evening, we had a group discussion about the collected material of that day. These twenty days of field research with professor He's field research group further stimulated my interest in the stories of individual farmers. I learned that the essence of field research is not only collecting primary data, but also gaining a deeper, experience-based understanding of rural contexts and farmers' perspectives. I also would like to thank professor Wang Youke (汪有科) who I never met in person. When I conducted the field research in the Loess Plateau area (Chiniuwa village), farmers told me about "climate change". Back in Maastricht, I wrote an email to Professor Wang about this, and he was so kind to provide detailed answers to all my questions and to invite me and my supervisors to visit his meteorological station in Mizhi County. In addition, I also would like to thank professor Zhang Zhongchao (张忠潮 ) of Northwest A\&F University who was my supervisor during my Masters. Thank you that you introduced me to the academic road. I call you nearly every Chinese traditional festival. Your encouraging words make me feel braver.

I would like to thank all of the interviewed farmers in the three villages. Without all of you, I definitely could not have finished this dissertation. I feel that farmers are among the most friendly people in China. Each time when I came to your homes for an interview, you smiled and let me in. Usually you made a cup of tea for me and then we started our conversation. You shared your own and your family's stories and provided me with valuable first-hand information. Several months of field research in the villages, while living in farmers' homes and having meals together every day, helped me to understand farmers much better.

I would like to thank all of my colleagues and friends at ICIS. Carijn, you coached me during the first and second year of my PhD research. You really helped me a lot. You introduced all kinds of academic literature and videos to me, which helped me to start up my research step by step. You spent much time to meet with me and to give me enlightened guidance. Julia and Ceren, you are two of my best friends in the Netherlands. I received a lot of kind help from you in my daily life and my research. I even felt comfortable to share my feelings with both of you. I enjoyed our time together (meal time, chocolate milk time, party time...), which made me feel relaxed and at home. I was lucky to have both of you as my friends. Bingtao (Bingbing or Taotao 苏冰涛), you always say that I helped you to settle down in Maastricht, but I really want to say that you helped me a lot too. We were each other's "psychological safe haven". We were always there for each other, whenever and wherever help was needed. We always had things to talk about, because we shared the same experience. Astrid, you were always so kind to help me when I was confronted with difficulties relating to quantitative methods and SPSS. You were so patient to run SPSS for me to find a solution to my 
problems. I learned a lot from you. You are very busy every day and still you spend much time to help the PhD fellows. Lukas, I am happy to have shared the office with you. You are a knowledgeable person. I loved to discuss with you because I always learned some new insights from our conversations. Laura, thank you that you organized so many memorable PhD fellow dinners. It was so nice to get together with all the other PhD fellows, the room was always filled with laughter. Sjouke, I am also happy to have shared the office with you and Julia. You made our office so beautiful and warm. Bram, thank you for your suggestions about the maps in this dissertation. Alex, thank you for helping me to correct my English. Esther, Nia, and Atika, thanks to all of you for making my PhD life full of happiness. Atika, it was nice to share the office with you, and our conversations made us understand each other better. Many thanks also go to Anja, Annet, Ron, and Pim. Thanks for your support during my PhD period. You made ICIS a unit which is like a family. I also thank my other ICIS colleagues, Marc, Maud and René, for the nice conversations. Thanks to all of my ICIS colleagues: you provided me with a memorable and valuable four-year stay abroad. I loved our ICIS family.

Now it is time to thank my friends and relatives. Dr Hai Lijuan (in Berlin) and Dr Liu Jing (in Copenhagen), we three girls prepared for IELTS together and applied for foreign universities together. Also, in Europe, we traveled together. We did so many girl things together, and I am proud that I have you two as my closest friends. Dr Zhu Xiaoging, Dr Liu Yilin, and Dr Zhou Fang, I will always remember how we four girls supported each other in Maastricht. Your company made my life in Maastricht full of beautiful memories. Jing Yingying, you are a sweet girl and you are the confirmation that "a friend in need is a friend indeed". I'm lucky to have you as one of my best friends. We also supported each other a lot in Maastricht. I could always call you when I had difficulties, and you always responded quickly. Dr Xu Jinhua and Dr Nie Hongguang, we met in my last year in Maastricht. Thank you for your encouragement. Thanks also go to Dr Zhao Jinjin (I call you Jinjin sister). You gave me a lot of valuable information when I had just arrived at Maastricht. I very much like your smile and positive attitude. I also thank my friend Jian Li, and many other friends that I haven't mentioned by name. You guys make me feel lucky and happy for having so many friends around the world.

My relatives, you are the ones that I love the most in the world. My grandparents (杨秀 芝, 王配福), I grew up in your home. Thank you for loving me so much, but also for requiring me strictly to study hard. I learned a positive attitude from my grandfather, who always keeps smiling even when there are many difficulties in life. In addition, I will never forget that "no matter how successful you are, you always should be a kindhearted person”. My parents (阊淑英, 王广军), I love both of you very deeply. I do not want to lose you. When you were in the hospital, my heart was broken. However, I know that it is time for me, having grown up, to take care of you and our family. From both of you, I learned that working hard brings happiness. My Uncle (王广民), I respect you very much. I know quite well that you love me very much and treat me like 
your daughter. You try to protect and take care of our big family. I learned from you that loving my brothers will make our big family full of love. I also thank my parents-inlaw (王志民, 杨学惠), my aunt (王素芬), my uncle (杨爱军), my four handsome brothers (王伟, 杨明, 杨旭, 王宁). My little nephew (王子衡), I wish you will grow up healthily. All of us love you very much. Yan Xiaoli (闩小力), we are from the same hometown. I would like to thank you for your help in times I lost hope. You were so kind-hearted to help me to contact the expert to do the operation for my father. You are one of the persons who I respect most. I learned from you that I should help other people whenever I can. In the end, I would like to thank my beloved husband (王伟然). Four years of distance love is really difficult. However, we can be proud that we overcame all difficulties, and it made our relationship stronger. You made many sacrifices to support me, words fail me to express my gratitude. Each time, when I returned to China, I went to the case study villages to do interviews. However, you supported me without complaining and accompanied me to the villages. Sometimes, you also offered me valuable suggestions for the field research. This dissertation also belongs to you.

All of you are the main reasons that I love this beautiful life and this beautiful world. 


\section{Curriculum vitae}

Jing Wang was born on 5th of September, 1985 in Xinglong county of Hebei Province, China. She started her bachelor study in Northwest Agriculture \&Forestry University in Shaanxi Province in 2005. Her major was public service administration, and her bachelor thesis is relating to environmental protection and administration in county areas. She gained her management bachelor degree. During her bachelor study, she gained the first-class professional scholarship in 2007 and 2008. In 2009, she was chosen to be a post-graduate student without entrance examination in Northwest A\&F University. Her master major was the Philosophy of Science and Technology, and her main research direction was relating to sustainable development. During the period of her postgraduate study, she completed the thesis "View of the ecological civilization of moderate consumption". The main focal point is to discuss how to achieve sustainable development from the view of moderate consumption. She also participated in Shaanxi Province's Philosophy of Science and Technology Forum and made a presentation on the issue of the ethic of applied science and technology in 2011. She gained the first-class professional scholarship in 2009 and 2010. She was chosen as the excellent postgraduate student of Northwest A\&F University in 2012.

In September 2012, she attained a position within a PhD training program supported by the China Scholarship Council (CSC). She joined International Centre for Integrated assessment and Sustainable development (ICIS) at Maastricht University as a Ph.D student under the supervision of prof. dr. ir Harro van Lente and dr Joop de Kraker. Within her research, she mainly conducted the study on sustainable agricultural development, including the assessment of agricultural problems, policies, and farmers' perspectives and practices. She used several months to do the in-depth field research in three villages (Guanzhong Plain area, Loess Plateau area and Qinba mountainous area) of Shaanxi Province. In 2014, she visited the Research Centre of Rural Governance at Huzhong University of Science and Technology. Between July and August of 2014, she joined professor He Xuefeng's (贺雪峰) PhD field research group, and she conducted in-depth field research with other Chinese PhD candidates in Guanzhong plain area. She understood that the essence of field research is not only collecting primary data, but also gaining a deeper, experience-based understanding of rural contexts and farmers' perspectives. She is interesting to topics relating to agriculture, farmers, and villages. She is especially interesting to small-holding farmers' narrations of their stories and emphasizes that small-holding farmers' voices should be heard in the process of agricultural policy making. 



\section{List of publications}

1. Wang, J. (2016). The role of cultural diversity in sustainable development: a case study of three villages in Shaanxi province. In R. Cörvers, J. de Kraker, R. Kemp, P. Martens, \& H. van Lente (Eds.), Sustainable Development Research at ICIS: Taking stock and looking ahead Maastricht: ICIS Maastricht University.

2. 王敬. 农业范式视角下的农业多功能性研究一一以陕西省关中地区小农生计 问题为例 [J]. 农业现代化研究，2016, 37(1): 23-28.

Wang J. The analysis of agricultural multi-functions from the perspective of agricultural paradigm: A case of small holding farmers' livelihood in Guanzhong Plain of Shaanxi Province[J]. Research of Agricultural Modernization, 2016, 37(1): 23-28. 


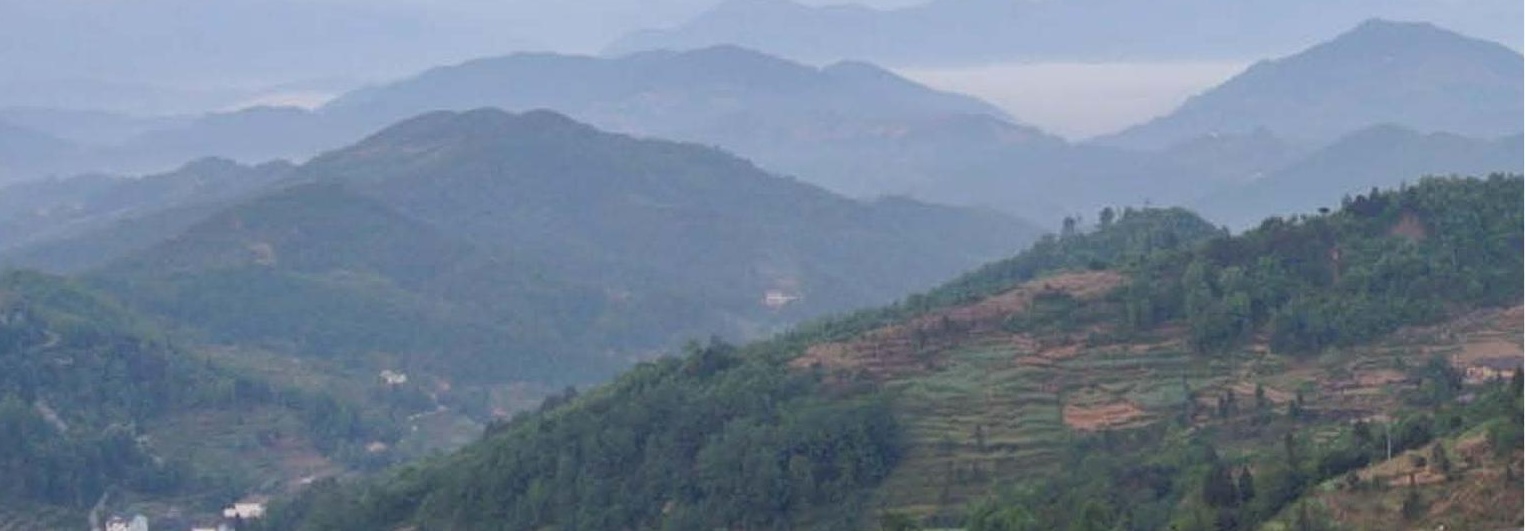

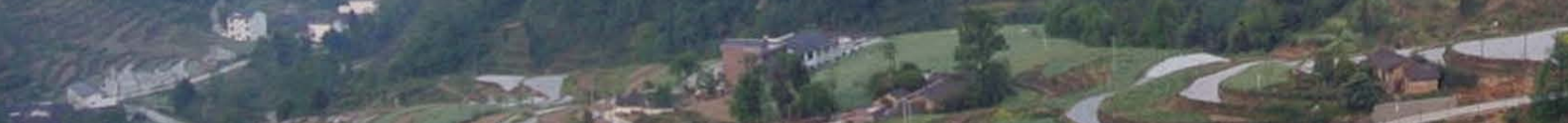
$-\infty+b x+5)$ and $\Rightarrow$

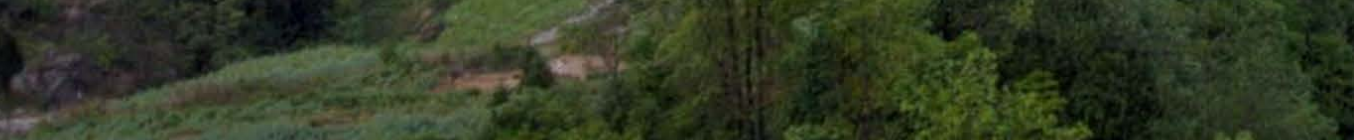

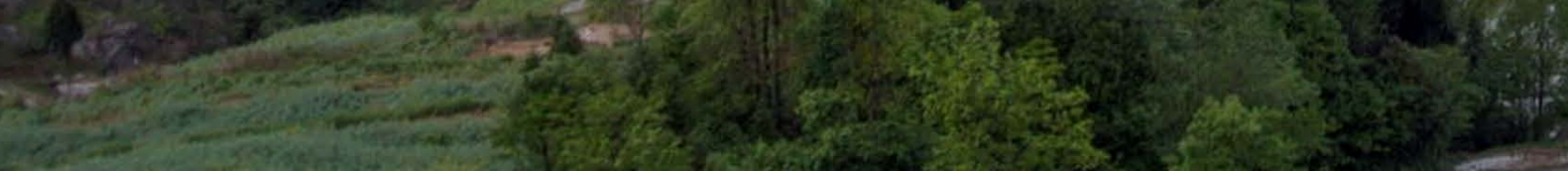

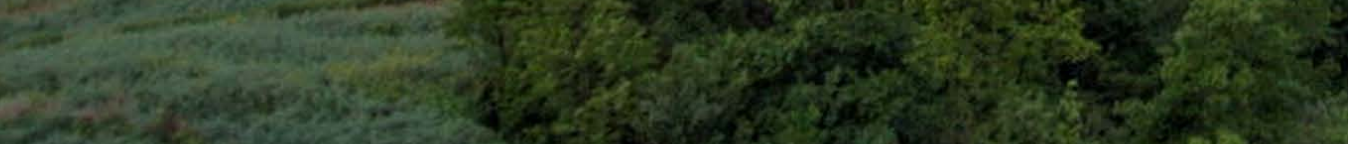

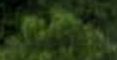

